\title{
Genetic variations involved in congenital and acquired long QT syndrome : identification and functional characterization
}

Citation for published version (APA):

Paulussen, A. D. C. (2003). Genetic variations involved in congenital and acquired long QT syndrome : identification and functional characterization. [Doctoral Thesis, Maastricht University]. Universiteit Maastricht. https://doi.org/10.26481/dis.20030515ap

Document status and date:

Published: 01/01/2003

DOI:

10.26481/dis.20030515ap

Document Version:

Publisher's PDF, also known as Version of record

Please check the document version of this publication:

- A submitted manuscript is the version of the article upon submission and before peer-review. There can be important differences between the submitted version and the official published version of record.

People interested in the research are advised to contact the author for the final version of the publication, or visit the DOI to the publisher's website.

- The final author version and the galley proof are versions of the publication after peer review.

- The final published version features the final layout of the paper including the volume, issue and page numbers.

Link to publication

\footnotetext{
General rights rights.

- You may freely distribute the URL identifying the publication in the public portal. please follow below link for the End User Agreement:

www.umlib.nl/taverne-license

Take down policy

If you believe that this document breaches copyright please contact us at:

repository@maastrichtuniversity.nl

providing details and we will investigate your claim.
}

Copyright and moral rights for the publications made accessible in the public portal are retained by the authors and/or other copyright owners and it is a condition of accessing publications that users recognise and abide by the legal requirements associated with these

- Users may download and print one copy of any publication from the public portal for the purpose of private study or research.

- You may not further distribute the material or use it for any profit-making activity or commercial gain

If the publication is distributed under the terms of Article $25 \mathrm{fa}$ of the Dutch Copyright Act, indicated by the "Taverne" license above, 
(c) Aimee D.C. Paulussen, Maastricht 2003

Genetic variations involved in Congenital and Acquired Long QT Syndrome

ISBN 90-9016744-7

Cover Design

Monique de Bruijn

Cover Title

"The Spiral Helix" (Monique de Bruijn)

Printing Agency

Datawyse/Universitaire Pers Maastricht 


\title{
Genetic variations involved in Congenital and Acquired Long OT Syndrome
}

\author{
Identification and functional characterization
}

\section{Proefschrift}

ter verkrijging van de graad van doctor aan de Universiteit Maastricht,

op gezag van de Rector Magnificus,

Prof.dr. A.C. Nieuwenhuijzen Kruseman, volgens het besluit van het College van Decanen, in het openbaar te verdedigen, op donderdag 15 mei 2003 om 14.00 uur door Aimée Dymphne Catherine Paulussen geboren te Middelburg op 17 december 1971 


\section{Promotor}

Prof. dr. M. Borgers

\section{Co-Promotores}

Dr. ir. J. Aerssens (J\& Pharmaceutical Research and Development, Belgium)

Dr. H.J. Smeets

\section{Beoordelingscommissie}

Prof. dr. J.P.M. Geraedts (voorzitter)

Prof. dr. H.J.G.M. Crijns

Prof. dr. L. Hondeghem (Hondeghem Pharmaceutical Consulting n.v., Belgium)

Prof. dr. M.J. Janse (University of Amsterdam)

Prof. dr. J.F.M. Smits

The investigations described in this thesis were carried out at the Johnson \& Johnson Pharmaceutical Research and Development, Beerse, Belgium

Financial support by the Johnson \& Johnson Pharmaceutical Research and Development is gratefully acknowledged. 
"The mast exciting phrase to hear in science, the one that heralds new discoveries, is not 'Eureka' (I found it!) but 'That's funny....." Isaac Asimov 



\section{Contents}

List of abbreviations

CHAPTER 1 Introduction

CHAPTER 2 A novel mutation (T65P) in the PAS domain of the potassium channel HERG results in the long QT syndrome by trafficking deficiency.

CHAPTER 3 Mutation analysis in congenital long QT syndrome: a case with missense mutations in KCNQ1 and SCN5A.

CHAPTER 4 Characterization of novel mutations E698X and P872f5877 in the C-terminus of the HERG potassium channel that cause the long QT syndrome.

CHAPTER 5 Analysis of the human KCNH2 (HERG) gene: identification and characterization of a novel mutation $Y 667 X$ associated with long QT syndrome and a non-pathological 9 bp insertion.

CHAPTER 6 Two linked variations in transcriptional regulatory elements of the CYP3A5 gene constitute the major genetic determinant of polymorphic activity in humans.

CHAPTER 7 Genetic susceptibility to acquired long QT syndrome: the impact of congenital long QT genes and drug metabolising enzyme genes.

CHAPTER 8 General Discussion

Summary

Samenvatting

Dankwoord

Curriculum Vitae

Publications

Appendices 



\section{Abbreviations}

\begin{tabular}{|c|c|}
\hline$A P-3$ & Activator protein-3 \\
\hline aLQTS & Acquired long QT syndrome \\
\hline$B A C$ & Bacterial artificial chromosome \\
\hline bp & Base pair \\
\hline BTE & Basic transcription element \\
\hline CDNA & Complementary DNA \\
\hline cLOTS & Congenital long QT syndrome \\
\hline CLSM & Confocal laser scanning microscope \\
\hline$C t$ & Threshold cycle \\
\hline CYP450 & Cytochrome P450 \\
\hline DMEM & Dulbecco's modified eagle's medium \\
\hline DMSO & Dimethyl sulfoxide \\
\hline DNA & Deoxyribonucleic acid \\
\hline $\mathrm{dNTP}$ & Deoxyribonucleoside triphosphate \\
\hline $\mathrm{ECG}$ & Electrocardiogram \\
\hline $\mathrm{ECL}$ & Enhanced chemiluminescence \\
\hline EDTA & Ethylenediaminetetraacetic acid \\
\hline ER & Endoplasmic reticulum \\
\hline FAM & 6-carboxy-fluorescein \\
\hline gDNA & Genomic DNA \\
\hline GiFP & Green fluorescent protein \\
\hline HEK & Human embryonic kidney \\
\hline HEPES & 4*(2-Hydroxyethyl)-piperazine-1-ethanesulfonic acid \\
\hline HERG & Human ether-a-go-go related gene \\
\hline HRP & Horseradish peroxidase \\
\hline HPLC & High-performance liquid chromatography \\
\hline $\operatorname{lgG}$ & Immunoglobulin 6 \\
\hline $\mathrm{kb}$ & Killabase \\
\hline $\mathrm{kDa}$ & Killodalton \\
\hline $\mathrm{kHz}$ & Killo Hertz \\
\hline LQTS & Long QT Syndrome \\
\hline $\mathrm{nM}$ & Nano Molar $\left(10^{-9} \mathrm{M}\right)$ \\
\hline MR & Metabolic ratio \\
\hline$M \Omega$ & Mega Ohm \\
\hline mRNA & Messenger RNA \\
\hline NADP & Nicotinamide adenine dinucleotide phosphate \\
\hline PAGE & Polyacrylamide gel electrophoresis \\
\hline PAS & Per-Arnt-Sim \\
\hline PBS & Phosphate buffer saline \\
\hline
\end{tabular}




$\begin{array}{ll}\text { PCR } & \text { Polymerase chain reaction } \\ \text { PVDF } & \text { Polyvinylidene difluoride } \\ \text { RFLP } & \text { Restriction fragment length polymorphism } \\ \text { RNA } & \text { Ribonucleic acid } \\ \text { SD } & \text { Standard deviation } \\ \text { SDM } & \text { Site-directed mutagenesis } \\ \text { SDS } & \text { Sodium dodecylsulfate } \\ \text { SEM } & \text { Standard error of the mean } \\ \text { SSCP } & \text { Single strand conformation polymorphism } \\ \text { TdP } & \text { Torsade de pointes } \\ \text { TE } & \text { Tris-EDTA } \\ \text { UV } & \text { Ultraviolet } \\ \text { Wt } & \text { Wild-type }\end{array}$




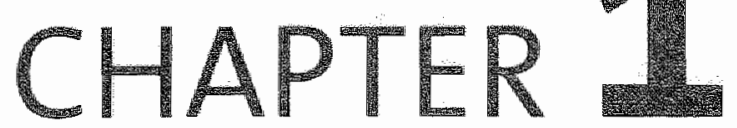

Introduction:

Congenital and Acquired Long QT Syndrome

PART 1: Congenital long QT syndrome PART 2: Acquired long OT syndrome 


\section{PART 1: Congenital long QT syndrome}

\subsection{The history of long QT syndrome}

In 1856 Meissner (1) described the story of a young student at the Leipzig School for the Deaf who collapsed and died suddenly while being admonished by the Director. As it turned out, she was the third member of the family who died suddenly, since her two deaf brothers already died at young age after periods of fright and rage. Already then, signs of genetic inheritance were apparent. One century later, in 1957, Jervell and Lange-Nielsen (2) presented the first formal description of long QT syndrome describing a Norwegian family with six children. Whilst the parents were normal, four of the six siblings were affected by deafness and a prolonged $Q T$ interval on the electrocardiogram ( $E C G$ ), and three out of four affected siblings died suddenly. $A$ few years later, in 1963, Romano (3) described a similar case of a young girl with a prolonged QT interval, experiencing syncopal attacks but without deafness. Independently, Ward (4) reported in 1964 on another family with three family members affected by syncopic attacks, prolonged OT intervals, but no deafness. Today, the Romano-Ward syndrome (RWS) is known as the autosomal dominant inherited form of the disease, whilst the Jervell Lange-Nielsen syndrome (JLNS) is defined as the autosomal recessive form. The prevalence of these disorders is estimated at approximately $1 / 250.000$ for the Jervell and Lange-Nielsen syndrome compared to $1 / 10.000$ for the Romano-Ward syndrome.

\subsection{Clinical features and ECG characteristics}

The clinical symptoms of long QT syndrome (LQTS) include the occurrence of sudden loss of consciousness (syncopes), seizures, cardiac arrest or eventually even sudden death. These symptoms are in many cases preceded by "agitating" factors such as emotions (anger, rage or fright), physical exercise (swimming, football) or auditory arousal (alarm elock, telephone, thunder). Because more than twenty-five cases of LQTS were reported between 1958 and 1970, it was decided in 1979 to start a LQTS registry to study epidemiological and inherited characteristics (5). This registry lead to several studies on the clinical features of LQTS in over 300 different famillies $(6,7)$. The clinical features, risk factors and course of LQTS in probands (symptomatic), affected (asymptomatic) and unaffected family members were evaluated. Individuals were classified as affected on the basis of QT-interval prolongation (Figure 1) and the corrected QT-value (QT) was calculated with Bazett's formula (Figure 1) (8). Major risk factors determined in these studies included $\mathrm{QT}_{\mathrm{c}}$ value, history of cardiac event and heart rate. Compared to asymptomatic affected and non affected members, probands were more likely to have syncopes at young age (50\% by age 12), to be female (69\%), to have a $\mathrm{OT}_{\mathrm{c}} \geq 500 \mathrm{msec}(52 \%)$, and to have a history of ventricular arrhythmia (47\%) $(6,7)$. 


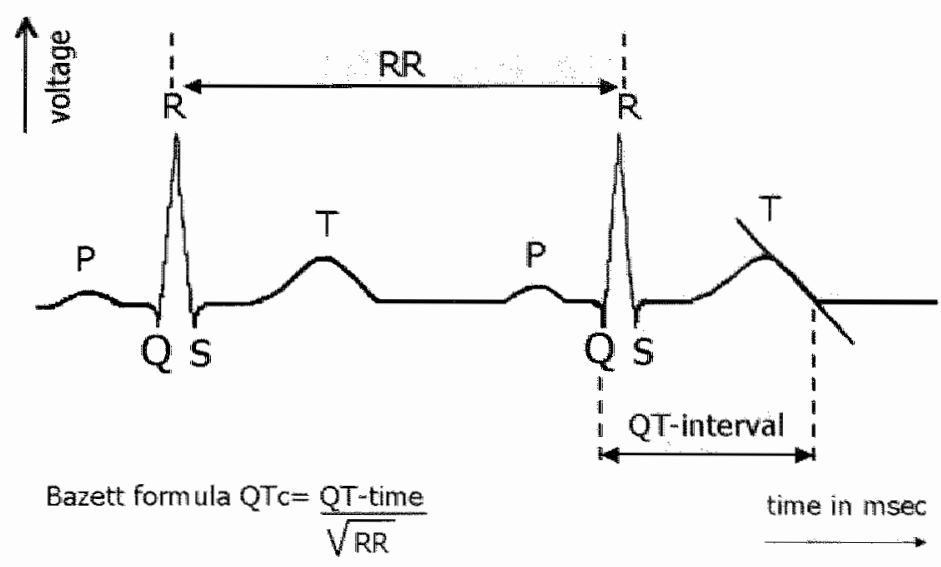

Figure 1. Reflection of a single heart beat on an ECG. The P-wave represents atrial electrical depolarisation and contraction of both atria, the QRS-complex represents left ventricular depolarisation and the end of the T-wave represents ventricular repolarization. The QT interval is defined as the distance between the beginning of the of the $Q$ wave to the end of the T-wave. Bazett's formula used to calculate the QT-interval corrected for the heart rate.

Whilst prolongation of the heart rate-corrected $\mathrm{QT}$-interval ( $\mathrm{QT}_{\mathrm{c}}$ ) is the classical electrocardiographic feature of LQTS, several other ECG changes are in line with the spatial and temporal heterogeneity displayed by repolarisation in LQTS. These changes include T-wave (wide based, double hump) and U-wave abnormalities and relative bradycardia. The episodes of polymorphous ventricular tachycardia that may be evoked, are called Torsades de Pointes (TdP) (Figure 2). This term was first used by Dr. Dessertenne ( 9 ) in 1966 and refers to the morphologic features of the QRS complexes that are of changing amplitude and that appear to twist around an isoelectric point. This rapid ventricular arrhythmia can self terminate, but can also degenerate into ventricular fibrillation. In the latter case, a loss of synchronisation between heartbeat and pulse results in a lack of cardiac output, causes syncope and, if not defibrillated, sudden death.

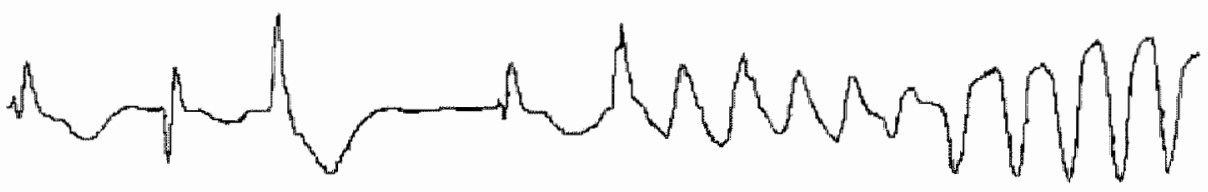

Figure 2. Example of an episode of Torsades de Pointes.

A survey of studies between 1985 and 1991 on the diagnostic criteria of LoTS indicated that better specifications were needed (6). A fixed value of $0.44 \mathrm{sec}$ as a cutoff point for the diagnosis of LQTS had limitations since women turned out to have longer averaged $\mathrm{QT}_{c}$ intervals then men (10). Furthermore, other aberrations in the 
ECG profile besides the QT winterval were not yet implemented in the criteria, nor the early patterns of inheritance of LQTS. Therefore, Schwartz al. (11) refined the diagnostic criteria for LQTS, which are indicated in Table 1 . These criteria provide a scoring system based on clinical characteristics and define the probability of LOTS: a total score of $\leq 1$ : low prabability of LQTS, 2 to 3 points: intermediate probability of LQTS and $\geq 4$ : high probability of LQTS (Table 1 ).

Table 1. Diagnostic criteria for LQTS according to Schwartz et al. (11).

\begin{tabular}{|c|c|}
\hline ECG finding $s^{a}$ & Points \\
\hline \multicolumn{2}{|l|}{$\mathrm{QT}_{\mathrm{c}}^{\mathrm{bb}}$} \\
\hline$\geq 480 \mathrm{msec}^{1 / 3}$ & 3 \\
\hline $460-470 \mathrm{msec}^{1 / 2}$ & 2 \\
\hline $450 \mathrm{msec}^{1 / 3}$ (in males) & 1 \\
\hline Torsade de pointes" & 2 \\
\hline T-wave alternans & 1 \\
\hline Notched T wave in three leads & 1 \\
\hline Low heart rate for age $e^{d}$ & 0.5 \\
\hline \multicolumn{2}{|l|}{ Clinical history } \\
\hline \multicolumn{2}{|l|}{ Syncope } \\
\hline With stress & 2 \\
\hline Without stress & 1 \\
\hline Congenital deafness & 0.5 \\
\hline \multicolumn{2}{|l|}{ Family history ${ }^{e}$} \\
\hline A) Family members with definite LQTS ${ }^{f}$ & 1 \\
\hline B) Unexplained sudden cardiac death below the & 0.5 \\
\hline age of 30 among immediate family members & \\
\hline
\end{tabular}

"In the absence of medications or disorders known to affect these electrocardiographic features, "${ }^{\circ} T_{x}$ calculated by Bazett"s formula, "Mutually exclusive "Resting heart rate below the second percentile for age (1.2), "The same family member cannot be counted in A and B. 'Definite LoTs is defined by a LOTS score 24.

\subsection{Genetic inheritance of long QT syndrome}

In 1991 Keating et al. $(13,14)$ applied genetic linkage analysis in a large 5-generation LQTS family. They established linkage chromosomal location 11 p15.5 which was confirmed in six other small LQTS families (15). However, locus heterogeneity was suspected in LQTS because several groups (16-19) were unable to link other definite LQTS families to locus 11p15.5. Linkage analysis in the latter families revealed two additional loci for LQTS, respectively on chromosomes 7 and $3(20)$. In order of discovery, the loci were named LQT1 (11p15.5). LQT2 (7q35-36) and LQT3 (3p21-24) 
(Figure 3). Further linkage analysis, positional cloning and candidate gene approach led to the identification of the responsible genes KCNQ1, KCNH2 and SCN5A (Figure 3). In addition, increasing numbers of families revealed three other loci LQT4 (ANKB), LOT5 (KCNE1) and LQT6 (KCNE2) (21-23) (Figure 3).
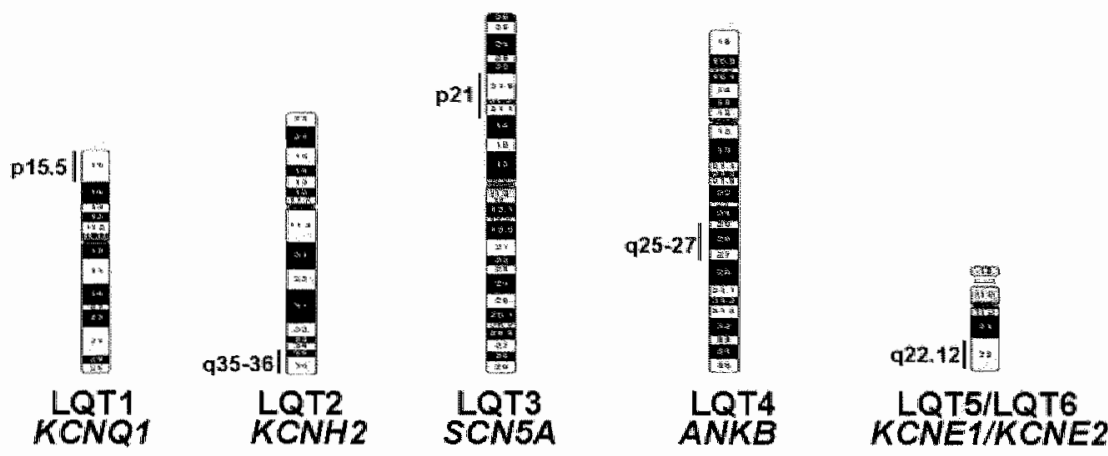

Figure 3. Loci and corresponding genes linked to LOTS.

\subsection{Cardiac ion channel genes}

\subsubsection{LOT1: KCNO1 gene, encoding KVLOT1}

In 1996 a gene with high similarity to a voltage-gated potassium channel, named KCNO1, was discovered at chromosomal location 11p15.5 (24). Furthermore, sixteen distinct LQTS families were found to carry heterozygous mutations in this gene, providing further genetic evidence that mutations in KCNQ1 cause chromosome 11 linked Romano-Ward LQTS (24). The genomic structure of the KCNQ1 gene comprises 16 exans, encompassing approximately $400 \mathrm{~kb}$ (25). Several splice variants of the gene were detected (26) some of which were either non-functional (27) or expressed a dominant negative effect on other splice variants (28). The KCNQ1 gene was found to be widely expressed in different organs or tissues including heart, lung, placenta, pancreas and inner ear, but not in skeletal muscle or brain (29). The encoded KVLQT1 protein forms the $\alpha$-subunit of a voltage gated potassium channel and consists of 6 transmembrane domains with a putative voltage sensor in 54 and a potassium selective pore between 55 and 56 (Figure 4) (24). KVLQT1 $\alpha$-subunits interact with a $\beta$ subunit minK, encoded by the KCNE1 gene, to form a fully functional potassium channel (Figure 4). This channel constitutes the slow component ( $\|_{\mathrm{ks}}$ ) of the delayedrectifier potassium $\left(K^{+}\right)$current that is responsible for the repolarisation of cardiac action potentials (30). Heterozygous mutations in the $K C N Q 1$ gene lead to the dominant Romano-Ward syndrome and many have been reported $(31,32)$. Homozygous mutations in the KCNO1 gene may occur when the same mutation is 
inherited from both the father and the mother, leading to the recessive Jervell LangeNielsen syndrome. As the KVLOT1 protein is also expressed in the inner ear, this syndrome also causes bilateral deafness (33). Also homozygous mutations in the $\beta$ subunit encoded by KCNE1 lead to JLNS (34) as well as two separate heterozygous mutations in KCNQ1 (compound heterozygasity) (35). Recently, the original genotypic descriptions of RWS and JLNS have been questioned with the discovery of homozygous (recessive) mutations in KCNQ1 without deafness, therefore causing RW and not ILN syndrome $(36,37)$. A complete overview of all KCNQ1 mutations identified at present, including functional consequences where available, is presented in Appendix 1.

\subsubsection{LQT2: KCNH2 gene, encoding HERC}

Shortly after linkage of LOTS to chromosome 7. Warmke and Ganetzky (38) identified a novel human cDNA from a hippocampal cDNA library by homology to the Drosophila ether-a-go-go (eag) gene. This human gene, initially called the human ether-ä-go-gorelated gene (HERG), and later assigned the gene symbol KCNH2, shares approximately $50 \%$ amino acid sequence homology to eag. The eag family members have, however, several common structural features such as the hydrophobic domains, a conserved domain (PAS domain) in the cytoplasmic $\mathrm{N}$-terminal end (first 150 aminoacids) and a cytoplasmic C-terminal domain that is very similar to the cyclic nucleotide-binding domain (CNBD) of cyclic nucleotide-gated cation channels in vertebrate photoreceptors (38). Because the Drosophila eag gene encodes a $\mathrm{Ca}^{2+}$. modulated potassium channel (39) and $K C N H 2$ was mapped to chromosomal location 7q35-936, KCNH2 became an obvious candidate for LQTS. Curran et al. (40) reported on additional LQTS families that were all linked to markers on chromosome 7q35-36 and delivered final proof for linkage of $K C N H 2$ to LOTS. They showed that $K C N H 2$ is strongly expressed in the heart and identified six KCNH2 mutations associated with LQTS. The KCNH2 gene comprises 15 exons, encompassing approximately $19 \mathrm{~kb}$ (41). Also KCNH2 encodes a potassium channel $\alpha$-subunit (Figure 4) and analogous to other shaker potassium channels, four of these $\alpha$-subunits form a homo-tetramer (42). Studies in Xenopus oocytes revealed that the HERG potassium channel displays biophysical properties nearly identical to the rapidly activating delayed rectifier $\mathrm{K}^{+}$current $\left(\|_{\mathrm{K} t}\right)$ in cardiac myocytes $(43,44)$. The HERG channel possesses very unique properties: although the HERG protein has the structure of the depolarisation-activated $\mathrm{K}^{+}$ channel family with six transmembrane domains, it exhibits an inward rectification as seen in channels with only two transmembrane domains $(45,46)$. The inward rectification in HERG channels is the result of very rapid voltage-dependent inactivation, reducing the conductance at more positive voltages (45). Electrophysiological studies revealed a spectrum of electrophysiological changes that lead to diminished $I_{k r}$ and delayed repolarisation (47): non-functionality and changed gating properties of channels. Another mechanism involves defects in biosynthetic processing of the channel proteins leading to retention of mutated proteins in the 
endoplasmic reticulum $(48,49)$. A complete overview of all KCNHZ mutations, including functional consequences where available, is presented in Appendix 2.
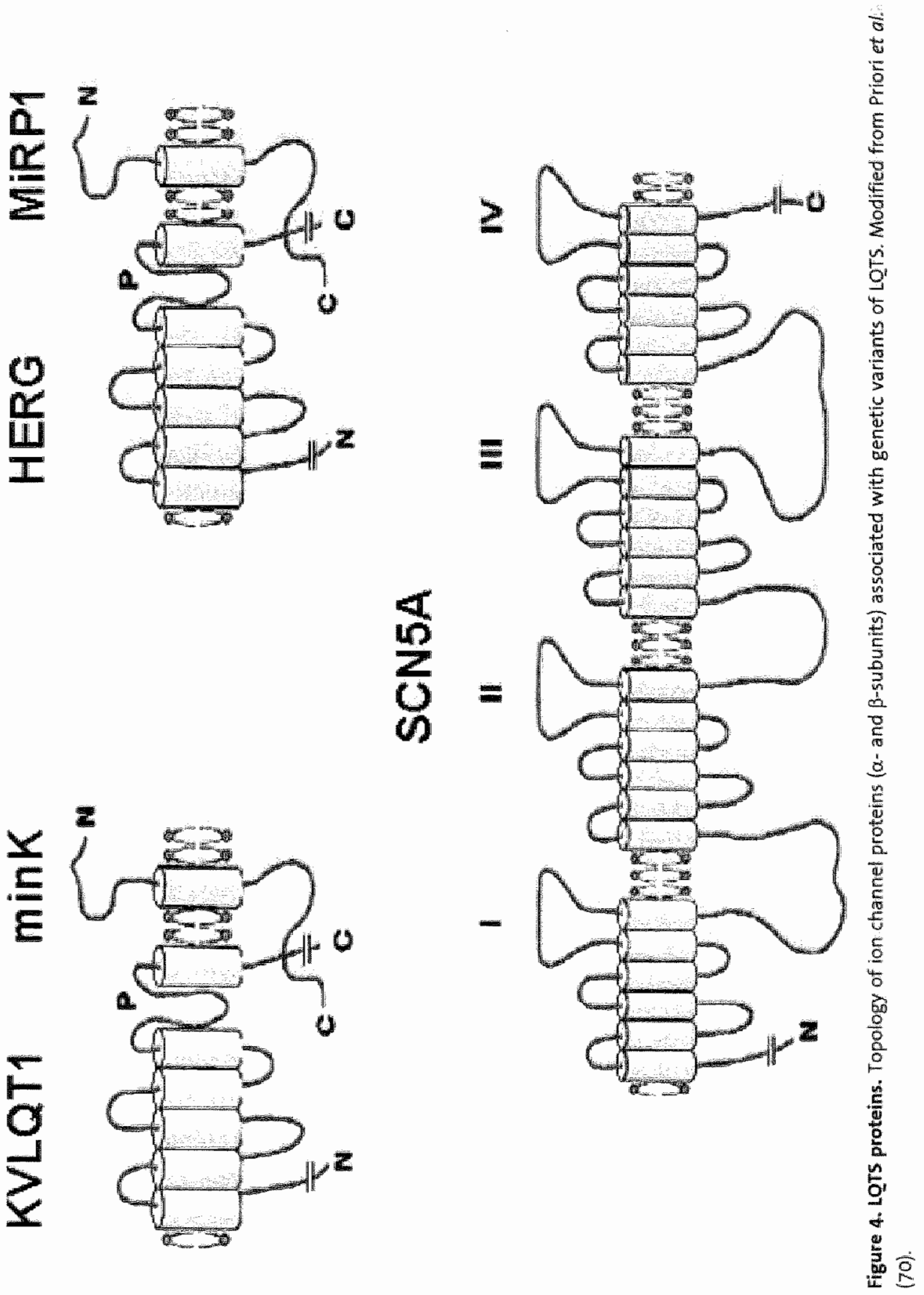


\subsubsection{LQT3: SCN5A gene, encoding SCN5A}

Subsequent to initial linkage of LOTS to the LOT3 locus on chromosome 3 (20), Wang et al. (50) showed that mutations in the cardiac sodium channel gene SCN5A caused LQT3. This gene was cloned and characterised earlier by Gellens et al. (51); it comprises 28 exons which are distributed over a genomic region of $80 \mathrm{~kb}$ and encodes a protein of 2016 amino-acids. The structure of the SCN5A protein is similar to other previously characterised sodium channels: It consists of four homologous domains (DI to DIV), each containing six membrane-spanning segments ( $\$ 1$ to 56 ) with a structure similar to the potassium channel $\alpha$-subunits (Figure 4). Together, these four domains form a fully functional channel. Consequently, in contrast to HERG and KVLOT1, assembly and co-expression of multiple $\alpha$-subunits is not required to produce a functional sodium channel. The SCN5A channel is responsible for the initial depolarising upstroke of the action potential $\left(I_{\mathrm{Na}}\right)$. The mutations detected by Wang et al. (50) were functionally studied in Xenopus oocytes and showed generation of a late phase of inactivationresistant current either by dispersed reopening after the initial transient current or by both dispersed reopenings as well as long lasting bursts $(52,53)$. In contrast to "the lack of function" in LQT1 and LQT2 mutations, LQT3 mutations mostly result in a "gain of function" mechanism, leading to a sustained, non-inactivating inward sodium current during the plateau phase, thereby explaining the prolongation of the action potential. Yet, other mechanisms are possible as An et al. demonstrated (54); mutation D1790G was associated with changed kinetic properties due to interactions with $\beta$ subunits and not with a persistent inward current. It was also discovered that abnormal function of SCN5A channels due to mutations caused other heart diseases such as the Brugada syndrome, progressive cardiac conduction defect and sudden infant death syndrome (55-58). The Brugada syndrome is a familial disease that is characterised by right bundle branch block and ST-segment elevation in leads V1-V3, but with a normal QT-interval. The first two Brugada mutations in SCN5A, described by Chen et al. (59), were located in different regions of the gene as compared to the LQTS mutations. Therefore, a distinction between the two syndromes based on position appeared logical. However, novel mutations detected in both syndromes have abolished this distinction. For instance, a single mutation (1795insD) has been detected that causes both LQTS and Brugada syndrome phenotypes (60). Another mutation has been detected in both LOTS and Brugada syndrome and is located in the same codon, changing the wild-type amino-acid to two different residues $(\mathrm{Y} 1795 \mathrm{C} / \mathrm{Y1795H})(61)$. It is becoming apparent that both syndromes are very closely related in genetic respect but may differ with respect to their phenotypic manifestations. For a complete overview of all detected SCN5A mutations and their phenotypic representation, see Appendix 3. 


\subsubsection{LQT4: ANKB gene, encoding ankyrin-B}

In 1995, linkage to a fourth LQTS locus was established in a four generation LQTS family of 65 members (21). According to the diagnostic criteriz by Schwartz et al. (Table 1), 21 members had high probability scores for LQTS. The phenotypic characteristics of affected family members were different from those observed in other LQTS families (severe sinus node dysfunction, atrial fibrillation and uncommon T-wave morphology, which may explain the exclusion from the other known LQTS loci. Linkage analysis mapped this family to locus $4925-27$ with a maximal LOD score of 7.05. Very recently the gene responsible for LQT4 in this family has been identified (194). A loss-of-function mutation E1425G in the ankyrin-B gene (ANKB) was shown to cause dominantly inherited type 4 LOTS in affected family members. The ANKB gene is member of a family of versatile membrane adaptors and is therefore so far the only LQTS gene encoding a protein that is not an ion channel or subunit.

\subsubsection{LQT5: KCNE1 gene, encoding mink}

The KCNE1 gene was originally cloned from rat kidney and was localised to chromosomal location 21q22.1 (62). The minK protein, encoded by KCNE1, consists of a small 130 amino-acid protein with a single membrane-spanning domain $(63,64)$. The human mink protein only showed functionality in Xenopus oocytes through interaction with endogenous KVLQT1 proteins and thereby functions itself as an ancillary $\beta$-subunit. By co-expression of $\alpha$-subunits (KVLQT1) and $\beta$-subunits (minK) the channel characteristics most closely resemble the native $1_{\mathrm{k}: s}$ cardiac potassium current $(29,30)$. McDonald et al. reported that minK may also interact with the HERG $\alpha$-subunit to modulate the rapid delayed rectifier current $I_{\mathrm{Kr}}(65)$. MinK mammalian mRNA was detected in several tissues including heart and inner ear $(66,67)$, which made the KCNE1 gene an excellent candidate for both RWS and ILNS. In 1997 Splawski et al reported two KCNE1 mutations in separate RWS families both causing a reduction in $I_{k s}$ when coexpressed with KVLQT1 (22). Whilst first excluded as a candidate for JLNS (68), later studies indicated that mutations in KCNE1 Can also cause JLN syndrome (69). For a complete overview of all detected KCNE1 mutations and their phenotypic representation, see Appendix 4.

\subsubsection{LQT6: KCNE2 gene, encoding MiRP1}

The KCNE2 gene was cloned and characterised in 1999 by Abbott et al. (23). The KCNE2 gene was mapped to chromosome 21q22.1, close to KCNE1. The encoded MiRP1 protein consists of a small integral potassium channel $\beta$-subunit of 123 amino acids that contains a single transmembrane segment. Similar to co-assembly of mink with KVLOT1, the MiRP1 protein was found to co-assemble with HERG and modulate its channel function. Abbott et al. detected three mutations in this gene. Two of these were detected in congenital LQTS families, one other was detected in a patient with drug-induced arrhythmia. For an overview of detected mutations in KCNE2 and their functional significance, see Appendix 5. 


\subsection{Involvement of LQTS genes in the cardiac action potential}

The electrical potential of myocardial cells is based on a series of ionic events. The delicate balance between these ionic currents form the cardiac action potential. For several of these currents the responsible genes have been identified (Figure 5). The proteins (and genes) that were described in the previous sections because of their involvement in LOTS, all fulfil important contributions to the cardiac action potential (Figure 6). The 5CN5A protein is largely responsible for the depolarising upstroke (phase $O_{i} \|_{\text {N. }}$ ), while the potassium channel proteins KVLQT1, HERG, minK and MiRP1 are mainly involved in the rapid and slow component of cardiac repolarisation (phase 2 and $3, l_{k r}$ and $\left.\|_{k s}\right)$. Mutations in the genes encoding these proteins cause a prolongation of the ventricular action potential by a reduction in outward currents $\left(I_{k r *}\right.$ $I_{K_{3}}$ ) or an enthancement of inward current $\left(I_{\mathrm{Na}}\right)$. The functional consequences of a mutation can be studied by expression of mutated channels in heterologous systems such as Xenopus oocytes or mammalian cell lines. Mutations have shown to lead to a broad scala of dysfunctional channels among which non-functionality, reduced or modified gating at the plasma membrane, or non-expression at the cell membrane by deficient transport from the endoplasmic reticulum. As a consequence of tetrameric channel formation by $\alpha$-subunits (KVLQT1 and HERG), heterozygous mutations, which are detected in the majority of RWS patients, may cause additional negative effects on channel function (Figure 7 ).
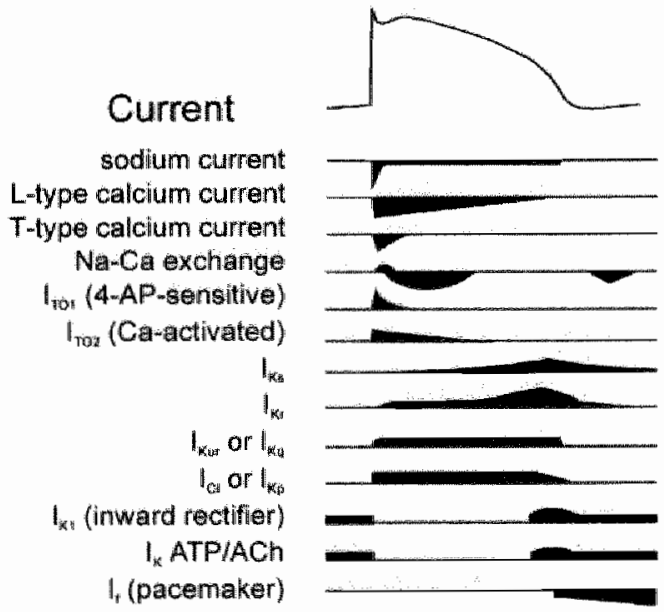

\section{Probable clone}

$\mathrm{HhH} 1$

$a_{\text {:C }}$ dihydropyridine receptor

$\alpha_{19}$

$\mathrm{Na}-\mathrm{Ca}$ exchanger

KV4.2/4.3

-.

KVLOTH+minK

HERG + ?

KV1.5

CFTR N TWIK

Kir2 tamily

GIRK1+4/Kir6. 2+SUR1

HCN2

Figure 5. Ionic currents and responsible genes. Separated ionic currents contributing to the regulation of the cardiac action potential. The time dependency of activation of the currents is shown in relation to the phases of the action potential and the direction of the flow: inward currents are represented under the line, outward currents are represented above the line. From Snyders et al. (74).

Incorporation of mutant subunits can disrupt the function of the wild-type subunits. $(47,71)$. which is called a "dominant negative" effect. A strong dominant negative effect is expected if one abnormal subunit is sufficient to completely inactivate 
channel function. In this case, only $6.25 \%$ of the channels will be functional (Figure 7 ). Mutations in the LQT3 gene SCN5A usually cause extra sodium channel activity during the plateau phase of the action potential ("gain of function"), leading to additional inward current and thereby prolonging action potential duration (53.72).

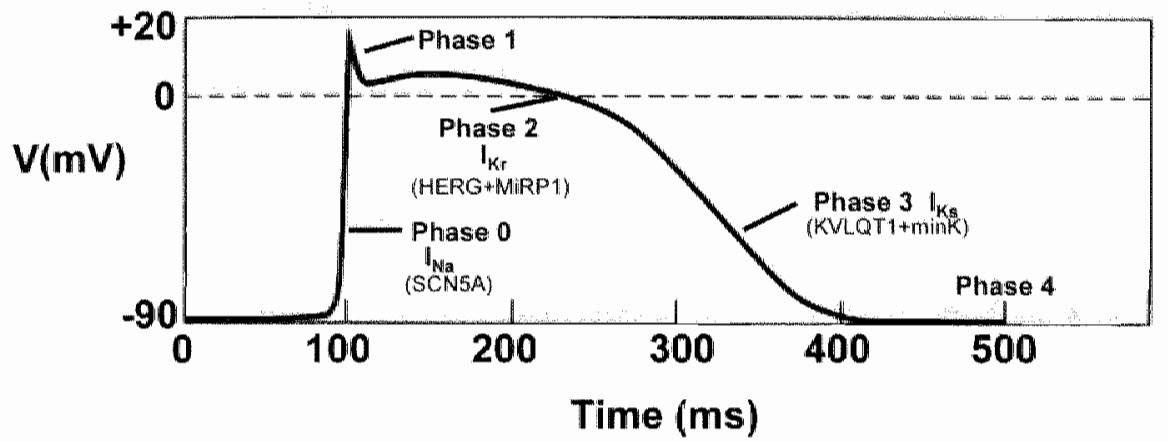

Figure 6. LQTS genes involved in the cardiac action potential. Many proteins together form the cardiac action potential (Figure 5), of which so far 5 are implicated in the LOTS. The time course of the action potential can be divided into five phases: upstroke of rapid depolarisation (phase o), which is mostly the result of rapid inflow of sodium ions (SCNSA); early repolarisation after the peak (phase 1) is primarily the result of $\mathrm{K}^{*}$ current $l_{\text {ioj }}$ the plateau (phase 2) where there is a balance of the inward currents caused by calcium and sodium and outward currents caused by chloride and potassium $\left(\mathbb{k}_{k,}\right.$. HERG, MiRP1); repolarisation after the plateau (phase 3), predominantly caused by outward potassium current (I:s, KVLQT 1, minK); and the period between the maximum negativity (maximum diastolic potential) and the upstroke of the next action potential (phase 4) caused by the balance between slow inward sodium current and outward potassium current. From Towbin et al. (73).

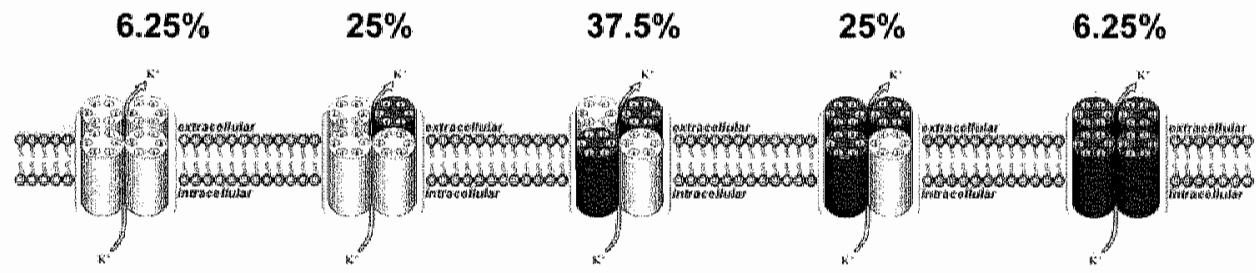

Figure 7. Tetrameric chanmel formation. Functional potassium channels are formed by coassembly of four KLOT1 or HERG a-subunits. In the dominant RW syndrome, patients inherit one normal allele and one mutamt allele from their parents. With the availability of $50 \%$ wild-type subunits (light grey) and $50 \%$ mutant subunits (dark grey), the statistical distribution of possible co-assembled tetramers is presented above.

\subsection{Genotype-phenotype correlations in LQTS}

The availability of genetic screening and the continuously growing number of LQTS families have initiated correlation studies between genotype and phenotype. On one hand, correlations were made on the basis of clinical symptoms (age at onset: recurrences and lethality). For example, Zareba et al (75) indicated that the risk of 
experiencing cardiac events was higher in LQT1 and LOT2 mutation carriers, although the likelihood of dying at an event was significantly higher among LQT3 carriers. On the other hand, correlations were made on the basis of ECG characteristics. Moss et al. (76) showed that ECG T-wave patterns were different among LQT1, LQT2 and LOT3 forms; specific details per genotype include the unusual large distance between the start of the Q-wave and the beginning of the T-wave in LQT3 mutation carriers, the extremely low T-wave amplitude in LQT2 mutation carriers and the long duration time of the T-wave in LQT1 mutation carriers. Although a typical pattern cannot always be found, this method can eventually be usefull to select the first gene to be screened for mutations (77). An additional characteristic that may point to the gene affected, is the trigger for cardiac events. Exercise related events seem to dominate the clinical picture in LQT1 (78), with a particularly high incidence caused by swimming (79-81). Triggers initiating cardiac events in LQT2 are dominated by auditory stimuli such as alarm clocks, thunder, telephone ring, etc. $(82,83)$. The majority of cardiac events in LQT3 patients is triggered by rest or sleep (83).

\subsection{Therapy in congenital Long QT Syndrome}

\subsubsection{Acute treatment}

Intravenous administration of magnesium is usulally very effective to rapidly end non self-terminating TdP and prevent recurrences. Magnesium is therefore the first choice of treatment, although the exact mechanism of action is unknown (84). If magnesium therapy fails, cardiac pacing may be effective. Cardiac pacing prevents pauses and shortens the $\mathrm{QT}_{c}$-interval by enhancing repolarising potassium currents (85).

\subsubsection{Chronic treatment}

\subsubsection{B-Adrenergic blocking drugs}

B-blockers are the first choice of treatment for symptomatic LQTS patients. The effectiveness of $\beta$-blockers lies in the suppression of adrenergic stimulation, which is often the trigger for arrhythmias $(86,87)$. Advantages of this treatment include high effectiveness and no need for direct surgery. Long-term use of 3 -blockers has shown to significantly reduce cardiac events in LQTS patients (88). However, $\beta$-blocker therapy is more effective in LQT1 and LQT2 patients than LQT3 patients. The latter group may benefit more from a sodium channel blocker such as mexiletine (89). Patients who remain symptomatic despite $\beta$-blocker therapy require additional treatment $(87)$. With more genetic information becoming available, effectiveness of therapy may be optimised in the future when it can be adjusted to genotype.

1.7.2.2. Cardiac pacemakers.

Additional cardiac pacing is required in patients who remain symptomatic despite maximal doses of $\beta$-blockers $(90,91)$. Especially patients with pause-dependent or bradycardiac arrhythmias may benefit from this therapeutic option. These include 
many LQT3 mutation carriers of whom the majority experience symptoms at rest during slow hart rates (92). Pacemaker therapy should always be complemented with $\beta$-blockers to suppress possible arrhythmias triggered by adrenergic stimulation (93).

\subsubsection{Left Cardiac Sympathetic Denervation}

Initially, an unequal contribution of left sympathetic cardiac innervation compared with right sympathetic innervation was considered responsible for QT prolongation. Therefore, in case of failing results with $\beta$-adrenoceptor blockade, left sympathetic denervation was introduced in the late 1960 s (94). The discovery that cardiac ion channel malfunctions are responsible for LOTS has called this "sympathetic imbalance" theory into question. Long-term studies have shown however that left cardiac sympathetic denervation reduces arrhythmic risk when $\beta$-blockers fail, possibly also by blocking adrenergic pathways (95). Like pacemakers, this therapeutic option should also be complemented with $\beta$-blockers.

\subsubsection{Implantable Cardioverter Defibrillator}

Implantable cardioverter defibrillators (ICD's) were introduced in the 1980s (96). This device does not prevent torsade de pointes, but rather prevents sudden death when torsades de pointes is prolonged or degenerates into ventricular fibrillation (VFi). The ICD will give shocks to bring the heart back to sinus rhythm, and therefore works as a "fail-save" mechanism. This therapy, in combination with $\beta$-blockers, has shown to reduce mortality rates in patients with spontaneous life-threatening arrhythmias (97). When considering ICD implantation, one should keep in mind economical issues such as costs, limited lifetime expectancy and long-term complications $(98,99)$. In addition. personal issues such as the psychological effect of inappropriate shocks and restrictions on sports or driving should not be overlooked $(100,101)$.

\subsubsection{Gene specific therapy}

The identification of the molecular basis of LQTS opened the door towards genespecific and possibly mutation-specific therapy. Realising that LQT genotypes differ in clinical and electrocardiographic characteristics has led to the assumption that blocking the $\mathrm{Na}^{*}$ inward current may be a more effective treatment in LQT3 patients while enhancement of repolarising $K^{*}$ currents may be more beneficial in LQT 1 and LQT2 patients. Schwartz et al. (89) tested the efficacy of mexiletine, a knowin Na' channel blocker, in LQT2 and LQT3 patients and showed that mexilletine significantly shortens the QT interval among LOT3 patients but not in LQT2 patients. In addition, this study showed that LQT3 patients shorten their QT interval much more than LQT2 patients in response to an increased heart rate. Therefore, restriction of exercise may not be needed in LQT3 patients. Two other sodium channel blockers, lidocaine and tocainide, have also proven to shorten abnormal QT prolongation in LQT3 mutation carrilers (102). Beta-blockers remain the first line of therapy to suppress adrenergic activated triggers in LQT1 and LQT2 patients, although other options are also being tested. Since these patients have inadequate potassium outflow currents, augmentation of the outward currents and shortening of QT-intervals can be achieved 
by raising potassium serum levels $(103,104)$. Even therapies for patients with a specific mutation are now being developed. For example, long-term normalisation of the QT interval was accomplished with flecainide but not with lidocaine (105) for the D1790G mutation in SCN5A. Also trafficking deficient mutations in the $K \mathrm{CNH}_{2}$ gene and the SCN5A gene are the topic of mutation-specific therapy. For example, the trafficking deficient mutation N47OD in KCNH2 could be rescued with fexofenadine without blocking the channels (106) and mutation M1765L in SCN5A could be rescued with mexiletine, although the persistent late sodium current displayed by the rescued protein still needs to be resolved (107). The development of gene-specific and mutation-specific therapy is promising and may significantly improve treatment for LQTS patients. As mutation-specific therapy will usually only be useful in a single family, the financial support to develop such therapies will probably be the greatest challenge.

\section{PART 2: Acquired long QT syndrome}

QT prolongation and increased QT dispersion are risk factors in a number of cardiovascular diseases. Many different classes of drugs have QT-prolonging potential, including anti-arrhythmics, antihistamines, antibiotics and antipsychotics (Table 2). The largest group form the class III anti-arrhtyhmics, which very effectively stop reentrant tachycardias by selectively blocking $\mathrm{K}^{*}$ channels. By doing so, however, they also prolong the cardiac repolarization and may therefore induce TdP. Between $1 \%$ and $8 \%$ of the patients receiving these QT-prolonging antiarrhythmic drugs develop $\mathrm{TdP}$ (108). Because the clinically observed symptoms clearly resemble the symptoms in congenital long QT syndrome, this disorder is being referred to as acquired long QT syndrome.

In addition to the trigger drug(s), other risk factors are usually involved in acquired LQTS, such as female sex, electrolyte disturbances, other heart disease, concomitant medication and baseline QT prolongation. In the following sections the most important acquired LOTS causing drugs (section 1.8) and risk factors (section 1.9) are discussed. 
Table 2. Drugs that prolong the QT-interval and/or induce TdP.

Source: www Torsades.org.

\begin{tabular}{ll}
\hline Type of drugs & Examples \\
\hline Anti-arrhythmic drugs & $\begin{array}{l}\text { amodarone, disopyramide, dofetilide, } \\
\text { flecainide, ibutilide, procainide, quinidine, } \\
\text { sotalol }\end{array}$ \\
Anti-biotics & $\begin{array}{l}\text { clarithromycin, erythromycin, gatifloxacin, } \\
\text { levofloxacin, moxifloxacin, sparfloxacin }\end{array}$ \\
Anti-depressants & fluoxetine, paroxetine, sertraline, venlafaxine \\
Anti-histamines & astemizole, terfenadine \\
chti-psychotics & $\begin{array}{l}\text { mesoridazine, pimozide, quetiapine, } \\
\text { risperidone, thioridazine, ziprasidone }\end{array}$ \\
Miscellaneous & arsenic trioxide, bepridi, cisapride, dolasetron, \\
& felbamate, foscarnet, fosphenytoin, \\
halofantrine, indapamide, isradipine, & levomethadyl, moexipril, nicardipine, \\
naratriptan, octreotide, pentamidine, & salmeterol, sumatriptan, tacrolimus, \\
tamoxifen, tizanidine, zolmitriptan
\end{tabular}

\subsection{Drugs causing QT-prolongation and torsades de pointes}

\subsubsection{Antiarrhythmic drugs}

\section{Class IA drugs}

Examples of Class IA drugs causing TdP are quinidine, disopyramide and procainamide. These agents decrease ventricular automaticity and thereby reduce ectopic beats that may trigger reentrant tachycardias. The effect of these drugs in slowing conduction velocity in fast channel tissue is the basis for their use in the control of the rate of existing reentrant tachycardias. Between $1 \%$ and $3 \%$ of patients receiving quinidine develop TdP, the majority in the presence of hypokalemia, slow heart rates or concomitant medication (109). Case reports on TdP during disopyramide and procainamide treatment have also been reported (110), although with less frequency than quinidine.

\section{Class III drugs}

Examples of Class III drugs causing TdP are sotalol, amiodarone, ibutilide and dofetilide. Class III drugs increase action potential duration (APD) without effecting conduction by selectively blocking $K^{*}$ channels in fast channel tissue. Reentry is made more difficult when the refractory period of myocardial fibers in the reentrant circuit is prolonged to such an extent that the propagating reentrant impulse no longer finds 
excitable myocardium. However, these drugs can also be pro-arrhythmic because prolongation of the APD can lead to "early after depolarisations" and cause TdP. sotallol has been associated with TdP in numerous case studies, especially in the presence of hypokalemia (111) or overdose (112). In a large sotalol study, between $2 \%$ and $5 \%$ of the treated patients developed TdP, with threefold greater odds for women to develop TdP than men (113). Case reports on TdP evoked by amiodarone are numerous, although the overall incidence of $T d P$ under amiodarone therapy is relatively small and below $1 \%$ (114). Ibutilide and dofetilide are new generation Class III anti-arrhythmic drugs. Unlike sotalol and amiodarone, these new drugs mediate their effect selectively by prolonging APD through augmentation or blockade of specific ionic currents. Approximately $3 \%$ to $4 \%$ of patients receiving intravenous dofetilide and $0.8 \%$ to $1.5 \%$ of patients on oral dofetilide therapy experience TdP (115). Development of TdP is a well-recognised side effect of all the above-described drugs, although this does not withhold them from still being frequently used. The reasons are probably because these drugs are used to prevent death in the presence of acute life-threatening arrhythmias and because competitive drugs devoid of TdP-inducing side effects are currently lacking.

\subsubsection{Second generation antihistamines}

\section{Terfenadine and Astemizole}

Antihistamines are therapeutic agents used for the treatment of allergic diseases, e.g. seasonal and perennial rhinitis (cold), urticaria (nettle rash) and pruritus (itches). Because of their excellent safety record in the past half century, most of them can be obtained without prescription. Cases of TdP development caused by terfenadine and/or astemizole treatment have been reported since the 1980's, initially only due to overdoses, but later also due to normal doses or concomitant medication (116-118). After several "black box" warnings, terfenadine was removed from the US market in 1997 followed by astemizole one year later. Several in vivo studies in laboratory animal models have indicated that both terfenadine and astemizole can prolong the QT interval $(119,120)$. Additional in vitro studies indicated that both drugs significantly block $I_{k r}$ (HERG) current in a dose-dependent manner (121).

\subsubsection{Antibiotics}

\section{Erythromycin and Clarithromycin}

Erythromycin and clarithromycin are antibiotics used to treat a wide variety of bacterial infections, such as infections of the respiratory tract, the middle ear, and $5 \mathrm{kin}$. Drici et al. (122) reported 346 cases of erythromycin related to cardiac arrhythmia in the FDA SRS database between 1970 and 1996. Fourty-nine of these cases were life threatening ventricular arrhythmias or death directly related to intravenous erythromycin lactobionate (123). Development of $\mathrm{TdP}$ with the sole administration of clarithromycin has been reported but is rare (124). Whilst both drugs can be the sole cause of TdP development, the majority of reported cases involved concomitant 
administration of another QT-prolonging drug (See also section 1.9.4). For instance, in case of the prokinetic drug cisapride $65 \%$ of the published reports involved concomitant administration of either erythromycin or clarithromycin (125). In vivo and in vitro studies have investigated the cardiotoxic effect of erythromycin. Daleau et al. (126) demonstrated that erythromycin inhibits $I_{\mathrm{K} r}$ in guinea pig myocytes while Rubart et al. (127) demonstrated that prolongation of the QT interval in canine Purkinje fibers was also due to $I_{k r}$ blockade. Antzelevitch et al. showed that erythromycin preferentially prolonged APD in canine M-cells but not in endo- or epicardial cells. The resulting marked dispersion of repolarization across the ventricular wall creates "early after depolarisations" and was shown to set the stage for TdP development (128). Recently, Volberg et al. showed that both clarithromycin and erythromycin black stably expressed HERG channels in HEK293 cells in a concentration dependent manner (129).

\subsubsection{Cholinergic antagonists \\ Cisapride}

Cisapride is a gastrointestinal prokinetic agent that has been widely prescribed for the treatment of a variety of gastrointestinal motility disorders, including gastroparesis and gastroesophageal reflux disease (130). Until 1999, cisapride was associated with 341 reports of heart rhythm disturbances including QT prolongation, syncope, serious ventricular arrhythmia (TdP) and sudden death (131). After 3 "black box" warnings, cisapride was withdrawn from the market in the USA in 2000. Several electrophysiological experiments and animal studies have determined a reasonable explanation for cisapride's QT-prolonging and TdP-inducing abilities; cisapride has proven to be a very potent blocker of HERG potassium channels $\left(l_{k_{1}}\right)(132-134)$ and has demonstrated to cause "early after depolarisations" in anaesthetized rabbits (135).

\subsubsection{Antipsychotics}

Thioridazine, Haloperidol and Droperidol

Thioridazine is a phenothiazine used to treat schizophrenia and other psychotic disturbances such as depression and anxiety. It is also used for the treatment of autistic children and of epileptic children with behavioural disorders. Haloperidol is an antipsychotic drug mainlly used to treat schizophrenia, but is also being prescribed for Gilles de la Tourette syndrome and manias. Both thioridazine and haloperidol have sedative effects that make them very suitable for violent and agitated patients. Droperidol is usually applied as a sedative or a treatment for nausea and vomiting. The first reports of sudden arrhythmic death with thioridazine appeared in 1963 (136) and reports until today are numerous. Newer drugs haloperidol $(137,138)$ and droperidol have also been associated with $\operatorname{TdP}(139,140)$. In vivo experiments in perfused guinea pig hearts and in vitro experiments in tsA201 cells have demonstrated that thioridazine blocks the delayed rectifier potassium current $I_{k,}$ (HERG) (141). Experiments in Xenopus oocytes indicated that haloperidol blocks the HERG potassium 
channel by binding to the channels in the inactivated state at haloperidol concentrations similar to plasma levels found in patients with haloperidol-induced TdP (142). Finally, experiments in HEK293 cells showed very potent HERG block of droperidol at therapeutic concentrations (143).

\subsection{Risk factors for acquired LQTS}

\subsubsection{Age and gender}

During childhood the length of $\mathrm{QT}_{c}$ intervals are similar for girls and boys. However, during puberty men shorten their $\mathrm{QT}_{c}$ interval, whilst the $\mathrm{QT}_{\mathrm{c}}$ intervals for women remain unchanged (144). These age- and sex- differences are also apparent in individuals affected by congenital long QT. Locati et al. showed that, consistent with $\mathrm{QT}_{c}$-interval development, the risk of cardiac events in LQTS mutation carriers is higher in males until puberty and higher in females during adulthood (145). Analogous to the gender differences observed in the clinical manifestations of congenital LOTS (146), there is also a higher risk for adult women to develop acquired LQTS. This higher risk for women to develop acquired arrhythmia is illustrated by the large number of feminine case reports $(122,147)$ (Table 3 and 5). The mechanisms for the age and sex differences remain currently unclear, although preliminary animal studies have indicated that sex hormones may contribute to QT interval shortening in males or the lack of shortening in females $(148,149)$.

\subsubsection{Electrolyte disturbances}

Electrolyte disturbances such as hypokalemia are reported as a contributing factor in many individual TdP case reports. This additional risk factor is explained by the modulation of $\mathrm{I}_{\mathrm{kr}}$ by external potassium (150). Unlike other $\mathrm{K}^{+}$currents, the magnitude of outward HERG current amplitude is paradoxically reduced upon removal of extracellular $K^{*}$. The reduced HERG current amplitude thus explains the prolonged ventricular repolarization in hypokalemic patients. Because the majority of the drugs causing acquired LQTS act through blockade of the HERG channel, hypokalemia can exaggerate this effect (151). As a consequence, administration of potassium supplements can sometimes be useful in these patients.

\subsubsection{Other heart disease}

Not surprisingly, patients with underlying structural heart diseases are more vulnerable to drug-induced TdP. QT prolongation in patients recovering from myocardial infarction has been well documented (152). It was shown that 9 out of 13 patients suffering from TdP had an underlying structural heart disease such as ischaemic, valvular or hypertensive heart disease (153). As also seen in congenital LQTS type 3, bradycardia can also play an important role in the trigger for TdP (154). 


\subsubsection{Underlying congenital LQTS}

In 1982, Moss et al. (155) hypothesized that some drug-induced arrhythmias may depend on genetic predisposition and represent forme fruste cases of the congenital LOTS. This hypothesis was intensified later when it became apparent that some KCNH2 mutation carriers had normal OT intervals (156). It was hypothesized that the latter group of individuals would be particularly susceptible to drug-induced LQTS. Indeed, sporadic forme fruste cases of congenital LOTS have been reported (Table 3). In addition, common polymorphisms in LQTS genes might modify arrhythmia susceptibility in potential gene carriers. Sesti et al. (157) demonstrated that a common polymorphism in KCNE2 (T8A) contributed to acquired LQTS because of altered sensitivity of HERG/MiRP1 channels to an antibiotic (Table 3). However, studies in larger groups of acquired LOTS patients $(158,159)$ showed that only a minority of the cases could be explained by underlying mutations in currently known LOTS genes. The majority of acquired LQTS patients often carry several risk factors, but still the development of life-threatening arrhythmias remains unpredictable.

\subsubsection{Concomitant medication and metabolism}

Drug interactions accur when the effectiveness or toxicity of a drug is altered by the administration of another drug. Often this is caused by an inhibition of the metabolism of a drug due to co-administration of another drug. Such drug metabolism inhibition results in elevated plasma drug concentrations with an increased potential for adverse effects (164).

The family of cytochrome P450 (CYP450) enzymes accounts for the majority of oxidative biotransformation of xenobiotics and endogenous chemicals. In the human genome more than 50 different $\mathrm{CYP} 450$ genes are present, that are classified into different subfamilies on the basis of sequence homology. One of these subfamilies is the CYP3A family, consisting of CYP3A4, CYP3A5 and CYP3A7 respectively. The CYP3A members are the most abundant CYP450 enzymes in the human liver and small intestine (165) and catalyse the oxidative, peroxidative and reductive metabolism of structurally diverse endobiotics, drugs and procarcinogenic molecules (166). The totall CYP3A activity is responsible for the biotransformation of approximately $60 \%$ of all oxidised drugs (167). The contribution of each of these CVP3A genes to the total CYP3A activity is still largely under debate. It has been shown that CXP3A7 is predominantly expressed in foetal life and that its expression seems to be silenced shortly after birth. However, some people express CVP3A7 mRNA into adulthood and contribution of CYP3A7 in these individuals to metabolism is unclear (168).

The CYP3A4 and CYP3A5 enzymes have wide overlapping substrate specificity and it is therefore very difficult to separate the metabolism of these two enzymes. Many of the drugs described in the previous sections are, at least among others substrates or inhibitors of the CYP3A4/5 enzymes (Table 4). These substrates however also block the 
HERG potassium rectifier current. Inhibition leads to elevated drug plasma levels and this can result in a higher potency for HERG block, QT-prolongation and an increased risk of developing TdP. Drug-induced TdP as a result of concomitant drug administration is illustrated by the increasing number of individual case reports (Table 5).

For both CYP3A4 and CYP3A5 activity there is evidence for a wide variation in expression. Several studies have shown, for instance, that in only $10 \%$ to $30 \%$ of adult human livers CYP3A5 expression can be detected (191). The genetic basis for this variability in expression, if any, is currently under research $(192,193)$. The contribution of CYP3AS expression may however play an important role as a study by Gibbs et al. (194) demonstrated: it was shown that liver and intestinal microsomes that contained an equal or greater amount of CYP3A5 in addition to CYP3A4, were less susceptible to inhibition by ketoconazole and fluconazole. It was therefore concluded that variable CYP3A5/CYP3A4 enzyme expression in gut and liver may contribute significantly to the inter-individual variability in adverse drug-drug interactions, such as TdP. associated with concomitant ketoconazole- and fluconazole administration. 


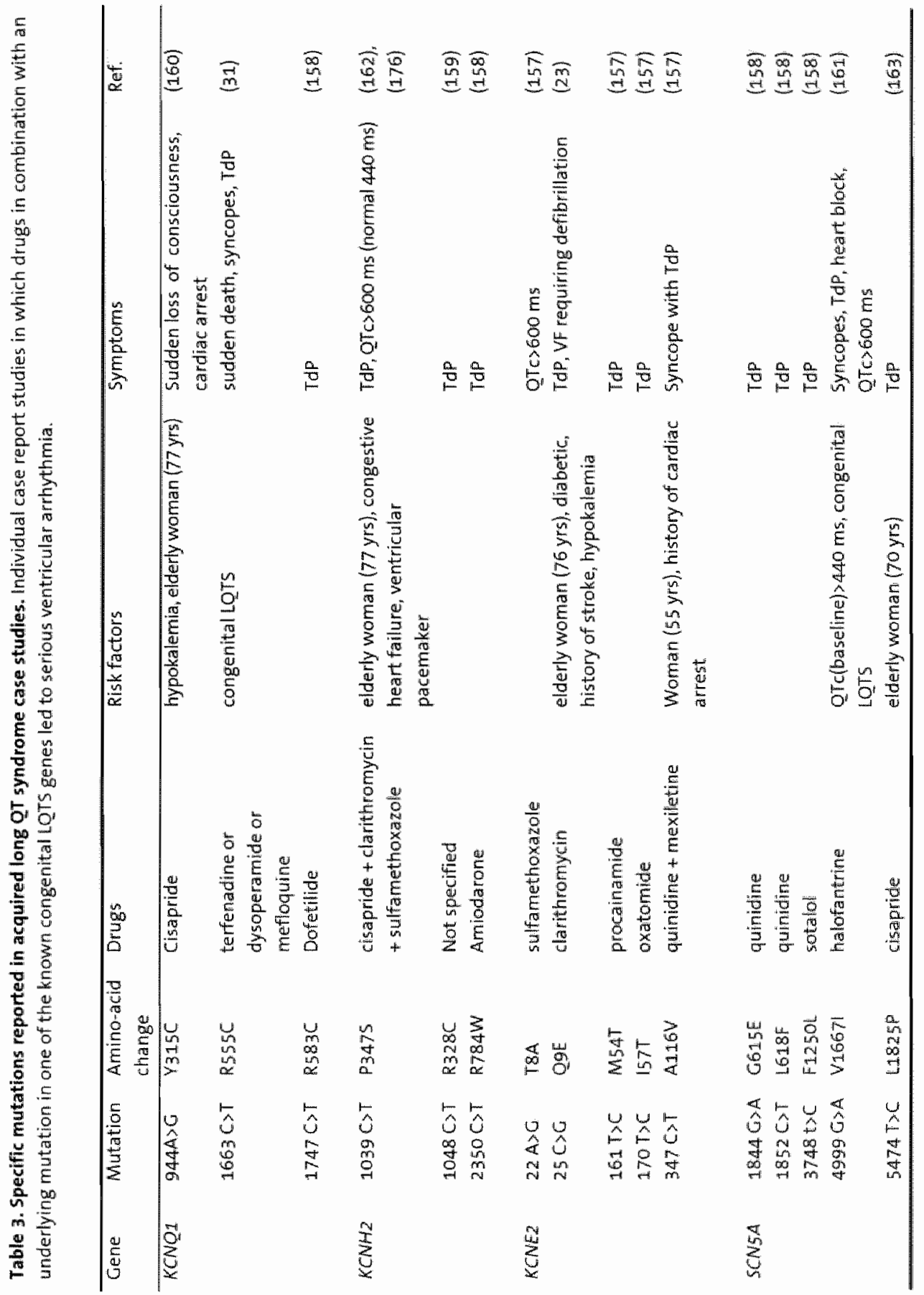


Tablle 4. Drugs netabohised by cytochrome P450 $344 / 5$ and its clinically most relewant inhibitors.

\begin{tabular}{|c|c|c|}
\hline \multicolumn{2}{|c|}{ CVPA4/S substrates } & \multirow{2}{*}{$\begin{array}{l}\text { CVP3A/S inhibitors } \\
\text { Cimetidine }\end{array}$} \\
\hline Amiodarone & Midazolart & \\
\hline Astemizole & Whifediphe & Clarthromycin \\
\hline Garbamazepine & Pimozide & Cyclosporin \\
\hline Cisapride & Propafenone & Diltiarem \\
\hline Cyclosporin & Qunindine & Erythromycin \\
\hline Dapsone & Tacrolimus: & Fluconazole \\
\hline Diltiazem & Tamoxifen & Fluoxetine \\
\hline Dusopyramide & Terfenadine: & Fluvoxamine \\
\hline Erythromycin & Testosterane & Grapefruit juice \\
\hline Felodipine & Valpirolc acid & Itraconazole \\
\hline Lidocaine & Verapamil & Ketoconazole \\
\hline Indinavir & & Miconazole \\
\hline Lovastatin & & Ritonavir \\
\hline
\end{tabular}

Adapted firom Dresser et al. $2000(164)$.

Table 5. Reported cases of acquired LQTS by concomitant medication.

\begin{tabular}{|c|c|c|c|c|c|}
\hline Drumg $\mathbb{1}$ & Drug 2 & $\operatorname{sex}$ & Age (yrs) & Symptoms & Reference \\
\hline Astamizole & Ketoconiazole & Female & 63 & $T d P$ & $(169)$ \\
\hline Astemizole & Erythtiromycin & Female & 30 & $\operatorname{TdP}$ & $(170)$ \\
\hline Astemizole & Cimetidine & Female & 77 & $T d P$ & $(171)$ \\
\hline Terfemadine & Htraconazole & Female & 26 & TdP & $(172)$ \\
\hline Terfenadine & Katoconazole & Femalle & 39 & $T d P$ & $(118)$ \\
\hline Terfenadine & Itraconazole & Female & 36 & $T d P$ & $(189)$ \\
\hline Cisappide & Ketoconazole & Female & 57 & $T d P, V F$ & $(175)$ \\
\hline Cisapride & Erythromycin & Female & 18 & $T d P$ & $(175)$ \\
\hline Ciisapridle & Clarithromycin & Female & 77 & TdP & $(176)$ \\
\hline Cisapride & Clarithromycin & Femalle & 53 & $T d P$ & $(177)$ \\
\hline Cisapride & Erythromycin & Male & 64 & $T d P$ & $(178)$ \\
\hline Cisapride & Erythromycin & Male & 30 & TdP & $(179)$ \\
\hline Cisapride & Diltiazem & Female & 45 & $\begin{array}{l}\text { Syncope, } \mathrm{QT}^{\top} \\
\text { prolonged }\end{array}$ & $(187)$ \\
\hline Cisapride & $\begin{array}{l}\text { Eryhtromycim } \\
+ \text { Fluconazole }\end{array}$ & Female & 8 & VTT & $(180)$ \\
\hline Chisapride & Clarithromyciti & Female & 52 & $T d P$ & $(181)$ \\
\hline Cisapride & Conlatiluromycin & Malle & 83 & TdP & $(18 \mathrm{H})$ \\
\hline Quintidine & Propiafanone & Fenale & 77 & TdP & $(182)$ \\
\hline Quinidime & Erythromycin & Male & 95 & $\begin{array}{l}\text { TdP, cardiac } \\
\text { arrest }\end{array}$ & $(173)$ \\
\hline Quinidine & Verapamil & Fiemale & 65 & $T d P$ & $(174)$ \\
\hline Disopyranide & Clarithromycin & Female & 76 & TdP & (184) \\
\hline Pimozide & Clarithromycin & Male & 27 & SD & $(185)$ \\
\hline Mosapride & Flecainide & Male & 68 & $T d P, P M$ & $(186)$ \\
\hline Disopyramide & Clarithromycin & Female & 76 & TIdP & $(188)$ \\
\hline Droperidol & $\begin{array}{l}\text { Cyclopenzaprine } \\
+ \text { Fluoxetine }\end{array}$ & Female & 59 & TdP, VF & $(183)$ \\
\hline
\end{tabular}

TdP:= Torsades de Pointes, VF= ventricular fibrillation, VTw ventricular tachycardia, SD= sudden death. 


\section{Aims of this thesis}

The first aim of this thesis was to study congenital LOTS. The identification and subsequent characterization of (novel) LQTS mutations fulfils several purposes for both the affected family and the clinicians who counsel and treat them. The first aim was therefore to apply genetic screening for the identification of (novel) causal mutations in the probands of phenotypically diagnosed LOTS families (Chapters 2,3 and 4). The novel identified mutations can then be used to identify other "silent" mutation carriers within the family and provide proper counselling about the individual risks and treatment options. Therapy may be improved if the molecular and biochemical mechanisms behind the pathogenic nature of mutations are understood. To serve this aim a heterologous expression system (human embryonic kidney cells) was used to functionally characterize the identified mutations (Chapters 2 and 4).

The second part of this thesis aims to study the input of genetic variations on the development of acquired LOTS. In Chapter 5, we investigated the possibility of underlying genetic susceptibility of a volunteer who participated in a clinical trial and clearly showed QT prolongation after drug intake. Because this study indicated that genetic susceptibility in acquired LOTS might be underestimated, we subsequently evaluated the impact of underlying congenital LOTS mutations in a group of 34 acquired LQTS patients (Chapter 7). Concomitant medication is a reported major risk factor in acquired LOTS and often results in an inhibition of hepatic enzymes responsible for the metabolic pathway of the drugs. Among these enzymes, the CYP3A5 enzyme has a wide variation in expression, although possible underlying genetic determinants are unknown. In Chapter 6 we attempted to explain this variable CYP3A5 expression. Finally, we evaluated the importance and relevance of these findings in a larger group of acquired LQTS patients (Chapter 7). 


\section{References}

1. Meissner $\mathrm{FL}$. Taubstummheit und Taubstummenbildung. Leipzig and Heidelberg. Winter'sich Verlagshandung 1856: 119-120.

2. Jervell $A$, Lange-Nielsen $F$. Congenital deaf-mutism, functional heart disease with prolongation 0 the Q-T interval and sudden death. Am Heart J 1957; 54:59-68.

3. Romano $C_{\text {, Gemme }} G_{\text {, }}$ Pongiglione $R$. Aritmie cardiache rare dell'eta pediatrica. Clin Pediatr 1963 45: 656-683.

4. Ward OC. A new familial cardiac syndrome in children.J Jrish Med AssoC 1964: 54: 103-106.

5. Schwartz PJ. The idiopathic long QT syndrome: the need for a prospective registiry. Eur Heart $1983 ; 4: 529$.

6. Moss AJ, Schwartz PJ, Crampton RS, Locati E, Carleen E. The long QT syndrome: a prospectiv international study. Circulation $1985 ; 71: 17-21$.

7. Moss Al, Schwartz PJ, Crampton RS, Tzivoni D, Locati EH, MacCluer J, Hall J, Weitkamp L, Vincent $M$ Garsan Ir A, Robinson $\mathrm{J}$, Benhorin $\rfloor$, Choi 5 . The long $\mathrm{QT}$ syndrome. Prospective longitudimal stud of 328 families. Circulation 1991; 84: 1136-1144.

8. Bazett HC. An analysis of the time relations of electrocardiogram. Heart 1918; 7: 353-370.

9. Dessertenne F, La tachycardie ventriculaire a deux foyers opposes variables. Arch Mal Coeur 1960 59: 263 .

10. Merri M, Benhorin I, Alberti M, Lacati E, Moss AJ. Electrocardiographic quantitation of ventricula repolarization. Circulation 1989; 80: 1301-1308.

11. Schwartz PJ, Moss AJ, Vincent GM, Crampton RS. Diagnostic criteria for the long OT syndrome. A update. Circulation 1993; 88: 782-784.

12. Davignon A, Rautaharju B, Boiselle E, Soumis F, Megelas $M_{4}$ Choquette A. Normal ECG standards fo infants and children. Pediatr Cardiol 1980; 1:123-130.

13. Keating $M$, Atkinson D, Dunn $C$, Timothy $K$, Vincent $M$, Leppert $M$. Linkage of a cardiac arrhythmia the Long QT Syndrome, and the Harvey ras-1 gene. Science 1991; 252: 704-706.

14. Keating $M$. Linkage analysis and long $Q T$ syndrome. Using genetics to study cardiovascular disease Circulation 1992; 8.5: 1973-1986.

15. Keating $M$, Duinn $C$, Atkinson D, Timothy $K$, Vincent $G M$, Leppert $M$. Consistent linkage of the lon QT syndrome to the Harvey ras-1 locus on chromosome 11. Am $\mathrm{J}$ Hum Genet 1991; 49: 1335-1339.

16. Towbin $\amalg A$, Pagotto L, Siu B, Rabinson J Moss A, McCabe ERB, Hejtmancik IF. Romano-War syndrome (RWLQTS): evidence of genetic heterogeneity. Pediatr Res 1992; 31: 23 A.

17. Benhorin J, Kalman YM, Medina A, Towbin JA, Rave-Harel N, Dyer TD, Blangero J, Maccluer JM Kerem B. Evidence for genetic heterogeneity in the long QT syndrome. Science 1993; 260: 1960 1962.

18. Curran $M$, Atkinson $D$, Timothy $K$, Vincent $G M$, Moss $A J$, Leppert $M$, Keating $M$. Locus heterogeneit of autosomal domainant long $\mathrm{OT}$ syndrome. $J$ Clin Invest. 1993; 92: 799-803.

19. Towbin JA, Li H, Taggert RT, Lehmamn MH, Schwartz P., Satler CA, Ayyagari R, Robinson JL, Moss A Hejtmancik JF. Evidence of genetic heterogeneity in Romano-Ward long QT syndrome. Analysis 0 23 families. Circulation 1994; $90: 2635-2644$.

20. Jiang C, Atkinson D, Towbin JA, Splawski I, Lehmann MH, Li H, Timothy K, Taggert RT, Schwartz P. Vincent $M$, Moss AJ, Keating MT. Two long QT syndrome loci map to chromosomes 3 and 7 wit evidence for further heterogeneity. Nat Genet. 1994; 8: 141-147.

21. Schott 1 , Charpentier $F$, Pellier S, Foley P, Drouin E, Bouhour JB, Donnelly $P$, Vergnaud $G$, Bachner Moisan JP, Le Marec $\mathrm{H}$, Pascal O. Mapping of a gene for long QT syndrome to chromosome 4925 27. Am J Hum Genet. 1995: 57: 1114-1122.

22. Splawski I, Tristani-Firouzi M, Lehmann MH, Sanguimetti MC, Keating MT. Mutations in the hmin gene cause long $\mathrm{OT}$ syndrome and suppress $I_{\mathrm{ki}}$ function. Nat Genet. 1997; 17 : 338-340. 
23. Abbatt GW, Sesti F, Lehmann MH, Timothy KW. Keating MT, Goldstein SAN. MiRP1 forms $\|_{\text {Rif }}$ potassium channels with HERG and is associated with cardiac arrhythmia. Cell 1999:97:175187.

24. Wang Q, Curran ME, Splawski I, Burn TC, Millholland JM, VanRaay TJ, Shen J, Timothy KW, Vincent $G M$, de Jager T, 5 chwartz PJ, Towbin JA, Moss AJ, Atkinson DL, Landes GM, Connors TD, Keating MT. Positional claning of a novel potassium channel gene: KVLQT1 mutations cause cardiac arrhythmias. Nat Genet 1996; 12: 17-23.

25. Splawsiki I, Shen J, Timothy KW, Vincent GM, Lehmann MH, Keating MT, Genomic structure of three Long QT syndrome genes: KVLOT1, HERG and KCNE1. Genomics 1998; 51: 86-97.

26. Lee MP, Hu RJ, Johnson LA, Feinberg AP. Human KVLOT1 gene shows tissule-specific imprinting and encompasses Beckwith-Wiedemann syndrome chromosomal rearrangements. Nat Genet 1997; 15: 181-185.

27. Wollnik B, Schroeder BC, Kubisch C, Esperer HD. Wieacker P, Jentsch T. Patho physiological mechanisms of dominant and recessive KVLQT1 $K^{*}$ channel mutations found in inherited cardiac arrhythmias. Hum Mol Gienet 1997; 6: 1943-1949.

28. Demolombe S, Baró I, Péréon $Y_{v}$ Bliek J, Mohammad-Panah R, Pollard $H$, Morid S, Manmens $M_{*}$ Wilde A, Barhanin J, Charpentier F, Escande D. A dominant negative isoform of the long QT syrindrome 1. gene product. I Biol Chem 1998; 12: 6837-6843.

29. Sanguinetti MC, Curran ME, Zou A, Shen J, Spector PS, Atkinson DL, Keating MT. Coassembly of $K_{4}$ LQT1 and mink (IsK) proteins to form cardiac $I_{\mathrm{Ks}}$ potassium channel. Nature 1996; 384: 80-83.

30. Barhanin J, Lesage $F$, Guillemare $E_{\text {, Fink }} M_{n}$ Lazdunski $M_{0}$. Romey G. $K_{2}$ LQT1 and IsK (mink) proteins associate to form the $I_{k,}$ cardiac potassium current. Nature $1996 ; 384: 78-80$.

31. Donger C, Denjoy $I_{\text {, Berthet }} M_{*}$ Neyroud $N$, Cruaud $C$, Bennaceur $M$, Chivoret $G$, Sclowartz $K_{*}$ Coumel $P$, Guicheney $P$. KVLLT1 C-terminal missense mutation causes a forme fruste long QT syndrome. Circulation 1997; 96: 2778-2781.

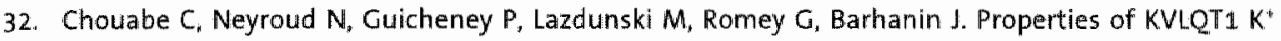
channel mutations in Romano-Ward and Jerwell and Lange-Nielsen inherited cardiac arrhythmias. EMBO 1997; 16: 5472-5479.

33. Neyroud N, Tesson F, Denjoy I, Leibovici M, Donger $C$, Barhamin J, Fauré S, Gary F, Coumel P, Petit C, Schwartz K, Guicheney P. A novel mutation in the potassium channel gene KVLQT1 causes Jervell and Lange-Nielsen cardioauditory syndrome. Nat Genet 1997; 15: 186-189.

3.4. Tyson J, Tranebjaerg L, Bellman 5, Wren C, Taylor JF, Bathen J, Aslaksen B, Sorland S., Lund O, Malcolm S, Pembrey $M$, Bhattacharya S, Bitner-Glindzicz M. IsK and KVLQT1: mutation in either of the two subunits of the slow component of the delayed rectifier potassium channel can cause Jervell and Lange-Nielsen syndrome. Hum Mal Genet 1997; 6: 2179-2185.

35. Tyson ل, Tranebjaerg L, McEntagart M, Larsen LA, Christiansen M, Whiteford ML, Bathen J, Aslaksen $B$, Sorlland SJ, Lund O, Pembrey ME, Malcolm S, Bitner Glindzicz M. Mutational spectrum in the Cardioauditory syndrome of Jervell and Lange-Nielsen. Hum Genet 2000; 107: 499-503.

36. Priori SG, Schwartz PJ, Napolitano C, Bianchi L, Dennis A, De Fusco M, Brown AM, Casari G. A recessive variant of the Romano-Ward long $Q T$ syndrome? Circulation 1998; $97 ; 2420-2425$.

37. Chouabe C, Neyroud N, Richard P, Denjoy I, Hainque B, Romey G, Drici MD, Guicheney P, Barhanin J. Novel mutations in KVLOT1 that affect $I_{K s}$ activation through interactions with IsK. Cardiovasc Res 2000; 45: $971-980$.

38. Warmke $\mathbb{E}$, Ganetzky $\mathrm{B}$. A familly of potassium channel genes related to Eag in Drosophila and mammals. Proc Natl Acad Sci USA 1994; $91: 343.8 * 3442$.

39. Bruggeman $A$, Pardo LA, Struhmer $W$, Pongs $O$. Ether-a-go-go encodes a voltage-gated channel permeable to $\mathrm{K}^{7}$ and $\mathrm{Ca}^{2 *}$ and is modulated by CAMP. Nature $1993 ; 365: 445-448$.

40. Curran ME, Splawski I. Timathy KW, Vincent GM, Green ED, Keating MT. A molecullar basis for cardiac arrhythmia: HERG mutations cause long QT syndrome. Cell 1995; 80: 795-803. 
41. Itoh T, Tanaka T, Nagail R, Kamlya T, Sawayama T, Nakayama T. Tomoike H, Sakurada H, Yazaki Y, Nakamura Y. Genomic organisation and mutational analysis of HERG, a gene responsible for familiall long or syndrome. Hum Genet 1998; 102:435-439.

42. Mckinnon R. Determination of the subunit stoichiometry of a voltage-activated potassium channel. Nature 1991; 350:232-235.

43. Sanguinetti MC, liang $C$, Curran ME, Keating MT. A mechanistic link between an inherited and an acquired cardiac arrhythmia: HERG encodes the lkr potassium channel. Cell 1995; 81: 299-307.

44. Trudeau MC, Warmke JW, Ganetzky $B$, Robertson GA. HERG, a human inward rectifier in the voltage-gated potassium channel family. Science 1995; 269: 92-95.

45. Smith $\mathrm{PL}$, Baukrowitz $T$, Yellen $\mathrm{G}$. The inward rectification mechanism of the HERG cardiac potassium channel. Nature 1996; 379:833-836.

46. Zhou Z, Gong Q, Ye B, Fan Z, Makielski JC, Robertson GA, Jainuary CT. Properties of HERG channels stably expressed in HEK293 cells studied at physiological temperature. Biophys I 1998; 379:230241.

47. Sanguinetti MC, Currain ME, spector PS, Keating MT. Spectrum of HERG $K^{*}$-channel dysfunction in an inherited cardiac arrhythmia. Proc Natl Acad Sci USA 1996; 93: 2208-2212.

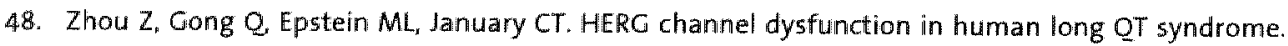
Intracellular transport and functional defects. J Biol Chem 1998; 273: 21061-21066.

49. Zhou $Z$, Gong $Q$, January $C T$. Correction of defective protein trafficking of a mutant HERG potassium channel in human long $Q T$ syndrome. Pharmacological and temperature effects. I Biol Chem 1999; 274:31123-31126.

50. Wang $\mathrm{Q}$, Shein J, Splawski I, Atkinson D, Li Z, Robinson JL, Moss AI, Towbin JA, Keating MT. SCN5A mutations associated with an inherited cardiac arrhythmia, long QT syndrome. Cell 1995: 80: 805* 811.

51. Gellens $M$, George $A$, Chen $L$, Chahine $M$, Horn R, Barchi R, Kallen R. Primary structure and functional expression of the human cardiac tetrodoxin-insensitive voltage-dependent sodium channel. Proc. Natl. Acad. Sci. 1992; 89: 554-558.

52. Bennett PB, Vazawa $K$, Makita N, George AL. Molecular mechanism for an inherited cardiac arrhythmia. Nature 1995; 376: 683-685.

53. Dumaine R, Wang $Q$, Keating MT, Hartmann HA, Schwartz PJ, Brown AM, Kirsch GE. Multiple mechanisms of $\mathrm{Na}^{*}$ channel-linked long QT syndrome. Circ Res 1996; 78: 916-924.

54. An RH, Wang XL, Kerem B, Benhorin J, Medina A, Goldmit M, Kass RS. Novel LQT-3 mutation affects $\mathrm{Na}$ ' channel activity through interactions between $\alpha$ - and $\beta_{3}$-subunits. Circ Res 1998; 83: 141-1.46.

55. Brugadla P, Brugada J. Right bundle branch block, persistent ST segment elevation and sudden cardiac death: a distinct clinical and electrocardiographic syndrome. Am J Coll Cardiol 1992; 20: $1391-1396$.

56. Brugada J, Brugada $R$, Brugada P. Right bundle-branch block and ST-segment elevation in leads. $V$, through $V_{3}$. A marker for sudden death in patients without demonstrable structural heart disease. Circulation 1998; $97: 457-460$.

57. Schott J., Alshinawa $C$, Kyndt F, Probst $V$, Hoorntje TM, Hulsbeek M, Wilde AAM, Escande D, Mannens MMAM, Le Marec $\mathrm{H}$. Cardiac conduction defects associated with mutations in SCNSA. Nat Genet 1999: 23: 20-21.

58. Schwartz PJ, Priori SG, Dumaine $R_{*}$ Napolitano C. Antzelevitch C, Stramba-Badiale M, Richard TA, Berti MR. Bloise R. A molecular link between the sudden infant death syndrome and the long $Q T$ syndrome. N Eng J Med 2000; 3443:262-267.

59. Chen $Q$, Kirsch GE, Zhang D, Brugada R, Brugada J, Brugada $P$, Potenza D, Moya A, Borggrefe $M$, Breithardt $G$, Ortiz-Lopez $\mathbb{R}$, Wang $Z$, Antzelevitch $C$, $O^{\prime} B$ rien RE, Schulze-Bahr $E$, Keating MT, Towbin JA, Wang $Q$. Genetic basis and molecular mechanism for idliopathic ventricular fibrillation. Nature $1998 ; 392: 293-295$. 
60. Bezzina C, Veldkamp MW, Van den Berg MP, Postma AV, Rook MB, Viersma IW, Van Langen IM, Tan-Sindhunata $G$, Bink-Boelkens MthE, Van der Hout AH, Mannens MAM, Wilde AAM. A single Na* channel mutation causing both long-OT and Brugada syndromes. Circ Res 1999:85: 1206 1213.

61. Rivolta I, Abriel $H$, Tateyama $M$, Liu $H$, Memmi $M$, Vardas $P$, Napolitano $C$ Priori $5 G_{3}$ Kass RS. Inherited Brugada and long QT-3 syndrome mutations of a single residue of the cardiac sodium channel confer distinct channel and dinical phenotypes. I Biol Chem 2001: 276: 30623-30630.

62. Takumi $T$, Ohkubo $H$, Nakanishi S. Cloning of a membrane protein that induces a sllow voltage. gated potassium current. Science 1988; 242: 1042-1045.

63. Murai T, Kakizuka A, Takumi T, Ohkubo H, Nakanishi S. Molecular cloning and sequence analysis of human genomic DNA encoding a novel membrane protein which exhibits a slowly activating potassium channel activity. Biochem Biophys Res Commun 1989; 161: 176-181.

64. Chevillard $C_{*}$ Attali B, Lesage F, Fontes M, Barhanin 1, Lazdunski M, Mattei MC. Localization of a potassium channel gene (KCNE1) to 21q22.1-q22.2 by in situ hybridisation and somatic cell hybridisation. Genomics 1993; 15: 243-245.

65. McDonald TV, Yu Z, Ming Z, Palma E, Meyers MB, Wang KW, Gioldstein SA, Fishman Gl. A MinkHERG complex regulates the cardiac potassium current $I_{k r}$. Nature 1997: 388: 289-292.

66. Folander K, Smith JS, Antanavage J, Bennett C, Stein RB, Swanson R. Cloning and expression of the delayed-rectifier IsK channel from neonatal rat heart and diethylstilbestrol-primed rat uterus Proc Natl Acad Sci USA 1990; 87: 2975-2979.

67. Sakagami M, Fukazawa K, Matsunaga T, Fujita H, Mori N, Takumi T, Ohkubo H, Nakanishi S. Cellular localization of rat Isk protein in the stria vascularis by immunohistochemical obsenvation. 1991. Hear Res, 5,6: 168-172.

68. Tesson F, Donger $C$, Denjoy I, Berthet $M$, Bennaceur M, Petit $C$, Coumell $P_{y}$ Schwartz $K$, Guicheney $P$. Exclusion of KCNE1 (ISK) as a candidate gene for Jervell and lange-Nielsen syndrome. Mol Cell Cardiol 1996; 28: 2051-2055.

59. Schulze-Bahr $E$, Wang $Q$, Wedekind $H$, Haverkamp W, Chen $Q$, Sun Y. KCNE1 mutations cause Jervell and Lange-Nielsen syndrame. Nat Genet 1997; 17: 267-268:

70. Priori SG, Barhanin J, Hauer RNW, Haverkamp W, Jongsma HJ, Kleber AG. Mckenina WJ, Roden DM, Rudy Y, Schwartz K, Schwartz PJ, Towbin JA, Wilde AM.Genetic and molecular basis of cardiac arrhythmias: Impact on clinical management Parts I and II. Circulation 1999; 99: 518-528.

71. Franqueza $L$, Lin M, Splawski I, Keating MT, Sanguinetti MC. Long OT syndrome-associated mutations in the 54-S5 linker of KVLQT1 potassium channels modify gating and interaction with mink subunits. J Biol Chem 1999; 274: 21063-21070.

72. Ackerman MJ, Siu BL, Sturner WQ, Tester DJ, Valdivia CR, Makielski JC, Towbin JA. Postmortem molecular analysis of SCN5A defects in sudden infant death syndrome. JAMA 2001; 286: 22642269 .

73. Towbin JA, Vatta M. Molecular biology and the prolonged QT syndromes. Am J Med 2001; 110: $3.85-398$

74. Snyders DJ. Structure and function of cardiac potassium channels. Cardiovasc Res 1999; 42: 377390 .

75. Zareba W, Mass AJ, Schwartz PJ, Vincent GM, Robinson JL, Priori SG, Benhorin J, Locati EH, Towbin JA, Keating MT, Lehmann MH, Hall WJ. Influence of the genotype on the clinical course of the long QT syndrome. N Eng J Med 1998; 339: 960-965.

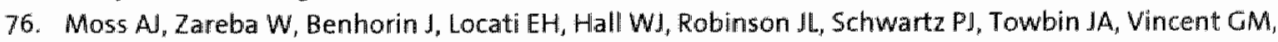
Lehmann MH, Keating MT, MacCluer JW, Timothy KW. ECG T-wave patternis in genetically distinct forms of the hereditary long OT syndrome. Circulation 1995; 92: 2929-2934.

77. Zhang L. Timothy KW, Vincent GM, Lehmann MH, Fox J Giuli LC, Shen J, splawski I. Priori SG, Compton 5J, Yanowitz F, Benhorin L, Mass AJ, Schwartz PJ, Robinson IL, Wang Q Zareba W, Keating MT, Towbin $\Downarrow A$, Napolitano C, Medina A. Spectrum of $5 T-T$-wave patterns and repolarization 
parameters in congenital long $\mathrm{QT}$ syndrome. ECG findings identify genotypes. Circulation 2000; 102: 2849-2855.

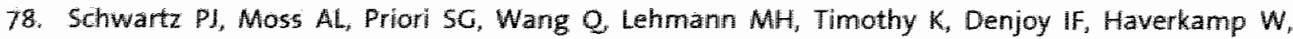
Guicheney P, Paganini V, Scheinman MM, Karnes PS. Gene-specific influence on the triggers for cardiac arrest in the long or syndrome. Circulation 1997; 96: 1212. Abstract.

79. Ackerman MJ, Tester DJ, Porter CI, Edwards WD. Molecular diagnosis of the inherited long $\mathrm{QT}$ syndrome lin a woman who died after near-drowning. New Eng I Med 1999; 341: 1121-1125.

80. Ackerman M, Tester DJ, Porter CJ. Swimming, a gene-specific arrhythmogenic trigger for inherited long QT syndrome. Mayo Clin Proci 1999; 74: 1088-1094.

81. Moss AJ, Robinson JL, Gessman L, Gillespie R, Zareba W, Schwartz PJ, Vincent GM, Benhorin I, Locati Heilbron E, Towbin IA, Priori SG, Napolitano $C$, Zhang L, Medina A, Andrews ML, Timothy K. Comparison of clinical and genetic variables of cardiac events associated with loud noise versus swimming among subjects with the long QT syndrome. Am J Cardiol 1999; 84; 876-879.

82. Wilde $A A M$, Jongbloed RJE, Doevendans PA, Duren DR, Hauer RNW, van Langen $I M$, van Tintelen JP, smeets HJM, Meyer $H$, Geelen ILMC. Auditory stimuli as a trigger for arrhythmic events differentiate HERG-related (LQTS $)_{2}$ patients from KVLOT1-related patients (LQTS ${ }_{1}$ ). I Am Coll Cardiol 1999; 33: $327-332$.

83. Schwartz PJ, Priori SG, Spazzolini C, Moss AJ, Vincent GM, Napolitano C, Denjoy I, Guicheney P, Breithardt $G$, Keating. MT, Towbin JA, Beggs AH, Brink P, Wilde AAM, Toivonein L, Zareba W, Robinson $\|_{L}$, Timothy $\mathrm{KW}$, Corfield $\mathrm{V}$, Wattanasirichaigoon $\mathrm{D}$, Corbett $C$, Haverkamp W, SchulzeBahr E, Lehmann MH, Schwartz K, Coumel P, Bloise R. Genotype-phenotype correlation in the long QT syndrome. Gene specific triggers for life-threatening arrhythmias. Circulation 2001; 103: 89-95.

84. Tzivani D, Banai S, Schuger C, Benhorin J, Keren A, Gottlieb S, Stern S. Treatment of torsade de pointes with magnesium sulphate. Circulation 1988; $77 ; 392-397$.

85. Damiano BP, Rosen MR. Effects of pacing on triggered activity induced by early afterdepolarizations. Circulation 1984; 69: 1013-1025.

86. Viskin $S$, Fish $R$. Prevention of ventricular arrhythmias in the congenital long QT syndrome. Curr Cardiol Rep. 2000; 2: 492-497.

87. Moss AJ. Management of patients with the hereditary long OT syndrome. I Cardiovasc Electrophysiol 1998; 9: 668-674.

88. Moss AJ, Zareba W, Hall WJ, Schwartz PJ, Crampton RS, Benhorin I, Vincent CM, Locati EH, Priori SG, Napolitaino C, Medina A, Zhang L, Robinson JL, Timothy K, Towbin JA, Andrews ML. Effectiveness and limitations of $\beta$-blocker therapy in congenital long $Q T$ syndrome. Circulation 2000; 101: 616 623.

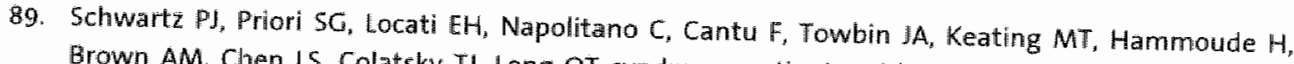
Brown AM, Chen LS, Colatsky TJ. Long QT syndrome patients with mutations of the SCNSA and HERG genes have differential responses to $\mathrm{Na}^{*}$ blockade and to increases in heart rate: implications for gene-specific therapy. Circulation 1995; 92: 3381-3386.

90. Visikin 5. Cardiac pacing in the long QT syndrome: review of available data and practical recommendations. J Cardiovasc Electrophysiol 2000: 11: 593-600.

91. Moss AJ, Liu JE, Gottlieb S, Locati EH, Schwartz PJ, Robinson JL. Efficacy of permanent pacing in the management of high-risk patients with long QT syndrome. Circulation 1991; 84: 1524-1529.

92. Van den Berg MP, Wilde AAM, Viersma IW, Brouwer \, Haaksma J, Van der Hout A, Stolte-Dijkstra I, Bezzina C, Van Langen IM, Beaufort-Krol GCM, Cornel JH, Crijns HIGM. Possible bradycardic mode of death and successful pacemaker treatment in a large family with features of long QT syndrome type 3 and Brugada syndrome. \Cardiovasc Electrophysiol 2001; 12: 630-636.

93. Dorostkar PC, Eldar M, Belhassen B, Scheinman MM. Long-term follow-up of patients with lang $Q T$ syndrome treated with $\beta$-blockers and continuous pacing. Circulation 1999: 100: 2431-2436.

94. Moss AJ, MCDonald J. Unilateral cervicothoracic sympathetic ganglionectomy for the treatment of long QT interval syndrome. N Eng.J Med 1970; 285: 503-511. 
95. Schwartz PI, Locati EH, Moss AJ, Crampton RS, Trazzi R, Ruberti U. Left cardiac sympathetic denervation in the therapy of congenital long QT symarome a warldwide report. Cinculation 1991; 84: $503-511$.

96. Mirowski M, Reid PR, Mower MM, Watkins L, Gott WL, schauble JF Langer A, Heilman MS, Kolenik SA, Fischell RE; Weisfeldt ML. Termination of malignant ventricular arrhythmias with an implanted automatic defibrillator in human beings. N Eng IMed 1980; 303:322-324.

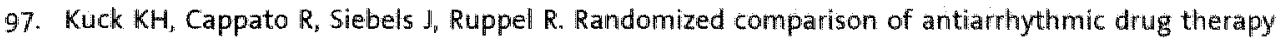
with implantablle diefibrillators in patients resuscitated from cardiac arrest: the Cardiac Arrast Stuldy Hamburg (CASH). Circulation 2000; 102: 748-754.

98. Groh WH, Silka MJ, Oliver RP, Halperim BD, MCAnulty JH, Kron J. Use of implantable cardioverterdefibrillators in the congenital long QT symdrome. Am J Cardiol 1996; 78:703-706.

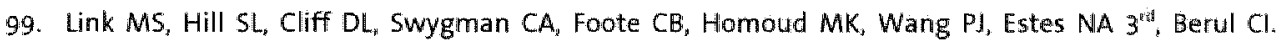
Comparison of frequency of complications of impiamtable cardioverter-defibrillators in children versus adults. Am J Cardiol 1999: 83: 263-266, A5-A6.

100. Sears SF Jr, Todaro JF, Lewis TS, sotile W, Conti JB. Examining the psychosocial impact of implantable cardioverter defibrillators: a literature review. Clin Cardiol 1999; 22: 481-489.

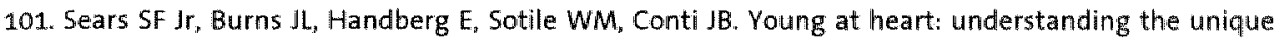
psychosocial adjustment of young implantable cardioverter defibrillator recipients. Pacing Cilin Electrophysiol 2001; 24: 1113-1117.

102. Rosero S, Zareba W, Robinson J, Moss A. Giene specific therapy for long QT syndrome: QT shortening with lidocaine and tocainide in patients with mutation of the sodium chanmel gene. Ann Noninwasive Electrocardiol 1997; 3: 274-278.

103. Compton SJ, Lux RL, Ramsey MR, Strelich KR, Sanguinetti MC, Green LS, Keating MT, Mason IW. Genetically defined therapy of inherited long QT syndrome Correction of abnormal repolarisation by potassium. Circullation 1996; 94: 1018-1022.

104. Tan HL, Alings M, Van-Olden RW, Wilde AAM. Long term (subacute)potassilum treatment in congenital HERG-related long QT syndrome (LQTS2). J Cardiovasc Electrophysioll 1999; 10: 229-233.

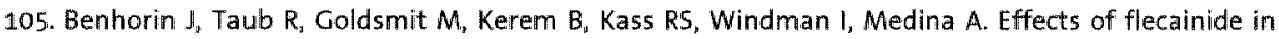
patients with new SCN5A mutation. Mutation-specific therapy for long QT syndrome? Circulation 2000; 101: 1698-1706.

106. Rajamani S, Anderson CL, Anson BD, January CT. Pharmacological rescue of human $K^{*}$ chanmel Long-QT2 mutations. Human Ether-a -ga-go-related gene rescue without block. Circulation 2002; 105: $2830-2835$.

107. Valdivia CR, Ackerman MJ. Tester Dل, Wada T, McCormack J, Ve B. Maklelski JC. A nowel SCNSA arrhythmia mutation, M1766L, with expression defect rescued by mexiletine. Cardiovasc Res 2002; 55: $279-289$.

108. Viskin S. Long QT syndromes and torsade de pointes. Lancet 1999: 354: 1625-1633.

109. Roden DM, Thompson KA, Hoffman BF, Woosley RL Clinical features and basic mechanisms of quinidine-induced arrhythmias. J Am Coll Cardiol 1986; 8: 73 A $\times 78 \mathrm{~A}$.

110. Tziwoni D, Keren A, Stern 5 , Gottlieb 5 . Disopyramide-induced torsade de pointes. Arch Int Med $198: 1 ; 141: 946,947$.

111. McKibbin JK, Pocock WA, Barlow JB, Miltar RN, Obel IW. Sotalol, hypokalemia, syncope, and torsade de pointes. Brit Heart $\ 1984 ; 5: 1: 157-162$.

112. Elonen $E$, Neuwonen PJ, Tarssanen L, Kala R. Sotalol intoxication with prolonged Q-T interval and severe tachyarithythmas. Br Med J $1979 ; 1: 1184$

113. Lehmann MH, Hardy S, Archibald D, Quart B, MacNell DJ. Sex Difference in Risk of Torsade de Pointes With d, l. Sotalol. Circulation 1996; $94: 2535-2541$

114. Hohnloser $5 \mathrm{H}$, Klingenheben $\mathrm{T}$, Singh BN. Amilodarone-associated proarthythmic effects. A review with special reference to torsade de pointes tachycardia. Ann Int Med 1994; 121: 529-535.

115. A-Dashti R, Sami M. Dofetilide: a new class lll antiarrhythmic agent. Can J Cardiol 2001; 17:63-67. 
116. Craft TM Torsade de pointes after astemizole overdose. Br Med $\ 1986 ; 292: 660$.

117. Davies $A$, Harindra $V$, McEwan $A$, Ghose $\mathbb{R} R$. Cardiotoxic effect with convulsions in terfenadine overdose. Br Med J 1989: 298: 325.

118. Monahan BP, Ferguson CL, Killeavy ES, Lloyd BK, Tray J, Cantilena LR. Torsades de pointes occurring in assiocidition with terfenadine use. JAMA 1990; 264:2788-2790.

119. Hey $J A_{s}$ del Prado $M, C$, central nervous system and cardiovascular profiles of histamine $\mathrm{H}_{\mathrm{I}}$ antagonists: Comparative studies with loratadine, terferiadine and sedating histamines in guinea pigs. Clin Exp Allergy 1995; 25: 9744984.

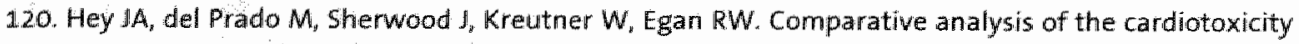
proclivities of second generation antihistamines in an experimental model predictive of adverse dinical ECG effects. Arzneimforsch Drug Res 1996; 46:53-58.

121. Taglialatela $M$, Pannacciorie $A$, Castaldo $P$, Giorgio $G$, Zhou $Z$, January $C T$, Genovese $A$, Marone $G$, Annunziato L. Molecular basis for the lack of HERG K* channel block-related cardiotoxicity by the $\mathrm{H}_{\mathrm{a}}$ receptor blocker cetirizine compared with other second-generation antihistamines. Mol Pharmacol $1998 ; 54: 113-121$.

122. Drici MD, Knollmann BC, Wang WX, Woosley RL. Cardiac actions of erythromycin. Influence of female seX. IAMA 1998; 280: 1774-1776.

123. Oberg KC. Bauman JL. QT interval prolongation and torsades de pointes due to erythromycin lactobionate. Pharmacother 1995; 15:687-692.

124. Lee $\mathrm{KL}$, Jim MH, Tang SC, Tal YT. QT prolongation and torsades de pointes associated with clarithromycin. Am I Med 1998; 104: 395-396.

125. Michalets EL, Williams CR. Drug interactions with cisapride. Clinical implications. Clin Pharmacokinet 2000; 39; 49-75.

126. Daleau $P$, Lessard $E$, Groleau $M$, Turgeon J. Eryhthromycin blocks the rapid component of the delayed rectifier potassium current and lengthens repolarization of guinea pig ventricular myocytes. Circulation 1995: 91: 3010-3016.

127. Rubart M, Pressler ML. Pride HP, Zipes DP. Electrophysiological mechanisms in a canine model of erythromycim-associated long QT syndrome. Circulation 1993; 88: 1832-1844.

128. Antzelevitch $C$, sun $Z Q Q$, Zhang $Z$, Yan GX. Cellular and ionic mechanisms underlying erythromycin-induced long QT intervals and torsade de pointes. J Am Coli Cardiol 1996; 28: 1836 1848.

129. Volberg WA, Koci BJ "SU W, Lin J, Zhou J. Blockade of human cardiac potassium channel human Ether-a-go-go-related gene (HERG) by macrolide antibiotics. J Pharmacol Exp Ther 2002; 302:320-
32.7 .

130. Wiseman LR, Faulds D. Cisapride. An updated review of its pharmacology and therapeutic efficacy as a prokinetic agent in gastrointestinal motility disorders. Drugs 1994; 47: 116-52.

131. Wysowski DK, Corken A, Gallo-Torres $H$, Talarico L. Rodriguez EM. Postmarketing reports of $Q T$ prolongation and ventricular arrhythmia in association with cisapride and Food and Drug Administration regulatory actions. Am J Gastroenterol. 2001; 96: 1698-703.

132. Rampe D, Roy ML, Dennis A, Brown AM. A mechanism for the proarrhythmic effects of cisapride (Propulsid): high affinity blockade of the human cardiac potassium channel HERC. FEBS letters $1997: 417: 28 \cdot 32$

133. Mohammad $S$, Zhou $Z$, Gong $Q$, Jamwary $C T$. Blockade of the HERG human cardiac $K^{*}$ chamnel by the gastrointestinal prokinetic agent cisapride. Am I Physiol Heart Circ Physiol. 1997; 273: H2534-
H2538.

134. Walker BD, singleton $C B$, Bursill JA, Wyse $K R$, Valenzuela $S M$, Oiu MR, Breit $S N$, Campbell TJ. Inhibition of the human ether-a-go-go-related gene (HERG) potassium channel by cisapride: affinity for open and inactivated states. Br I Pharmacol 1999: 128; 444-450. 
135. Carlsson $L$, Amos GJ, Andersson B, Drews $L$, Duker G, Wadstedt G. Elemtiophysiological characterization of the prokinetic agents cisparide and mosapride in who and in vitro: Implkations for proarrhythimic potential? J Pharmacol Exp Ther $1997 ; 282: 220-227$.

136. Kelly $\mathrm{HG}_{4}$ Fay JE, Lawery SG. Thioridazine hydrochloride (Mellaril) its etfects on the electrocardiogram and a report of two fatalities with electrocardiographic abrommallies. Can Med Assoc $1963 ; 89: 546-554$.

137. Sharma ND, Rosman HS, Padhi ID, Tisdale JE. Torsades de pointes associated whth intravenous haloperidol in critically ill patients. Am J Cardiol 1998; 81:238-240.

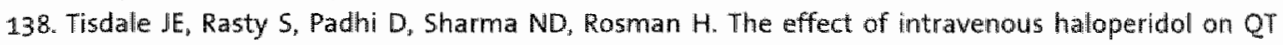
interval dispersion in critically ill patients: Comparison with QT prolongation for assessment of ris of torsades de pointes. I Clin Pharmacol 2001; 41: 1310-1318.

139. Lawrence KR, Nasraway SA. Conduction disturbances associated with administration of butyrophenone antipsychotics in the critically ill: a review of the literature. Pharmacother 1997; $17: 531-537$.

140. Reilly JG, Ayis SA, Ferrier IN, Jones SI, Thomas SHL. OT,-interval abnormalities arnd psychotropic drug therapy in psychiatric patients. The Lancet 2000; $355: 1048-105.2$.

141. Drolet $B$, Wincent $F$, Rail J, Chahine $M$, Deschenes $D$, Nadeau $S$, Khalifa $M$, Hamelin BA, turgeon 1. Thioridazine lengthens repolarization of cardiac ventricular myocytes by blocking the dielayed rectifier potassium current. J pharmacol Exp Ther 1999; 288: 1261-1268.

142. Suessbrich $H$, Schonherr $R$. Heimemann $S H$, Attali $B$, Lang $F$, Busch AE. The inhibitory effect of the antipsychotic drug haloperidol on HERG potassium channels expressed in Xenopus oocyter. Br I Pharmacol 1997: 120:968-974.

143. Drolet $B$, Zhnag $S$, Deschenes $D$, Rail $\rrbracket$, Nadeau 5 , Zhou z, January CT, Turgeon J. Droperido: lengthens cardiac repolarization due to block of the rapid component of the delayed rectifier potassium current. J Cardiowasc Electrophysiol 1999: 10: 1597-1604.

144. Rautaharju PM, Zhou SH, Wong S, Calhourn H, Berenson GS, Prineas R, Davignon. A Sex differences in the evolution of the electiocardiographic QT interval with age. Can J Cardiol 1992; 8:690-695.

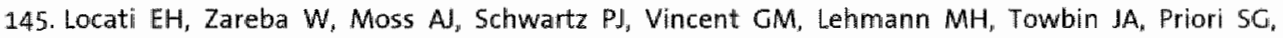

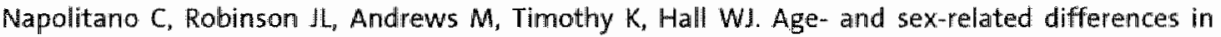
clinical manifestations in patients with congenital long QT syndrome. Findings from the International LQTS Regilstry. Circulation 1998; 97: 2237-2244.

146. Lehmann MH, Timathy KW, Framkovich D, Fromm BS, Keating M, Locati EH, Taggert RT, Towbinn JA, Moss A, Schwartz PJ, Vincent GM. Age-gender influence on the ratecorrected $Q T$ interval and the QT-heart rate relation in families with genotypically characterized long OT symdrome. JACC 1997: 29: 93-99.

147. Makkar RR, Fromm BS, Steinmann RT, Meissner MD, Lehmann MH. Female gender as a risk factor for torsaide de pointes associated with cardiovascular drugs. JAMA 1993; 270; 2590-2597.

148. Drici MD, Burklow TR, Haridasse V, Glazer Rl, Woosley RL. Sex hormones prolong the QT interval and downregulate potassium channel expression in the rabbit heart. Circulation 1996; $94: 1471-$ 1474 .

149. Boyle M, Maclusky N, Naftolin F, Kaczmarek L. Hormonal regulation of K' channel messenger RNA in rat myometrium during oestrus cycle and in pregnancy. Nature 198: $330: 373-375$.

150. Sanguinetti MC, Jurkiewicz NK. Role of external $C^{2+}$ and $K^{*}$ in gatimg of cardiac delayed rectifier $K^{*}$ currents. Pflugers Arch 1992:420: 180-186.

151. Yang T, Roden DM. Extracellular potassium modulation of drug block of $\mathrm{I}_{\text {. }}$ Implications for torsade de pointes and reverse use-dependence. Circulation 1996; 93: 407-411.

152. Halkin $A$, Roth $A$, Lurie I, Fish R, Belhassen B, Viskin S. Pause-dependent torsade de pointes following acute myocardial infarction: a variant of the acquired long OT syndrome, I Am Coll Cardiol 2001; 38: 1168-1174. 
153. Tong $\mathrm{KL}$, Lau $\mathrm{YS}$, Teo WS. A case series of drug-induced long $\mathrm{QT}$ syndrome and torsade de pointes. Singapore Med J 2001; $42: 566 \% 570$.

154. Shimizu $W$, Tanaka $K$, Suenaga $K$, Wakamoto $A$. Bradycardia-dependent early after-depolarizations in a patient with $Q T$ Tu prolongation and torsade de pointes in association with marked bradycardia and hypokatemia. PACE 1991; 14: 1105-1111.

155. Moss AJ, schwartz PI. Delayed repolarization (QT or QTU prolongation) and malignant ventricular arrhythmias. Mod Concepts Cardiovasc Dis 1982; 51: 85-90.

156. Priont $\mathrm{SG}_{8}$ Napolitano $C_{x} 5 \mathrm{chwartz} \mathrm{PJ}$. Low penetrance in the long $\mathrm{QT}$ syndrome. Clinical impact. Circulation 1999; 99: 529-533.

157. Sesti F, Abbott GW, Wei \, Murray KT, Saksena S, Schwartz PI, Priori SG, Roden DM, George AL Jr, Goldstein SAN. A common polymorphism associated with antibiotic-induced cardiac arrhythmia. Proc Nati Acad Sci USA 2000; 97 : 10613-10618.

158. Yang $P$, Kanki $H$, Drolet $\mathbb{B}_{\text {, Yang }} B$, Wei d, Viswanathian $P C_{n}$ Hohnloser $S H$, shimizu W, Schwartz PJ,

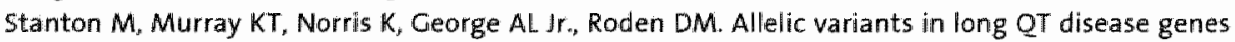
in patients with drug-associated torsade de pointes. Circulation 2002; 105: 1943-1948.

159. Chevalier P, Rodriguez $C$, Bontemps L, Miquel $M_{0}$ Kirkorian $G$, Rousson R, Potet $F$, Schott JJ, Baro I, Touboul P. Non-inwasive testing of acquired long $Q T$ syndrome: Evidence for multiple arrhythmogenic substrates. Cardiovasc Res 2001; 50: 386-398.

160. Napolitano C, Schwartz PJ, Brown AM, Ronchetti E, Bianchi L, Pinnavaia A, Acquaro G, Priori SG. Evidence for a cardiac ion channel mutation underlying drug-induced QT prolongation and lifethreatening arrhythmias. J Cardiovasc Electrophysiol 2000; 11: 691-696.

151. Piipo K, Holmstrom S, Swan $H$, Viitasalo M, Raatikka $M$. Toivonen L, Kontula K. Effect of the antimalarial drug halofantrine in the long $\mathrm{QT}$ syndrome due to a mutation of the cardiac sodium channel gene SCN5A. Am J Cardiol 2001; 87: 909-911.

162. Paulussen et al, unpublished observations.

163. Makita $N$, Horie $M$, Nakamura T, Ai T, Sasaki K, Yokoi H, Sakurai M, Sakuma I, Otani $H$, Sawa $H$, Kitabatake A. Drug-induced lang QT syndrome associated with a subclinical SCN5A mutation. Circulation 2002; 106: 1269-1274.

164. Dresser GK, Spence JD, Bailey DG. Pharmacokinetic-pharmacodynamic consequences and clinical relevance of Cytachrome P450 3A4 inhibition. Clin Pharmacokinet 2000; 38:41-57.

155. Cholerton S, Daly AK, Idle JR. The role of individual human cytochromes P450 in drug metabolism and clinical response. Trends Pharmacol Sci 1992; 13: 434-439.

166. Rendic S, DiCarlio F. Human Cytochrome P450 enzymes: a status report summarizing their reactions, substrattes, inducers and inhibitors. Drug Metab Rev 1997; 29: 413-580.

167. Guengerich FP. Cytochrome P-450 3A4: regulation and role in drug metabolism. Annu Rev Pharmacol Toxicol 1999; 39: 1-17.

168. Schuetz. JD, Beach DL, Guzelian PS. Selective expression of cytochrome P450 CYP3A mRNA's in embryonic and adult human liver Pharmacogenetics 1994; 4: 11-20.

169. Tsai WC, Tsai LM, Chen JH. Combined use of astemizole and ketoconazole resulting in torsade de pointes. I Formos Med Assac 1997; 96: 144-146.

170. Hsieh MH, Chen SA, Chiang CE, Tai CT, Lee SH, Wen ZC, Chang MS. Drug-induced torsades de pointes in one patient with congenital long QT syndrome. Intern J Cardiol 1996; 54: 85-88.

171. Keda S, Oka H, Matınaga K, Kubo S, Asai S, Miyahara Y, Osaka A, Kohno S. Astemizole-induced torsades de pointes in a patient with vasospastic angina. Jpn Circ J 1998; 62; 225-227.

172. Pohjola-Sintonen 5 , Viitasalo $M$, Toivonen $L$, Neuvonen $P$. Itraconazole prevents terfenadine metabolism and increases risk of torsades de pointes ventricular tachycardia. Eur $\Downarrow$ Clin Pharmacol 1993; 45: 191-193.

173. Lin JC, Quasny HA. QT prolongation and development of torsades de pointes with the concomitant administration of oral erythromycin base and quinidine. Pharmacotherapy 1997; 17:626-630. 
174. Karch $M$, Schmitt $C$, Plewan $A$ schmidt $G$, Schomig A. Torsade de pointes tachycardia during administration of quinidine and verapamil in atrial fibrillation. Herz $1997 ; 22: 51-56$.

175. Vitola $\rfloor_{i}$ Vukanovic J, Rodien DM. Cisapride-induced torsades de pointes. J Cardiovasc Electrophysiol 1998; 9: 1109-1113.

176. Piquette RK. Torsade de pointes induced by cisapride/clarithromycin interaction. Ann Pharmacother 1999; 33:22-26.

177. Gray VS. Syncopal episodes associated with cisapride and concurrent drugs. Ann Pharmacol 1999; 32: $648-651$.

178. Bran S, Murray WA, Hirsch IB, Palmer JP. Long QT syndrome during high-dose cisapride. Arch Intern Med 1995; 155: 765-768.

179. Jenkins IR, Gibson J. Cisapride, erythromycin and arrhythmia. Anaesth Intens Care 1995; 24: 728.

180. Pettignano $R$, Chambliss $C R$, Darsey $E$, Heard $M$, Clark R. Cisapride-induced dysarrhythmia in a pediatric patient receiving extracorporeal life support. Crit Care Med 1996; $24: 1.268-1271$.

181. Sakkarie MA. Torsades de pointes in two chronic renal failure patients treated with cisapride and clarithromycin. Am J Kidney Dis 1997; 30: 437-439.

182. Hii IT, Wyse DG, Gillis AM, Cohen JM, Mitchell LB. Propafenone-induced torsade de pointes: crossreactivity with quinidine. Pacing Clin. Electrophysiol. 1991; 14: 1568-70.

183. Michalets EL, Smith LK, Van Tassel ED. Torsade de pointes resulting from the addition of droperidol to an existing cytochrome P450 drug interaction. Ann Pharmacother. 1998; 32: 761-765.

184. Choudhury $L_{v}$ Grais $I M_{0}$ Passman RS. Torsades de pointes due to drug interaction between disopyramide and clarithromycin. Heart Disease 1999; 1: 206-207.

185. Flockhart DA, Drici MD, Kerbusch T, Soukhova N, Richard E, Pearle PL, Mahal SK, Babb VJ. Studies on the mechanism of a fatal clarithromycin-pimozide interaction in a patient with Tourette syndrome. J Clin Pharmacol 2000; 20: 317-324.

186. Ohki R, Takahashi M, Mizuno O, Fujikawa H, Mitsuhashi T, Katsuki T, lkeda U, Shimada K. Torsades de pointes ventricular tachycardia induced by mosapride and flecainide in the presence of hypokalemia. Pacing Clin Electrophysiol. 2001; 24: 119-121.

187. Thomas AR, Chan LN, Bauman NL., Olopade CO. Prolongation of the QT interval related to cisapridediltiazem interaction. Pharmacother. 1998; 18: 381-385.

18.8. Hayashi $\mathrm{V}$, Ikeda U, Hashimoto T, Watanabe $T$, Mitsuhashi T, Shimada K. Torsades de pointes ventricular tachycardia induced by clarithromycin and disopyramide in the presence of hypokalemia. Pacing Clin Electrophysiol. 1999; 22: 672-674.

189. Romkes $\mathrm{JH}$, Froger $\mathrm{CL}$, Wever $\mathrm{EF}$, Westerhof $\mathrm{PW}$. Syncopes during simultaneous use of terfenadine and itraconazole. Ned Tijdschr Geneesk. 1997: 141: 950-953.

190. Wrighton SA, Brian WR, Sari MA, Iwasaki M, Guengerich IF, Raucy IL, Molowa DT, Vandenbranden $M$. Studies in the expression and metabolic capacities of human liver cytochrome P450IIIA5 (it 1 . p3). Mol Pharmacol 1990; 38: 207-213.

191. Paulussen A, Lavrijsen $K$, Bohets $H$, Hendrickx $J_{*}$ Verhasselt $P$, Luyten W, Konings $F$, Armstrong $M$. Two linked mutations in the transcriptional regulatory elements of the CYP3A5 gene constitute the major genetic determinant of polymorphic activity in humans. Pharmacogenetics 2000; 10; 415-424.

192. Jounaidi $Y$, Hyrailles $V$, Gervot $L$, Maurel $P$. Detection of CYP3A5 allellic variant a candidate for polymorphic expression of the protein? Biochem Biophys Res Commun 1996; 221: 466-470.

193. Gibbs MA, Thummel KE, Shen DD, Kunze KL. Inhibition of cytochrome P-450 (CYP3A) in human intestinal and liver microsomes: comparison of $K_{i}$ values and impact of CYP3A5 expression. Drug Metab Dispos 1999; 27: 180-187.

194. Mohler PJ, Schott Jل,Gramolini AO, Dilly KW, Guatimosim $S$, duBell WH, Song LS, Haurogné K, Kyndt F, Ali ME, Rogers TB, Lederer WI, Escande D, Le Marec $\mathrm{H}_{2}$ Bennett V. Ankyrin-B mutation causes type 4 long-QT cardiac arrhythmia and sudden cardiac death. Nature 2003; 42:634-639. 


\section{CHAPTER 2}

\section{A novel mutation (T65P) in the PAS domain of the human potassium channel (HERG) results in the long QT syndrome by trafficking deficiency}

Aimée Paulussen ${ }^{1,2}$, Adam Raes ${ }^{3}$, Gert Matthijs ${ }^{4}$, Dirk J. Snyders ${ }^{3}$ Nadine Cohen ${ }^{4}$, Jeroen Aerssens ${ }^{*}$.

'Department of Pharmacogenomics, Johnson \& Johnson Pharmace utical Research \& Development. Beerse, Belgium, and Raritan, New Jersey, USA: ${ }^{2}$ Cardiovascular Research institute Maastricht (CARM), Department of Genetics \& Cell Biology, University of Maastricht, The Netherlands; 'Laboratory for Molecular Biophysics, Physiology and Pharmacology, Department of Biomedical Sciences, University of Antwerp (UIA) and Flanders Institute for Biotechnology (VIB), Belgium; "Department of Human Genetics, University of Leuwen. Bellgium.

Journal of Biological Chemistry, 2002;277(50):48610-48616

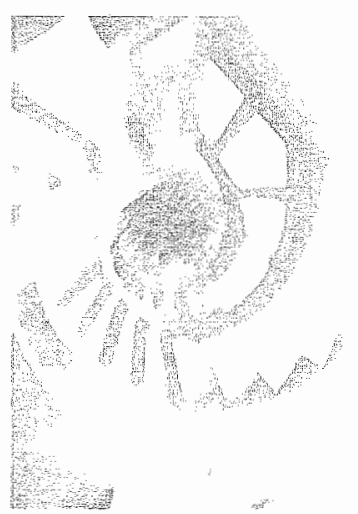




\section{Abstract}

The congenital long OT syndrome is a cardiac disease characterized by an increased susceptibility to ventricular arrhythmias. The clinical hallmark is a prolongation of the QT interval that reflects a delay in repolarization caused by mutations in cardiac ion channel genes. Mutations in the human ether-a-go-go related gene KCNH2 (HERG) can cause a reduction in $I_{k r}$ one of the currents responsible for cardiac repolarization. We describe the identification and characterization of a novel missense mutation T65P in the Per-Arnt-Sim (PAS) domain of HERG, resulting in defective trafficking of the protein to the cell membrane. Defective folding of the mutant protein could be restored by decreased cell incubation temperature and pharmacologically by cisapride and $\mathrm{E}-4031$. When trafficking was restored by growing cells at $27^{\circ} \mathrm{C}$, the kinetics of the mutated channel resembled that of wild type channels although the rate of activation, deactivation and recovery from inactivation were accelerated. No positive evidence for the formation of hetero-tetramers was obtained by co-expression of WT with mutant subunits at $37^{\circ} \mathrm{C}$. As a consequence the clinical symptoms may be explained rather by haplo-insufficiency than by dominant negative effects. This study is the first to relate a PAS-domain mutation in HERG to a trafficiking deficiency at body temperature, apart from effects on channel deactivation.

\section{Introduction}

Congenital llong QT Syndrome (CLOTS) is a disorder of the electrical system of the heart. The disorder manifests itself by a prolonged QT-interval on the electrocardiogram (ECG) and by a propensity for tachyarrhythmias causing syncope's and sudden death (1). The human ether-à-go-go-related gene KCNH2, encoding the $\alpha$ subunits of the voltage-gated potassium channel HERG, is one of five genes linked to this disease. The HERG potassium channel has been shown to encode the $\alpha$-subunit of the cardiac rapidly activating, delayed rectifying current $I_{K r}(2)$ that plays an important role in the repolarization of the cardiac action potential $(3,4)$. Although the role of other factors contributing to $I_{k r}$ current, such as $K C N H 2$ splice variants $(5,6,7)$ and interacting $\beta$-subunits ( 8 ) are still under investigation, it is clear that mutations in the KCNH2 gene are one of the most common causes of congenital LQTS. In most cases these mutations reduce the outward potassium current during repolarization, and thus lengthen the action potential duration, which increases the risk of ventricular arrhythmia (9). More than one hundred different mutations in the KCNH2 gene have been described for CLQTS families including frame shifts, deletions, insertions, missense and nonsense mutations $(10,11)$. There is a great deal of genetic evidence that the mutations identified are the cause of the disease in the different families however, in many cases the molecular mechanism by which channel function is disrupted, has not 
been unequivocally identified. Thus far, all except one (12) of the mutant HERC channels characterized, cause a net reduction in outward potassium current during repolarization through loss of function. The latter may result from different mechanisms including non-functionality $(13,14)$, altered gating properties $(15,16,17)$ or abnormal trafficking from the endoplasmic reticulum (ER) to the cell membrane (18-22). Especially this last category of mutants has recently become a focus of interest, because such mutant subunits may display WT properties, once they are inserted in the cell membrane. Defective protein processing has been described for other congenital human diseases, including cystic fibrosis and nephrogenic diabetes insipidus (23-25). In these diseases, the mutation causes very subtle differences in protein folding, which lead to ER retention. However, lower cell incubation temperatures or chemical chaperones could restore trafficking in these cases. Thus far, six trafficking-deficient mutations have been described in the $\mathrm{KCNH} 2$ gene (Figure $1,18-22)$. These mutations reside in different regions of the HERG protein and seem to determine temperature or chemical chaperone dependent rescue. For example, trafficking of mutant channels G601S, N470D and R752W $(19,20,21)$ was restored by lower incubation temperatures, but only G601S and N470D channels were restored by chemical chaperones. A561V (22) was not rescued by either temperature or chemical chaperones and even expressed a dominant negative effect on wild type current.

In this study, we describe the identification of a novel missense mutation $193 . A>C$ in exon 2 of the $\mathrm{KCNH} 2$ gene in a case of congenital long QT syndrome. This mutation is located in the amino-terminal Per-Arnt-Sim (PAS) domain of the HERG protein and leads to an amino-acid substitution T65.P (threonine to proline). Previous studies have focussed on this $\mathrm{N}$-terminal PAS-domain, since it may interact with the $\$ 4-55$ linker, thereby controlling channel deactivation $(15,26)$. Using functional analysis, we demonstrate that the T65P HERG protein also displayed an accelerated deactivation, but only if it was transported to the cell membrane. The primary dysfunction of the T65P mutation was a trafficking deficiency and therefore may provide new information on additional functions of this protein domain. 


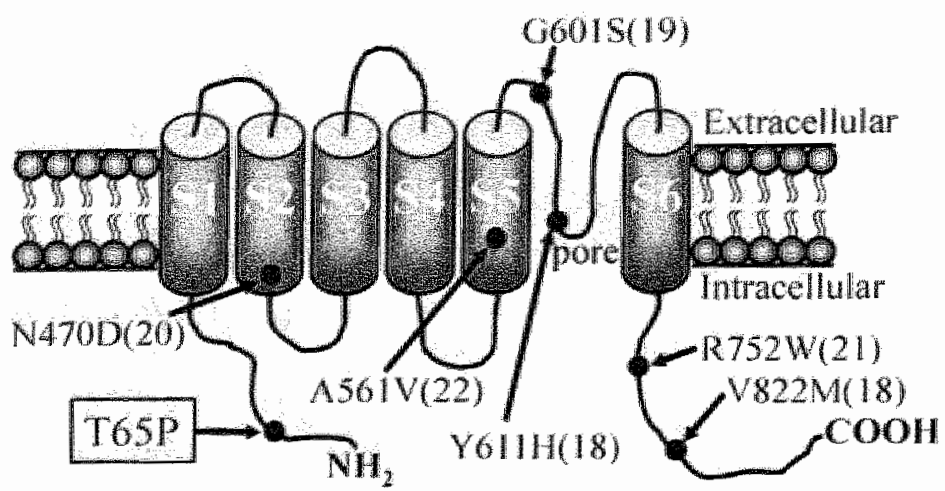

Figure 1. HERG $\alpha$-5ubunit. Representation of a single HERG protein subunit with six trans membrane domains (51-S6), the pore region between $\$ 5$ and $S 6$, and the intracellular $N$-and C-terminal end5. Black dots indicate reported trafficking-deficient mutations. The novel T65P mutation described in this study is marked with a black square.

\section{Experimental procedures}

\section{Study subjects}

The pedigree of the Caucasian family in which the congenital long QT syndrome (LQTS) was diagnosed is shown in Figure 3A. Five of the family members (subjects 1,2 , 3,4 , and 6) are being treated with beta-blockers because of a prolonged OT interval. Subject 2 has suffered from a cardiovascular collapse at the age of 25, but was successfully resuscitated. Apart from an aberrant ECG pattern (sinus tachycardia, diffuse repolarisation disturbances) subject 3 is asymptomatic. Because of the abnormal ECG pattern and the highly extended QT intervals, subject 4 and her daughter (subject 6) are being treated with beta-blockers. Moreover, subject 6 suffered numerous syncopic episodes in the past. Subject 5 died suddenly at the age of 31 shortly after the start of an antibiotic treatment for otitis, which is highly suggestive for drug-induced LOTS. Subject 7, a sister of subject 1, has died suddenly at the age of 42 years. Finally, no information is available for two additional sisters of subject 1 . Informed consent for genetic analysis was given prior to the collection of blood samples for DNA extraction from subjects 1,2 and 3. Samples from other family members were not available for genetic testing analysis.

Screening of clots genes

The DNA of subject 1 was screened for all currently known LOT genes KCNQ1 (LOT1, KVLOT1), KCNH2 (LQT2, HERG), SCNSA (LOT3, SCN5A), KCNE1 (LQT5, MinK) and KCNE2 (LQT6, MiRP1). PCR primers used for amplification of individual exons were described previously $(8,27-29)$. PCR products were directly sequenced and aligned with the respective wild type sequences in order to detect genetic variations. 
Detection assay for the T65P mutation

A PCR-RFLP assay was designed for the detection of the identified mutation $193 \mathrm{~A} \times \mathrm{C}$ (T65P) in exon 2 of the $K C N H 2$ gene (Figure $3 B$ and $C$ ). Primers used were $5^{\prime}-C A C-G C G$. CAC-TCT-CCT-CAC-CG-3' (MG430, forward) and 5'-CGC-CCC-GGC-CCG-CTC-CTA-C-3" (MG431, reverse). The PCR mix of $30 \mu$ l consisted of $1 \times$ PCR buffer $11,200 \mathrm{nM}$ of dNTP's, $1.5 \mathrm{mM}$ of $\mathrm{MgCl}_{2}, 250 \mathrm{nM}$ of each primer, 0.75 units of AmpliTaq Gold polymerase and approximately $100 \mathrm{ng}$ of genomic DNA. PCR conditions were $95^{\circ} \mathrm{C}$ for $10 \mathrm{~min}, 35 \mathrm{cyclles}$ of $95^{\circ} \mathrm{C}(45 \mathrm{sec}), 60^{\circ} \mathrm{C}(45 \mathrm{sec}), 72^{\circ} \mathrm{C}$ (45 sec) and a final extension step of $72^{\circ} \mathrm{C}$ for 10 $\min$. The resulting PCR product of 278 bp was digested with restriction enzyme $B s p$ MI. A control group of 90 anonymous, healthy volunteers (180 alleles) was screened with the PCR-RFLP test for the T65.P mutation.

\section{Site-directed mutagenesis and constructs}

The wild type HERG/PCDNA3 (HERG-WT) expression construct was kindly donated by Dr. Craig January and Dr. Zhengfeng Zhou (University of Wisconsin-Madison). Mutant T65P-HERG/pCDNA3 (HERG-T65P) was created using the GeneEditor ${ }^{\text {TM }}$ in vitro SiteDirected Mutagenesis System (Promega, Madison, US) according to the manufacturers instructions. Primer 5'-AGT-CGC-AGG 'GGC-AGG-GTC-G-3" was used as the synthetic oligonucleotide to create the mutant HERG CDNA (mutation in bold and underlined). The introduction of mutation 193 A>C (T65P) in the wild type HERG CDNA was verified by direct sequencing. Wild type (WT-GFP) and mutant T65P HERG CDNA (T65P-GFP) were sub cloned downstream of the coding region of a green fluorescent protein (GFP) in expression vector pcDNA3.1_NT_GFP (Invitrogen, Paisley, UK) using restriction sites KpN-I and ECo-RI. The ATG startcodon of the KCNH2 CDNA was 24 bp downstream of the final GFP codon. The complete sequence of the constructs, encoding the in-frame fusion GFP-HERG protein, was verified using direct sequencing.

\section{Stable transfection of HERG WT and T65P constructs in HEK293 cells}

Human embryonic kidney 293 cells (HEK293) were cultured in DMEM supplemented with $10 \%$ foetal bovine serum, $1 \%$ L-glutamine /penicillin/streptomycin and $1 \%$ nonessential amino acids under a $5 \% \mathrm{CO}_{2}$ atmosphere. $\mathrm{HEK} 293$ cells were transfected stably with FUGENE Transfection Reagent (Roche Diagnostics, Basel, Switserland) according to the manufacturers instructions. Between five and ten HERG WT/PCDNA3 or HERG T65P/PCDNA3 stable cell lines were selected by their G-418 resistance and the level of HERG protein expression was determined by western blot analysis using a HERG specific antibody (Alomone labs, Jerusalem, Israel). Cell lines with the highest HERG protein expression were used for follow up experiments.

\section{Western blot analysis}

Membrane protein preparation and Western blot analysis were performed as previously described (30). Membrane proteins isolated from the stable cell lines, cultured at $37^{\circ} \mathrm{C}$, were subjected to $4-12 \%$ SDS-polyacrylamide gel electrophoresis and 
electrophoretically transferred onto polywinylidene difluoride (PVDF) membranes. The membranes were incubated overnight at $4^{\circ} \mathrm{C}$ with anti-HERG antibody at the recommended dilution. Membranes were incubated with HRP-conjugated donkey anti-rabbit antibody and HRP-bound protein was detected with an ECL+Plus detection kit. In order to study defects in biosynthetic processing of the T65P mutant protein, Western blot procedures were repeated at incubation temperature of $27^{\circ} \mathrm{C}$. The effects of chamel blocking agents cisapride and E-4031 on HERG protein trafficking were studied at $37^{\circ} \mathrm{C}$ in a concentration range between 0 and $10 \mu \mathrm{M}$.

\section{Confocal imaging:}

HEK293 cells were cultivated as described in the previous section, but on cover slips. HEK 293 cells were transiently transfected with $0.5 \mu \mathrm{g}$ of either WT-GFP or T65P-GFP constructs. In addition, $0.1 \mu \mathrm{g}$ of a red fluorescent marker for the endoplasmic reticulum (DsRed-ER) was cotransfected to distinguish between ER retained and membrane bound proteins (31). Confocal images were obtained 48 hours after transfection on a Zeiss CLSM 510, equipped with an argon laser for the visualization of GFP and DsRed tagged proteins.

\section{Whole cell current recordings and data analysis}

HEK293 cells were cultured at $37^{\circ} \mathrm{C}$ or at $27^{\circ} \mathrm{C}$, when indicated. Current recordings were made with an Axopatch-20OB amplifier (Axon instruments, Union City, CA) in the whole cell configuration using suction pipettes as described previously (32). Glass patch pipettes were pulled with a P2000 laser puller (Sutter instruments, Novato, CA) from $1.2 \mathrm{~mm}$ Starbore borosilicate glass (Radnoti, Monrovia, CA) and had resistances between 1.5 and $3.5 \mathrm{M} \Omega$. All currents were recorded at room temperature $\left(20-22^{\circ} \mathrm{C}\right)$ and were sampled at 1 to $10 \mathrm{kHz}$ with a Digidata $1200 \mathrm{~A}$ data acquisition system (Axon instruments), after appropriate low-pass filtering. Command voltages and data storage were controlled with pClamp8 software (Axon instruments). Cells were perfused with HEPES-buffered Tyrode's solution containing $145 \mathrm{mM} \mathrm{NaCl}, 4 \mathrm{mM} \mathrm{KCl}, 1$ $\mathrm{mM} \mathrm{MgCl}$, $1.8 \mathrm{mM} \mathrm{CaCl} 2$, $10 \mathrm{mM}$ glucose and $10 \mathrm{mM}$ HEPES ( $\mathrm{pH} 7.35$ with $\mathrm{NaOH}$ ). The internal pipette solution contained $110 \mathrm{mM} \mathrm{KCl}, 2 \mathrm{mM} \mathrm{MgCl}, 5 \mathrm{mM} \mathrm{K}_{2} A T P$, $5 \mathrm{mM}$ $\mathrm{K}_{4} \mathrm{BAPTA}$ and $10 \mathrm{mM}$ HEPES ( $\mathrm{pH} 7.2$ with $\mathrm{KOH}$ ). After seal formation and establishing the whole cell configuration, the access resistance varied between 2.5 and $8 \mathrm{M} \Omega$. Series resistance was compensated to ensure that voltage errors were $<5 \mathrm{mV}$. No leak subtraction was applied and the holding potential was $-80 \mathrm{mV}$, unless noted otherwise. The voltage protocols are presented in the figure legends. The voltage dependence of channel activation was fitted with a Boltzmann equation according to $y=1 /\left\{1+\exp \left[-\left(E-V_{y}\right) / k\right]\right\}$, where $V_{1 / 2}$ represents the voltage at which $50 \%$ of the channels are open and $k$ the slope factor. Activation, deactivation and recovery from inactivation kinetics were fitted with a single or a double exponential function using a non-linear least-squares (Gauss-Newton) algorithm. Data are presented as mean \pm 
SEM and the Student's t-test was used for statistical analysis: n represents the number of cellls.

\section{Results}

Screening of LQT genes

Mutation screening by direct sequencing revealed a novel mutation in exon 2 of the KCNH2 gene in the DNA of subject. 1. This missense mutation, changing base pair 193 from an $A$ to $C$, leads to an amino-acid change from a threonine to a proline (T65P) and is located in the N-terminal PAS domain of the KCNH2 gene (Figure 1,2).

A PCR-RFLP assay was developed, based on the loss of recognition site by restriction enzyme Bsp-Ml due to the mutation. In the presence of the 193 A>C (T65P) mutation, a recognition site for restriction enzyme Bsp-MI is lost and results in a 278 bp product. In the absence of the mutation, the PCR product is cut in two fragments of 155 and 123 bp, respectively. All three available LQTS family members (subjects 1, 2, and 3) were found to be heterozygous carriers of this mutation (Figure 3), while the mutation was not found in a control population of 90 healthy unrelated volunteers.

\section{Western blot analysis}

It has been shown previously that expression of the wild type HERG protein in HEK293 cells results in two distinct bands on Western blot analysis: the upper band of $155 \mathrm{kDa}$ represents the complexly glycosylated mature form of the HERG channel inserted the cell membrane while the lower band (135 kDa) represents the immature coreglycosylated form of the HERG channel retained in the ER (30). Upon Western blot analysis, the $T 65 \mathrm{P}$ protein incubated at $37^{\circ} \mathrm{C}$ for 24 hours resulted only in the lower $135 \mathrm{kDa}$ band, while the wild type protein resulted in both bands (Figure 4A). However, the mature $155 \mathrm{kDa}$ band was detected after a decrease in incubation temperature to $27^{\circ} \mathrm{C}$ for at least 24 hours (Figure 4A), indicating that trafficking was restored. The stable HERG T65P cell line was also incubated with 2,5 and $10 \mu \mathrm{M}$ of HERG channel blocking agents cisapride and E-4031. Both agents were able to restore trafficking of the T65P protein in a concentration dependant manner (Figure $4 \mathrm{~B}$ ), as assessed from the appearance of the $155 \mathrm{kDa}$ protein. 
A

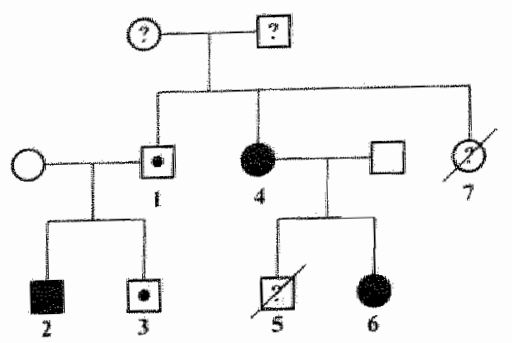

B

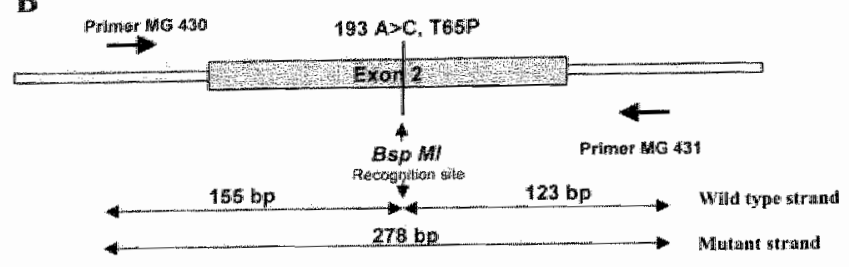

C

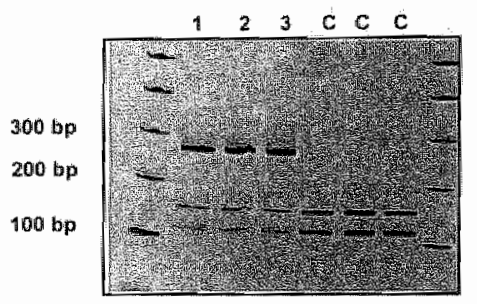

Figure 3. Pedigree of LQTS family and PCR-RFLP assay for mutation detection. A, family pedigree, indicating the index numbers of the family members. Black symbols, clinically affected subjects with LOTS; symbols with black dot, asymptomatic subjects carrying the LQTS gene mutation; question mark, suspected gene carrier; squares, males; circles, females. B, Schematic overview of the PCR-RFLP assay used for the detection of the 193 A>C (T65P) mutation in the KCNH2 gene. $C$, results from the PCR-RFLP assay tested on family members. Lane numbers at the top of the lanes of the $12.5 \%$ polyacrylamide gel indicate the subject numbers $(1-3)$ or control subjects (C). bp $=$ basepairs. 


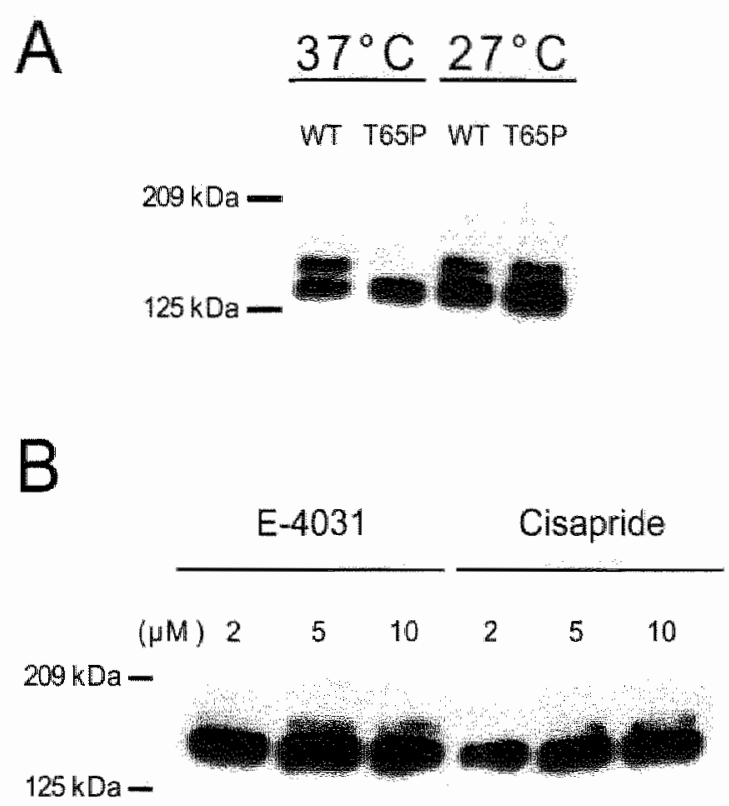

Figure 4. Western blot analysis of WT and T65P mutant HERCi channels. $A_{8}$ Influence of incubation temperature on protein trafficking. Incubations were performed at $37^{\circ} \mathrm{C}$ and $27^{\circ} \mathrm{C}$ for 24 hours. $B$, Influence of HERG blocking drugs cisapride and E-4031 on T65P protein trafficking. Crude membrane fractions were isolated $24 \mathrm{hrs}$ after transfection. $35 \mu \mathrm{g}$ of protein was loaded in each lane. Upper bands represent the glycolysated, membrane bound, mature form of HERG protein (155 kDa), lower bands represent immature HERG protein retained in the endoplasmic reticulum (135 $\mathrm{kDa}$ ).

\section{Confocal microscopy}

To confirm Western-blotting results, GFP was tagged to the N-terminus of HERG subunits and expressed in HEK293 cells. Sub cellular trafficking of WT-GFP and T65PGFP was investigated after incubation for $48 \mathrm{hrs}$ at $37^{\circ} \mathrm{C}$ or $27^{\circ} \mathrm{C}$. A red fluorescent endoplasmic reticulum (DsRed-ER) vector was co-transfected to distinguish between HERG protein retained in the ER and membrane bound HERG proteins. Confocal images (Figure 5) clearly show the presence of WT channels in the plasma membrane (Figure $5 \mathrm{~A}, \mathrm{~B})$ as well as in the ER $\left(37^{\circ} \mathrm{C}\right)$, while the T65P mutant protein $\left(37^{\circ} \mathrm{C}\right)$ was exclusively present in the $\mathbb{E R}$ (Figure $5 \mathrm{C}, \mathrm{D}$ ). Upon incubation at $27^{\circ} \mathrm{C}$, however, trafficking of mutant T65P HERG protein was restored and the protein was incorporated in the cell membrane, as evidenced by the selective green fluorescence at the level of the plasma membrane (Figure 5E, F). 
N-GFP
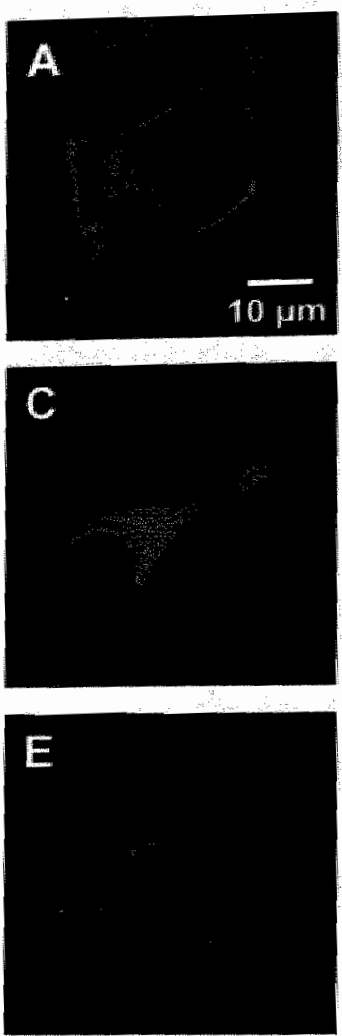

\section{+ER-DsRED}
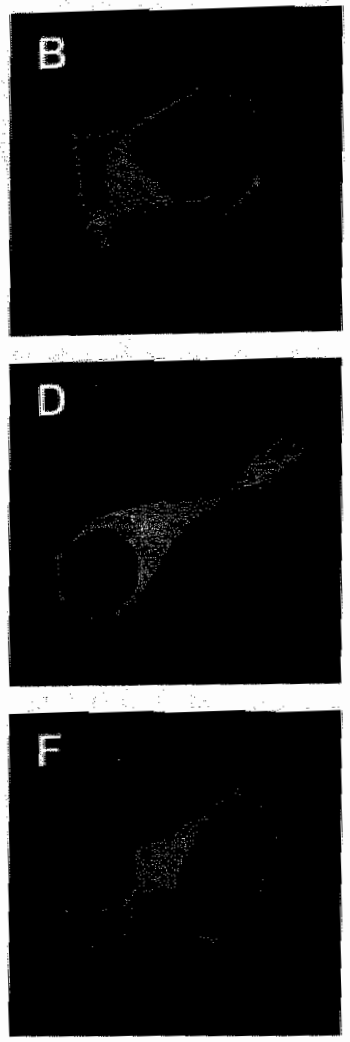

Figure 5. Subcellular distribution of WT HERG and T65.P channels. Confocal imaging of GFP tagged WT (WT-GFP) and T65P (T65P-GFP) HERG channels in HEK293 cells. GFP tagged constructs were transfected transiently together with an endoplasmic reticulum targeted DsRed marker (DsRed-ER). Left panels, GFP fluorescence images for WT $\left(37^{\circ} \mathrm{C}\right), T 65^{\mathrm{P}}\left(37^{\circ} \mathrm{C}\right)$ and T65P $\left(27^{\circ} \mathrm{C}\right)$ HERG channels. Right panels, superimposed images of double stained (green GFP and red DsRed) HERG WT ar T65P channels. Note the absence of (green) membrane bound protein of $T 65 \mathrm{P}$ at $37^{\circ} \mathrm{C}(\mathrm{C}$ and $\mathrm{D})$ and the restoration of $T 65 \mathrm{P}$ protein trafficking at $27^{\circ} \mathrm{C}(E$ and $F)$.

\section{Biophysical properties of HERG WT and T65P channels}

Because Western blot analysis and confocal imaging suggested dysfunctional trafficking of T65P mutant to the cell membrane, we performed whole cell patch clamp recordings on stable HERG WT and T65P cells, in order to study the functional expression. Figure 6 shows representative current recordings for HERG-WT and HERGT65P channels. T65P stable cells only generated small currents (Figure $6 \mathrm{C}$ ) as compared to WT stable cells after incubation at $37^{\circ} \mathrm{C}$. Incubating $T 65 \mathrm{P}$ cells at $27^{\circ} \mathrm{C}$ for 24 hours significantly increased T65P current density (Figure 6D), suggesting temperature dependent trafficking of $T 65 \mathrm{P}$ proteins. The voltage dependence of 
activation was determined for WT and T65P channels (grown at $37^{\circ} \mathrm{C}$ and $27^{\circ} \mathrm{C}$ ) by plotting the maximum tail current amplitude at $-40 \mathrm{mV}$ (Figure 6) as a function of the prepulse voltage. These data were fit with a Boltzmann function, which revealed no significant differences in the mid-point potential $\left(V_{y_{2}}\right)$ and slope factor $(k)$ between WT and $T 65 \mathrm{P}$ channels (Figure $7 \mathrm{~A}$ ).

A

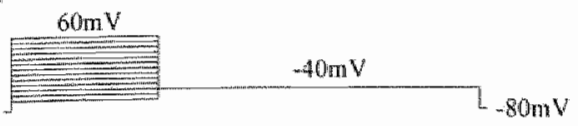

B HERG-WT $\left(37^{\circ} \mathrm{C}\right)$

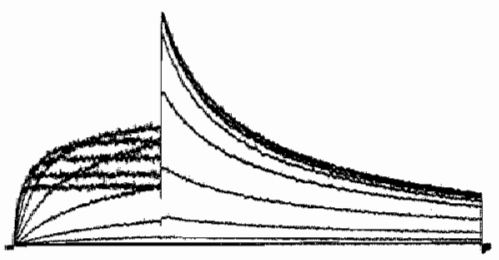

$\mathrm{C}$ HERG-T65P $\left(37^{\circ} \mathrm{C}\right)$

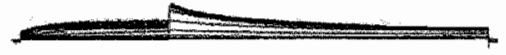

$\mathrm{D}$ HERG-T65P $\left(27^{\circ} \mathrm{C}\right)$

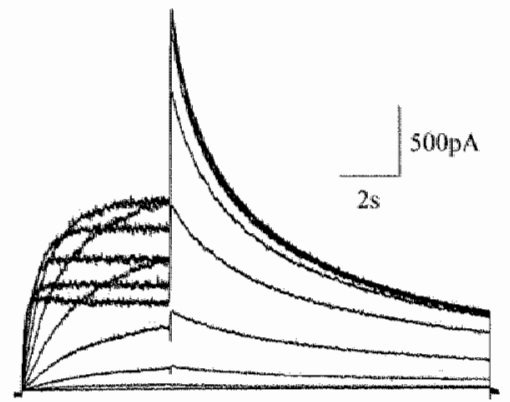

Figure 6. Voltage clamp recordings of HERG WT and T65P channels. A, voltage protocol, HERG currents were activated by $5 \mathrm{sec}$ depolarising steps between -60 and $+60 \mathrm{mV}$ (in 10-mV increments) from a holding potential of $-80 \mathrm{mV}$. Cells were clamped to $-40 \mathrm{mV}$ for $10 \mathrm{sec}$ to elicit tail currents. Representative HERG currents elicited from WT stable cells after incubation at $37^{\circ} \mathrm{C}(B, n=10)$, T65P stable cells after incubation at $37^{\circ} \mathrm{C}(\mathrm{C}, n=9)$ and T65P stable cells after incubation at $27^{\circ} \mathrm{C}(D, n=7)$.

To determine the time constants of activation, deactivation and recovery from inactivation, current traces were fit with a single or double exponential function as appropriate. The kinetics for $\mathrm{T} 65 \mathrm{P}$ cells grown at $27^{\circ} \mathrm{C}$ were analyzed over the whole voltage range, whilst for cells grown at $37^{\circ} \mathrm{C}$, the current amplitudes were too small for full analysis. At voltages resulting in the highest current amplitudes, the current kinetics of $\mathrm{T} 65 \mathrm{P}$ cells grown at $37^{\circ} \mathrm{C}$ were comparable to the kinetics of T65P cells grown at $27^{\circ} \mathrm{C}$ (data not shown). Time constants for activation and deactivation are presented in Figure 7 C. T65 P channels $\left(27^{\circ}\right)$ activated and deactivated faster than WT channels. The time constants for recovery from inactivation are presented in Figure 7D. Recovery from inactivation was also faster for T65P channels than WT channels. Co-expression of WT and mutant T65P was performed by transient transfection of the T65P-pcDNA3 construct on the WT stable cell line. Maximum tail current amplitudes as obtained according to the pulse protocol in Figure 6, were compared to maximum tail current amplitudes from stable WT cells alone. In cells grown at $37^{\circ} \mathrm{C}$, no increase in HERG current density was observed while cells grown at $27^{\circ} \mathrm{C}$ displayed a significant 
increase in HERG current density (Figure 8 ). These results suggest that WT subunits $d$ not interact with $T 65 \mathrm{P}$ subunits at $37^{\circ} \mathrm{C}$.

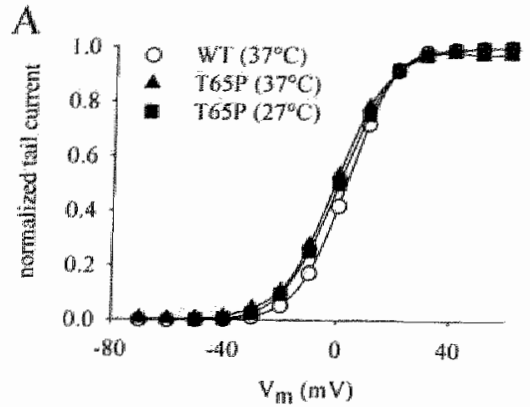

C

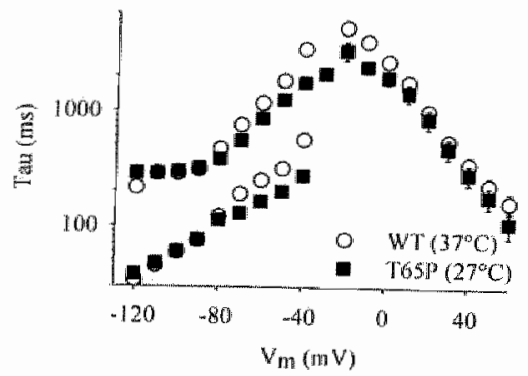

B

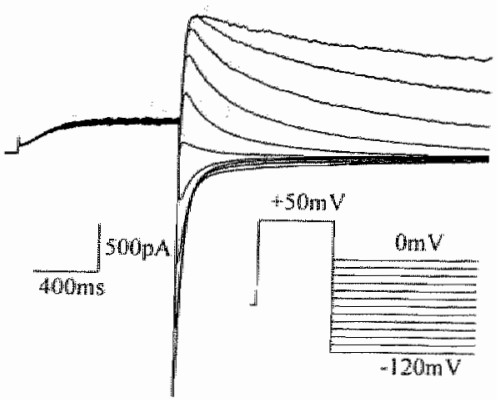

D

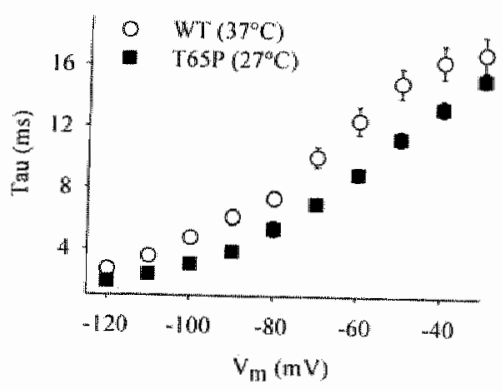

Figure 7. Voltage dependence and kinetics of HERG WT and T65P channels. A, Voltage dependence of steady-state HERC activation. Relative tail currents were derived from current recordings as shown in figure 5. HERG WT and T65P (cell culture at $37^{\circ} \mathrm{C}$ and $27^{\circ} \mathrm{C}$ ) currents were fit with a Boltzmann function to determine midpoint of activation $\left(V_{k_{2}}\right)$ and slope factor $(k)$. WT $(n=10): V_{y_{2}}=2.53 \pm 1.47, k=-7.3 \pm 0.13$, T65P $37^{\circ} \mathrm{C}(n=9): V_{1 / 2}=-1.19 \pm 2.39, k=-7.56 \pm 0.36, T 65 \mathrm{P} 27^{\circ} \mathrm{C}(n=7): V_{1 / 2}=-0.57 \pm 2.82, k=-7.73 \pm 0.32 .8$, pulse protocol eliciting deactivating tail currents. HERG channels were fully activated by a 1 -second prepulse to $+50 \mathrm{mV}$ and then clamped to voltages between 0 and $-120 \mathrm{mV}$ in $10 \mathrm{mV}$ increments for 4 sec. $C$, Time constants of current activation were determined by fitting activating currents between -20 and $60 \mathrm{mV}$ as shown in Figure 5 to a single exponential function. Slow and fast component of current deactivation were determined by fitting deactivating tail currents (as in panel $B$ ) to a double exponential function. D, time constant for recovery from inactivation was determined by fitting the first 15 ms after the 1 -second activating pulse (as im panel $B$ ) to a single exponential function. 


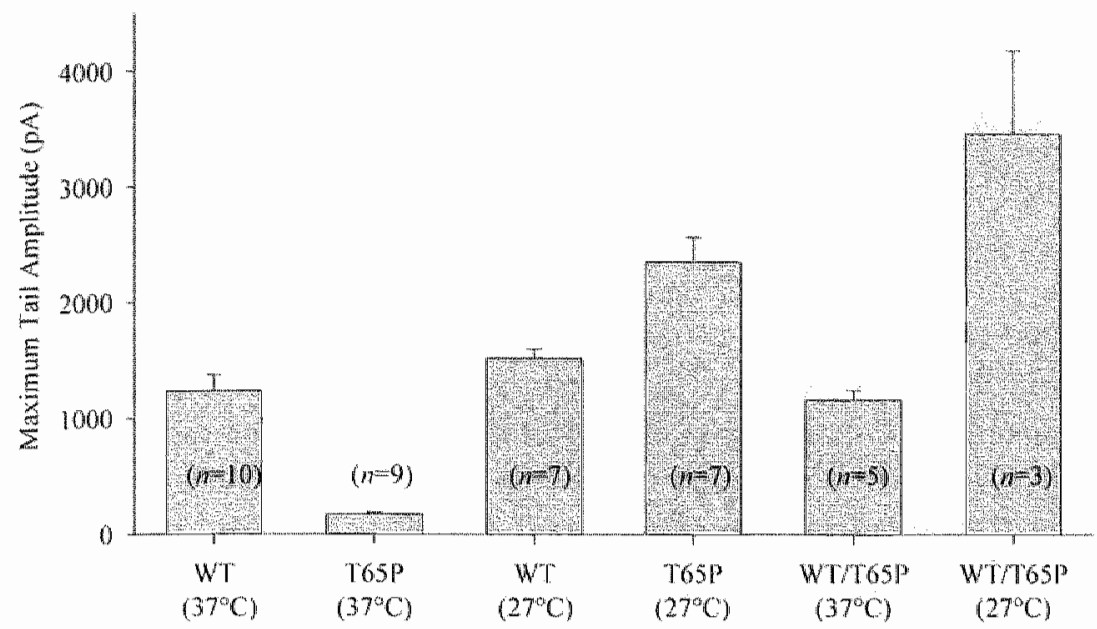

Figure 8. Co-expression of HERG WT and T65P mutant channels. As a measure for channel density at the plasma membrane level, maximal tail amplitudes were determined from current recordings as in Figure 5 after 24 hours of transfection. Tail currents from WT and T65P cell lines, cultivated at $37^{\circ} \mathrm{C}$ or $27^{\circ} \mathrm{C}$ are shown in column 1 to 4 . To study co-expression, $5 \mu \mathrm{g}$ of HERG-T65P was transientlly transfected on the HERG-WT stable cell line (column 5 and 6). After transfection, cells were either incubated at $37^{\circ} \mathrm{C}$ or at $27^{\circ} \mathrm{C}$. Error bars represent \pm S.E.M.

\section{Discussion}

A novel CLQTS causing mutation, T65P in the KCNH2 gene, was detected in a Caucasian LOTS family. Two sudden deaths occurred in this family indicating a high risk for development of lethal arrhythmias. Three members participating in the study were all heterozygous carriers of this mutation while the mutation was not detected in a control group of 90 individuals (Figure 3).

Previously, characterized KCNH2 mutations have been shown to cause a reduction in $I_{k,}$ current in the repolarization phase of the cardiac action potential. This reduction in $I_{\mathrm{K}}$ current can be the result of different mechanisms. Mutant channels, such as A561V, $5818 \mathrm{~L}$ and $\mathrm{Y} 667 \mathrm{X}$, can cause a complete loss of function $(9,13,33)$, while other mutated channels can form functional channels, but with altered gating kinetics (16). Recently, a third mechanism for dysfunctional behaviour of mutant HERG proteins was described involving protein trafficking $(18,19)$. It was proposed that these mutations prevented correct protein folding such that these proteins fail the "quality control" and are retained in the endoplasmic reticulum (ER). In the present study, the Western blot analysis of the T65P mutant protein showed a single $135 \mathrm{kDa}$ band, while WT HERG protein normally shows two bands (Figure 4A): the immature, coreglycolysated protein synthesized in the ER (135 kDa) and the further develloped, fully glycolysated, mature protein that is incorporated in the cell membrane (155 $\mathrm{kDa}$ ). such aberrant trafficking was initially described for the HERG mutants $\mathrm{Y} 611 \mathrm{H}$ and 
V822M by Zhou et al. (18). A later study by the same group (20) demonstrated that defective trafficking could be restored by lowering incubation temperatures $\left(27^{\circ} \mathrm{C}\right)$ of the cell culture or by treatment with HERG channel blocking drugs such as cisapride or E-4031. Also in the case of T65P we observed that trafficking of the mutant protein could be restored by both lower incubation temperatures as well as pharmacological drugs (Figure 4B). The latter pharmacological chaperone "rescue" of mutant HERG proteins has opened the first door towards therapy. Ficker et al. demonstrated that rescue of trafficking deficient HERG proteins can be domain-restricted and that potency of drug related rescue was directly linked to channel block potency (34). However, Rajamani et al. showed very recently that at least for some misprocessed HERG proteins, fexofenadine had a more that 300 -fold higher affinity towards HERG channel rescue than block (35). In this study it appeared that only misprocessed proteins that showed small currents at $37^{\circ} \mathrm{C}$ could be rescued but not the ones that showed no current at all at $37^{\circ} \mathrm{C}$. Since the T65P protein also showed small currents at $37^{\circ} \mathrm{C}$, fexofenadine might allso restore trafficking of this mutated channel.

Interestingly, the novel T65P mutation resides in the $\mathrm{N}$-terminal end of the HERG protein, which was shown to possess a so-called Per-Arnt-Sim (PAS) domain (36). Although this domain displays large amino acid sequence diversity in several proteins, it was however proposed as a domain family $(36,37)$. In HERG the $\mathrm{N}$-terminal residues from $S 26$ to $K 135$ were crystallized (26). A database search revealed a high similarity with the three-dimensional structure of the PAS domain containing photoactive yellow protein (PYP) (37) although the sequence similarity is low. The crystal structure contains five antiparallel $\beta$-sheet strands pressed against a long strand, composed of a coil and one turn of a $3_{10}$ helix with three $\alpha$-helices on the sides. The substitution of the threonine by a proline could have several consequences on HERG channels. 1) The T65P mutation is located just before the single turn of the $3_{30}$ helix, which might affect the formation of this helix. 2) A putative hydrogen bond between the T65 with D67 would not be possible with the proline substitution and could destabilize the structure of the N-terminus. 3) Although residue T65 is located in a more or less loosely packed regilon of the $\mathrm{N}$-terminus, it can not be excluded that steric hindrance induced by the rigid proline side chain could cause misfolding. 4) Any of the above effects could affect the local structure of the long strand. The latter, containing the $3_{10}$ helix and T65, connects the $\alpha$-helices located at both sides of the sheet of $\beta$-strands. A distortion of this connector could then change the 3 -dimensional structure in other parts e.g. the sheet of $\beta$-strands. The PAS domain in HERG is highly conserved among species (Figure 2). 


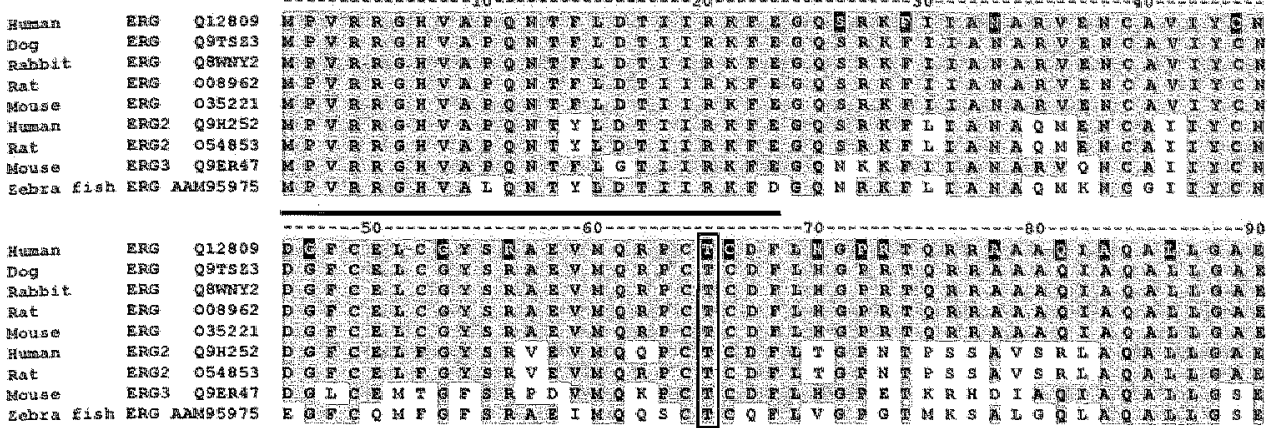

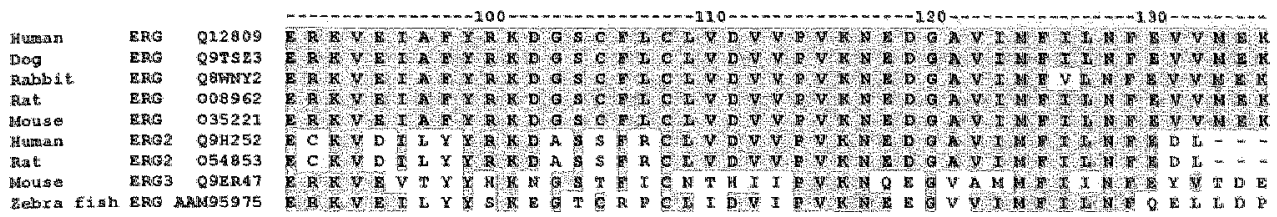

Figure 2. Alignment of $\mathrm{N}$-terminal amino-acid eag domain in different species. Each amino-acid sequence is preceded by its Swiss Prot accession number. Grey shaded areas mark the identical residues. A rectangular box indicates the newly identified T65.P mutation that has been characterized in this study. Mutated amino acids in the PAS domain of the human HERG protein that have been reported previously are indicated by white coding on a black background. The thick black line indicates the core PAS domain as described by Pellequer et al. (38). The crystal structure as obtained by Morais-Cabral et al. (26) extends from $\mathrm{S} 26$ to $\mathrm{K} 135$.

Previously it was shown that removal of the $\mathrm{N}$-terminal end, including the PASdomain, accelerates channel deactivation $(38,39)$. Furthermore, splice variants that lack a part of the $\mathrm{N}$-terminal domain display a faster deactivation rate $(6,7)$. A similar effect on the deactivation rate was observed with mutations in the 54-55 linker and it was suggested that this linker and the PAS domain might interact $(17,39)$ as was demonstrated for eag channels (40). Using an oocyte expression system chen et al. (1999) investigated the effects of several LOT associated PAS domain mutations on deactivation kinetics, and showed for eight mutations that HERG channel deactivation was accelerated, although to a different extent. The novel T65P mutation was analyzed with a mammalian expression system at $37^{\circ} \mathrm{C}$ and also revealed some accelerating effect on channel deactivation, but we consider this effect of secondary importance compared to the trafficking deficiency displayed by the T65P mutant protein. Chen et al. did not report trafficking deficiency in their study as the typical low incubation temperature of oocytes might have concealed trafficking deficiency. It is therefore conceivable that some of these eight mutant proteins may be deficient in trafficking at $37^{\circ} \mathrm{C}$. This hypothesis is supported by the results of Ficker et al. (21), who showed large currents for a trafficking deficient HERG protein (R752W) in the oocyte expression system as compared to the lack of current in the mammalian expression system. 
A functional HERG channel is composed of four a-subunit proteins, encoded by the KCNH2 gene, forming a tetramer. Most LOTS patients have the dominant RomanoWard form, inheriting one wild type allele and one mutant allele. Therefore, the best approach to mimic the phenotypic result of the genetic profile of these patients is the study of co-expression of WT CDNA with mutant cDNA. In some cases the ability of mutant HERC proteins to form hetero-tetramers with wild type subunits is lost, leading to haplo-insufficiency. In other cases, interaction of WT subunits with mutant subunits leads to alterations in the biophysical properties or amplitude of the assembled ion channel, causing a dominant negative effect. Although the gating kinetics of T65P channels were slightly different from WT channels, it is most likely that the prolonged $Q T$ interval is caused by a reduction of $I_{K r}$ by ER retention of the T65P subunits. The co-expression of $T 65 \mathrm{P}$ with WT subunits at $37^{\circ} \mathrm{C}$, mimicking the patients' actual genotype, showed no significant differences in current density or kinetics as compared to WT expression alone (Figure 8). This result indicates that T65P and WT subunits do not form hetero-tetramers; indeed, a decreased current density should have been observed upon ER retention of WT/T65P hetero-tetramers or an increased current density should have been observed upon incorporation in the cell membrane of these hetero-tetramers. Whether the increased current density of cotransfected WT and T65P subunits at $27^{\circ} \mathrm{C}$ is caused by hetero-tetramers or separate WT and T65P homo-tetramers remains to be investigated.

In summary, genetic analysis revealed a novel mutation (T65P), located in the PAS domain of HERG, which causes trafficking deficiency of the protein, and clinically leads to the long QT syndrome. This study suggests that a correctly folded PAS-domain has a major rolle in proper trafficking of the (tetrameric) channel complex. Furthermore, these results indicate that analysis of $\mathrm{KCNH} 2$ mutations in oocytes may at best be insufficient to delineate all possible molecular mechanisms by which the mutation can cause the disease.

\section{Acknowledgments}

We thank Ann Marien and Wim Keysers for their excellent technical support and we thank Jean-Pierre Timmermans for the use of the confocal microscope. This work was supported by Johnson \& Johnson Pharmaceutical Research and Development, Flanders Institute for Biotechnology Grant PRJO5 and National Institutes of Health/National Heart, Lung, and Blood Institute Grant HL59689. 


\section{References}

1. Priori SG, Barhanin J, Hauer RN, Haverkamp W, Jongsma HJ, Kleber AG, McKenna W, Roden DM;

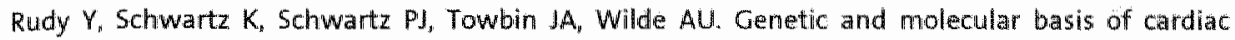
arrhythmias: impact on clinical management parts I and If. Circulation 1999; 99:518-528.

2. Warmke JE, Ganetzky B. A family of potassium channel genes retated to Eag in Drosophilo and mammals, Proc. Nat! Acad. Sci. U.S.A. 1994; 91: 3438-3442.

3. Sanguinetti MC, Jiang C, Curran ME, Keating MT. A mechanistic link between an inherited and an acquired cardiac arrhythmia: HERG encodes the $\mathrm{Kr}$ potassium channel. Cell 1995: 81: 299-307.

4. Trudeau MC, Warmke SW, Ganetzky $B_{4}$ Robertson GA. HERG, a human inward rectifier in the voltage-gated potassium channel family. Science 1995; 269: 92-95.

5. Kupershmidt S. Snyders DJ, Raes A, Roden DM. A K + chaninel splice wariant commion in human heart lacks a $C$. terminal domain required for expression of rapidly activating delayed rectifier current. I Biol Chem 1998; 273: $27231-27235$.

6. London B, Trudeau MC, Newtom KP. Beyer AK, Copeland $N_{n}$ Gillbert DI, Jenkins NA, Satier NA, Robertson GA. Two isoforms of the mouse ether-a-go-go-related gene coassemble to form chamnels with properties simillar to the rapidly activating component of the cardiac delayed rectifier K+ current. Circ Res 1997; 81: 870-878.

7. Lees.Miller JP, Kondo C, Wang L, Duff HJ. Electrophysiological characterization of an alternativelly processed ERG K + channel in mouse and human hearts. Circ Res 1997; 81: 719-726.

8. Abbott CW, Sesti F, Splawski I, Buck ME, Lehmann MH, Timothy KW, Keating MT, Goldstein SAN. MiRP1. forms IKF potassium channels with HERG and is assaciated with cardiac arrhythmia. Cel/ 1999; 97: 175-187.

9. Sanguinetti MC, Curran ME, Spector PS, Keating MT. Spectrum of HERC K+-channel dysfunction in an inherited cardiac arrhythmia Proc Nat/ Acod Sci USA 1996; 93: 2208-2212.

10. Jongbloed RJ, Wilde AA, Geellen IL, Doevendans P, Schaap C, van Langen I, van Fintelen JP, Cobben JU, BeaufortKrol GC, Geraedts JP, Smeets HJ. Novel KCNQ1 and HERG missense mutations in Dutch long-QT families. Hum Mut 1999; 13: 301-310.

11. Splawski 1 , Shen J, Timothy KWW, Lehmann MH, Priari S, Robinson JL, Moss AJ, Schwartz PJ, Towbin JA, Vincent GM, Keating MT. Spectrum of mutations in long-QT syndrome genes. KVLOT1, HERG, SCN5A, KCNE1, and KCINE2. Circulation 2000; 102: 1178-1185.

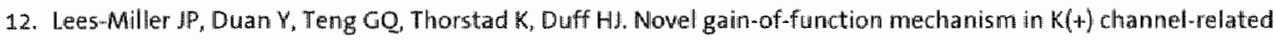
long-QT syndrome: altered gating and selectivity in the HERG1 N629D mutant. Circ Res 2000; 86: 507.513.

13. Nakajima $T_{*}$ Kurabayashi $M_{*}$ Ohyama $Y_{\text {, Kaneko }} Y_{\text {, Furukawa }} T$, Itoh $T$, Taniguchi $Y_{\text {, Tanaka }} T$, Nakamural $Y$. Hiraoka M. Nagai R. Characterization of 5818. mutation in HERG C-terminus in LQT2. Modification of activation deactiwation gating properties. FEBS letter' 2000; 481: 197-203.

14. Huang FD, Chen J, Lin $M$, Keating MT, Sanguinetti MC. Long QT syndrome associated missense mutations in the pore helix of the HERG potassium channel. Circulation 2001; 104: 1071-1075.

15. Chen $J_{1}$ Lou A, Splawski l, Keating MT, Sanguinetti MC. Long QT syndrome-associated mutations in the PerArnt-Sim (PAS) domain of HERG potassium channels accelerate channel deactivation. I Biol Chem 1999: 274: 10113-10118.

16. Nakajima T, Furukawa T, Hirano Y, Tanaka T, Sakurada H, Takahashi T, Nagai R, ltoh T, Katayama Y, Nakamura $Y$. Hiraoka M. Voltage-shift of the current activation in HERC S4 mutation (R5344C) ir LOT2. Cardion Res 1.999; 4.4: $283-293$.

17. Sanguinetti MC, XU QP. Mutations of the $54-55$ linker alter activation properties of HERG potassium channels expressed in Xenopus oocytes. A Physiol 1999; 514.3: 667-675.

18. Zhou Z, Cong Q. Epstein ML. lanwary CT. HERC chamnel dysfunction in human long QT synidrome. Intracellular transport and functional defects. S Biol Chem 1998; 273:21061-21066.

19. Furutani $M$, Trudeau MC, Hagiwara $N$, Seki $A$, Gong $Q$, Zhou $Z$, Imamura $S$, Nagas hima $H$, Kasanuki H, Takao A.

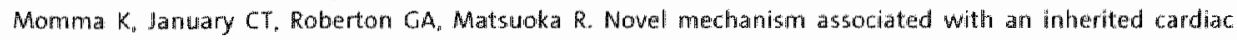
arrhythmia: defective protein trafficking by the mutant HERG (C601S) potassium channel. Circulation 1999; 99:2290-2294.

20. Zhou $Z$, Gong $Q$, january $C T$. Correction of defective protein trafficking of a mutant HERG potassium channel in human long $Q T$ syndrome. Pharmacological and temperature effects. B Biol Chem 1999; 274; 31123-31126. 


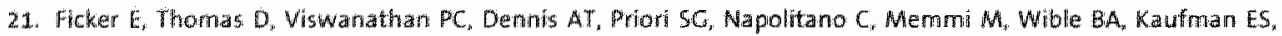
lyengar S, Schwartz PJ, 足udy Y. Browf AM. Nowel characteristics of a misprocessed mutant HERG channel linked to hereditary long QT syndrome. Am I Physiol heant Cire Physiof 2000; 279: H1748-41756.

22. Ficker E, Dennis AT, Obejera-Paz CA, Castaldo P, Taghalatela M, Brown AM. Retention in the endoplasmic reticul um as a mechanism of domimant-negative current suppression in human long QT syndrome. $J$ Mol Cell Cardial 2000; $32: 2327-2337$.

23. Denning GM, Anderson MP, Amara JF, Marshall, Smith AE, Welsh Mi. Processing of mutant cystic fibrosis transmembrane conductance regulator is temperature-sensitiwe. Noture 1992; $258: 761-764$.

24. Kopitio RR. Biosyrither is and degradation of CFR. Physiol Rev 1999, 79: $5167 \times 5173$.

25. Tamarappoo $\mathrm{K}_{*}$ Verkman AS. Defectlve aquaporin-2. trafficking in nephrogenic diabetes insipidus and comection by chemical chaperones. A Clim Invest 1998; 101:2257-2267.

26. Moralis-Cabral JH, Lee $A$, Cohen $S L$, Chait B, Li M, Mackinnon R. Crystal structure and functional analysis of the HERC potassimin channel N terminus: a eukaryotic PAS domain. Cell 1998; 95: 649-655.

27. Neyroud $N$, Richard $P_{i}$ Vignier $N_{\text {, Donger }}$, Demjoy 1, Demay $L$, Shkolnikowa M, Pesce $R$, Chevalier $P$, Hainque: $B$, Coumel $P$, Schwartz $K$, Guicheney $P$. Genomic organization of the $K C N Q 1 K+$ Channel gene and identification of Coterminal mulations in the long-QT 5yndrome. Cinc Res: 1999; 84: 290 - 297.

28. Wang $Q$. L Z, shen J. Keating MT. Genomic organization of the human SCNSA gene encoding the cardiac sodium channel, Genomics $1996 ; 34: 9-16$.

29. Splawski 1, Shen J, TḦmothy KW. Vincent GM, Lehmanin MH, Keating MT. Genomic sitructure of three long OT syndrome genes: KVLQT1, HERG, and KCAE1. Genomics 1998; 51: 86-97.

30. Zhou 2, Gong $Q$, Ye $B_{s}$ fan Z, Makielski JC, Robentson GA, January CT. Properties of wERG chanmels stably expressed in HEK 293 cells studied at physiological temperature. Biophys / 1998; 74: $230-241$.

31. Ottschytsch N, Raes A, Van Hoorick D, Snyders DJ. Obligatory heterotetramerization of three previously uncharacterized Kw channel alpha-subunits identified in the human genome. Proc Nat Acad 5ri 2002; $99: 7986$ 7991.

32. Hamill $O P_{\text {, Marty }} \mathrm{A}_{\text {, Neher }}$, Salkmani $\mathrm{B}_{\text {. Sigworth }} \mathrm{F}$. Improved patch-clamp techniques fior high-resolution current recording from cells and cell-free membrane patches. Pflugers Archiv-Eur J Physiol 1981; 391: 85-100.

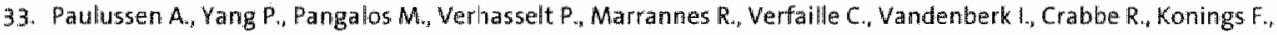
Luyten W. Armstrong M. Analysis of the Human KCNH2 (HERG) Gene: Identification and Characterization of a Novel Mutation Y $667 X$ A.5sociated with Long QT Syndrome and a non-pathological 9 bp Insertion. Hum Mut $2000_{i 1} 15(5): 483$.

34. Ficker E, Obejero-Paz CA, Zhao S, Brown AM. The binding site for chanmel blockers that rescue misprocessed human long QT syndrome type 2 ether-a-gogo-related gene (HERG) mutations. J Biol Chem 2002; 277; 49894998 .

35. Rajamani S, Anderson $\mathrm{CL}$, Anson BD, January $\mathrm{CT}$. Pharmacological rescue of human $\mathrm{K}(+)$ channel long-OT2. hut

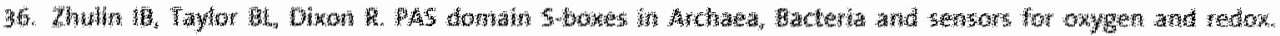

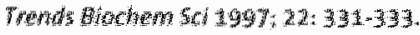

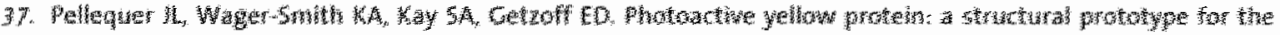

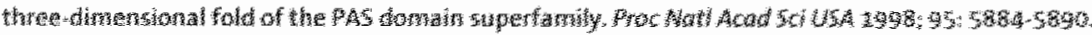

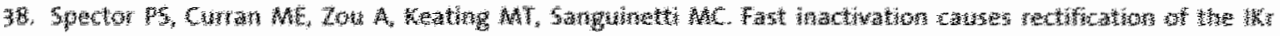

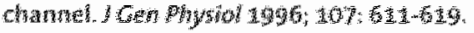

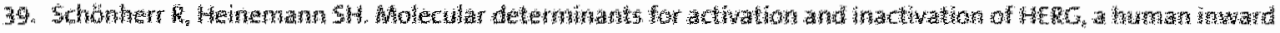

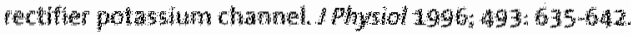

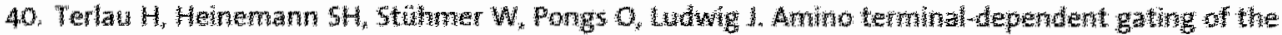

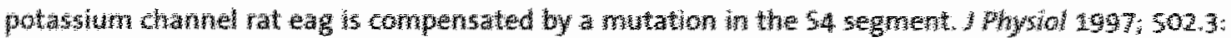
537.549 


\section{CHAPTER}

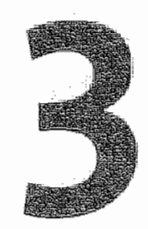

\section{Mutation analysis in congenital long QT syndrome - a case with missense mutations in KCNQ1 and SCN5A}

Aimée Paulussen ${ }^{1,5}$ "Gert Matthijs ${ }^{3}$, Marc Gewillig, Peter Verhasselt ${ }^{2}$, Nadine Cohen ${ }^{4}$, Jeroen Aerssens ${ }^{1}$

${ }^{1}$ Departments of Pharmacogenomics and ${ }^{2}$ Genomic Technologies, Johnson \& Johnson Pharmaceutical Research and Development, Beerse, Belgium; ${ }^{3}$ Center for Human Genetics and ${ }^{4}$ Pediatric Cardiology, University of Leuven, Belgium; "Cardiowascular Research Institute Maastricht (CARIM), University of Maastricht, The Netherlands.

Genetic Testing, 2003; 7 (1):57-61

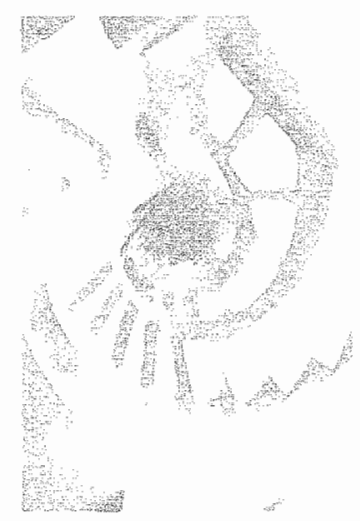




\section{Abstract}

Long QT Syndrome (LOTS) is a cardiac disease characterised by a prolonged QT interval on a surface ECG and by clinical symptoms such as seizures, syncopes and cardiac sudden death. At present, causal mutations of LQTS have been identified in five cardiac ion channel genes. Because a causal mutation is usually unique to a specific family and can be located at any region of one of these five genes, a mutation analysis effort may require screening of the complete coding region of each of these genes. The causative nature of a detected mutation can then be determined either by family history or by functional studies, such as an electrophysiological signature of the mutation. Here we describe a mutation analysis of a LQTS patient who carries two heterozygous missense mutations in two different LQTS genes. The first mutation identified, A572D in 5CN5A, was not linked with clinical LQTS features in the two other mutation carriers in the family, but was not identified in 90 healthy controls either. Therefore, this mutation most likely has either a mild effect on cardiac ion channel function or represents a very rare polymorphism. The second mutation, V254M in KCNO1, co-segregated with higher QT-intervals and symptoms in other family members, and was previously reported in another LQTS family. Because the clinical LQTS symptoms are most pronounced in the proband, a combined effect of both mutations cannot be excluded, allthough no functional data are available to support such hypothesis. We conclude that, for newly presented LQTS cases, a mutation analysis strategy should routinely screen the complete coding region of all LQTS genes, followed by an evaluation of the identified mutation(s) in conjunction with family or functional data.

\section{Introduction}

Congenital long QT syndrome (LOTS) is a potentially lethal cardiac disease, wisible on a surface ECG by a prolongation of the QT interval. Clinically, the disorder is manifested by syncopes and eventually by sudden cardiac death due to polymorphic wentricular tachycardia, also called Torsade de Pointes (1). Depending on the mode of genetic transmittance, the disorder can be divided in two forms: the autosomal dominant Romano-Ward syndrome representing the majority of the cases $(2,3)$, and the autosomal recessive Jervell-Lange-Nielsen syndrome that is characterized by both $\mathrm{QT}$ prolongation and congenital deafness (4). Our understanding of the genetic basis of LQTS has improved significantly over the last decade, with the demonstration of mutations that cause LQTS in five different genes, and the identification of one additional genetic locus on chromosome 4 that is associated with LQTS but for which the responsible gene has not been discovered yet. These known genes encode cardiac ion channel proteins that are involved in the depolarisation (SCN5A) and the repolarisation ( $K C N Q 1, K C N H 2, K C N E 1$, and $K C N E 2$ ) of the cardiac action potential. 
Typically, a new mutation in one of the LQTS genes is identified in each LOTS family. Once a new mutation is identified in a patient, only functional studies can truly confirm its causal relationship with LoTS. It is, however, not feasible for many genetic laboratories to perform such functional studies, including electrophysiological experiments. For molecular diagnostic purpose, therefore, the functional relevance of a new mutation can often only indirectly be assumed.

Mutation analysis of all five LOTS genes is time and labour consuming, because of the large number of exons to be screened. Apart from KCNE1 and KCNE2 that are intronless, KCNH2 harbours 15 different exons, KCNQ1 comprises 19 exons, and SCN5A consists of 28 exons (5-8). Because, in addition, some large exons require screening of multiple DNA fragments, a full mutation analysis of all five LQTS genes involves the screening of 65-75 different DNA fragments (appraximately $21 \mathrm{~kb}$ in total). Obviously, it is very attractive to perform mutation screening of the LOTS genes only up to the point when a new or known mutation is found that is likely to explain the disorder in a patient and his family. In this respect, genetic variations that cause an alteration in the amino acid sequence of the ion channel protein are potentially good candidates to explore further. During evaluation of an identified mutation within a family, the variation in penetrance of LQTS mutations may complicate the link between a new mutation and the disease (9). In such case, functional studies are required to confirm the causal relationship between a mutation and LoTS.

Although typically only one mutation is responsible for the disease in a Romano-Ward form of LOTS $(10,11)$, it has been hypothesized recently that affected subjects may carry multiple heterozygous mutations in different genes, whereby some mutations could have only mild functional consequences (12). In the present study, we report on a complete mutational screening in a Romano-Ward LQTS family, in which we detected two heterozygous missense mutations in two different LQTS genes in the proband.

\section{Materials and Methods}

\section{Subjects}

The Caucasian proband was an 11-year-old boy who was brought to our attention with clinical symptoms indicative for LQTS. The patient experienced syncopes at the age of 6 and 7 . QTc interval was measured to be $483 \mathrm{msec}$ at rest. Since the age of 7 . the boy was treated with $\beta$-blockers and did not experience further syncopes since then. Family members were invited to participate in the study. Three family members from the maternal side and nine members from paternal side participated in the study (Figure 1). Among the paternal side of the family, one relative died of unexplained sudden death and another family member experienced syncopes at childhood (index 
number 2). All family members gave informed consent prior to genetic analysis. An anonymised group of 90 healthy Caucasian volunteers was used to screen for the presence of the novel identified LQTS gene mutation. All volunteers consented prior to genetic analysis.

\section{Mutational screening}

Genomic DNA from the proband was used for mutational screening of all five known congenital LQTS genes by direct sequencing. Oligonucleotides used for PCR amplification of the individual exons, including intron-exon boundaries, have been previously described by Itoh et al., (KCNH2, [7]) Abbott et al., (KCNE2, (6)), Wang et al., (SCN5A, (8)) and Splawski et al, (KCNQ1, KCNH2 and KCNE1, (5)). PCR products were verified on $1.5 \%$ agarose, purified (Qiagen PCR purification kit), directly sequenced using the big dye terminator kit on an ABI-Prism 3700 DNA Analyzer (Applied Biosystems InC, Foster City, CA), and aligned with the respective wild type sequences.

\section{Detection assay for A572D in SCN5A}

A PCR-RFLP detection assay was developed for the $1715 \mathrm{C}>\mathrm{A}$ (A572D) mutation in exon 12 of the SCN5A gene. PCR primers used were 5'-TGG-CCC-CTG-CGC-CGG-AC-3' (primer 1305, forward) and 5'-AGG-AGG-TGG-CTT-CCT-GGG-G-3" (primer 1306, reverse). The $30 \mu \mathrm{l}$ PCR mix contained $1 \times$ GeneAmp PCR buffer $\| 1,200 \mathrm{nM}$ dNTPs, 1.5 $\mathrm{mM} \mathrm{MgCl}, 250 \mathrm{nM}$ of each primer, 0.75 units of AmpliTaq Gold polymerase and approximately $100 \mathrm{ng}$ of genomíc DNA. PCR conditions were $10 \mathrm{~min} 95^{\circ} \mathrm{C}$, followed by 35 cycles of $95^{\circ} \mathrm{C}(45 \mathrm{sec}), 55^{\circ} \mathrm{C}(45 \mathrm{sec})$ and $72^{\circ} \mathrm{C}$ ( $\left.45 \mathrm{sec}\right)$, and a final extension step at $72^{\circ} \mathrm{C}$ for $10 \mathrm{~min}$. The PCR product was digested with $\mathrm{Bmyl}$ for 3 hours at $37^{\circ} \mathrm{C}$ and the resulting DNA fragments were separated on $12.5 \%$ polyacrylamide gels. In the absence of the $1715 C>A$ mutation, the PCR product is cut into two fragments of 140 bp and 24 bp, respectively. In the presence of the mutation, the 164 bp PCR product remains undigested (Figure 2 ).

\section{Detection assay for V254M in KCNQ1}

A PCR-RFLP assay was developed for the detection of the $760 G>A(V 254 M)$ mutation in exon 5 of the KCNO1 gene. PCR primers used were $5^{*}$-AGG-GGC-AGG-GGC-AGGGAC-AC-3' (primer 288, forward) and 5'-CGG-GGC-CTC-AGC-GCA-TCT-CA-3' (primer 289, reverse). The 30 ul PCR mix contained $1 \times$ GeneAmp PCR buffer 1,200 nM dNTP5, 1.5 $\mathrm{mM} \mathrm{MgCl}, 250 \mathrm{nM}$ of each primer, 0.75 units of AmpliTaq Gold polymerase and approximately $100 \mathrm{ng}$ of genomic DNA. After an initial period of $10 \mathrm{~min} 95^{\circ} \mathrm{C}, 35$ cycles were performed consisting each of $95^{\circ} \mathrm{C}(1 \mathrm{~min}), 63^{\circ} \mathrm{C}(1 \mathrm{~min})$ and $72^{\circ} \mathrm{C}(1 \mathrm{~min})$, and finally followed by an extension step at $72^{\circ} \mathrm{C}$ for $10 \mathrm{~min}$. The 300 bP PCR product was digested for 3 hours at $37^{\circ} \mathrm{C}$ with $\mathrm{Ncol}_{*}$ the resulting DNA fragments were separated on $12.5 \%$ polyacrylamide gels. The 760 G>A mutation creates a Ncol restriction site in the DNA sequence of the PCR product; restriction enzyme digestion of the mutated fragment therefore results in two fragments of 120 and $180 \mathrm{bp}$, respectively (Figure 3). 


\section{Results}

\section{Mutation screening of CLQTS genes in the LQTS proband}

Two missense mutations were detected in two different genes by direct sequencing in the DNA of the proband with the baseline QTc of $483 \mathrm{~ms}$. One mutation, A572D, was detected in exon 12 of the SCN5A gene: a base substitution of $C$ to $A$ at position 1715 . altering codon 572 from alanine to aspartic acid. Sulasequently, a second mutation, V254M, was identified in exon 5 of the KCNQ1 gene: a base substitution of $G$ to $A$ at position 760 , altering codon 254 from valine to glutamic acid. The proband was heterozygous for both mutations.

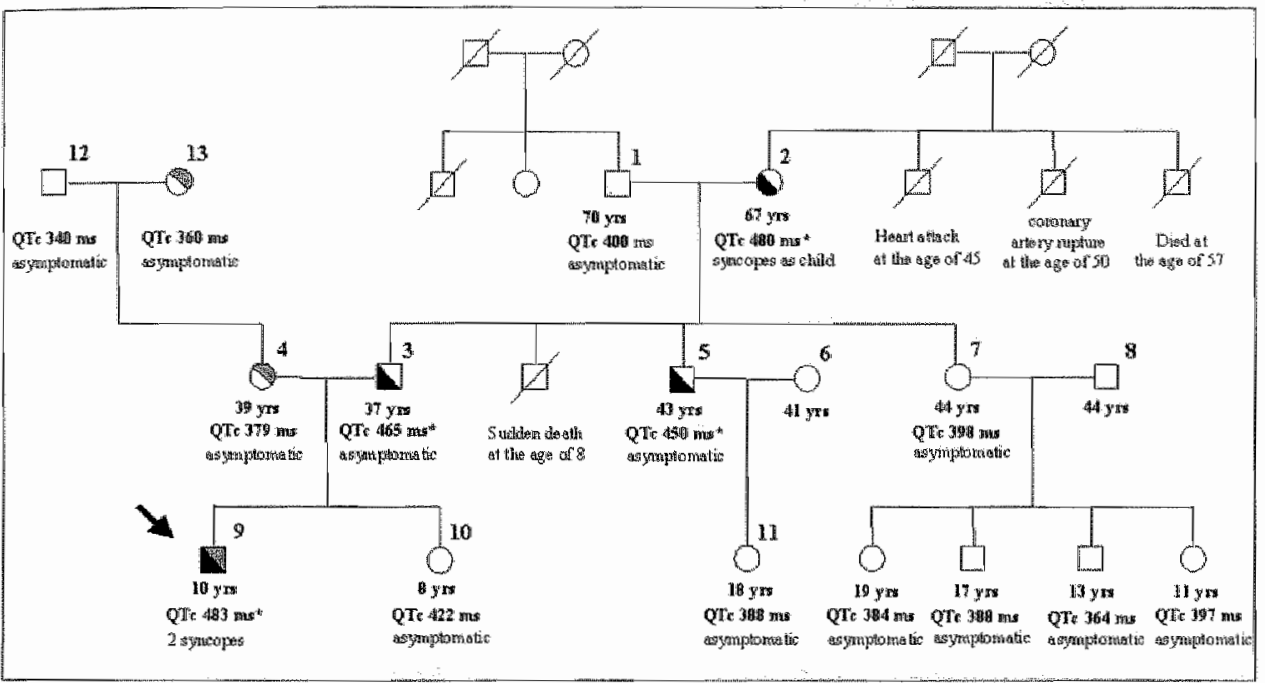

Figure 1. Family tree of the LQrs proband. The clinical phenotype, QRc interval and mutation carrier status for SCN5A A572D and KCNQ1 V254M are indicated for individual family members. Arrow, indicates the proband; $y$ rs, years of age; squares, males: circles, females; upper half areo in grey, heterozygous carriers of the A572D mutation in $5 C N 5 A_{;}$lower half area in black, heterozygous carriers of the V254M mutation in KCNQ1. An asterisk indicates a high or borderline QTe interval according to the diagnostic criteria for LOTS by Schwartz et al. (13).

\section{A572D mutation in the SCN5A gene}

The PCR-RFLP designed to detect the A572D mutation in the SCN5A gene (Figure 2) was used to screen the proband's parents and subsequently all available family members (Figure 1). In addition to the proband, two family members from maternal side (index numbers 4 and 13) were also heterozygous carriers of the A572D mutation. Both carriers, however, had normal OTe values and did not have a history of clinical symptoms related to LQTS. The mutation was not detected in 90 healthy volunteers, and can therefore be excluded as a common polymorphism. 


\title{
(A)
}

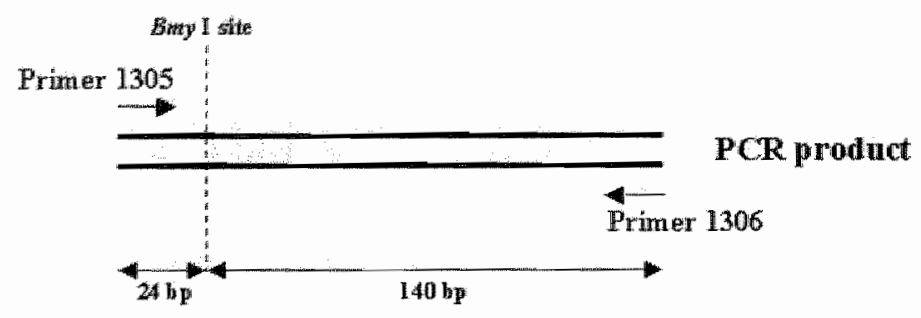

(B)

$\begin{array}{llllll}1 & 2 & 3 & 4 & 5 & 6\end{array}$

$300 \mathrm{bp}-$

\author{
$200 \mathrm{bp}$
}

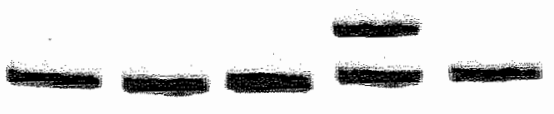

$100 \mathrm{bp}$

Figure 2. PCR-RFLP for mutation A572D in SCN5A. (A) Design of the PCR-RFLP assay for the rapid detection of the AS72D mutation in SCN5A. (B) Example of $12.5 \%$ polyarrylamide gel with different individual genotypes. Lane 1: 100 bp ladder; lane 2, 3,4 and 6: subjects with homozygous wild type (A/A) genotype; lane 5; subject with the heterozygous mutant (A/D) genotype.

\section{V254M mutation in the KCNQ1 gene}

The PCR-RFLP designed to detect the V254M mutation in the KCNQ1 gene (Figure 3) was used to screen the proband's parents, and subsequently all available members from the paternal side of the family (Figure 1). In addition to the proband, three other family members (index numbers 2, 3 and 5) were heterozygous carriers of the V254M mutation. The QTe interval of these three individuals was higher than normal, but only one of them had suffered from syncopes at young age. The two other mutation carriers were clinically asymptomatic. It can be assumed that at least one other family 
member who died by sudden death at the age of 8 years, also carried the mutation. but no DNA was available to confirm this hypothesis.

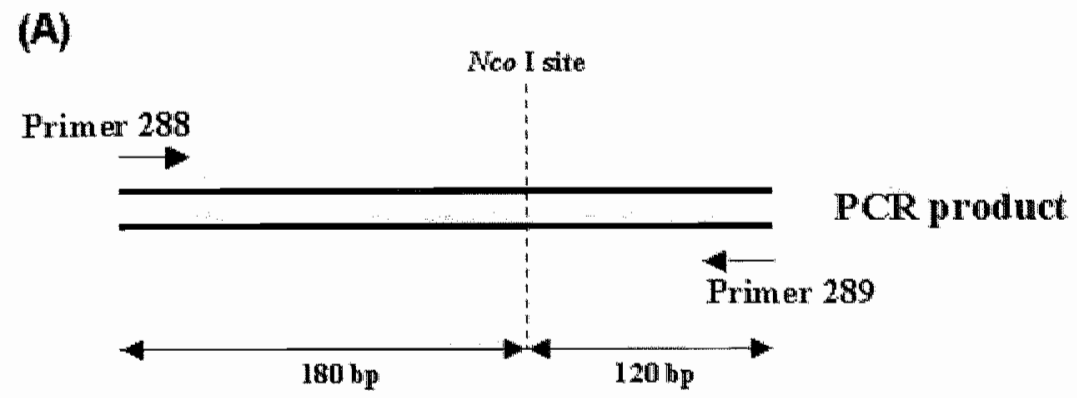

(B)

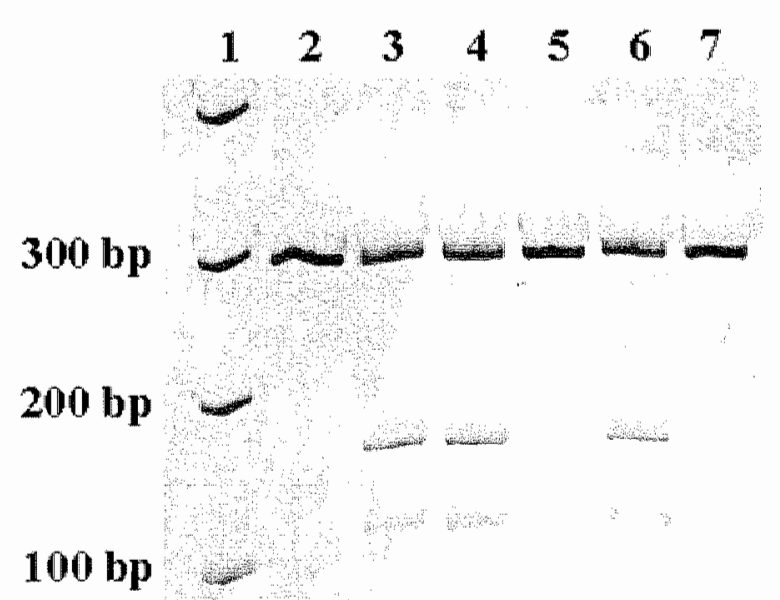

Figure 3. PCR-RFLP for mutation V254M in KCNQ1. (A) Design of the PCR-RFLP assay for the rapid detection of the V254M mutation in KCNQ1. (B) Example of $12.5 \%$ polyacrylamide gel with different individual genotypes. Lane 1: 100 bp ladder; lane 2,5 and 7: subjects with homozygous wild type (V/V) genotype; lane 3, 4 and 6: subject with the heterozygous mutant (V/M) genotype. 


\section{Discussion}

Congenital long QT syndrome is caused by an abnormal prolongation of the cardia action potential duration, leading to susceptibility of developing ventricula arrhythmia. Prolongation of the action potential duration can be caused $b$ dysfunction of ion channels. Today, five genes that all encode cardiac ion channel have been associated with LOTS by the identification of causal mutations. The presen study demonstrates that mutational screening in a newly presented case o congenital LOTS should be done thoroughly, including the exons of all known LOT: genes, and complemented with the evaluation of the pattern of inheritance in the family and/or functional studies for any newly identified mutation.

During the analysis of the reported LOTS family, we firstly detected the heterozygous A572D mutation in the SCN5A gene of the proband. This mutation is located in the cytoplasmic connector between the first and second domain of the sodium channel, where no mutation has been reported yet. The mutation was not found in 180 alleles from unrelated healthy controls, suggesting that A572D is indeed a causal mutation for LOTS or, alternatively, a very rare coding polymorphism. Apart from the proband, two other family members (mother and grandmother) carried the mutation, but were asymptomatic and had normal QTC intervals. Thus, surprisingly, the SCN5A mutation was inherited from the maternal family side that had no history of LQTS, whilst the mutation was not found at the paternal side that had a LOTS family history. Therefore, the other LOTS genes were screened in a search for additional mutations that might explain the family history at the paternal side. As a result, mutation V254M was detected in the KCNQ1 gene. This mutation was reported earlier in a large LOTS family by Wang et al. (14) and was later also functionally characterized in an oocyte expression system (15).

This is to our knowledge the first report that describes two heterozygous missense mutations in two different LQTS genes in a single LQTS patient. It clearly exemplifies that the identification of a new, rare missense mutation in a LOTS gene of a patient alone is not sufficient evidence to claim a causal relationship with the disease. The avalability of substantial clinical data on family members, and the discordance of these data with the inheritance pattern of the initially discovered mutation in the SCN5A gene, led to the correct hypothesis that another mutation - eventually in another LQTS gene - should be present.

Interestingly, the clinical symptoms and $Q T$ prolongation appeared to be more profound in the proband than in the other tested carriers of the KCNO1 mutation within the family. Such a low penetrance of phenotypic symptoms is a common feature in many LOTS families (9). Alternatively, one could speculate that the 
additional SCN5A missense mutation might partially contribute to the LQTS phenotype, but no functional data are available to support such hypothesis. Mutations in KCNQ1 have been shown to delay the repolarisation phase of the action potential, whilst mutations in SCN5A may sustain inward sodium current during cardiac depolarisation $(15,16)$. In combination, both mutations could lead to the significant prolongation of the QTC interval in the proband, and consequently increase the risk for ventricular arrhythmia. Heterozygous carriers of one of the mutations, on the other hand, could remain asymptomatic with a normal or borderline QTc interval. This can, however, not explain the sudden death of a family member at the age of 8 years who presumably carried only the V254M KCNQ1 mutation. We therefore hypothesize that the additional missense mutation in the SCN5A gene might possibly facilitate but is not required for the development of the clinical symptoms of LQTS in patients with a V254M mutation in KCNQ1.

In conclusion, this is to our knowledge the first study demonstrating that symptomatic Romano-Ward LQTS patients can carry multiple heterozygous missense mutations in different LQTS genes. It further demonstrates that complementary data (e.g., family or functional studies) are required to confirm the causal nature of a newly identified mutation in a LOTS gene. Our results are supportive for a mutation analysis strategy that routinely screens the coding sequence of all LOTS genes in any newly presented case of congenital LQTS in a molecular diagnostic laboratory.

\section{Acknowledgments}

This work was supported by Johnson \& Johnson Pharmaceutical Research and Development, and the Belgian Foundation for Research in Pediatric Cardiology.

\section{References}

1. Roden DM, Lazzara $R$, Rosen $M$, Schwartz PJ, Towbin JA, Vincent GM. Multiple mechariisms in the long QT syndrome. Current knowledge, gaps, and future directions. The SADS Foundation Task Force on LOTS. Circulation 1996:94:1996-2012.

2. Romano $C$, Gemme G, Pongiglione $R$. Aritmie cardiache rare dellieta pediatrica. La Climica Pediatrica $1963 ; 45: 656-683$.

3. Ward DC. A new familial cardiac syndrome in children. JMrish Med Ass 1964: 54: 103-106.

4. Jervell $A$., Lange-Nielsen $F$. Congenital deaf-inutism, functional heart disease with prolongation of the $Q-T$ interval and sudden death. Am Heart $J 1957 ; 54: 59-68$.

5. Splawski I, Shen J, Timothy KW, Vincent GM, Lehmann MH, Keating MT. Genomic structure of three long QT syndrome genes:KVLQT1. HIERG and KCNE1. Genomics 1998; 51;86-97.

6. Abbott GW, Sesti F. Splawski I, Buck ME, Lehmann MH. Timothy KW, Keating MT, Goldstein SAN. MRP1 forms $I_{k r}$ potassium channels with HERG and is associated with cardiac arrhythmia. Call 1999; 97:175\% 187 .

7. Loh T. Tanaka T. Nagai R, Kamiya T. Sawayama T, Nakayama T, Tomoithe H. Sakurada H, Yazaki Y. Nakamura $Y$. Genomic organization and mutational analysis of $H E R G_{\text {a }}$ a gene responsible for familial long QT syndrome. Hum Gener 1998; 102:435-439.

6. Wang $\mathrm{Q}$, Li Z Shen J, Keating MT. Cenomic organization of the human SCN5A gene encoding the cardiac sodium channel. Genomics $1996 ; 34: 9-16$ 
9. Profi so, Wapolitamo C. Schwant P. Low penetrance in the lang OT syndrome: dinical impact. Circulation 1989: $99: 529-533$

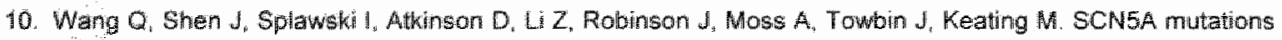
associated with an inherted cardiac arhythma; fong QT syndrome. Cell 1995; 60:1-20.

11. Splawski I, shen J, Timothy KW, Lehmann MH. Priori S, Robinson UL, Moss AJ. Schwartz PJ. Towbin JA, Vincent GM, Keating MT. Spectrum of mutations in long OT syndrome genes. KVLOT, HERG. SCN5A, KCME1 and KCNE2. Circulation 2000:102:1178-1185.

12. Lupoglazoff JM, Cheav T, Baroudi $G$, Berthet M, Denjoy I, Cauchemez $B$. Extramiana $F$. Chahine $M$, Guicheney P. Homozygous SCNSA mutation in Long QT syndrome with functional two-to-one atrioventricular block. Circ Ret 2001; 89:e16-e21.

13. Schwartz PS, Moss Au, Vinceni GM, Crampton RS. Diagnostic criteria for the Long OT syndrame. An update. Circulation $1993 ; 88: 782-784$.

14. Wang Q, Curran ME, Splawski I, Bum TC, Millholland JM, VanRaay TJ, Shen a, Timothy KW, Vincent GM, de Jager $T$, Schwartz P.J. Towibin JA, Moss AJ, Atkinson DL. Landes GM, Connors TD, Keating MT. Posittional cloning of a novel potassium channel gerne: KVLQT mutations cause cardiac anrhythmias. Nat gorert 1996; $12: 17-23$

15. Wang $Z$, Tristani-Firouz M, Xu Q. Lin M, Keating MT, Sanguinetti MC. Functional effects of mutations in KVLQT that cause Long QT syndrome. I Cardiovasc Electrophysiol 1999: 10:817-826

16. Ackerman MJ, Siu BL. Sturner WQ, Tester D., Valdwia CR, Makielski JC, Towbin JA. Postmortem molecular analysis of SCNSA defects in suddern infant death syndrome. JAMA 2001; 28: 2264-2269. 


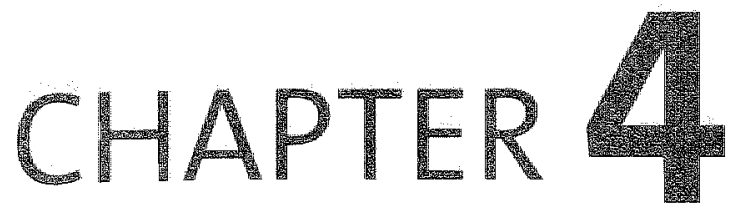

\section{Characterization of novel mutations E698X and P872fs877 in the C-terminus of the human potassium channel (HERG) that cause the long QT syndrome}

Aimée Paulussen, Nadine Cohen, Jeroen Aerssens, Roselie Jongbloed, Hubert Smeets, Adam Raes, Dirk J. Snyders, Arthur Wilde.

Department of Pharmacogenomics, Johnson \& Johnson Pharmaceutical Research \& Develiopment, Beerse, Belgium, and Raritan, New Jersey, USA, Cardiowascular Research Institute Mastricht (CARIM), Department of Cenetics \& Cell Biology, University of Maastricht, The Netherlands, Laboratory for Molecular Biophysics, Physiology and Pharmacology. Department of Biomedical Sciences, University of Antwerp (UIA) and Flanders Institute for Biotechnology (VIB), Belghum, Experimental and Molecular Cardiollogy Group, Academic Medical Centre, Amsterdam, The Netherlands.

Manuscript in preparation

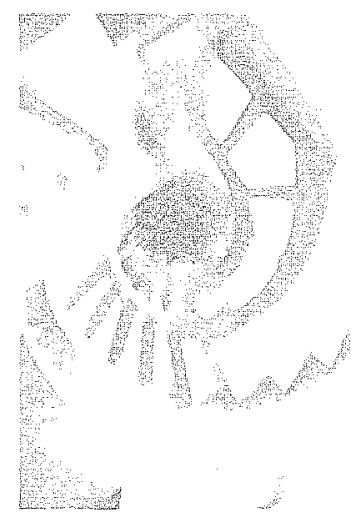




\section{Background}

Mutations in the KCNH2 (HERG) gene are responsible for the chromosome 7 -linked long $\mathrm{OT}$ syndrome. Mutations are associated with a reduction in the fast component of the delayed rectifier current $I_{k}$, thereby delaying repolarisation of cardiac cells and rendering patients vulnerable to ventricular arrhythmias and sudden death.

\section{Methods and Results}

We describe the identification and characterisation of two mutations (P872fs877 and E698X) in the C-terminus of the KCNH2 gene in two large Dutch LQTS families. Both mutations lead to premature stop codons causing C-terminal truncations of the HERG protein. Biochemical and confocal microscopy techniques were used to investigate protein expression and trafficking. Electrophysiological methods were performed to assay potassium ion channel function. Only the $P 872 \mathrm{fs} 877$ truncated protein was expressed and functional. The $P 872 \mathrm{f} 5877$ protein showed aberrant trafficking due to accumulation of the protein in the ER. Homologous expression of P872fs 877 channels produced similar currents as wild type channels although with reduced amplitudes. Heterologous co-expression of wild type and P872fs 877 subunits changes the typical inward rectification behaviour of HERG likely because of the formation of heterotetramers.

\section{Conclusions}

C-terminal HERG mutations result in LOTS and the mechanisms leading to aberrant channel function in this region of the protein are a combination of aberrant trafficking and altered gating properties. 


\section{Introduction}

The long QT syndrome (LQTS) is an inherited cardiac disease, which usually becomes apparent through symptoms like syncopes, loss of consciousness and sudden death (1). The clinical manifestation of the disease shows itself by prolongation of the QT interval on the surface ECG, which is indicative for aberrant lengthening of the cardiac action potential (2). Mutations in the genes KCNQ1 (KVLOT1, LOT1), KCNH2 (HERG, LOT2), SCN5A (LOT3), KCNE1 (MINK, LOT5) and KCNE2 (MIRP1, LQT6) have been identified to cause the disease $(3-7)$. The human ether-a-go-go related gene $\mathrm{KCNH2}$ (HERG) encodes the $\alpha$-subunit of the rapidly activating, delayed rectifier potassium ion channel $I_{k,}$ an important component of the action potential duration $(8,9)$. Functional studies performed by various groups have indicated that mutations in $K C N H 2$ may result in reduced outward potassium current due to multiple mechanisms. The reduced outward current can be the result of non-functionality (10), altered gating properties (11), or abnormal protein trafficking (12) of mutated channeis.

Based on the protein structure, HERG belongs to the eag voltage gated potassium channel family (13). Important functional regions in this family of proteins include six membrane-spanning domains $\left(S_{1}\right.$ to $\left.S_{6}\right)$, flanked by intracellular animo (N)- and carboxyl (C)-terminal regions and an ion-conducting pore between transmembrane domains $S_{5}$ and $S_{6}$. Because the six membrane domains and the pore constitute important parts of the channel subunits form and function, initial genetic screening focussed on these important regions of HERG. Over time however, also mutations in the $\mathrm{N}$ - and $\mathrm{C}$-terminal regions have been identified in LQTS families. Currently, more than twenty mutations have been detected in the $\mathrm{N}$-terminus of HERG. Functional characterization of nine $\mathrm{N}$-terminal mutations has demonstrated that accelerated deactivation is a common factor in these mutated channels (14). Recently, trafficking deficiency has also been implicated in this $\mathrm{N}$-terminal region (15), indicating that assignment of specific functional defects to protein regions is not always obvious. At least twenty different mutations have been identified in the C-terminal region of HERG, but functional data on the effects of these mutations are rather limited. Two mutations ( $R 752 \mathrm{~W}$ and $\mathrm{V}_{822 \mathrm{M}}$ ) in the C-terminus resulted in defective trafficking of the mutated proteins to the cell membrane $(16,17)$ and mutation S818L caused complete non-functionality, albeit with some dominant negative effect on wild-type channel function (10).

In order to elucidate additional mechanisms that may be involved in the incorrect functioning of HERG proteins with C-terminal mutations, we studied the functional consequences of two newly identified C-terminal $\mathrm{KCNH} 2$ mutations. The mutations E698X and P872fs877 were identified in two distinct Dutch LOTS families, and resulted both in truncated HERG proteins. We studied protein expression and trafficking with 
biochemical methods and we used a whole cell patch clamp system to characterise channel function.

\section{Methods}

\section{LQTS families}

Families \#1718 and \#2714 are two large Dutch families with diagnosed long QT syndrome (Figures 1 and 2). Based on the clinical symptoms of the proband, other family members were initially evaluated by 12 lead ECG registration. Informed consent for participation in this study was obtained from 31 family members (13 females and 18 males) of family \#1718 and from 21 members (14 females and 7 males) of family $\$ 2714$. Both families originated from a Caucasian population.

\section{Genetic analysis}

Genomic DNA was extracted from peripheral blood samples as described previously. All exons, encoding the entire region of the $K C N H 2$ gene, were amplified by PCR and mutation screening was performed using SSCP or DHPLC as previously described $(18,19)$. Aberrant SSCP conformers and/or abnormal DHPLC elution profiles were subsequently analysed by automatic sequencing on an ABI377 (Applied Biosystems). After identification of the causative mutation in the proband, other mutation carriers in the LQTS families were identified by direct sequencing (P872f5877) or a PCR-RFLP test developed specifically for the mutation (E698X).

\section{Site-Directed Mutagenesis and $\mathrm{KCNH} 2$ constructs}

The wild type cDNA HERG/pCDNA3 expression construct was kindly donated by Dr. Craig January and Dr. Zhengfeng Zhou (University of Wisconsin-Madison). The HERG E698X and P872f5877 mutations were generated by site-directed mutagenesis of the wild type HERG/pCDNA3 construct using the GeneEditor ${ }^{\text {rM }}$ in vitro Site-Directed Mutagenesis System (Promega) according to the manufacturers instructions. Primers 5'-AGT-ACT-CCT-AGA-GGC-GCT-G-3' (E698X) and 5'-CGT-ACT-GCC-GG-GGA-GCC-C-3' (P872f5877) were used as the synthetic oligonucleotides to create the mutant constructs (mutations in bold and underlined). The introduction of mutation $2092 \mathrm{G}>\mathrm{T}$ (E698X) and the deletion of basepair 2616 (P872fs877) in the wild type HERG CDNA were verified by direct sequencing. Wild type (WT-GFP), E698X (E698X-GFP) and P872fs877 (P872fs877-GFP) HERG cDNAs were also subcloned downstream of the coding region of a green fluorescent protein (GFP) in expression vector PCDNA3.1_NT GFP (Invitrogen) using restriction sites KpN I and Eco RI. The ATG start codon of the HERG CDNA was 24 bp downstream of the final GFP codon. In addition, willd type (WT-HisB), E698X (E698X-HisB) and P872fs877 (P872fs877-HisB) HERG CDNAs were allso subcloned downstream of a polyhistidine region (His) in expression vector PCDNA3_HisB (Invitrogen) using restriction sites Bam HI and Eco RI. The ATG start codon of the HERG CDNA was 84 bp downstream of the last of six histidine 
codons. The complete sequence, coding for the in-frame fusion GFP-HERG or HisBHERG proteins, including restriction sites, was directly sequenced.

\section{Western blot analysis}

Both mutations E698X and P872f 5877 result in truncated HERG proteins lacking the last C-terminal 282 or 461 amino acids respectively (Figure 3A). Protein expression and/or stability were investigated using Western blot analysis. Human embryonic kidney 293 cells (HEK293) were cultured and transfected as described earlier (20). Equal amounts of WT-HisB, E698X-HisB or P872fs.877-HisB constructs were transiently transfected with FUGENE transfection reagent and subsequent isolation of crude membrane fractions and membrane protein preparation were performed as previously described $(15,20)$. For Western blot analysis, the membranes were incubated overnight at $4^{\circ} \mathrm{C}$ with $6 \times \mathrm{HH}$ is monoclonal antibody (Clontech) at a dilution of 1:5000. Subsequently, membranes were incubated with HRP-conjugated anti-mouse antibody (Amersham Biosciences) for one hour at a dilution of 1:5000. HRP-bound protein was detected with an $\mathrm{ECL}+\mathrm{Pl}$ lus detection kit (Amersham Biosciences)

\section{Confocal imaging}

HEK293 cells were cultivated on cover slips as described (20). HEK293 cells were transiently transfected with WT-GFP, E698X-GFP or P872fs877-GFP constructs. A red fluorescent endoplasmic reticulum (DsRed-ER) marker was cotransfected to distinguish ER retained from membrane bound proteins as described previously $(15,21)$. Because all family members are heterozygous carriers of the P872fs877 mutation, coexpression studies were performed to investigate potential dominant negative effects on protein trafficking. For this purpose, equal amounts of WT and P873fs877 constructs were transiently transfected, with either one of the constructs tagged with GFP. Confocal images were obtained 48 hours after transfection on a Zeiss CLSM 510, equipped with an argon laser for the visualisation of CFP and DsRed tagged proteins.

\section{Voltage clamp and data analysis}

HEK293 cells were cultured at $37^{\circ} \mathrm{C}$ and transiently transfected with wild type, P872f5877 or E698X constructs (in pcDNA3). A GFP tagged expression vector was cotransfected to discriminate between transfected and untransfected cells. Potassium current recordings were made with an Axopatch-200B amplifier (Axon instruments, Union City, CA) in the whole cell configuration using suction pipettes as described previously (22). Glass patch pipettes were pulled with a P2000 laser puller (Sutter Instruments) from $1.2 \mathrm{~mm}$ Starbore borosilicate glass (Radnoti) and had resistances between 1.5 and 3.5 M . All current recordings were performed at room temperature $\left(20-22^{\circ} \mathrm{C}\right.$ ) with an axopatch $200 \mathrm{~B}$ amplifier (Axon Instruments) and were low pass filtered and sampled at 1 to $10 \mathrm{kHz}$ with a Digidata $1200 \mathrm{~A}$ data acquisition system (Axon instruments). Command voltages and data storage were controlled with 
PCLAMP8 software (Axon instruments). Cells were perfused with HEPES-buffered Tyrode's solution containing $145 \mathrm{mM} \mathrm{NaCl}, 4 \mathrm{mM} \mathrm{KCl}, 1 \mathrm{mM} \mathrm{MgCl}, 1.8 \mathrm{mM} \mathrm{CaCl} 2,10$ $\mathrm{mM}$ glucose and $10 \mathrm{mM}$ HEPES ( $\mathrm{pH} 7.35$ with $\mathrm{NaOH}$ ). The internal pipette solution contained $110 \mathrm{mM} \mathrm{KCl}, 2 \mathrm{mM} \mathrm{MgCl}, 5 \mathrm{mM} \mathrm{K}{ }_{2}$ ATP, $5 \mathrm{mM} \mathrm{K}{ }_{4}$ BAPTA and $10 \mathrm{mM}$ HEPES $(\mathrm{pH} 7.2$ with $\mathrm{KOH})$. The access resistance varied between 2.5 and $8 \mathrm{M} \Omega$. Series resistance was compensated to ensure that voltage errors were <5 mV. No leak subtraction was applied and the holding potential was $-80 \mathrm{mV}$. HEK293 cells displayed a small-amplitude of endogenous current during depolarising steps that was not present during the recordings of the taill current (20). The voltage dependence of channel activation was determined by fitting maximal tail currents to a Boltzmann equation according to $y=1 /\left\{1+\exp \left[-\left(\mathrm{E}-\mathrm{V}_{1 / 2}\right) / \mathrm{k}\right]\right)$, where $V_{\mathrm{w} / \mathrm{t}}$ represents the voltage at which $50 \%$ of the channels are open and $k$ the slope factor. Deactivation kinetics were fitted with a double exponential function using a non-linear least-squares (GaussNewton) algorithm. The inward rectification behaviour was quantified by normalizing the steady-state current amplitude at different voltages to the peak tail current a mplitude at $-40 \mathrm{mV}$. Data are presented as mean \pm SEM and the Student's $t$-test was used for statistical analysis.

\section{Results}

\section{Clinical characteristics}

A pedigree of family \#1718 is presented in Figure 1. Clinical investigation identified seven family members with clinical features of LQTS and/or an aberrant ECG. These family members included 5 females (subjects $113,114,1113,1114$ and 11115 ) and 2 males (III2 and 11112 ). Of all events (syncopes, cardiac collapse) that occurred in these individuals, 4 were triggered by arousal, 3 by emotion or stress, 2 at rest or during sleep and 1 by exercise. An implantable cardioverter defibrillator (ICD) was implanted in subject 11115 at age 18 as a result of persistent symptoms under beta-blocker therapy. A pedigree of family $\$ 2714$ is presented in Figure 2 . Of the 22 patients included in the study, 10 individuals presented with variable phenotypes. Aberrant ECGs (dubious T-top, disappeared U-wave, prolonged QT interval) were observed in subjects $111,112,115,117,118,1111,1112,1113,1115$ and 1116 . Subject 117 (proband) experienced syncopes immediately after giving birth to her first child. Initially, torsades de pointes were registered in the ambulance, which later deteriorated into cardiac arrest. The patient was successfully resuscitated and an ICD was implanted. Subject 112 experienced several syncopes during menstruations or without any recognisable trigger. 


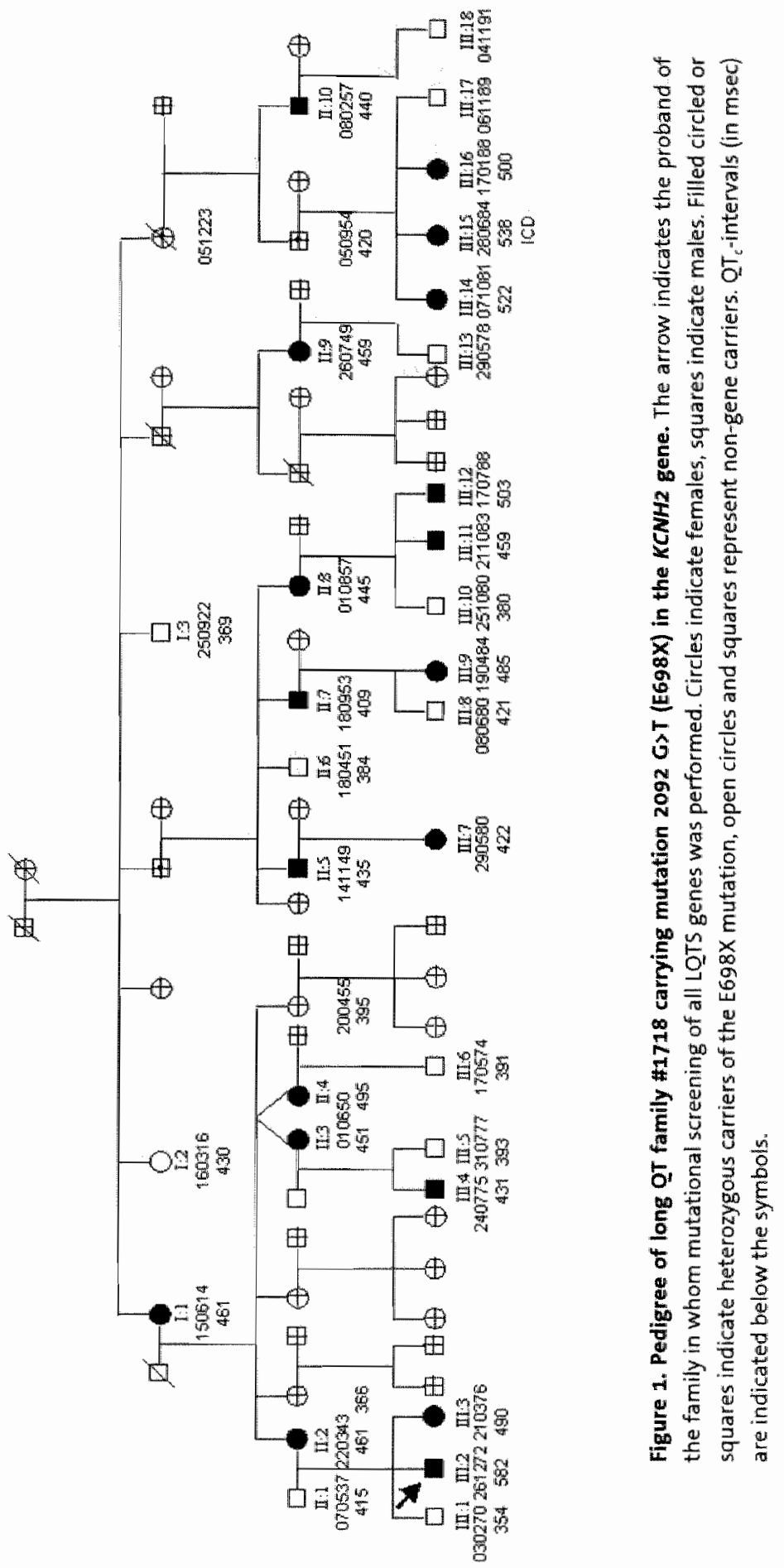



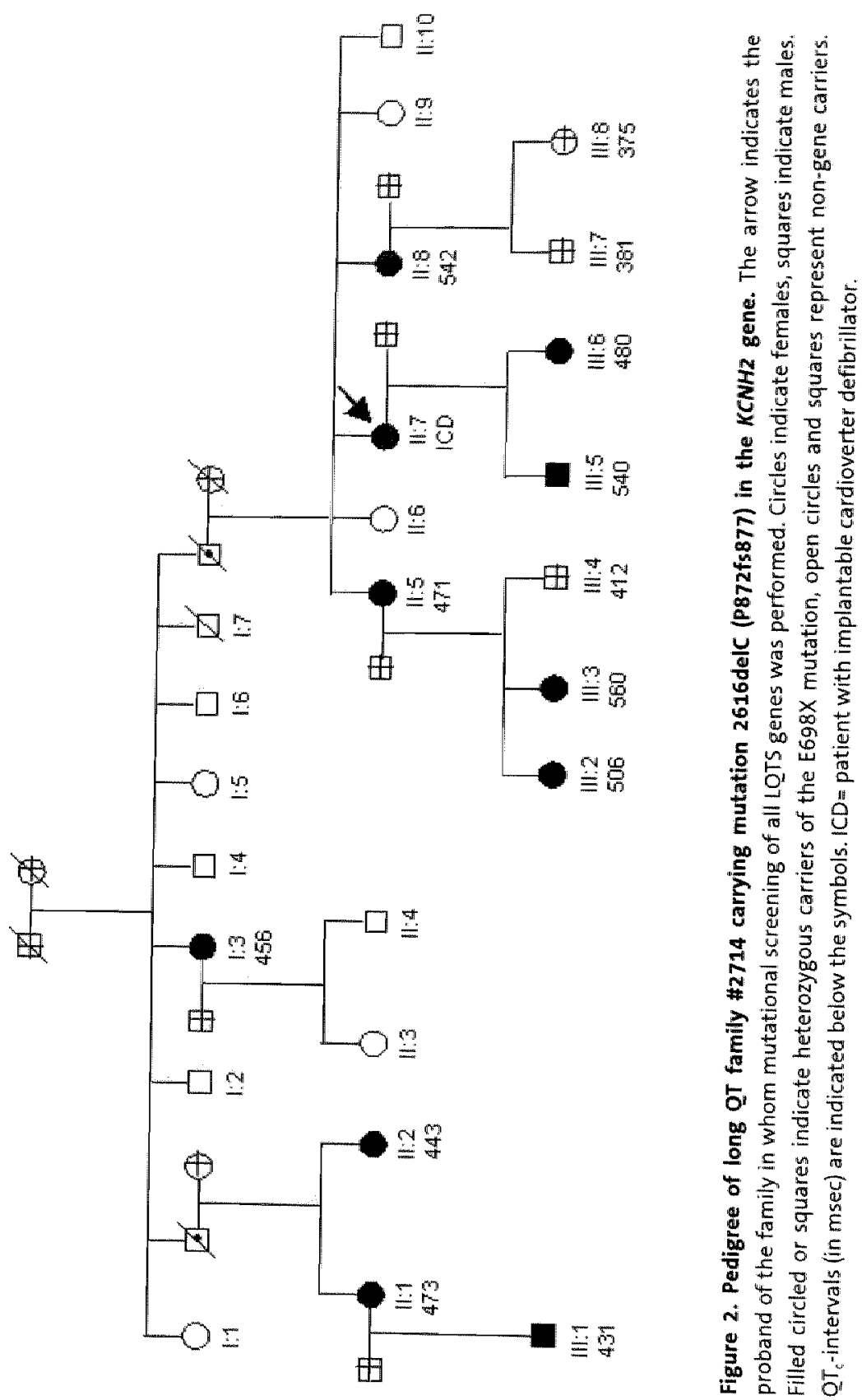


\section{Genetic analysis}

Genetic screening resulted in the identification of a nonsense mutation in exon 8 of the $K C N H 2$ gene in the proband of family \#1718 (Figure 1, subject III2). The mutation 2092 G $>$ T changes codon 698 from glutamic acid into a stop codon (E698X). This stop codon truncates the HERG protein with 461 amino acids and ends the protein between 56 and the cyclic nucleotide-binding domain (CNBD). Of 31 individuals, participating in the study, 19 members were heterozygous carriers of the E698X mutation (Figure 1). A deletion of one nucleotide (2616delC) in codon P872 was detected in exon 9 in the proband of family \#2714 (subject II7). This single base pair deletion introduces a frame shift, which leads to a premature stop codon at amino acid position 877 (P872fs877). The mutation is located downstream of the CNBD and causes a truncation of the HERG protein by 282 amino acids. Of 21 members screened, 11 individuals were heterozygous carriers of this mutation (Figure 2).

\section{Western blot analysis}

6xHis monoclonal antibody was used to study expression of the truncated proteins (Figure 3). Computational calculations (VNTi) estimate the molecular sizes of WT, E698X and P872fs877 HERG proteins at 131,81 and $101 \mathrm{kDa}$, including the His-tag. Figure $3 \mathrm{~B}$ shows all expected protein sizes, although expression levels were lower for the mutant proteins. Particularly expression of the E698X protein was very low. Only for the WT HERG protein both the core-glycosylated (135 kDa) and the fullyglycosylated ( $155 \mathrm{kDa}$ ) form were detected (20); for the mutant proteins only the coreglycosylated form was visible.

\section{Confocal imaging}

To study subcellular transport of mutant channels, HEK293 cell were transiently transfected with GFP tagged WT, P872fs877 or E698X HERG constructs. Confocal images show the presence of WT protein in the ER and plasma membrane (green, Figure $4 A$ ), whilst the red fluorescence is purely situated in the ER (Figure $4 B$ ). The P872f5877 protein was present within the plasma membrane (Figure $4 C, D$ ), although the protein was also partly accumulated in clusters and retained in the ER (green dots). Upon co-expression of equal amounts of WT and P872f5877 constructs (Figure 4 E,F,G and $H$ ) partial retainment of heterotetramers was still observed, indicating a dominant negative effect of mutant subunits on WT channels. In line with highly decreased expression levels of the E698X protein with Western blotting, no E698X protein was detected in the plasma membrane (Figure I, J). 


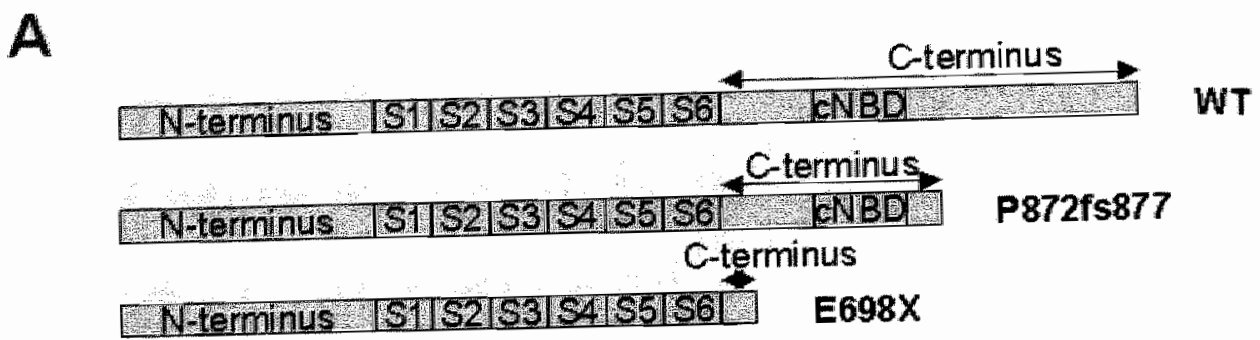

B

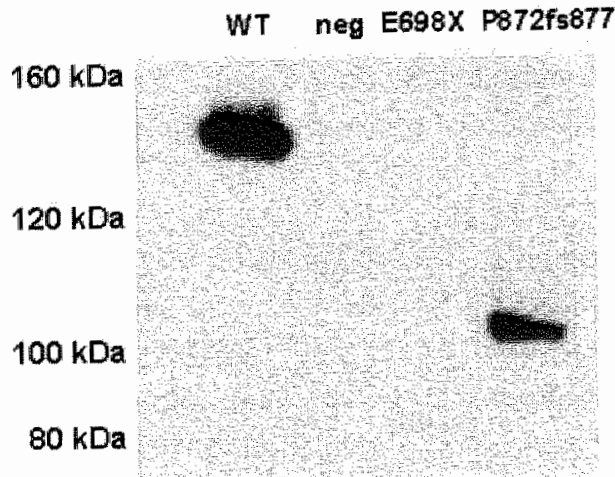

Figure 3. Western blot analysis of WT, P872fs:77 and E698X HERG proteins. A, graphic representation of HERG proteins and C-terminal truncations caused by mutations 2616delC ( $P 872 f 5877$ ) and $2092 \mathrm{G}>\mathrm{T}$ (E698X). Br, Western blat analysis of HisB-tagged HERG proteins. Crude membrane fractions were isolated $24 \mathrm{hr}$ rs after transfection and $35 \mu \mathrm{g}$ of total protein was loaded in each lane. Note the reduced length and reduced expression of both the truncated proteins. Especially, the E698X HERG protein expresston was very low.

Current recordings of homomultimeric and heteromultimeric WT and mutant channels Figures $5 \mathrm{~A}$ to $\mathrm{D}$ show representative current recordings of HERG WT, P872fs877 and E698X channels. The voltage clamp protocol is presented in Figure 5A. HERC currents were activated by $5 \mathrm{sec}$ depolarising steps between -60 and $+60 \mathrm{mV}$ (in $10 \mathrm{mV}$ increments) from a holding potential of $-80 \mathrm{mV}$. Cells were clamped to $-40 \mathrm{mV}$ to record tail currents. P872fs877 mutant channels produced currents resembling WT currents, although with reduced amplitudes. E698X mutant channels did not induce currents, even not after transfection with $10 \mu \mathrm{g}$ of E698X expressing construct (data not shown). In these experiments, only a small endogenous current was recorded. Peak-amplitude $\mathrm{I} V$ plots (Figure $5 \mathrm{E}$ ) were determined by plotting the current level at the end of the $5 \mathrm{sec}$ depolarising step versus command voltage. The $1-\mathrm{V}$ plots indicated no significant shifts for the $P 872 \mathrm{fs} 877$ channels, but only reduced amplitudes. The voltage dependence of steady-state activation was determined by fitting the maximum tail amplitudes to a Boltzmann function. These plots (Figure 5F) indicated 
no significant shifts between WT and P872fs877 channels in the midpoint of activation nor was there a difference in slope factor. The inward rectification behaviour was quantified by normalizing the steady-state current level to the peak tail amplitude at $-40 \mathrm{mV}$ (Figure 6). For WT HERG it is clearly shown that the steady state current level at $+20 \mathrm{mV}$ only amounted $\sim 40 \%$ of the peak tail amplitude. However, upon transfection of P872f5877 on a WT stable cell line, the inward rectification was clearly decreased and was even absent in some cases. The latter drastic changes are somewhat obscured in the data presentation (Figure 6) by averaging; as a consequence of transient expression some cells only express a little amount of transfected P872fs877 but still show WT HERG as the transfection is performed on a WT stable cell line. 


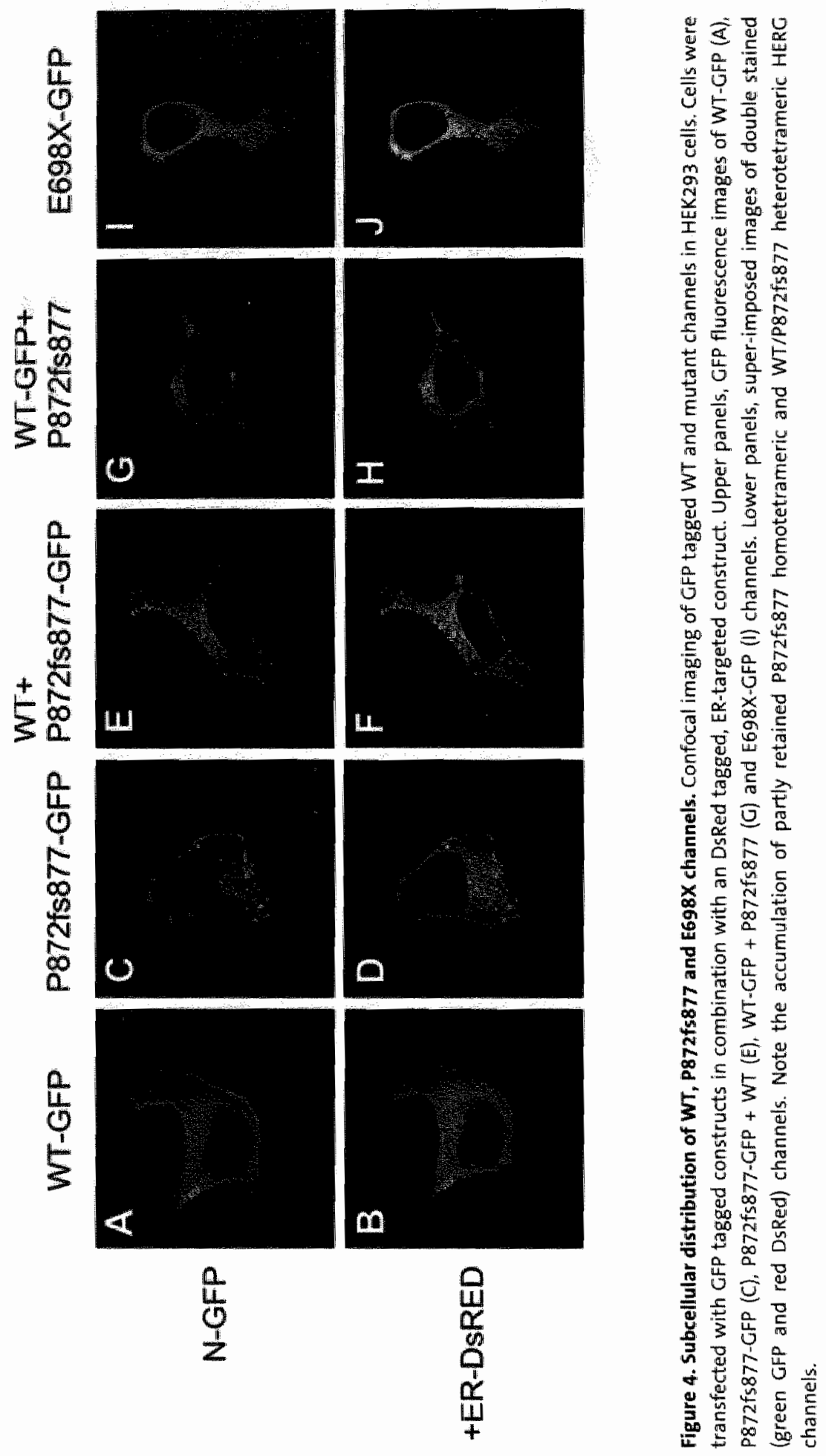


A

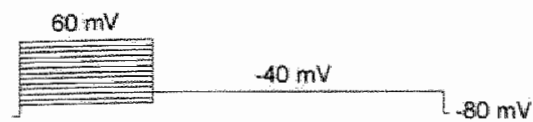

$\mathrm{C}$

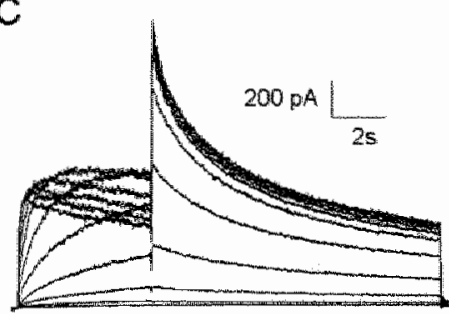

WT HERG

$E$

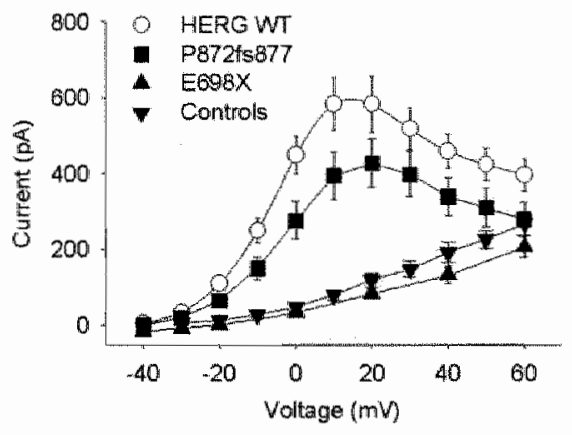

B

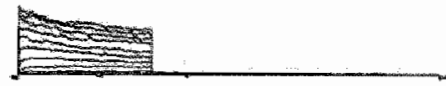

E698X HERG

D

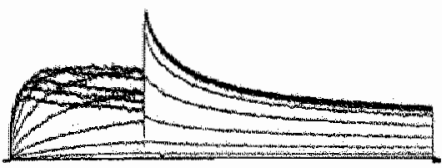

P872fs877 HERG

$\mathrm{F}$

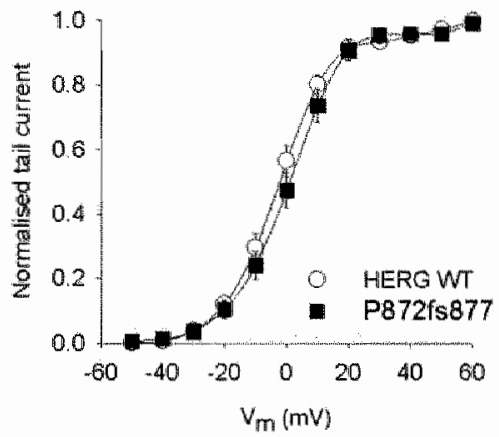

Figure 5. Voltage clamp recordings of HERG WT, P872fs877 and E698X channels. A, Voltage-clamp protocol and representative current recordings from transiently transfected $W T(B, n=7)$. $P 872 f s 877(C$, $n=8)$ and E698X cells $(D, n=3)$. E, peak amplitude I-V plots for HERG WT, P872fs877 and E698X channells. $\mathrm{I}-\mathrm{V}$ plots were determined by plotting the current level at the end of the $5 \mathrm{sec}$ depolarising step wersus the command voltage. Current amplitudes were reduced in P872f5877 currents. No current was recorded from E698X channels. $F$, woltage dependence of steadly-state activation. Relative tail currents were derived from the currents as shown in $C$ and $D$. Tail currents were fitted with a Boltzmann function to determine midpoint of activation $\left(V_{y / 2}\right)$ and slope factor $(k)$. HERG WT $(n=7): V_{y_{2}}=$ $-3.01 \pm 1.5, k=8.09 \pm 0.34$, HERG P872fs877 $(n=8): V_{k}=-0.03 \pm 2.22, k=8.13 \pm 0.17$. The mutant P $872 f 8877$ protein did not cause any significant differences in either the voltage dependence or the slope factor. 


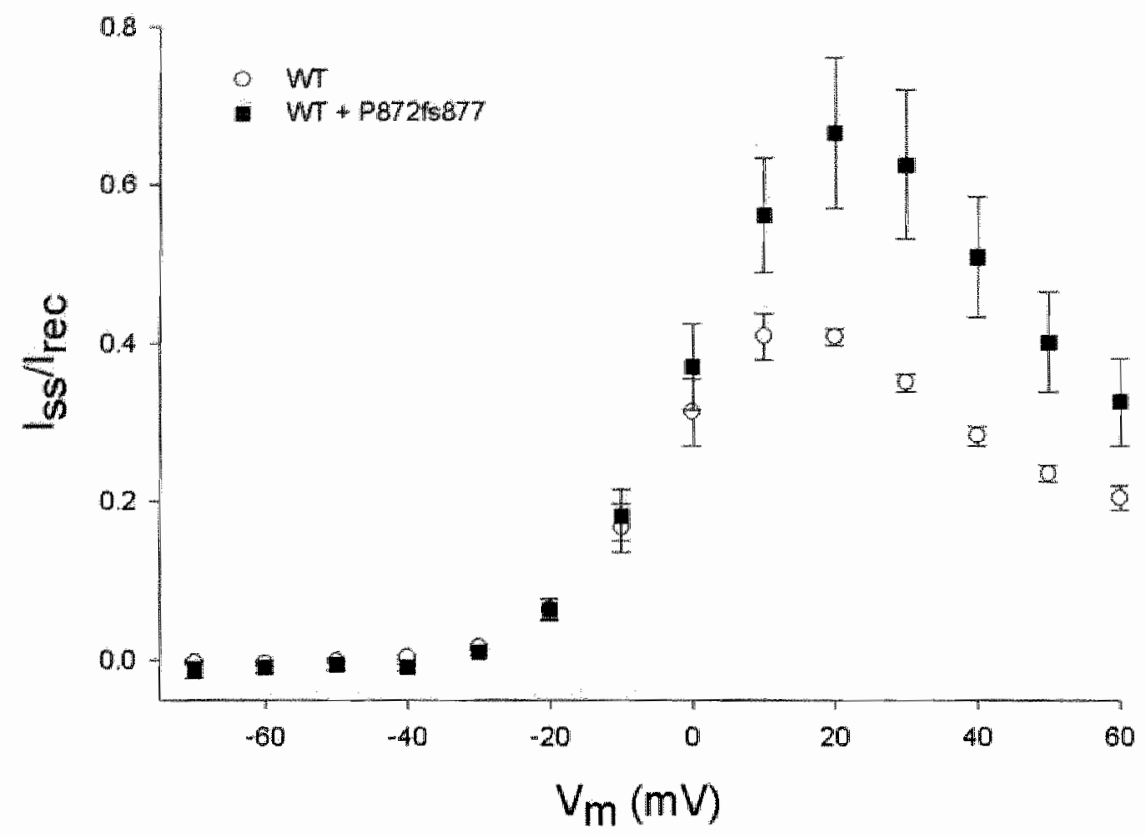

Figure 6. Inward rectification of HERG WT and WT+P872fs877. The inward rectification was determined by normalizing the steady-state current amplitude at the end of the voltage step as shown in figure $5 \mathrm{~A}$ by the peak tail amplitude at $-40 \mathrm{mV}$. The inward rectification of WT channels was maximal at $-60 \mathrm{mV}$ as the steady-state current level amounted only $\sim 20 \%$ of the peak tall amplitude. This behaviour was clearly changed upon transfection of P872fs877 on the WT stabile cell line. All values above $0 \mathrm{~m} V$ were significantly different $(n=5)$.

\section{Discussion}

In this study, we irvestigated the genetic origin of LQTS in two large families. Genetic screening revealed two previously unknown mutations in the C-terminus of the KCNH2 gene, which both co-segregated with prolonged QT-intervals in gene carriers. In one family, a single base pair mutation $2092 \mathrm{G}>\mathrm{T}$ in exon 8 of the KCNH2 gene was identified that leads to a premature stop codon at amino acid 698 (E698X). This mutated gene encodes a HERG protein lacking the last 461 amino acids. In a second family, a single base pair deletion in exon 9 of $K C N H 2$ was identified, resulting in a frameshift and a premature stop codon at amino acid 877 (P872fs877). This stop codon truncates the HERG protein by 282 amino acids.

Mutations in LQTS genes that lead to truncated proteins have been reported previously in the literature. Especially in the KCNH2 gene many frame shifts and nonsense mutations have been reported, but very few of them have been functionally characterised. An explanation may be that many of these mutations lead to a deletion 
of important regions of the HERG protein, such as the pore region or parts of the transmembrane domains, and may therefore appear of less interest for further studies as these proteins are expected to be non-functional. Indeed, some are non-functional with no influence on wild type channel function (23). Yet, at least one other nonsense mutation has been reported to be non-functional with a negative effect on wild type function (24). Moreover, it is also possible that truncated proteins may be functional, albeit with altered gating properties. Therefore, in this study, expression and functional behaviour of C-terminal truncated proteins were investigated.

Molecular techniques were applied to study protein expression and intracellular transport. Despite the deletion of a significant part of the C-terminus in both mutated HERG proteins, the truncated proteins were both detected. The expression of the E698X protein was however hardly visible, indicating that this truncation leads to either inefficient translation or early mRNA/protein degradation. It has been demonstrated for some diseases, such as cystic fibrosis and nephrogenic diabetes insipidus that some mutations lead to misfolding of proteins and retention in the endoplasmic reticulum. This trafficking deficiency was later also observed for some mutated HERG proteins $(12,17)$. We hypothesised that the HERG proteins with a truncated C-terminus may also show aberrant trafficking to the cell membrane and used confocal imaging to study subcellular trafficking of GFP-tagged WT and mutant proteins. In line with Western blotting results, no membrane bound proteins were detected for E698X channels. P872f5877 channels were only partly transported to the cell membrane, whilst part of the proteins were clustered together and retained in the ER. This partially retainment of mutant proteins may be the result of several mechanisms. Upon post- or cotranslational insertion of newly synthesized proteins in ER membranes, proteins bind with ER chaperone molecules whose role it is to facilitate protein maturation and folding (25). Incorrectly folded and/or assembled proteins are retained in or degraded from the ER into secretory pathways. One explanation for this retainment is that the proteins are immobilized through extensive interactions with chaperones, and are unable to move to $E R$ exit sites (25). The observed reduction in current amplituders of homotetrameric P872 5877 channels may therefore be caused by the partial retainment of proteins in the ER. Upon coexpression of WT and mutant P872fs 877 channels, transport still showed partial clustering of proteins in the ER, indicating that heterotetramers are formed and that the presence of mutant subunits in a tetramer has a dominant negative influence on the trafficking of channels.

To study functional properties of mutant channels, we performed whole cell patch clamp experiments. Some electrophysiological structure-function studies of HERG channels have been performed to investigate effects on channel function. Aydar et al. (26) performed sequential deletion analysis of the HERG C-terminus to delineate the minimum sequence necessary for channel function. They concluded that of the total 
length of the HERG protein (1159 amino-acids), at least 881 amino acids are necessary for channel function, since a deletion of 278 amino acids still produced functional channels and a deletion of 311 amino acids resulted in non-functionall channels. They further concluded that truncations generally lead to reduced current amplitudes, although not in a linear relation to the protein length. In addition, truncations greater than 236 amino acids resulted in accelerated deactivation rates. The P872fs877 mutation detected in our study has a C-terminal deletion of 282 amino acids. This truncated protein, however, did produce functional channels similar to WT channels, and therefore the minimum protein length needed for functional expression can be somewhat smaller than the $881(\Delta 278)$ amino acids. In accordance with this study, the homotetrameric P872f5877 channels produced currents with reduced densities as compared to wild type channels, but an acceleration of deactivation was not detected. This reduced current amplitude may , as indicated above, be the result of partial retainment of proteins in the ER. Kupersmidt et al. (27) functionally characterised a protein with a C-terminal deletion of 462 amino acids, which is only one amino acid less than the E698X protein. This mutated channel resulted in a non-functional channel in line with our results from E698X channels.

Co-expression studies of WT with P872f5877 channels produced some unexpected results because the typical inward rectification was absent in several of the analysed cells. This strongly indicates the formation of heterotetramers. At present, the origin of this alteration is not completely elucidated but may eventually be caused by changes in inactivation kinetics because the activation kinetics are not changed in the voltage range 10 to $60 \mathrm{mV}$ (data not shown).

In conclusion, the explanation behind LQTS diagnosis in these families is the result of mutated HERG channels causing (1) partial ER retention of mutant and or heterotetrameric subunits and (2) changes in the inward rectification behaviour of heterotetrameric channels.

\section{Acknowledgments}

We thank Ann Marien, Wim Keysers and Evy Mayeur for their excellent technical support and we thank Jean-Pierre Timmermans for the use of the confocal microscope. This work was supported by Johnson \& Johnson Pharmaceutical Research and Development, Flanders Institute for Biotechnology, Grant PRJ05, and by National Institutes of Health/National Heart, Lung, and Blood Institute Grant HL59689.

\section{References}

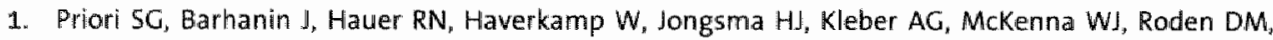
Rudy $Y$, Schwartz K, Schwartz $P \Downarrow$, Towbin $1 A$, Wilde AM. Genetic and molecular basis of cardiac arrhythmias: Impact on clinical management parts I and 11. Circulation 1999; 99: 518-528. 
2. Keating MT, Sanguinetti MC. Molecular genetic insights into cardiovascular disease. Science 1996 ; 272:681-685.

3. Curran ME, Splawski I, Timothy KW, Vincent GM, Green MD, Keating MT. A molecular basis for cardiac arrhythmia: HERG mutations cause long QT syndrome. Cell. 1995; 80:795-803.

4. Wang $Q$, Curran ME, Splawski I, Burn TC, Millholland JM, VanRaay TI, shen J, Timothy KW, Vincent GM, de Jager T, Schwartz PJ, Towbin JA, Moss A. Atkinson DL, Landes GM, Connors TD, Keating MT, Positional cloning of a novel potassium channel gene: KvLQT1 mutations cause cardiac arrhythmias. Nat Genet. 1996; 12:17-23.

5. Wang $\mathrm{Q}$. Shen J, Splawski 1, Atkinson D, Li Z, Robinson JL, Moss AJ, Towbin JA, Keating MT. SCN5A mutations associated with an inherited cardiac arrhythmia, long QT syndrome. Cell. 1995; 80:1-20.

6. Splawski I, Tristani-Firouzi $M$, Lehmann MH, Sanguinetti MC, Keating MT. Mutations in the hminK gene cause long QT syndrome and suppress $I_{\text {r.s }}$ function. Nat Genet. 1997; 17:338-340.

7. Abbott GW, Sesti F, Splawski 1, Buck ME, Lehmann MH, Timothy KW, Keating MT, Goldstein SAN. MiRP1 forms Ikr potassium chamnels with HERG and is associated with cardiac arrhythmia. Cell. $1999 ; 97: 175-187$.

8. Sanguinetti $M C$, Jiang $C$, Curran $M E_{n}$ Keating. MT. A mechanistic link between an inherited and an acquired cardiac arrhythmia: HERG encodes the $\mathrm{I}_{\mathrm{g}, \mathrm{r}}$ potassium channel. Cell. 1995; 81:299-407.

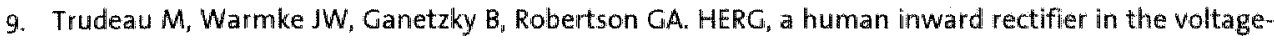
gated potassium channel family. Science. 1995; 269:92-95.

10. Nakajima $T$, Kurabayashi $M$, Ohyama $Y$, Kaneko $Y$, Furukawa $T$, Itoh $T$, Taniguchi $Y$, Tanaka $T$, Nakamura Y, Hiraoka M, Nagai R. Characterization of $5818 \mathrm{~L}$ mutation in HERC C-terminus in LQT2; Modification of activation-deactivation gating properties. FEBS. 2000; 481:197-203.

11. Sanguinetti MC, XU QP. Mutations of the S.4-S5 linker alter activation properties of HERG potassium channels expressed in Xenopus oocytes. I Physiol. 1999; 514,3:667-675.

12. Zhou $Z$, Gong $Q$, January $C T$. Correction of defective protein trafficking of a mutant HERG potassium channel in human long QT syndrome. $J$ Bial Chem. 1999; 274:311.23-31126.

13. Warmke JE, Ganetzky B. A family of potassium channel genes rellatedto Eag in Drosophila and mammals. Proc. Natl. Acad. Sci. U.S.A. 1991; 91:3438-3442.

14. Chen $J_{0}$ Zou A, Splawski I, Keating MT, Sanguinetti MC. Long QT syndrome-associated mutations in the Per-Arnt-Sim (PAS) domain of HERG potassium channels accelerate channel deactivation. I Biol Chem 1999; 274:10113-10118.

15. Paulussen $A_{0}$ Raes $A_{8}$ Matthijs $G_{8}$ snyders $D$, Cohen $N$, Aerssens $d$. A novel mutation (T65P) in the PAS domain of the human potassium channel (HERG) results in the long QT syndrome by trafficking deficiency. In press.

16. Ficker $E$, Thomas $D$, Wiswanathan PC, Dennis AT, Priori SG, Napolitano C, Mernini M, Wible BA, Kaufman ES, lyengar S, Schwartz PI, Rudy Y, Brown AM. Novell characteristics of a misprocessed mutant HERG channel linked to hereditary long QT syndrome. Am J Physiol Heart Circ Physiol 2000; 279:H1748-H1756.

17. Zhou Z, Gong $Q$, Epstein ML., January CT. HERG channel dysfunction in human long QT syndrome; intracellular transport and functionall defects. J Biol Chem 1998; 273:21061-21066.

18. Jongbloed RJ, Wilde AA, Geelen IL, Doevendans P, Schaap C. Van Langen I, van Tintelen JP, Cobben IM, Beaufort-Krol GC, Geraedts JP, Smeets HJ. Novel KCNQ1 and HERG missense mutations in Dutch long-QT families. Hum Munt. 1999; 13:301.-310.

19. Jongbloed $R$, Marcelis $C$, Velter $C_{\text {, }}$ Doevendans P, Geraedts J, Smeets H. DHPLC analysis of potassium ion channel genes in congenital long OT syndrome. Hum Mut. 2002; 20:382-391.

20. Zhou Z, Gong $Q$, Ye B, Fan Z, Makielski JC, Robertson GA, January CT. Properties of HERG channels stably expressed in HEK 293 cells studied at physiological temperature. Biophys / 1998; 74:230-241.

21. Ottschytsch $\mathbb{N}_{1}$ Raes A, Van Hoorick D, Snyders D. Proc Nat Acad Sci 2002; 99:7986-7991.

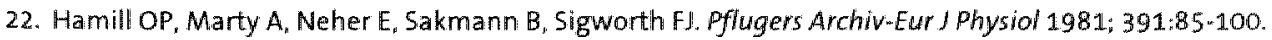


23. Paulussen $A$, Yang $P$, Pangalos $M$, Verhasselt $P$, Marrannes $R$, Verfaille $C$, Vandenberk $I_{s}$ Crabbe $R$, Konings. F, Luyten W, Armstrong M. Analysis of the human KCNH2 (HERG) gene: Identification and characterisation of a novel mutation $Y 667 X$ associated with long $Q T$ syndrome and a nonpathological 9 bp insertion. Hum Mut 2000; $15(5)$ : 483.

24. Li X, Xu J, Li M. The human $\triangle 1261$ mutation of the HERG potassium channel results in a truncated protein that contains a subunit interaction domain and decreases the channel expression. I Biol Chem 1997: $272(2): 705-708$.

25. Lippincott-Schwartz J, Roberts $\pi H$. Hirschberg $K$. Secretory protein trafficking and orgainelle dynamics in living cells. Anmu Rev Cell Dev Biol. 2000; 16: 557-589.

26. Aydar $E_{3}$ Palmer C. Functional characterization of the C-terminus of the human ether-à-go-gorelated gene $K^{*}$ channel (HERG). I Physiol 2001; 534.1: 1-14.

27. Kupersmidt $\$$, Snyders DS, Raes A, Roden DM. A K channel splice variant common in human heart lacks a C-terminal domain required for expression of rapidly activating delayed rectifier current. $J$ Bial Chem 1998; $273: 27231-27235$. 


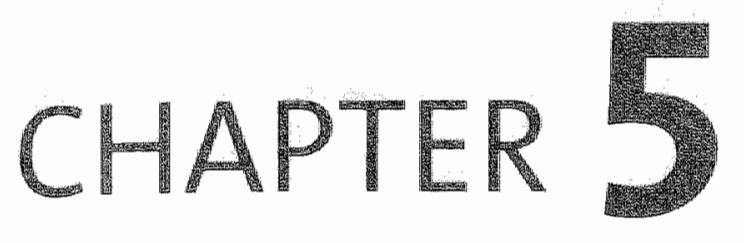

\section{Analysis of the Human KCNH2 (HERG) gene: Identification and characterization of a novel mutation Y667X associated with Long QT Syndrome and a non-pathological 9 bp insertion}

Aimée Paulussen ${ }^{\sharp}$, Ping Yang ${ }^{7}$, Menelas Pangalos ${ }^{2}$, Peter Verhasselt ${ }^{2}$, Roger Marrannes ${ }^{3}$, Christel Verfaille ${ }^{3}$, Ine Vandenberk ${ }^{3}$,Raf Crabbe ${ }^{4}$, Frank Konings ${ }^{5}$, Walter Luyten $^{6}$ and Martin Armstrong ${ }^{1}$

Departments of Pharmacogenomics ${ }^{1}$, Biotechnology "Neuropharmacology $y^{3}$, Clinical Pharmacology ${ }^{4}$, Global Development Operations and Technologies, Global Development Operations and Technologies: Functional Genomics", Janssen Research Foundation, Turnhoutseweg 30, 8-2340, Beerse, Belgitum. Pharmacology Research Division?, China Pharmaceuticall University ${ }_{n}$ Nanjing.

Human Mutation, 2000; 15 (5): 483. 


\section{Abstract}

Long QT (LQT) syndrome is a potentially life-threatening disorder, characterised by a distinct cardiac arrhythmia known as torsades de pointes. Mutations within a number of genes linked to the familial form, including that coding for a cardiac potassium channel called $\mathrm{KCNH}_{2}$ (HERG), have been described based on the characterized genomic organisation. A standardized method was developed to screen the entire gene for gene variants. We report a single base pair substitution, introducing a premature STOP codon at codon 667 of the gene in a healthy individual with an extended QTC interval (460 msec). In vitro expression of the codon Y667X variant in Xenopus oocyte suggests that the autosomal dominant variant does not function in a dominant/negative manner and cannot co-assemble to form a channel, resulting in a reduction of the $\mathrm{KCNH} 2$ current, and an extension of the $\mathrm{QT}$ interval. This indicates that pathogenic LQT gene variants exist in the apparently normal population, the prognosis and clinical consequences of which remain to be determined. The assays described should facilitate future studies into this area.

\section{Introduction}

Long QT syndrome (LOT) is a cardiac disorder that typically affects young, previously healthy individuals. The frequency of LOT is unknown but may be as common as 1 in 5,000 and may be responsible for 3,000-4,000 deaths per year in the Unites States. alone $(1,2)$. Using affected families the inherited form of the disease has been linked to 5 chromosomal regions. Five genes responsible for the syndrome have been identified within four of these chromosomal regions, and mutations within these genes have been shown to associate preferentially within affected families $(3,4)$. Here we describe the identification and electrophysiological characterization of a novel mutation $\mathrm{Y} 667 \mathrm{X}$ in exon 8 of the KCNH2 gene (LOT2; MIM\#152427), detected by single stranded conformation polymorphism analysis as well as a non-pathological 9 basepair insertion in exon 4 of this gene. 


\section{Materials and Methods}

\section{Subjects}

A volunteer in a Phase I clinical trial was brought to our attention, presenting with a prolonged $\mathrm{QT}_{\mathrm{c}}$ interval of $460 \mathrm{msec}$. All available family members of the proband were recruited for inclusion in our study. Eight volunteer subjects with a normal QTC interval ( $<440 \mathrm{msec}$ ) and no history of cardiac arrhythmia during trials were recruited as control subjects for the study.

\section{PCR-SSCP analysis}

DNA was extracted from peripheral leucocytes of all subjects. PCR primers $\$$ were designed based on the sequence obtained from a BAC clone (EMBL, accession numbers AJ010538 through AJ010551) and published data (5). To maximize detection efficiency, SSCP analysis was performed under two conditions: a $15 \%$ Excelgel run at $4^{\circ} \mathrm{C}$; a $12 \%$ Excelgel run at $15^{\circ} \mathrm{C}$ (gels from Pharmacia). Gels were run for 1.5 to 2.5 hours at $600 \mathrm{mV}$. Those gene fragments showing variant SSCP patterns were reamplified, purified (Qiagen PCR purification kit), sequenced directly on both sense and antisense strands using the $\mathrm{ABI}$ Big Dye Terminator cycle sequencing kit, and analyzed on an $\mathrm{ABI}$ 377. The obtained gene sequence was compared with the published sequence of ltoh et al. (5).

\section{Site-directed mutagenesis}

The full-length wild type $\mathrm{KCNH} 2$ CDNA was sub-cloned into the oocyte expression vector SP64T.GL. PCR amplification with primers 5'-GCAACATGGAGCAGCCACACATG$3^{\prime}$ and 5'-CCCCTCGAGTTACAGCCGCTGGATGATGGCC-3' (Restriction site for Xho I underlined, point mutation in bold) was performed using the full length $\mathrm{KCNH} 2$ construct as a template to create the STOP codon in the wild type sequence. The amplified PCR product and KCNH2 FL/PSP64T.GL were digested with Bg/ II and Xho I, gel purified, and ligated to create a final KCNH2-STOP/PSP64T.GL construct. Introduction of the stop codon and the absence of any PCR induced base pair changes were verified by full sequence analysis. Messenger RNA was synthesized from the wild type and mutant CDNA SP64T.GL constructs using the Ambion mMessage mMachine SPG in vitro Transcription kit, according to the manufacturers instructions.

\section{Electrophysiological characterization of the codon 667 variant}

Defolliculated Xenopus laevis oocytes were injected with $46 \mathrm{nl}$ of mRNA, containing either $\mathrm{KCNH} 2$ wt mRNA, mutant mRNA or combinations of both. Recordings were made at $19-22{ }^{\circ} \mathrm{C}$ with a two-electrode voltage clamp amplifier (Turbo TEC O1C or $10 \mathrm{CD}, \mathrm{Npi}$ electronics). Microelectrodes were filled with $3 \mathrm{M} \mathrm{KCL}$ and the holding 
potential was $-80 \mathrm{mV}$. Stimulation and data acquisition were controlled with the Pulse software (HEKA electronik), which was connected to the amplifier via an ITC-16 interface (Instrutech Inc.). Data analysis was performed by means of the programs Pulsfit (HEKA) and Igor Pro (Wavemetrics Inc.).

\section{Results}

\section{Analysis of variant sequences}

The subject with the QTC of 460 msec showed a variant band pattern on SSCP analysis of exon 8 . Sequence analysis revealed that this subject was heterozygous for a base substitution of $C$ to $A$ at position 2001, altering codon 667 from TAC, encoding tyrosine, to a STOP codon (TAA). A specific PCR-RFLP detection assay was developed, based on the loss of a recognition site for restriction enzyme Ava I associated with the mutation; Screening of available family members indicted that this mutation had been inherited from the maternal line. The probands mother was also a heterozygous carrier of the mutation with a prolonged OTC $(479 \mathrm{msec})$. A second variant band pattern was observed on SSCP analysis of exon 4 of a control subject. Direct sequencing of the double stranded PCR product indicated that the subject was heterozygous for a 9 base pair insertion, GCGCGCGCG, beginning at position 568 of the cDNA sequence. This insertion leads to an in-frame insertion of three amino-acids, Gly Alla Gly, between codons 189 and 190 of the published gene sequence. This subject had a QTC of $367 \mathrm{msec}$ and no medical history associated of cardiac arrhythmias or associated problems.

\section{Electrophysiological characterization of the codon $667 \mathrm{KCNH} 2$ variant}

The first test was to investigate the influence of the $Y 667 X$ mutation on channel function (Figure 1). Oocytes injected with wt mRNA expressed a normal $\mathrm{KCNH} 2$ current (Figure 1A), while oocytes injected with up to $400 \mathrm{ng} / \mu \mathrm{l}$ of the $\mathrm{KCNH} 2$ mutant did not express functional channels at all, even up to 6 days after injection of the mRNA (Figure $1 B$ ). The generated currents with the mutant mRNA were identical to those in the non-injected oocytes (Figure 1 C). The hypothesis that $\mathrm{KCNH} 2$ mutant subunits are translated equally well as wt subunits, assemble equally well with the wt subunits and that the presence of at least one mutant subunit in a hetero-tetrameric channel would make the channel non-functional, was rejected upon co-injection of $100 \mathrm{ng} / \mu \mathrm{l}$ of wt with $300 \mathrm{ng} / \mu \mathrm{l}$ of mutant $\mathrm{KCNH} 2$. The current after co-injection was much higher than the expected 1/64 part of the current after injection of only 100 $\mathrm{ng} / \mu \mathrm{l}$ of $\mathrm{KCNH} 2$ wt. 


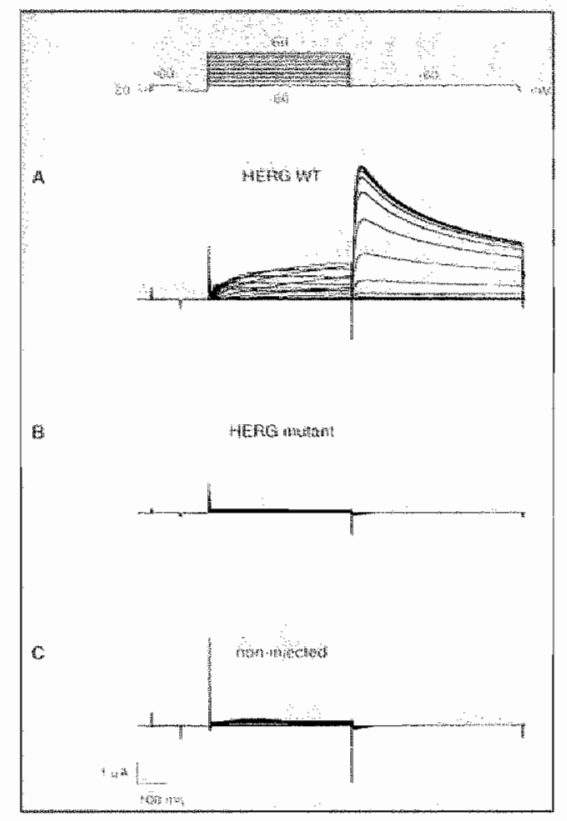

Figure 1. Electrophysiological characterization of the codon $667 \mathrm{KCNH} 2$ gene variant. A. Oocyte injected with $200 \mathrm{ng} / \mu \mathrm{l}$ of $\mathrm{KCNH} 2 \mathrm{wt}$. From a $-80 \mathrm{mV}$ holding potential, a 100 -msec pulse to $-60 \mathrm{mV}$ was given to measure the leak current. After a 100 -msec interval at $-80 \mathrm{mV}, 500-\mathrm{msec}$ depolarizing test pulses from $-60 \mathrm{mV}$ to $+60 \mathrm{mV}$ were given, followed by a $600-\mathrm{msec}$ period at $-60 \mathrm{mV}$, which elicited the KCNH2tail current. B. Oocyte injected with $400 \mathrm{ng} / \mathrm{\mu l}$ of the mutant. The mutant does not produce functional KCNH2 channels. C. Non-injected oocyte.

In order to explain why the heterozygous patients display a prolonged QT-interval, the $\mathrm{KCNH} 2$ "normalized" tail current amplitude after injection of oocytes with $400 \mathrm{ng} / \mu \mathrm{l}$ wt was compared to that of oocytes co-injected with $200 \mathrm{ng} / \mu \mathrm{l} w \mathrm{wt}+200 \mathrm{ng} / \mu \mathrm{l}$ mutant. Because the current amplitude increased over time, the tail current amplitude was divided by the average tail current of the $400 \mathrm{ng} / \mu \mathrm{K} \mathrm{KCNH} 2$ wt-injected oocytes measured at the same experimental day. The normalized tail current amplitude was significantly smaller in the group of oocytes co-injected with $200 \mathrm{ng} / \mu \mathrm{l} \mathrm{wt}+200 \mathrm{ng} / \mu \mathrm{l}$ mutant than in the group of oocytes injected with $400 \mathrm{ng} / \mu \mathrm{KCNH} 2$ wt (Table 1 ). In addition, there were no significant differences in normalized tail current amplitudes, half-activation potentials, rate of activation and deactivation and in inactivation between the oocytes co-injected with $200 \mathrm{ng} / \mu \mathrm{l} w \mathrm{wt}+200 \mathrm{ng} / \mu \mathrm{l}$ mutant and the oocyte group injected with $200 \mathrm{ng} / \mu \mathrm{l}$ wt alone (Table 1). All these electrophysiological experiments together strongly suggest that co-injection of this $\mathrm{KCNH} 2$ mutant does not influence the properties of the $\mathrm{KCNH} 2$ current induced by the $\mathrm{KCNH} 2$ wt subunits. 
Table 1. Infiluence of comjection of equal amounts of will type and mutant mRNA The baitches of oocytes 1 and 2 (first column) are independent experiments with oocytes obtained from different animals. The second column shows the type of injection. The third column gives the amplitude of the

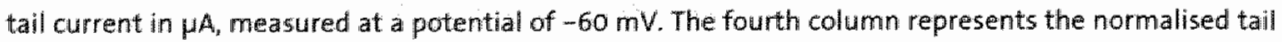
current, obtained by diwision of the tail current amplitude of each oocyte by the mean tail current of the WT 400 ngful injected oocytes on the same day, to take into account the increase in expression with time. The fifth columin represents the number of oocytes in each group.

\begin{tabular}{|c|c|c|c|c|}
\hline & Iniection & $\begin{array}{l}\text { Amplitude of tail current } \\
(\beta A)\end{array}$ & $\begin{array}{l}\text { Normalized amplitude of taill } \\
\text { current }\end{array}$ & $\mathbf{N}$ \\
\hline Docyte & WT $400 \mathrm{rg} / \mathrm{hll}$ & $2.772 \pm 0.468$ & $1.000 \pm 0.095$ & 27 \\
\hline bateh 1 & $\begin{array}{l}\text { WT } 200 \mathrm{ng} / \mathrm{\mu ll}+ \\
\text { Mut } 200 \mathrm{ng} / \mu \mathrm{l}\end{array}$ & $1.723 \pm 0.318$ & $0.609 \pm 0.089 *$ & 27 \\
\hline Docyte & WT $400 \mathrm{ng} / \mu \mathrm{H}$ & $3.466 \pm 0.435$ & $1.000 \pm 0.117$ & 20 \\
\hline \multirow[t]{2}{*}{ baltch 2} & $\begin{array}{l}\text { WT } 200 \mathrm{ng} / \mathrm{HH}+\mathrm{H} \\
\text { Mut: } 200 \mathrm{ng} / \mathrm{hl}\end{array}$ & $2.452 \pm 0.364$ & $0.575 \pm 0.075^{* *}$ & 28 \\
\hline & WT $200 \mathrm{ng} / \mu \mathrm{ll}$ & $2.382 \pm 0.388$ & $0.535 \pm 0.080^{\circ}$ & 24 \\
\hline
\end{tabular}

Results are expressed as mean \pm S.E.M." "P<0.01 (two-sided Student's t-test for independent samples) for the comparison with the group of occytes injected with $400 \mathrm{ng} / \mathrm{\mu l}$ l of the same batch of oocytes.

\section{Discussion}

Previous work has linked the KCNH2 gene, which encodes the channel responsible for the rapidly activating delayed rectifier $\mathrm{K}^{+}$phase of the cardliac cycle, to inherited LOT $(6,7)$. In this study we have identified two novel variations in the $K C N H 2$ gene; One variant, a 9 bp insertion between codons 189 and 190 in the amino terminal portion of the gene, produces an in frame insertion of 3 amino acids, and appears to be nonpathological in effect on QTc interval.

Conversely, however, the single base substitution ( $C>A)$ at position 2001 in exon 8 of the gene, was associated with a prolongation of the $\mathrm{QT}_{i}$ interval in the proband (460 $\mathrm{msec}$ ) as well as the mother of the proband $(479 \mathrm{msec})$, both subjects being heterozygous for the mutation. The fact that the substitution intraduces a STOP codon in the gene at position 667 , terminating translation of the protein $5^{\prime}$ to the coding region for the nucleotide-binding domain and truncating the protein by 492 amino acids from the carboxy-terminal end of the protein provides further evidence for a causal association.

In order to fully characterize the effects of this mutation on channel function, electrophysiology experiments were performed, comparing both wild type and mutant forms of the channel. Knowing that $\mathrm{KCNH} 2$ belongs to a superfamily of $\mathrm{K}^{*}$ channels which are believed to assemble as tetramers (8), all data from the electrophysiological experiments obtained, can be explained by assuming that the KCNH2 mutant subunit does not assemble, neither with the mutant congeners nor with the $\mathrm{KCNH} 2$ wt subunits. This explains 1) that injection of the mutant alone does 
not form functional channels (Figure 1), 2) that this mutant has no influence on the amplitude and properties of the $\mathrm{KCNH} 2$ current after coinjection with wt and 3) that the normalized current with the "heterozygous" combination (200 ng/ $\mathrm{ll} w+200$ $n g / \mu l$ mutant) was smaller than that in the $400 \mathrm{ng} / \mu \mathrm{KCNH} 2 \mathrm{wt}$ group. The longer QT-interval in the patients heterozygous for this mutant can therefore probably be explained by the reduced amount of $\mathrm{KCNH} 2$ channels incorporated in the heart cell membrane, since a smaller amount of $\mathrm{KCNH} 2$ wt subunits is produced and the mutant subunits do not contribute to channel formation and to the $\mathrm{KCNH} 2$ current. Ludwig et al. (9) proposed that the C-terminal portion of the rat $K \mathrm{CNHZ}$ gene is important for coassembly. Our results suggest that this may also be the case in humans. It is apparent that the STOP (Y667X) mutation is acting in an autosomal dominant manner.

The subjects in this study were in excellent health and were identified only as a result of routine screening for entry into phase | clinical trials. One may thus question whether the prognosis and clinical implications for these individuals will be different to those having a family history or having presented with specific symptoms associated with an prolonged QTC. Presumably there exist within the population other asymptomatic individuals with similar variants which have not yet been described. Since we suspect that mutations within the same genes responsible for the familial form of the disease could also determine susceptibility to the acquired form of the disease, we suspect that these individuals may be at increased risk of drug induced $Q T$ prolongation. In this case diagnostic testing via genotyping may be useful to identify susceptible individuals. Until the majority of causative mutations are discovered and functionally characterised, molecular diagnosis still requires screening of the entire KCNH2 gene for mutations.

\section{Acknowledgements}

We would like to acknowledge the help of Bert Bruyninckx for the collection of blood samples and for the retrieval of subject data used in this report and Danielle Nieuwstraten for preparing RNA from the wild type and mutant CDNA constructs.

\section{References}

1. Sudden Arrhythmia Death Syndromes (SADS) Foundation. The long QT syndrome. Web site: http://www.ihc.com/research/longat.htm!

2. Willich $S \mathrm{~N}$, Levy $\mathrm{D}$, Rocco $\mathrm{MB}$, Tofler $\mathrm{GH}$, 5 tone $\mathrm{PH}$, Muller JE. (Circadian variation in the incidence of sudden deatth in the Framingham Heart Study papulation. Am. J. Cardiol. 1987; 60: 801.806.

3. Wang $Q$, Bowles NE, Towbin JA. The molecular basis of long QT syndrome and prospects for therapy. Mol Med Today 1998; 4: 382-388.

4. Abbott CW, Sesti F, Splawski I. Buck ME, Lehmann MH, Timothy KW, Keating MT, Goldstein SAN. MiRP1 forms $I_{k,}$ potassium channels with HERG and is associated with cardiac arrhythmila. Cell 1999: $97: 175-187$. 
5. Iton $T$, Tanaka $T$, Nagai R, Kamiya $T$, Sawayama $T$, Nakayama $T$, Tomoike $H$, Sakuradai $H$, Yazaki Nakanura $Y$. Cenomic organization arid mutational analysis of $H E R G$, a gene responsible $f$ familial long QT syndrome. Hum Genet. 1998; 102: 435-439.

6. Curran ME, Splawski I. Timothy KW, Vincent GM, Green ED, Keating MT. A molecular basis fi cardiac arrhythinia HERG mutations cause long QT syndrome. Cell 1995; 80: 795-803.

7. Tanaka $T$, Nagai $R$, Tomoike $H$, Takata 5 , Yano $K$, Yabuta $K$. Haneda $N$, Nakano O, Shibata

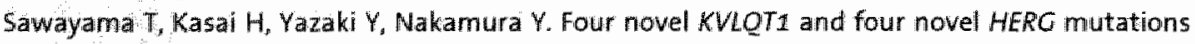
familiallong QT syndrome. Circulation 1997;95:565-567.

8. Mackinion R. Determination of the subunit stoichiometry of a voltage-activated potassiu channel Nature 1991; 350: 232-235.

9. Ludwig !, Owen $D_{1}$ Pongs $O$. Carboxy-terminal damain mediates assembly of the woltage-gated ether-a-go-go potassium channel. EMBO 1997; 16:6337-6345. 


\section{CHAPTER}

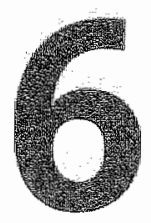

\section{Two linked variations in transcriptional regulatory elements of the CYP $3 A 5$ gene constitute the major genetic determinant of polymorphic activity in humans}

Aimée Paulussen ${ }^{1}$, Karel Lavrijsen ${ }^{2}$, Hilde Bohets ${ }^{2}$, Jan Hendrickx ${ }^{2}$, Peter Verhasselt ${ }^{3}$, Walter Luyten ${ }^{4}$, Frank Konings ${ }^{5}$, Martin Armstrong ${ }^{1}$

Departments of Pharmacogenomics ${ }^{2}$, Clinical Pharmacology $y^{7}$, Biotechnology $y^{3}$, Functional Genomics ${ }^{4}$ and Global Development Operations and Technologies". lanssen Research Foundation, Turnhoutseweg 30, B-2340, Beerse, Belgium.

Pharmacogenetics, 2000; $10: 415-424$ 


\section{Abstract}

Cytochrome P450 3A subfamily members (CYP3A) are the most abundant liver cytochrome $\mathrm{P} 450$ forms, responsible for the biotransformation of over $50 \%$ of all drugs. The expression and activity of isoforms CYP3A4 and CYP3A5 show wide interindividual variation, influencing both drug response and disease susceptibility. The molecular basis for this variation has never been defined. In this study, we use probe drug midazolam to determine the CYP3A5 phenotype in a panel of liver samples. A clear bimadality in metabolism was observed. Analysis of the $5^{\prime}$-flanking region of the CYP3A5 gene identified two linked polymorphisms, $T^{369} G$ and $A^{-45} G$, located in transcriptional regulatory elements, which are associated with increased expression and activity of the gene. A polymerase chain reaction based detection assay is described facilitating future studies into both the metabolic consequences of this variation and disease association studies relating to CYP3A5.

\section{Introduction}

The CYP3A enzymes represent one of the most important subfamilies of the cytochrome P450 (CYP) superfamily. The CYP3A subfamily comprises the most abundantly expressed cytochrome $P 450$ enzymes in human liver, and is responsible for the metabolism of over $50 \%$ of all clinically used drugs, including the dihydropyridines, cyclosporine, erythromycin and barbiturates (1). Wide inter-individual variation in the metabolism of CYP3A substrates has been noted and is a factor in determining. individual drug efficacy. Evidence also exists for the metabolism of an array of lipophilic environmental pollutants, including the activation of pro-carcinogens such as aflatoxin B1 by members of this subfamily (2). Consequently, inter-individual variation in activity may also represent a host susceptibility factor to a number of diseases with an environmental component.

To date, four CYP3A CDNAs have been identified in humans: CYP3A3, CYP3A4, CYP3A5 and CYP3A7. It is believed that CYP3A3 represents an allelic variant of CYP3A4, whilst CYP3A7 is the major foetal hepatic cytochrome and CYP3A4 is the predominant cytochrome $\mathrm{P} 450$ found in human adult liver (3). Initial experiments suggested that a polymorphism exists in CYP3A4 (4). However other studies, whilst confirming a wide range of inter-individual variation in CYP3A4 expression have failed to confirm the original bimodality $(5,6)$. Overlapping substrate specificities between CYP3A4 and CYP3A5 have previously made it difficult to separate metabolism by these isoforms; consequently little phenotyping data have been produced to study variation in CYP3A5 activity in humans. However, there is evidence for the polymorphic expression of CYP3A5. Both immunoblotting and Northern blot analysis have detected CYP3A5 expression in only $10-30 \%$ of human livers (7-9). More recently, analysis of 30 human 
liver samples using immunoblotting found that only $3 \%$ showed no detectable CYP3A5, whilst a large number had trace amounts, suggesting that a polymorphism in this enzyme may be regulatory as opposed to structural (10).

Comparisons of the 5' flanking regions from the CYP3A4, $3 A 5$ and $3 A 7$ genes have identified putative binding sites for several transcriptional regulatory factors common to all isoforms (11-13). However, the molecular basis, if any, for the inter-individual variation in expression of the CYP3A sub-family members has so far remained unclear. Indeed, it has been suggested that the host cellular environment may be a greater determinant of inducibility than gene structure (14). This would render prediction of CYP3A activity virtually impossible since it is difficult to identify (all) relevant inducers in the environment, and to quantify their levels.

The delineation of CYP3A4 and CYP3A5 metabolism has been shown to be possible using the sedative midazolam as a probe drug $(15,16)$. In this case, two metabolites are formed: 1-hydroxy midazolam (1-OHM) and 4-hydroxy midazolam (4-OHM). Samples containing a higher proportion of CYP3A5 compared to CYP3A4 have their metabolism driven towards the 1-OHM route and therefore show a higher ratio of 1 $\mathrm{OHM} / 4-\mathrm{OHM}$ than those containing only CYP3A4. Using this information, we have measured CYP3A5-mediated metabolism in microsomes prepared from a panel of human livers and compared the 5' flanking sequences of the corresponding CYP $3 A 5$ gene. Here we report the identification of two linked polymorphisms, located in putative transcriptional regulatory regions, which appear to cause increased CYP3A5 gene transcription leading to increased metabolic activity. The description of PCRbased assays for their detection will allow prediction of inter-individual variability in response to drugs metabolised by this isoform, as well as facilitating disease association studies. 


\section{Materials and Methods}

\section{Liver microsome preparation}

Human liver samples were obtained from kidney transplant donors, and flash-frozen immediately on removal. Ethical committee approval for the study was obtained. Human liver microsomes were prepared according to previously described protocols (17), and protein content was determined by the method of Lowry as modified by Miller (18).

\section{Midazolam hydroxylase assay}

The rates of midazolam overall metabolism and of the formation of 1- and 4-OHmidazolam were determined as follows. Each incubation vessel contained an aliquot of the microsomal suspension (containing $1 \mathrm{mg}$ of microsomal protein) in $1.15 \% \mathrm{KCl}$ $0.01 \mathrm{M}$ phosphate buffer $\mathrm{pH} 7.4 ; 10 \mu \mathrm{l}$ of a stock solution of $6 \mathrm{mM}$ midazolam dissolved in dimethyl suphoxide (DMSO) to reach a final midazolam concentration of $60 \mu \mathrm{M} ; 500 \mu \mathrm{l}$ of a cofactor mixture containing $0.5 \mathrm{mg}$ of glucose- 6 -phosphate, $0.5 \mathrm{mg}$ of $\mathrm{MgCl}_{2} .6 \mathrm{H}_{2} \mathrm{O}, 0.5 \mathrm{U}$ of glucose-6-phosphate dehydrogenase dissolved in $0.5 \mathrm{M} \mathrm{Na}-\mathrm{K}$ phosphate buffer, $\mathrm{pH} 7.4$ and a $1.15 \% \mathrm{KCl}-0.01 \mathrm{M}$ phosphate buffer $\mathrm{pH} 7.4$ to bring the incubation volume to $0.9 \mathrm{ml}$. After a pre-incubation for $5 \mathrm{~min}$ at $37^{\circ} \mathrm{C}$, the incubations were started by adding $100 \mu \mathrm{l}$ of a solution of $1.25 \mathrm{mg} / \mathrm{m} / \mathrm{NADP}$ to reach a final concentration of $0.125 \mathrm{mg} / \mathrm{ml}$. Tubes were continuously shaken at 100 oscillations/min in a Heto shaking waterbath (Heto Laboratory Equipment, Allerod, Denmark). Blank incubates with boiled microsomes were incubated under identical conditions as the control incubates. The incubations were stopped after $30 \mathrm{~min}$ by immersing the tubes in dry ice. Samples were stored at $-18^{\circ} \mathrm{C}$ until analysis. The incubation samples were analysed for unchanged midazolam and for its metabolites 1 '- and 4-hydroxymidazolam by high-performance liquid chromatography (HPLC) with ultraviolet (UV)-detection.

\section{HPLC determination of midazolam metabolites}

The 1-ml samples of midazolam were thawed and diluted with $1 \mathrm{ml}$ DMSO. Samples were sonicated for $10 \mathrm{~min}$, centrifuged and an aliquot of the supernatant was injected directly onto the HPLC-column. The HPLC apparatus consisted of a Waters 600 MS pump. The samples were injected automatically, using a WISP 717 (Waters, Milford, USA) plus automatic injector. Stainless steel columns (30 cm ( $4.6 \mathrm{~mm}$ inner diameter) were packed with Kromasill 18 ( $5 \mu \mathrm{m}$, Akzo Nobel, Eka Chemicals, Bohus, Sweden) bound phase by a balanced density slurry procedure (Haskel DSTV 122-C pump, 107 $\mathrm{Pa}$, Haskel, Burbank, USA). UV-detection at $230 \mathrm{~nm}$ was performed using a Waters 996 Diode Array Detector (Waters, Milford, USA). Elution at $1-\mathrm{ml} / \mathrm{min}$ started with a short gradient from $100 \% 0.1 \mathrm{M}$ ammonium acetate, $\mathrm{pH} 7.0$ (solvent system $\mathrm{A}$ ) to $50 \%$ of solvent system $\mathrm{A}$ and $50 \%$ of solvent system $\mathrm{B}$ containing $1 \mathrm{M}$ ammonium acetate $\mathrm{pH}$ 
7.0, methanol and acetonitrile (10/45/45), over a 1-min period, followed by a second gradient to $100 \%$ solvent system $B$ in $15 \mathrm{~min}$. This solvent composition was held for 2 min before equilibration with the starting conditions. The identity of the metabolites of midazolam was confirmed using mass spectroscopy. The conversion of UV-peak areas into ng was performed by a Millenium 2020 CDS system (Waters, Milford, USA) on a calibration curve of midazolam. This calibration curve was obtained after injection of known amounts of the drug $(0,1059,2117,3176$ and $5028 \mathrm{ng})$ and linear (weighted by $1 / x$ ) regression analysis of the corresponding UV-peak areas. The equation of the calibration curve was $n g=0.000333\left(\right.$ area $\left(r^{2}=0.9997, n=5\right)$. The metabolic activity was expressed as pmol metabolite formed/min $\mathrm{mg}$ protein, and a metabolic ratio was determined for each sample according to the ratio of $10 \mathrm{HM} / 40 \mathrm{HM}$ in each sample.

\section{Genomic DNA preparation}

DNA was isolated from frozen liver samples using a QIAmp Tissue Kit (QIAGEN, Hilden, Germany').

\section{RNA preparation}

RNA was isolated from the liver samples using a OIAGEN RNAeasy Midi Kit (QIAGEN). Twenty $\mu g$ of RNA was treated with RNAase-free DNAase I (Boehringer Mannheim, Brussells, Belgium), for $30 \mathrm{~min}$ at $37{ }^{\circ} \mathrm{C}$ in $20 \mathrm{mM}$ Tris $-\mathrm{HCl}_{,} \mathrm{pH} 8.0,100 \mathrm{mM} \mathrm{MgCl} 2$. Samples were phenol/chloroform extracted, ethanol precipitated and resuspended in $30 \mu \mathrm{l}$ of TE buffer. Two and a half $\mu \mathrm{g}$ of the treated sample was reverse-transcribed for 50 min at $42^{\circ} \mathrm{C}$ in $1 x$ First Strand Buffer (Life Technologies, Merelbeke, Belgium), 0.01 $M$ DTT and $0.5 \mathrm{M}$ dNTPs using $0.5 \mathrm{\mu g}$ of Oligo(dT) random primers and $200 \mathrm{U}$ SuperScript II Reverse Transcriptase (Gibco BRL, Life Technologies, Merelbeke, Belgium) for use on the ABI Prism 7700 Sequence Detection System (Foster City, CA, USA).

\section{Sequencing of the CVP3A5 5 'flanking region}

A 1343 bp $5^{*}$-flanking region of CYP3A5 was PCR-amplified from genomic DNA isolated from liver samples, using primers 3 A51 (5'-GGAAGCAACCTACATGTCCATC-3') and 3 A52 (5'-ATCGCCACTTGCCTTCTTC-3") based on the published sequence of Jounaidi et al. (13). PCR conditions were: one cycle of $95^{\circ} \mathrm{C}$ for $1 \mathrm{~min}, 30 \mathrm{cycles}$ of $95^{\circ} \mathrm{C}$ for $1 \mathrm{~min}, 57^{\circ} \mathrm{C}$ for $30 \mathrm{~s}, 72^{\circ} \mathrm{C}$ for $2.5 \mathrm{~min}$, and one final cycle of $72^{\circ} \mathrm{C}$ for $10 \mathrm{~min}$. PCR products were purified using a QIAquick PCR Purification Kit (OIAGEN). Sequencing primers were designed (Table 1), and used to sequence directly the PCR product on both sense and antisense strands by cycle sequencing using the $\mathrm{ABI}$ BigDye Terminator cycle sequencing kit (Perkin Elmer, Nieuwerkerk, The Netherlands). Sequencing reactions were analysed on an $\mathrm{AB} \mid 377$ automated sequencer (Foster City, CA, USA). Contig sequences were aligned and compared using the Sequence Editor version 1.0.3 software packages (Perkin Elmer) and manually edited for identification of heterozygous positions. 
Table 1. Primers used for sequencing the $5^{\prime \prime}$-flanking region of CYP3A5 from the polymerase chain reaction product 3 A $51 / 3$ A 52 (see text).

\begin{tabular}{|c|c|c|c|}
\hline Primer & Orientation $^{3}$ & Position & Sequence $\left(5^{n}\right.$ to $\left.3^{\prime}\right)$ \\
\hline $3 A 51$ & $F$ & -1238 to -1217 & GGAAGCAACCTACATGTCCATC \\
\hline 3A5po1 & $\mathrm{F}$ & -978 to -963 & AGTACAGGGAGCACAG \\
\hline 3 A.5po8 & $\mathrm{R}$ & -917 to -932 & CACCTATTCATTCCTG \\
\hline $3 \mathrm{ASpO2}$ & $F$ & -698 to -684 & TGCTATCACCACACAC \\
\hline 3A5p07 & $R$ & -689 to -704 & GGTGATAGCAATAGAC \\
\hline $3 \mathrm{ASpO} 3$ & $F$ & -364 to -349 & AGGATGTGTAGGAGTC \\
\hline 3ASpOE & $\mathrm{R}$ & -417 to -434 & CCTCACACACATGTAACC \\
\hline 3А5pO4 & $\mathrm{F}$ & -176 to -161 & TAAGAACTCAGGTTCC \\
\hline $3 \mathrm{ASpOS}$ & $R$ & -178 to -194 & CAGAAACTGAAGTGGAG \\
\hline $3 A 52$ & $\mathbb{R}$ & +105 to +87 & ATCGCCACTTGCCTTCTTC \\
\hline
\end{tabular}

${ }^{\bar{P}} \mathrm{~F}=5^{\prime}$ to $3^{\prime}, \mathrm{R}=3^{\prime}$ to $5^{\prime \prime}$. Primer locations are based on CYP $3 A 5$ sequence data of Jounaidi et $a^{\prime} .(13)$.

$P C R$ detection assays for the $A^{-45} G$ and $T^{369} G$ mutations

All PCR assays were performed utilizing a 1 in 100 dilution of the original 3A51/3A52 PCR product as template, under the following conditions: one cycle of $95^{\circ} \mathrm{C}$ for $1 \mathrm{~min}$, $30 \mathrm{cycles}$ of $95^{\circ} \mathrm{C}$ for $1 \mathrm{~min}_{*} 55^{\circ} \mathrm{C}$ for $30 \mathrm{sec}, 72^{\circ} \mathrm{C}$ for $1 \mathrm{~min}$, and 1 final cycle of $72^{\circ} \mathrm{C}$ for $10 \mathrm{~min}$. All products were sequenced to confirm the identity of the product as CYP3A5. Oligonucleotide mismatched primers utilized in the assays were: $3 A 5 \mathrm{~F} 1$ ( $5^{\prime \prime}-$ GGGTCTGTCTGGCTGCGC-3'), 3A5F2 (5'-GGGGTCTGTCTCGCTGAGC-3'), and 3A5R1 (5'TTTATGTGCTGGAGAAGGACG-3'), where positions of mismatch(es) are underlined. For the $A^{-45} G$ mutation, a $P C R$ was performed using primer pair $3 A 5 F 2$ and $3 A 5 R 1$. Twenty $\mu l$ of PCR product was digested for a minimum of $3 \mathrm{~h}$ at $65^{\circ} \mathrm{C}$ using $15 \mathrm{U}$ of Tail, and the restriction fragments visualized by ethidium bromide staining after electrophoresis on a $1.5 \%$ agarose gel. For the $T^{-369} \mathrm{G}$ mutation a PCR was performed using primer pair $3 A 5 F 2$ and $3 A 5 R 1$ as described above. Twenty $\mu$ l of $P C R$ product was digested with $15 U$ of $A l u$ I for a minimum of $3 \mathrm{~h}$, and restriction fragments were separated by electrophoresis on a $12.5 \%$ ExcelGel on a Pharmacia Multiphor Electrophoresis system (Pharmacia, Amersham Pharmacia, Uppsala, 5weden). Fragments were visualized by silver staining in a Hoeffer Automatic Gel Stainer (Pharmacia). To detect the presence of mutations on the same chromosome, the PCR was performed using primers $3 \mathrm{~A} 5 \mathrm{~F} 1$ and $3 \mathrm{~A} 5 \mathrm{R} 1$. Twenty $\mu \mathrm{l}$ of $\mathrm{PCR}$ product was digested for a minimum of $3 \mathrm{~h}$ at $65^{\circ} \mathrm{C}$ using $15 \mathrm{U}$ of $\mathrm{Mvnl}$, and the resulting restriction fragments were visualized by ethidium bromide staining after electrophoresis on a $1.5 \%$ agarose gel.

\section{Relative quantification and comparison of CYP3A5 RNA}

Relative levels of CYP3A5 mRNA were determined by real time quantitative PCR using the $A B \mid 7700$ Sequence Detection System (Perkin Elmer). Optimal primers and probes for the detection of CYP3A5 were designed using the PrimerExpress program, and subsequently checked to ensure specificity for CYP3A5. Primers utilized for the 
quantification PCR were: forward 5:-AAGTGGCGATGGACCTCATC-3; reverse 5:GAGGAGCACCAGGCT GACA-3'. The TaqMan probe was labelled with the $5^{\prime}$ reporter dye 6-carboxy-fluorescein (FAM), and had the sequence 5'-CAAATTTGGCGG TGGAAACCTGGC-3'. Optimal primer/probe ratios and concentrations were determined and the experiments run according to standard protocols for the $A B \mid 7700$ Sequence Detection System. CYP3A5 mRNA expression for all samples was normalized against the expression of B-actin IMRNA. The threshold cycle (Ct) is the PCR cycle number where the $A B I 7700$ begins to detect an increase in fluorescent signal associated with the linear amplification of PCR product. The $C t$ value is dependent on the initial amount of template copy. Quantities of CYP3A5 in each sample were determined by averaging the $C t$ from three separate PCR reactions of each sample. Relative differences in Ct between samples were calculated by subtracting the Ct of each sample from the highest $\mathrm{Ct}$ within the samples (lowest expression). Since the amount of PCR product doubles with every cycle in the linear range of a $P C R$, the differences in $C t$ were converted into estimated differences of MRNA quantity between the samples by calculating 2 " where $\delta \mathrm{Ct}$ is the difference in cycle threshold between two samples. Negative controls were performed on each run to ensure that no signals were due to DNA contamination. Control samples consisted of RNA samples, which had been treated in exactly the same manner as for the quantitative $P C R$, but without the addition of the reverse transcriptase.

\section{Statistical analysis}

Statistical analysis was performed on the JMP Statistical program version 3.2 .2 (5AS Institute Inc., Cary, NC, USA). Metabolic ratio and CYP3A5 mRNA expression data (2. ${ }^{\text {Bct }}$ ) were checked to ensure that they conformed to a normal distribution. CYP3A5 MRNA expression data did not conform to a normal distribution and were log-transformed, after which the data were normally distributed. Metabolic ratios and expression levells were compared between groups using a t-test.

\section{Western blot analysis}

Forty $\mu g$ of micirosomal protein prepared from each liver were solubilized in an equal volume of Laemmli samplle buffer (BioRad, Eke, Belgium) by four cycles of freezing and boiling for $10 \mathrm{~min}$. Samples were loaded onto pre-cast $10 \%$ SDS-PAGE Ready Gels. (BioRad) and electrophoresed for 1 hour at $180 \mathrm{~V}$. Separated proteins were transferred onto Hybond-P membranes (Amersham, Amersham Pharmacia, Uppsala, Sweden) using a Trans-blot SD apparatus (BioRad). Membranes were blocked by an overnight incubation at $4^{\circ} \mathrm{C}$ in $1 \times$ PBS containing $5 \%(w: v)$ nonfat milk and $0.1 \%(v: v)$ Tween 20 . Membranes were incubated at ambient temperature for 1 hour in a 1:3000 dilution of specific human CYP3A5 antibody (Gentest Co, MA, USA) in 1X (PBS, $2.5 \%$ (W:v) nonfat milk, then rinsed four times in $1 \times$ PBS, $2.5 \%$ (w:v) nonfat milk, $0.1 \%$ ( $v: v$ ) Tween. Membranes were incubated at ambient temperature for $1 \mathrm{~h}$ in a 1:5000 dilution of Anti-Rabbit IgG peroxidase conjugate (Sigma, Bornem, Belgium) in 1.x PBS, $2.5 \%$ (w:W) 
nonfat milk, and rinsed as previously. The membranes were developed using the $\mathrm{ECL}$ Plus Western Blotting Detection System (Amersham) according to manufacturer's instructions, and visualized by autoradiography using Kodak X-Omat film (Sigma, Bornem, Belgium).

\section{Results}

\section{Midazolam phenotyping}

A panel of 39 human liver samples was phenotyped for CYP3A5 activity, using the metabolism of midazolam to its 1-OH metabolite as a marker of activity. Human liver microsomal samples containing CYP3A5 in addition to CYP3A4 exhibit a significantly greater ratio of 1-OHM to $4-\mathrm{OHM}$ compared to samples containing only CYP3A4. For microsomes containing both CYP3A4 and CYP3A5, 1-OHM/4-OHM ratios between 5 and 9 were observed. Samples containing only CYP3A4 showed 1-OHM/4-OHM ratios $<4$ (Gorski et al., 1994). Analysis of the CYP3A5 phenotypes in our data set showed a clear bimodal distribution, with six samples (15\%) having metabolic ratios greater than 5 , and the remaining samples having metabolic ratios between 1.5 and 3.5 (Fig. 1a). Of the 39 liver samples from which microsomes were prepared for metabolic analysis, sufficient tissue was available for full DNA, RNA and protein analysis for 26 , which included six samples lying in the higher metabolic ratio range. In addition to these 26 samples, microsomes for protein analysis were available for a further three samples, all of which had metabolic ratios of $<4$.

A)

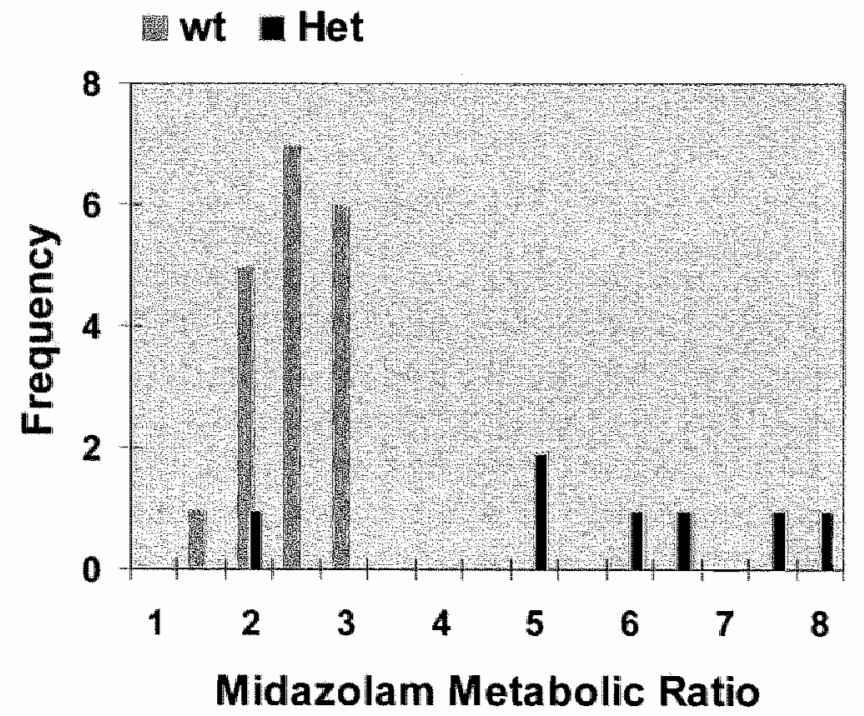




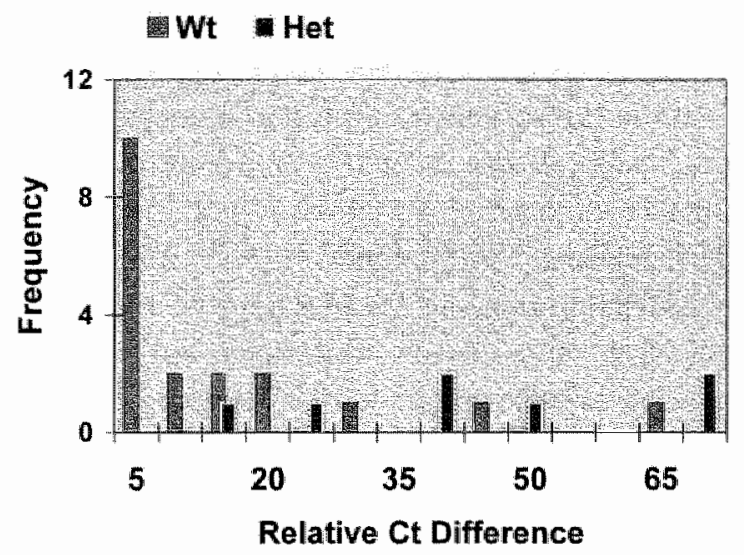

Figure 1. (a) Relationship between midazolam metabolic ratio and genotype for the linked $\mathrm{A}^{-15} \mathrm{G}$ and $\mathrm{T}^{-3 \mathrm{H}^{\circ}} \mathrm{G}$ mutations in the $5^{\prime}$ flanking region of the CYP3A5 gene. Midazolam metabolic ratio $=1-O H M / 4-O H M$. (b) Relationship between CYP3A5 mRNA expression and the linked $A^{-48} G$ and $T^{3 * 9} G$ linked mutations in the 5 flanking region of CYP3AS. Relative Ct difference = difference in threshold cycle between samples, as described in the Materials and methods section. wt $=$ samples with the wild type sequence in the 5 ' flanking region as previously published (13) Het = sampies heterozygous for the linked polymorphisms, $\mathrm{A}^{-45} \mathrm{G}$ and $\mathrm{T}^{369} \mathrm{G}$

\section{Analysis of CYP3A5 gene 5 ' flanking region}

The $5^{\prime}$ flanking region of CYP3A5 was PCR-amplified from genomic DNA of all 26 samples and sequenced in full, extending from -1238 to +105 (counting from the presumed transcription start site). Alignment showed that the region was well conserved. Only a small number of inter-individual variations were identified in addition to a few differences with the published sequence (Table 2). All nucleotide positions are based on the published sequence of Jounaidi et al. (13). All variants detected were heterozygous, and all samples heterozygous for the more frequent $A^{-45} \mathrm{C}$ mutation were also heterozygous for the $T^{-369} \mathrm{G}$ mutation, suggesting that the two mutations were linked. These two mutations fall within two separate putative regulatory elements, a basic transcription element (BTE: $A^{-45} G$, also called $S p 1$ site) and an activator protein-3 motif (AP-3: $T^{-369} \mathrm{G}$ ). None of the remaining variants fell within putative regulatory domains. $P C R$ assays were developed to confirm the presence of the $A^{-45} \mathrm{C}$ and $T^{* 369} \mathrm{C}$ mutations in each individual sample, and to ascertain if the two mutations were on the same, or on separate chromosomes. The PCR assay for the $A^{-45} G$ mutation was based on the creation of a recognition site for the restriction enzyme Tai-1 by utilizing an oligonucleotide mismatch primer (3A5R1). This primer introduces a Tain recognition site only when the wild type ' $\mathrm{A}$ ' nucleotide is present at position -45 . 
Digestion of the 369 bp PCR product with Tai-l yilelds fragments of 349 and 20 bp for the wild-type sequence, whilst the product remains undigested if the mutant " $G$ ' nucleotide is present (Fig. 2). Similarly, for the detection of the $T^{369} G$ mutation a second olligonucleotide mismatch primer was used (3A5F2). This primer introduces a recognition site for the restriction enzyme $A / U$-I when the wild-type ' $T$ ' nucleotide is present at position -369 , digesting the wild-type PCR product to yield fragments of 318,33 and $18 \mathrm{bp}$. This site is lost when the mutant ' $G$ nucleotide is present; Alu-il then yields digestion products of 336 and 33 bp (Fig. 3). To determine if the mutations were present on the same chromosome, a PCR assay was developed utilizing two oligonucleotide mismatch primers (3A5F1 and 3A5R1). Both primers introduce recognition sites for the restriction enzyme $M v n-1$ when the mutant nucleotides are present at positions -45 and -369 . If the mutations are present on different chromosomes then the original 369 bp product is digested to yield products of $349 / 350$ bp and 20/19 bp (inseparable by gel electrophoresis), whilst if present on the same chromosome the fragment is digested to yield products of 330 and $20 / 19 \mathrm{bp}$. In addition to confirming the individual genotypes of the samples as determined by sequencing, the two mutations were in all cases linked on the chromosome (data not shown).

Table 2. Variations found in the 5 flanking region of the $C Y P 3 A 5$ gene by sequencing.

\begin{tabular}{lll}
\hline Mutation & Nucleatide position* & Samples containing variant \\
\hline A to G & -45 & $10,11,16,20,32,37,38$ \\
G to $A$ & -160 & 36 \\
T to G & -369 & $10,11,16,20,32,37,38$ \\
T to C & -881 & 10,11 \\
G to T & -1212 & 12 \\
\hline
\end{tabular}

All mutations were detected in the heterozygous state only. Nucleotide numbering is based on the sequence of the CYP3A5 flanking sequence published by Jounaidi et al. (13). 
(a)
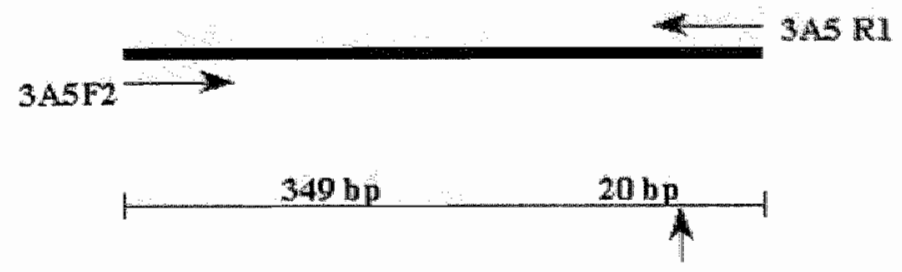

Tas I

(b)

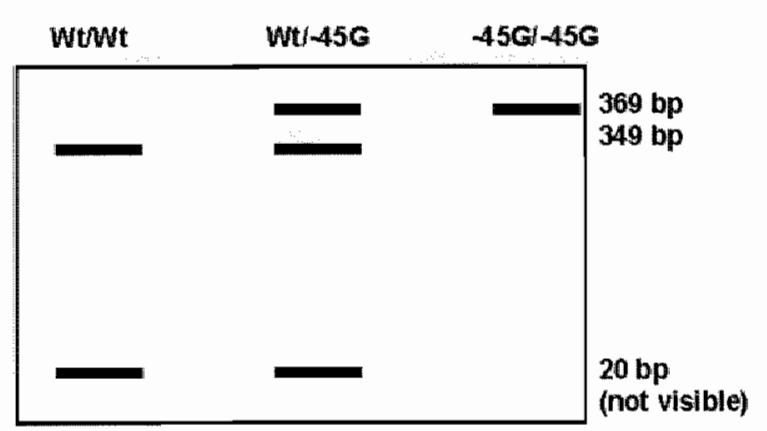

(c)

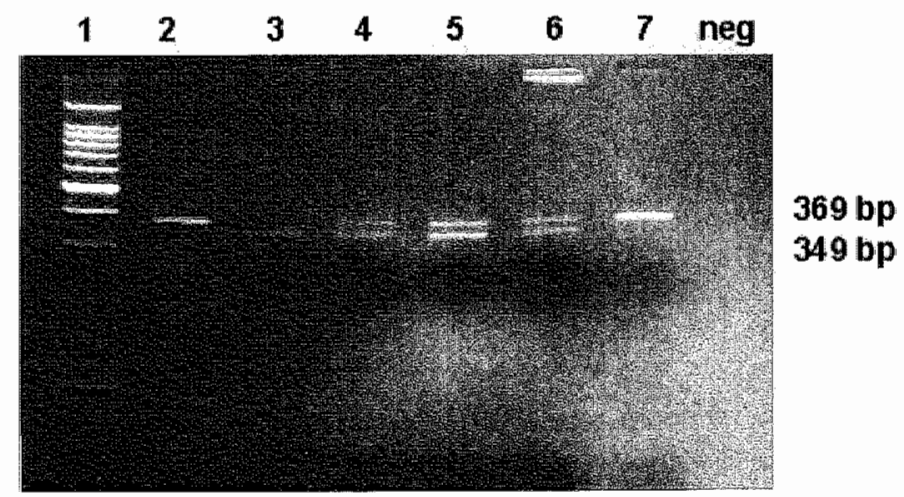

Figure 2. Polymerase chain reaction (PCR) assay for the detection of the $\mathrm{A}^{\cdot 45} \mathrm{G}$ mutation. (a) Diagram of relative position of primers, and of the recognition site for the restriction enzyme Tail, which is introduced into the PCR product utilizing mismatched primer 3ASR1 when the wild-type 'A' nucleotide is present at position -45 , and is lost when the mutant ' $G$ ' nucleotide is present. (b) Diagrammatical representation of expected restriction fragments for each possible genotype for the $A^{A 5} G$ mutation, i.e. homozygous wild type, heterozygous and homozygous mutant. (c) $1.5 \%$ agarose gel of Tail restriction digest af 3A5F2/3A5R1 PCR product for detection of the $A^{\text {As }} G$ mutation. Lane 1, 100 bp ladder; lanes 2 and 7, reference undigested PCR products; lane 3, sample homozygous for the wild-type 'A' nucleotide at position -45 ; lanes 4,5 and 6 , samples heterozygous for the $A^{-45} G$ mutation; last lane is a negative control. 
(a)
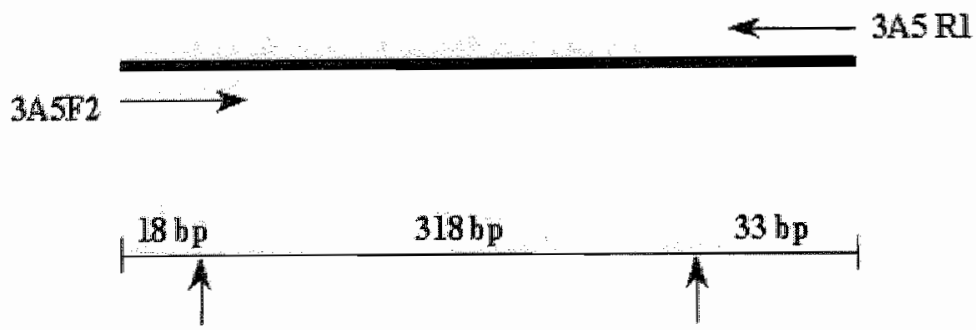

Alu I

Alrw I

(b)

Wt/Wt Wt/-369G $\quad-369 \mathrm{G} /-369 \mathrm{G}$

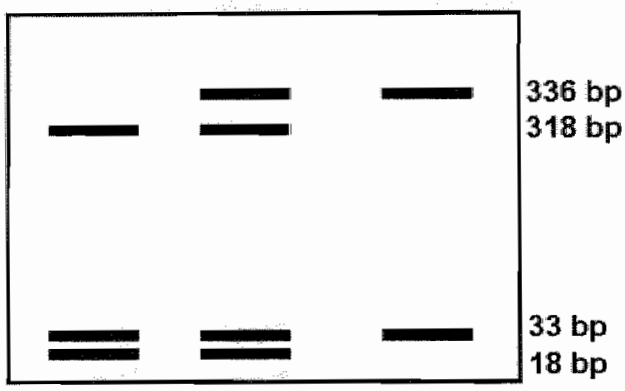

(c)

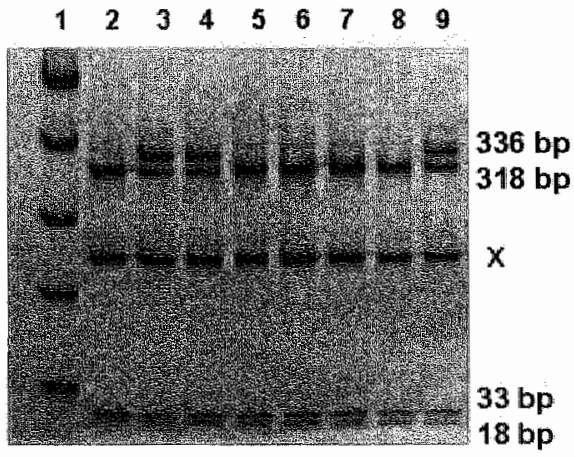

Figure 3. Polymerase chain reaction (PCR) assay for the detection of the $T^{-369} \mathrm{G}$ mutation. (a) Diagram of relative positions of primers, and of the recognition site for the restriction enzyme Alu-l. The forward recognition site is introduced into the PCR product utilizing mismatched primer $3 A 5 F 2$ when the wildtype ' $T$ " nucleotide is present at position -369 , and is lost when the mutant ' $C$ ' nucleotide is present. (b) Diagrammatical representation of expected restriction fragments for each possible genotype for the $\mathbb{T}$ ${ }^{369} \mathrm{G}$ mutation, i.e. homozygous wild type, heterozygous and homozygous mutant. (c) $12.5 \%$ polyacrylamide ExcelGel of Alu-l restriction digest of 3A5F2/3A5R1 PCR product for detection of the T. ${ }^{369} \mathrm{G}$ mutation. Lane 1,100 bp ladder; lanes $2,5,6,7$ and 8 , samples homozygous for the wild-type ' $T$ ' nucleotide at position -369 ; lanes 3,4 and 9 , samples heterozygous for the $T^{3.39} G$ mutation. Fragment $X$, additional digestion product resulting from reamplification of original template by primers 3A51/3A52. 
Relationship between CYP3A5 allelic variants, CYP3A5-mediated metabolism, CYP3A5 MRNA and protein expression

Samples were grouped according to genotype: 'wild-type" or "mutant' (containing the linked polymorphisms), and the 1-OHM/4-OHM metabolic ratios (mr) were compared between the groups (Fig. 4a). With the exception of one outlier (liver sample number $38, \mathrm{mr}=2.08$ ), all individuals carrying the linked mutations had metabolic ratios $>5.0$, whilst the wild-type group all possessed metabolic ratios of $<3.5$. The mean metabolic ratios for the mutant group were significantly higher than those from the wild-type group $(6.0 \pm 2.0$ versus $2.7 \pm 0.42$, mean $\pm S D ; P<0.001)$. Quantative PCR was used to ascertain if the mutations in the 5 ' flanking region were affecting gene expression. Whilst mRNA levels showed greater variation than the metabolic ratio data, a degree of bimodality was observed (Fig. 4b). The mutant group had CYP3A5 MRNA skewed towards the higher end of the expression range, showing significantly higher average levels of CYP3A5 mRNA than the wild-type group (mean $\ln C t=4.03,5 D=$ 0.97, against mean In $C t=2.06, S D=1.2, P<0.006$ ) (Fig. 4 b). In this case the outllier (presenting with the mutant genotype, but wild-type metabolic ratio) also fell within the lower range of expressilon ( $I n C t=2.9)$. The level of CYP3A5 protein expression levels was estimated for 29 liver samples by Western blot analysis using a CYP3A5specific antibody. A single band of $52 \mathrm{kDa}$ corresponding to CYP3A5 was clearly apparent in some samples. With the exception of the single outlier with the high expression genotype (mutant) and low metabolic ratio phenotype (wild-type), all samples which possessed the high expression genotype, a high metabolic ratio and high CYP3A5 mRINA expression level clearly show high levels of CYP3A5 protein expression when compared to those samples with the low expression genotype and phenotype (Fig. 5). The single outlier with the high expression genotype, but low expression phenotype showed levels of CYP3A5 expression similar to those in the low expression genotype group. Longer exposure of the Western blot indicated that a very low level of CYP3A5 expression was apparent in most samples (data not shown).

\section{Population allele frequencies}

Three hundred normal healthy Caucasian volunteers for phase I clinical trials were screened for the presence of the CYP3A5 gene mutations. The variant allele frequency was 0.092 (55 out of 600) with the wild-type allele frequency being 0.908 (545/600). The homozygous wild-type frequency was 0.820 (246/300), the heterozygous frequency was $0.177(53 / 300)$ and 1 individual was homozygous for the variant sequence (frequency 0.003$)$. These values are in Hardy-Weinberg equilibrium $(P=$ 0.2921. 
(a)

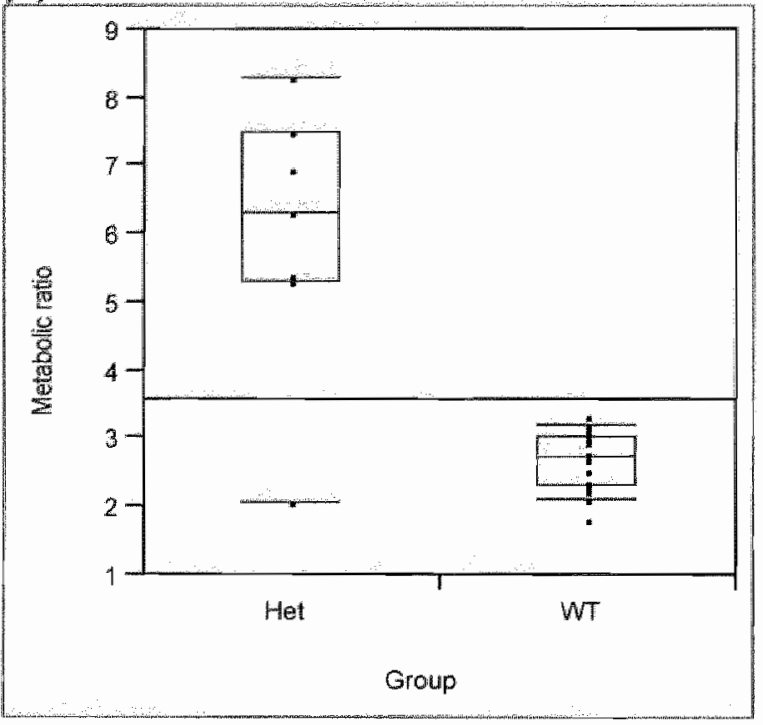

(b)

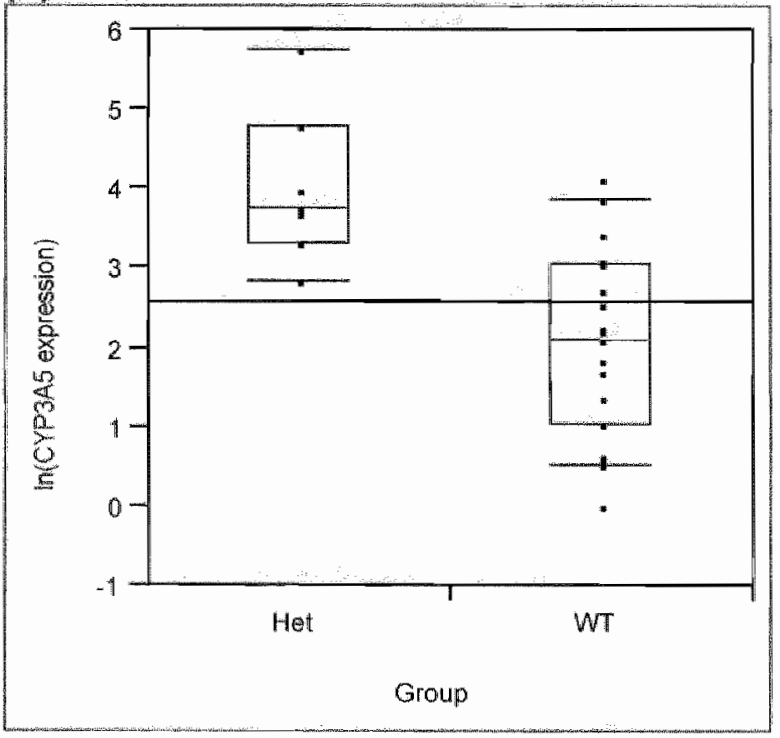

Figure 4. Comparison of $\mathrm{OH}-$ midazolam metabolic ratios and $\mathrm{CY} 3 \mathrm{~A}_{5}$, expression in samples with and without the linked mutations. (a) Comparison of 1-OHM/4-OHM metabolic ratios between samples with the linked mutations (HET group) and those wild-type for the mutations at positions -45 and -369 (WT group). Means and quartiles are shown for each group, as is overall mean for the combined groups. (central line). (b) Comparison of CYP3A5 expression log transformed) between samples with the linked mutations (HET group) and those wild type for the mutations at positions -45 and -369 (WT group). Means and quartiles are shown for each group, as is overall mean for the combined groups (central line). 


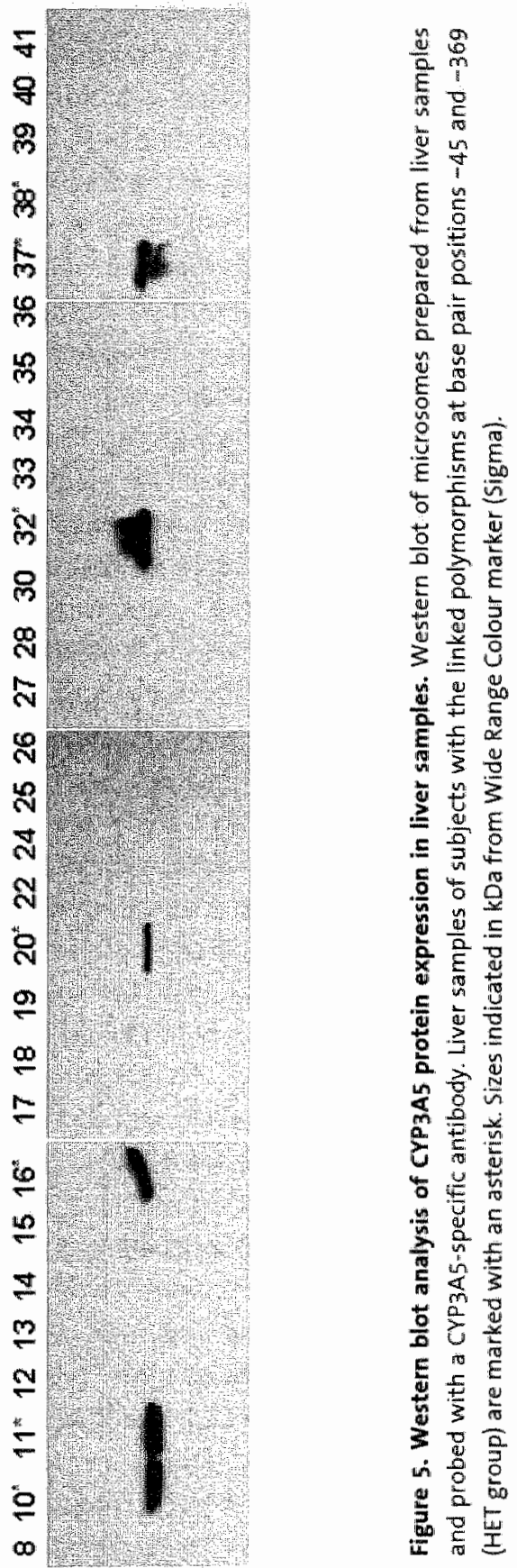

8 年 


\section{Discussion}

CYPIA subfamily members are the predominant CYP proteins expressed in the liver and play a major role in the metabolism of an ever-expanding list of therapeutic compounds and environmental toxins $(2,19,20)$. Inter-individual variability in activity of the subfamily members represents a major determinant of individual drug response/toxicity and may also play a role in susceptibility to environmental toxins. In this respect, the ability to predict metabolism levels, based on a simple diagnostic test, would allow not only safer use of drugs metabolised by the specific family member, but also facilitate disease association studies. To date, the genetic basis for any CYP3A variation has never been proven. In the present study, we describe the major genetic determinant of increased CYP3A5 activity, resulting from two linked polymorphisms in the $5^{\prime}$ flanking region of the gene, which result in increased levels of gene transcription. The $5^{\prime}$ flanking sequences of CYP3A5 obtained in this study show high levels of homology to those published by Jounaidi et al. (13), and show little interindividual variation. Interestingly, Jounaidi et al. (13) sequenced two human genomic clones, one of which contained the two linked mutations described in detail in this report. This would suggest that one clone was derived from an individual in the low expression group, and one from an individual in the high expression/metabolism group.

Previous studies have suggested that CYP3A5 is expressed in only 10-30\% of livers (79), whilst another study has stated that some expression is constitutive in all samples (10). The present study supports the findings that some CYP3A5 expression is constitutive, with some metabolic activity and mRNA being detected in all livers studied, although CYP3A5 protein was not convincingly demonstrated in all samples using the procedures described. We detected enhanced RNA and protein expression in $23 \%$ of the samples for which tissue was available (six out of 26 ), which is similar to the fraction of the population showing liver expression in previous studies. This supports the findings of Boobis et al. (10), that some low levell of expression is constitutive in all liver samples, although this can only be detected convincingly using more sensitive detection techniques (such as PCR), and not by Western or Northern blot analysis. Whilst both polymorphisms detected lie within putative transcriptional regulatory elements, we suspect that the variant within the BTE ( $S p 1$ site) is more likely to be responsible for altered expression since it has been reported that a BTE flanking the TATA box accounts for the constitutive expression of CYP1A1, and a similar region has been found in severall other CYP genes including CYP2B1, CYP2B2, CYP2E1 (21) CYP3A4 (12) and CYP3A7 (11). In the case of the CYP3A4 gene, this element has been shown to bind nuclear extracts (12) and a basic transcription element binding factor (BTEB) has been shown to interact with the $5^{\prime}$ regulatory region of the CYP $3 A 7$ gene (11), indicating a role of this region in the general control of cytochrome $\mathrm{P} 450$ expression. 
The exact mechanism of upregulation of CYP3A5 expression in the allelic variant described here remains to be determined, although the presence of one of the mutations within the $B T E$, and the relevance of this element for the expression of other P450s indicates a possible mechanistic link. Using methylation interference foot printing, it has been shown that all guanine residues within the BTE, and other guanine residues in the vicinity, interacted with the transcriptional factors BTEB (BTEbinding protein) and Sp1 (22). Given that the mutation within the BTE described in this paper alters an adenine residue to a guanine residue, increasing the percentage identity to the Sp1 binding site from $80 \%$ to $90 \%$, this could facilitate binding of transcription factors to the variant form of the BTE. Whilst preliminary data indicate that this is in fact the biochemical mechanism for the altered expression of CYP3A5 described here (unpublished observations), at this stage we cannot definitively rule out linkage disequilibrium with another mutation, which may be affecting gene expression or protein/RNA stability.

Although there is considerable overlap in the range of CYP3A5 MRNA levels seen in the homozygous and heterozygous group, the distribution of metabolic ratios is clearly bimodal, as is the amount of CYP3A5 protein (even allowing for the semi-quantitative nature of Western blots). We cannot exclude the presence of other polymorphisms that may affect the translation efficiency or protein stability of CYP3A5. Given the better correlation between DNA polymorphism and protein level and the notorious lability of RNA, the simpler explanation is that differential RNA degradation or yield (due to differences in sample handling) has blurred the distinction between high and low expressors. Whatever the explanation for the discrepancy at the MRNA level, it does not in any way diminish the predictive value of the DNA polymorphism described. There is, however, one individual whose genotype (heterozygous mutant) is not predictive of his metabolic phenatype (low expression). The fact that CYP3A5 protein as well as $m$ RNA levels were low in this outlier indicates that the explanation must be sought at the transcriptional level (e.g. in transcription factors controlling CYP3A5 expression). An AUG element in the $5^{\prime}$-untranslated region of the BTEB gene has been shown to be partly responsible for cell specific translational control of BTEB (23). Mutations within this region were shown to affect BTEB translation. Therefore, whilst the outlier in our study has a high expression genotype for CYP3A5 expression, this individual may have a 'low' expression phenotype for BTEB. Additionally, it is possible that a mechanism similar to that responsible for inducing CYP1A1 expression may also affect CYP3A5 expression. In addition to the BTE, CYP $1 A 1$ expression is mediated by a xenobiotic responsive element (XRE). In this case, inducers enhance expression by binding to a cytosolic receptor (Ah receptor), which is translocated into the nucleus (possibly in association with an accessory protein coded for at the Arnt gene), where it binds the XRE (24,25). Although variations in these and other transcription factors could further modulate CYP3A5 expression, this does not detract 
from the fact that the polymorphism described here seems to be the major determinant of CYP3A5 expression, at least in liver.

Despite the relatively small number of samples available for analysis in the present study, strong associations have been found between the two linked polymorphisms on the one hand and CYP3A5 MRNA, protein and activity levels in the liver on the other hand. The unravelling of genetic mechanisms for the polymorphic metabolism by CYP3A5 will have important consequences in the field of pharmacogenetics. The ability to predict metabolism by genotyping will greatly facilitate disease association studies and may also help to explain adverse reactions or poor response to therapeutics that are metabolised by this cytochrome $\mathrm{P} 450$ isoform. It will allso help in delimeating which factors affecting CYP3A5 activity are genetic and which are environmental; for both, further work will be required to understand fully the complex variation in expression observed with this enzyme.

\section{Note added after publication}

Shortly after publication of this article, another research group discovered that upstream of the CYP3A5 gene a smaller pseudogene, called CYP3A5P1, was present (Finta et al., Gene 2000; 260: 13-23). The CYP3A5P1 consists of an exon 1, identical to exon 1 of the CYP3A5 gene, and a novel exon 2 and 13 . Furthermore, sequence identity in the $5^{\prime}$ untranslated promoter region between the two genes was only $89 \%$. Subsequently, Kuehl et al, discovered that the two CYP3A5 polymorphisms described in our article above, were in fact located in this pseudogene, and could therefore not be functionally responsible for the polymorphic CYP3A5 expression (Kuehl et al., Nat Genet 2001; 27: 383-391). They detected complete linkage disequilibrium of the polymorphisms with another polymorphism located in intron 3 of the CYP3A5 gene, named CYP3A5*3. which causes an alternatively spliced mRNA and a truncated protein. Nevertheless, also in their study as well as in subsequent studies by several other groups, the correlation of the CYP3A5P1 genotype with CYP3A5 expression levels in the liver has proven to be highly predictive (Chou et al., Drug Metab Dispos 2001; 29: 1205-1209, Zhu et al., Acta Pharmacol sin 2002; 23: 567-571).

\section{Ackowledgements}

We would like to thank Jeroen Aerssens from the Molecular Genetics Department of the Janssen Research Foundation for help with statistical analysis and Evert Hoefnagel from the Biotechnology Department of the Janssen Research Foundation for help with the Western blot experiments. 


\section{References}

1. Cholerton S, Daley AK, Idle JR. The role of individual human cytochromes 8450 in drug metabolism and dinical response. Trends Pharmacol Sci 1992; 13:434-439.

2. Shimada $T$, Guengerich FP. Evidence for cytochrome P-45ONF, the nifedipine oxidase, being the principal enzyme involved in the bioactivation of aflatoxins in human liver. Proc Natl ACad Sci USA $1989 ; 86: 462-465$.

3. Komori M, Nishio K, Kitada M, Shiramatsu K, Muroya K, Soma M, Nagashima K, Kamataki T, Fetus specific expression of a form of cytochrome $P-450$ in human livers. Biochemistry 1990; 29: 44304433.

4. Hoyo-Vadillo C, Castenada-Hernandez G, Herrera JE, Vidal-Garate J, Moreno-Ramos A, Chavez F, Hong E. Pharmacokinetics of inifedipine slow release tablets in Mexican patients: further evidence for an oxidative polymorphism. J Clin Pharmacol 1989; 29:816-820.

5. Renwick AG, Robertson DRC, Macklin B, Challenor V, Waller DG, George CF. The Pharmacokinetics of oral nifedipine - a population study. Br J Clin Pharmacol 1988; 25: 701-708.

6. Schellens JHM, Soons PA, Breimer DD. Lack of bimodality in nifedipine plasma kinetics in a large population of healthy subjects. Biochem Pharmacol 1988; 37: 2507-2510.

7. Aoyama T, Yamano S, Waxman DJ, Lapenson DP, Meyer UA, Fischer $V$, Tyndale R, Inaba T, Kalow W, Gelboin HV. Cytochrome P450 hPCN3, a novel cytochrome P450llA gene product that is differentially expressed in adult human liver. I Biol Chem 1989; 264: 1038:8-10395.

8. Wrighton SA, Brian WR, Sari MA, "wasaki M, Guengerich FP, Raucy $L$, Malowa DT, Vandenbranden M. Studies in the expression and metabolic capabilities of human liver cytochrome P450lliA5 (HLp3). Mol Pharmacol 1990; 38: 207-213.

9. Schuetz J, Beach P, Guzelian PS. Selective expression of cytochrome P450 CYP3A mRNAs in embryonic and adult human liver. Pharmacagenetics 1994; 4: 11-20.

10. Boobis AR, Edwards RJ, Adams DA, Davies DS. Dissecting the function of cytochrome P450. Br J Clim Pharmacal 1996; 42:81-89.

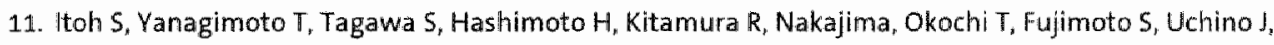
Kamataki $T$. Cenomic organisation of human fetal specific P-450llA7 (cytochrome F-450HFLa)related gene(s) and interaction of transcriptional regulatory factor with its DNA element in the $5^{\prime}$ flanking region. Biochem Biophys Acto 1992; 1130: 133-138.

12. Hashimoto $H$. Toide $K$, Kitamura $R$, Fujita $M$, Tagawa $S$, Itoh $S$, Karnataki $T$. Gene structure of CYP3A4, an aduit specific form of cytochrome P450 in human livers and its transcriptional regulation. Eur J Biochem 1993; 218:585 595

13. Jounaidi $Y$, Guzelian PS, Maurel $P$, Vilarem MJ. Sequence of the 5 -flanking region of CYP3A5: comparative analysis with CYP3A4 and CYP3A7. Biochem Biophys Res Commun 1994: 205: 17411747.

14. Barwick Jl, Quattrochi LC, Mills AS, Poternza C, Tukey RH, Guzelian PS. Trans-species gene transfer for analysis of glucocorticoid-inducible transcriptional activation of transiently expressed human CYP3A4 and rabbit CYP3A6 in primary cultures of adult rat and rabbit hepatocytes. Mol Pharmacol 1996; 50: 10-16.

15. Gorski IC, Hall SD, Jones DR, VandenBranden M, Wrighton SA. Regioselective biotransformation of midazolam by members of the human cytochrome P450 (CYP3A) subfarnily. Biochem Pharmacol $1994 ; 47: 1643-1653$.

16. Haehner $B D$, Gorski JC, Vandembranden $M$, Wrighton $S A$, Janardan $5 K$, Watkins $P B_{\text {. Hall SD. Bimodal }}$ distribution of renal cytochrome P450 3 A activity in humans. Mol Phormacol 1996; 50: 52-59.

17. Lavrijsen K, Van Houdt J. Thijs D, Meuldermans $W$, Heykants I. Induction potential of antifungals containing an imidazole or triazole moiety. Miconazole and ketoconazole, but not itraconazole are 
able to induce hepatic drug metabolising enzymes of male rats at high doses. Biochem Pharmacol 1986; $35: 1867+1878$.

18. Miller GL. Protein determination for large numbers of samples. Anal Chem 1959:31: 964.

19. Guengerich FP. Characterisation of human cytochrome P450 enzymes. FASEB I 1992; 6: 7:45-748.

20. Watkins $\mathrm{PB}$. Drug metabolism by cytochromes $\mathrm{P} 450$ in the liver and small bowel. Gastroenterol Clin North Am 1992: $21: 511-526$.

21. Fujï-Kuriyama $Y$, Imataka $H$, Sogawa K, Yasumoto KI, Kikuchi $Y$, Regulation of CYP1A1 expression. FASEE J 1992; 6: 706-710.

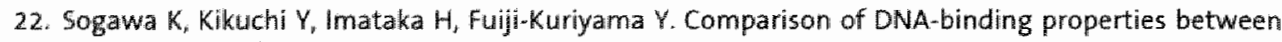
BTEB and $5 P$ 1. Biochemistry 1993; 114:605-609.

23. Imataka $H$, Nakayama $K$, Yasumoto $H$, Mizuno A, Fujii-Kuriyama $Y$, Hayami M. Cell-specific transiational control of transcription factor BTEB expression. The role of an upstream AUG in the 5 " untranslated region. J Biol Chem 1994; 269: 20668-20673.

24. Nebert DW. The Ah locus: genetic differences in toxicity, cancer, mutation and birth defects. Crit Rev Toxicol 1989: 20: $153-174$.

25. Hoffman EC, Reyes $H$, Chu FF, Sander $F$, Conley $L H$, Brooks BA, Hankinson $O$. Cloning of a factor required for activity of the $A$ (dioxin) receptor. Science 1991; 252:954-958. 


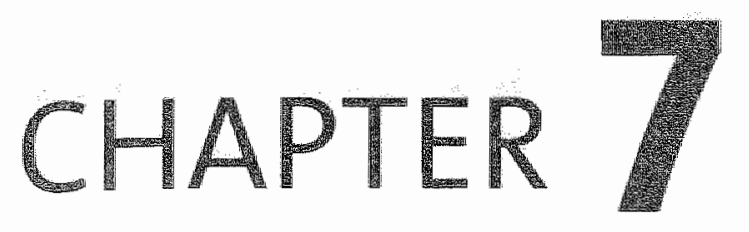

\section{Genetic susceptibility to acquired long QT syndrome: the impact of congenital long QT genes and drug metabolising enzyme genes}

Aimée Paulussen ${ }^{1,4}$, Ron Gillissen ${ }^{1}$, Jeroen Aerssens ${ }^{1}$, Pieter Doevendans ${ }^{3}$, Peter Verhasselt", Bert Smeets", Eric 5chulze-Bahr ${ }^{5}$, Wilhellm Haverkamp ${ }^{5}$, Günther Breithardt ${ }^{5}$, Nadine Cohen ${ }^{1}$, Martin Armstrong ${ }^{1}$.

Departments of "Pharmacogenomics and 'Cenomic Technologies, Janssen Research Foundation, Beerse, Belgium; "Department of Cardiology, Academic Hospital, Maastricht, The Netherlands; "Department of Genetics and Cell Biology, Cardiovascular Research Institute Masstricht (CARIM), Maastriclit, The Netherlands; "Hospital of the Westfalian Wilhelms-University, Department of Cardiology and Angilology and Institute for Arterlosclerosis Research at the University of Muenster, Germany.

Manuscript submitted

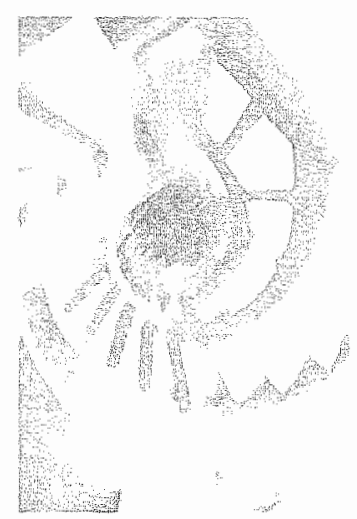




\section{Abstract}

Acquired Long QT Syndrome (aLOTS) is a disorder that predisposes to ventriculan arrhythmias, typically of the Torsade de Pointes (TdP) type, and sudden death. One of the major causes of aLOTS is drug administration, with concurrent drug therapy indicated in many reports. "Forme fruste" cases of congenital LOTS (cLOTS) and variations in drug concentrations have been implicated as risk factors. In this study we evaluated the role of genetic predisposition to aLoTS by mutational screening of cLOTS genes and mutation analysis of known variations in drug metabolising enzyme genes. Thirty-two unrelated aLoTS cases were recruited, all of whom had confirmed $T d P$ resulting from drug administration. The entire coding regions of all known cLOTS genes (KCNH2, KCNQ1, SCN5A, KCNE1, and KCNE2) were screened for mutations. Mutations that have previously been reported to be functionally relevant accounted for 2 out of 32 of aLQTS cases. Eleven novel polymorphisms were detected in the cL.QTS genes. In addition, known polymorphisms in the drug metabolising enzyme genes $C Y P 2 D 6, C Y P 3 A 4$ and $C Y P 3 A 5 P 1$ were assayed. Of note, all patients on drugs that undergo CYP3A mediated metabolism carried the genotype predictive of low CYP3A5 expression, while none of the aLQTS subjects with the genotype predictive of high CYP3A5 activity were treated with a drug that is metabolised via CYP3A.

in conclusion, exonic mutations in the cLOTS genes explain only a limited proportion of aLQTS cases. We hypothesise that inter-individual variation in CYP3A5 expression may also affect the risk for aLoTS when prescribing (combinations of) drugs metabolised by CYP3A.

\section{Introduction}

Congenital long QT syndrome (CLOTS) is a rare, yet in some cases lethal, cardiac disease caused by malfunctioning of ion channels in cardiac cells (1). The syndrome is characterised by symptoms such as syncope and seizures and typically manifests itself with specific, potentially fatal, ventricular arrhythmias of the Torsade de Pointes (TdP) type. The molecular basis of CLQTS is becoming increasingly understood and mutations in 5 genes have been identified as causative for the disease in cLoTS families. Mutations in the potassium ion channel genes KCNH2 (HERG, LQT2) and KCNE2 (LQT6) affect the rapid component of the delayed rectifier $i_{k r}$ whilst mutations in the genes KCNQ1 (KVLOT1, LQT1) and KCNE1 (LQT5) affect the slow component of the delayed rectifier $I_{\mathrm{Ss}}$. Mutations in the sodium ion channel gene SCN5A (LOT3) affect the current $l_{\text {Na }}$ responsible for the depolarisation of the cardiac action potential $(2,3)$. Linkage analysis suggests that at least one further susceptibility gene is present at locus 4925-27 (LOT4) (4). In total, over 200 different disease-causing mutations in these genes have been identified in CLOTS families. Only a minority of these mutations has been electrophysiologically characterised; for most other mutations there is a 
good deal of genetic evidence that the identified mutations are the causative basis of the disease in the respective families.

Acquired long QT syndrome (aLQTS) presents with symptoms that are very similar to those for CLQTS, although the conditions, risk factors and triggers for their occurrence differ. The major cause of aLQTS is through drug administration, with drug overdose and concomitant medications indicated in many case reports. Drug induced QT prolongation and $\mathrm{TdP}$ are rare side effects and as such may not become apparent during the drug development process. The idiosyncratic manner in which only some individuals develop QT prolongation and TdP in response to similar doses of the same drugs is not fully understood. Drugs from many different classes with diverse chemical structures have been reported to be capable of prolonging the QT interval and causing TdP (5-7). Many of the drugs that have been proven to cause aLOTS have been shown to interact directly with and block the cardiac ion channels coded for by the cLQTS genes (see also http://www.qtdrugs.org).

It has been proposed that some cases of aLQTS represent instances of "forme fruste" of CLOTS, i.e. these patients carry normal or borderline QT intervals resulting from "mild" mutations in one of the congenital LQTS genes and are, under normal circumstances, asymptomatic. On challenge with certain drugs, however, these individuals appear to be more susceptible to cardiac ion channel blockade and $\mathrm{QT}$ prolongation. In this respect, variations in the KCNE2 and KCNQ1 genes have been identified previously as causative in aLQTS case reports $(8,9)$. This suggests that some aLOTS patients may be identifiable by mutational screening of CLOTS genes, and may thus be preventable. Whilst some CLOTS gene variants have been reported in the literature for individual aLOTS cases, the importance of "forme fruste" as a risk factor for TdP in a larger population of aLQTS cases remains to be demonstrated.

Overdose with a trigger drug and concurrent medication(s) have been indicated in many cases of aLQTS, suggesting that variations in the concentration of trigger drugs at the cardiac myocyte level is an important determinant of increased susceptibility to aLOTS. The circulating plasma concentration of a drug depends largely on the activity of the enzymes responsible for its metabolism. Together, the cytochrome P450 (CYP) enzymes CYP2D6 and CYP3A are responsible for the hepatic metabolism of the majority of all clinically used drugs (10). CYP2D6 is involved in the metabolism of more than 50 drugs. The CYP3A subfamily consists of three members that show high levels of homology: CYP3A4, CYP3A5, and CYP3A7, the latter being expressed in foetal and newborn liver only. CYP3A4 is often regarded as the major isoform responsible for the drug metabolism, but CYP3A5 has wide overlapping substrate specificity and might therefore also be important. Inter-individual differences in CYP activity are partially due to variations within the genes coding for the enzymes. The genetic basis of interindividual variations in drug metabolism is becoming increasingly understood for the CYP enzymes, and has shown relevance in influencing the pharmacokinetic profile of a 
drug. In this respect it is now possible to reliably predict over $95 \%$ of CYP2D6 poot metabolisers on the basis of routine genotyping, whilst we have also recently described two linked variations in the CYP3A5P1 gene that predict CYP3A5 expression and activity in vitro. Genetic variations have also been described in CYP3A4, although the functional consequences of these remain to be determined.

Here we investigate the role of genetic variation in the cLOTS genes and the impact of inter-individual variations in CYP genes as risk factors in 32 patients presenting with acquired $\mathrm{QT}$ prolongation and TdP as a consequence of drug administration.

\section{Subjects and methods}

\section{Patient and control subjects}

A total of thirty-two unrelated aLOTS subjects were recruited from three centres: the Academic Hospital Maastricht, The Netherlands $(n=11)$, the Westfalian WilhelmsUniversity Muenster, Germany $(n=20)$ and the Ottawa Hospital, Ontario, Canada $(n=1)$. All subjects experienced TAP as a result of drug administration. Details of individual subjects are presented in Table 1. TdP was defined as either non-sustained or sustained ventricular tachycardia showing phasic variation in the electrical polarity of the QRS complex and a "short-long-short" initiating sequence (11). In addition, all subjects showed a QTC prolongation (OTC > $440 \mathrm{msec}^{1 / 2}$ ) and changes in the configuration of the T(-U) wave (i.e., biphasic $T$ waves, beat-to-beat changes in T wave morphology, post-extrasystolic $T$ wave abnormalities (i.e., an increased postextrasystolic T-U wave amplitude) or emergence of new large $U$ waves) compared to an electrocardiogram recorded prior to drug exposure implicated in the generation of TdP. In case no baseline and on-drug ECGs could be retrieved from the referring physicians, subjects were classified only as demonstrating TdP if the qualifying ECG showed the typical TdP pattern. Electrocardiographic intervals were measured from tracings as close as possible to the event. The Or interval was measured from electrocardiogram lead $\|$ or the available rhythm strip. For rate-correction, the Bazett equation was applied.

Genotype/allele frequencies of variations in drug metabolising enzyme genes identified in the group of aLOTS subjects were compared with a control group of 300 anonymous healthy Caucasians. This group of control subjects was recruited from a large pool of clinical trial volunteers available at the Janssen Research Foundation (Belgium). For genotype/allele frequency comparisons in the cLOTS genes, a randomly selected subset of 32 individuals of the control group was used. Because demographic and clinical information was not available for the anonymised control group, matching with the aLOTS group was impossible. Full IRB approval and subject informed consent was obtained from all participants. 
Mutational screening of long QT genes

Mutational screening of all individual exons and intron/exon boundaries of $\mathrm{KCNH}$, KCNO1, SCN5A, KCNE1 and KCNE2 was performed by PCR amplification and direct sequencing on an ABI-Prism-3700 sequencer (PE-Biosystems, Nieuwerkerk a/d IIssel, The Netherlands). Oligonucleotides (Eurogentec, Seraing, Belgium) used for amplification have been previously described by ltoh et al. (KCNH2) (12), Splawski et al. (KCNO1, KCNH2 and KCNE1) (13), Wang et al. (SCNSA) (14), and Abbott et al. (KCNE2) (15). All sequences were aligned with their respective wild type gene sequences reported in GenBank under accession numbers U04270 (KCNH2), AF071002 (KCNE1), NM_005136 (KCNE2), AF000571 (KCNQ1) and NM_000335 (SCN5A), using the Sequencher software package (Gene Codes Corporation, Ann Arbor, MI). Frequencies of known and novel genetic variations were determined in the panels of 32 aLQTS subjects and 32 control subjects.

\section{CYP450 genotyping}

Oligonucleotides were ordered from Eurogentec (Seraing, Belgium), restriction enzymes from New England Biolabs (Hertfords hire, UK), GeneAmp PCR buffer $\|, \mathrm{MgCl}_{2}$ and AmpliTaq Gold from PE-Biosystems (Nieuwerkerk a/d IJssel, The Netherlands), and dNTPs from Amersham-Pharmaciam-Biotech (Roosendaal, The Netherlands).

\section{CYP2D6}

Cenotyping was performed for the inactivating gene variations CYP2D6*3, *4, $5, * 6$. The ${ }^{*} 5$ inactivating gene deletion assay was performed as described previous ly (16). PCR-RFLP assays were developed for the * 3 , "4, and *6 variations and PCR conditions were 10 min $95^{\circ} \mathrm{C}$, followed by 35 cycles of $95^{\circ} \mathrm{C}, 45 \sec , 58^{\circ} \mathrm{C}\left({ }^{*} 4 /^{*} 6\right)$ or $55^{\circ} \mathrm{C}\left({ }^{*} 3\right), 45$ sec and $72^{\circ} \mathrm{C}, 45 \mathrm{sec}$. The reaction was terminated with a final extension step at $72^{\circ} \mathrm{C}$ for $10 \mathrm{~min}$. The PCR mix consisted of $1 \times$ GeneAmp PCR buffer II, $200 \mathrm{nM}$ dNTPS, 1.5 $\mathrm{mM} \mathrm{MgCl} 2,250 \mathrm{nM}$ of each primer, 0.75 units of Amplitaq Gold polymerase and approximately $100 \mathrm{ng}$ of genomic DNA, in a volume of $30 \mu \mathrm{ll}$. For the CYP2D6*3 variation 10\% DMSO was added to this PCR mix. The " 4 and " 6 variations were analysed in the same RFLP assay, using PCR primers 5"-GCA-AGA-AGT-CGC-TGG-AGC. CG-3" (forward, mismatch underlined) and 5'-CTC-CGT-CTC-TCG-CTC-CGC-AC-3' (reverse). The resulting $P C R$ product ( $342 \mathrm{bp}$ ) was digested with $\mathrm{SCr}$ FI at $37^{\circ} \mathrm{C}$ for 3 hours, and fragments were separated on $12.5 \%$ polyacrylamide. For the * 3 variation, PCR primers 5'GCC-TCG-GAA-GAG-CAG-GAT-TTG-CA-3' (forward) and 5'-GGC-TGG. GTC-CCA-GGT-CAT-AC-3' (reverse, mismatch underlined) were used. The PCR product (495 bp) was digested with Bsa Al $\left(37^{\circ} \mathrm{C}, 3\right.$ hours), and analysed on $12.5 \%$ polyacrylamide.

\section{CYP3A4}

PCR assays were developed for the detection of CYP3A4 allelic variants CYP3A4*2B, "2, 3. PCR conditions were $95^{\circ} \mathrm{C} 10 \mathrm{~min}$, followed by $35 \mathrm{cycles}$ of $95^{\circ} \mathrm{C}, 45 \mathrm{sec}, 59^{\circ} \mathrm{C}\left(\right.$ (* $\left.^{\circ} \mathrm{B}\right)$ 
or $58^{\circ} \mathrm{C}\left({ }^{*} 2\right)$ or $56^{\circ} \mathrm{C}\left({ }^{*} 3\right), 45 \mathrm{sec}$ and $72^{\circ} \mathrm{C}, 45 \mathrm{sec}$. The PCR was terminated with a final extension step of $72^{\circ} \mathrm{C}$ for $10 \mathrm{~min}$. PCR mixes were as described for CYP2D6 genotyping. For the CYP3A4*1B PCR, 10\% DMSO was added to the mix. Primers used for the CYP3A4"1 1 B PCR were 5'-AGG-CAC-ACT-CCA-GGC-ATA-GG-3' (forward) and 5'. TTC-TCC-ACC-TTG-GAA-GTT-GGC-3' (reverse).

Table 1.Clinical information of the examined aLors cases.

\begin{tabular}{|c|c|c|c|c|c|}
\hline $\begin{array}{l}\text { Calse } \\
\text { reference } \\
\text { number }\end{array}$ & $\begin{array}{l}\text { Age } \\
\text { (years) }\end{array}$ & Sex & $\begin{array}{l}\text { QTC at rest } \\
\left(\operatorname{msec}^{1 / 2}\right)\end{array}$ & $\begin{array}{l}\text { QTcafter drug } \\
\text { treatment } \\
(\text { imsec }\end{array}$ & $\begin{array}{l}\text { Suspected trigger drugs" and } \\
\text { concurrent medication(s) }\end{array}$ \\
\hline 5 & 68 & $F$ & 400 & 575 & Amiodarone", Sotallol", Digoxin \\
\hline 7 & 63 & $M$ & 400 & 510 & $\begin{array}{l}\text { Amiodarone*, Carbasalatecalcium, } \\
\text { Metoprolol }\end{array}$ \\
\hline 8 & 76 & $\mathrm{~F}$ & 450 & 562 & Ibutilide*, Verapamil, Omeprazole \\
\hline 9 & 84 & M & 440 & 531 & Digoxin*, Fexofenadine, Verapamil \\
\hline 10 & 81 & $F$ & 440 & 527 & $\begin{array}{l}\text { Arniadarone", Furosemidle, } \\
\text { Captopril, Bumetadine*, Digoxin }\end{array}$ \\
\hline 11 & 79 & $\mathbb{F}$ & 408 & 568 & $\begin{array}{l}\text { Furosemide*, Doxazosin, Lisinopril. } \\
\text { Salbutamol, Acenocoumarol }\end{array}$ \\
\hline 12 & 24 & $F$ & 400 & 496 & Ketanserin* \\
\hline 13 & 76 & $F$ & 430 & 585 & Sotalol* \\
\hline 14 & 65 & $M$ & 400 & 580 & Sotalol* \\
\hline 15 & 82 & $\mathrm{~F}$ & 391 & 502 & Amiodarone* \\
\hline 16 & 12 & $M$ & 420 & $n \cdot m . t$ & Amiodarone* \\
\hline 17 & 70 & $\mathrm{~F}$ & 454 & 477 & Quinidine* \\
\hline 18 & 77 & $\mathrm{~F}$ & 440 & 640 & Cisapride*, Clarythromycin" \\
\hline 19 & 75 & $f$ & 405 & 637 & Sotalol* \\
\hline 20 & 82 & $\mathrm{~F}$ & 400 & 510 & Sotalol*, Enallapril, Acenocoumarol \\
\hline 21 & 77 & $F$ & 440 & 560 & $\begin{array}{l}\text { Sotalol", Mirtazapine, Risperidone", } \\
\text { Digoxin, Captoprit* }\end{array}$ \\
\hline 22 & 80 & $\mathrm{~F}$ & 400 & 630 & $\begin{array}{l}\text { Sotalol*, Furosemide, Digoxin, } \\
\text { Tamoxifen*, Venlafaxine* }\end{array}$ \\
\hline 24 & 65 & $M$ & 490 & 504 & Sotalol* \\
\hline 25 & 60 & F & 378 & 428 & Sotalol* \\
\hline 27 & 64 & F & 440 & 600 & Amiodarone* \\
\hline 28 & 73 & $\mathrm{~F}$ & 420 & 560 & Amiodarone*, Sotalol* \\
\hline 29 & 56 & $M$ & $39 ?$ & 498 & Sotalol* \\
\hline 30 & 75 & $M$ & 450 & 600 & Sotalol ${ }^{*}$ \\
\hline 31 & 38 & $F$ & 402 & 459 & Sotalo ${ }^{*}$ \\
\hline 32 & 71 & $M$ & n.m. $\dagger$ & 564 & Quinidine* \\
\hline 33 & 75 & $\mathrm{~F}$ & 430 & 550 & Sotalol* \\
\hline 34 & 75 & $M$ & n.m. & 456 & Sotalol* \\
\hline 35 & 71 & $M$ & 420 & 550 & Amiodarone* \\
\hline 36 & 57 & $F$ & 400 & 515 & Sotalol* \\
\hline 37 & 70 & $M$ & 444 & 540 & Sotalol" \\
\hline 38 & 69 & $F$ & 470 & 471 & Sotalo' \\
\hline 42 & 51 & $F$ & 454 & 477 & Quinidine* \\
\hline
\end{tabular}

"Drugs that have been implicated in QT prolongation and TdP' (www.qtdrugs.org). 'Not measurable due to pacing. $F=$ female, $M=$ male; $m . m .=$ not measured. 
Primers used for the CYP3A4*2 PCR were 5'-AGC-GTC-TTT-GGG-GCC-TAC-AG-3' (forward) and 5'-TGA-TGA-TGG-TCA-CAC-ATA-TCT-TC-3' (reverse). PCR products (280 bp and 298 bp for " $1 B$ and *2, respectively) were purified and directly sequenced.

The CYP3A4*3 PCR-RFLP assay was performed using PCR primers $5^{\circ}-A T C-T A C-C A A-C G T-$ GGA-ACC-AG-3' (forward) and 5'-TGT-TCA-TGA-CAG-CAA-ACC-AC-3' (reverse, mismatch underlined). The 121 bp PCR product was digested with $N s p 1\left(37^{\circ} \mathrm{C}, 3\right.$ hours) and the DNA fragments were separated on $12.5 \%$ polyacrylamide.

\section{CYP3A5 - CYP3A5P1}

We reported earlier on the discovery of two linked polymorphisms in the promoter region of the CYP3A5 gene that are associated with a higher in vitro CYP3A5 expression and activity (17). Further studies have shown that these variations were in fact polymorphisms in the $5^{\prime}$ flanking region of the CYP3A5P1 pseudogene $(18,19)$. Nevertheless, these polymorphisms remain predictive of higher in vitro CYP3A5 activity and expression (19). Genotyping for the linked polymorphisms in the CYP3A5P1 gene was performed as described previously (17).

\section{Results}

\section{Subject Data and medication}

In addition to detailed patient information, Table 1 provides an extensive summary of trigger drugs, pre- and post-dose QTC, and concurrent medications for all aLQTS subjects. With exception of four patients, all subjects were older than 50 years. There were approximately twice as many female patients than male patients in this study (21 and 11, respectively). The average QTc interval for the aLQTS subjects prior to drug treatment was $425 \mathrm{msec}^{1 / 2}$ (malles $=433 \mathrm{msec}^{1 / 2}$, females $=422 \mathrm{msec}^{1 / 2}$ ), rising to 540 $\mathrm{msec}^{1 / 2}$ post-treatment (males $=533 \mathrm{msec}^{1 / 2}$, females $=542 \mathrm{msec}^{1 / 2}$ ). Table 2 shows for each of these drugs the route of metabolism in the body and the enzymes that are involved (where known).

\section{Mutational screening in LQT genes}

The LOT gene sequences of the aLOTS patients were compared to the wild type sequences deposited in GenBank. Table 3 summarises the 25 variations that were detected in the studied congenital LQTS genes, 14 of which had previously been reported in the LQT database ${ }^{2}$. Only two of these variations, however, have been found and confirmed to be the causal mutations for congenital LQTS $(3,8)$. Subject 16 was heterozygous for base pair substitution $22 \mathrm{~A}>\mathrm{G}$ in exon 1 of the KCNE2 gene, leading to a T8A amino acid substitution. This mutation has been described previously in a case report of an individual presenting with antibiotic drug-induced cardiac arrhythmia whilst taking, bactrim (trimethoprim and sulfmethoxazole), and has been functionally characterised as the causative mutation for the reported case (8). The suspected trigger compound for subject 16 was the antiarrhythmic drug amiodarone. 
This drug is a CYP3A substrate (20), and this subject carried a genotype predictive of low CYP3A5 expression (see below). Together, a picture of interacting risk factors may be constructed for this subject: a mutation in the ion channel KvLOT1, a trigger compound that is metabolised by CYP3A and low CYP3A5 mediated metabolism. Subject 18 was heterozygous for base pair substitution 1039 C>T in exon 5 of the $K C N H 2$ gene, resulting in amino acid substitution $\mathrm{P}_{3475}$, that was reported earlier as the causative mutation in a cLQTS family (4). The suspected trigger compound for subject 18 was cisapride (21), although the patient was also taking clarithromycin. Cisapride has been implicated in aLOTS cases and has the proven ability to block the HERG channel $(22,23)$. In addition, both cisapride and clarithromycin are metabolised by the CYP3A family, and this subject carried the genotype predictive of low CYP3A5 activity $(24,25)$. Thus, also for subject 18 , one can build up a picture of interacting risk factors: a mutation in the $K C N H 2$ gene; a trigger compound which can block the HERG channel; concurrent medication competing for metabolism by CYP3A and a low activity CYP3A5 phenotype, the latter which can conspire to raise the circulating plasma levels of cisapride to a level at which it can interact with a susceptible HERG channel.

Four further variations were found in the aLQTS patients that resulted in altered amino acid sequences (Table 3). All of these variations have been reported previously (26-29). Three of these variations, namely G38S in KCNE1, K897T in KCNH2, and H558R in SCN5A, were also frequently present in our control population, suggesting that these variations are non-functional polymorphisms rather than pathogenic mutations. The D85N variation in the KCNE1 gene was detected in two of the aLQTS subjects but not in the control subjects. Sixteen out of 19 of the other known or novel intragenic variations that were detected in our set of 32 aLQTS patients were also detected in our control population. None of these changed the amino acid coding sequence, nor is literature available that would suggest a possible role for one or more of these variations as the causal factor for the disease. The variations T377T and $6628 \mathrm{G}$ in KCNQ1 and variation IVS16-6 C>T in SCN5A were detected only ance in the aLOTS subjects but not in the control group. Because of the conservative nature of these variants, it might be expected that these variations represent low frequency polymorphisms with little or no effect on the functionality of the genes. 


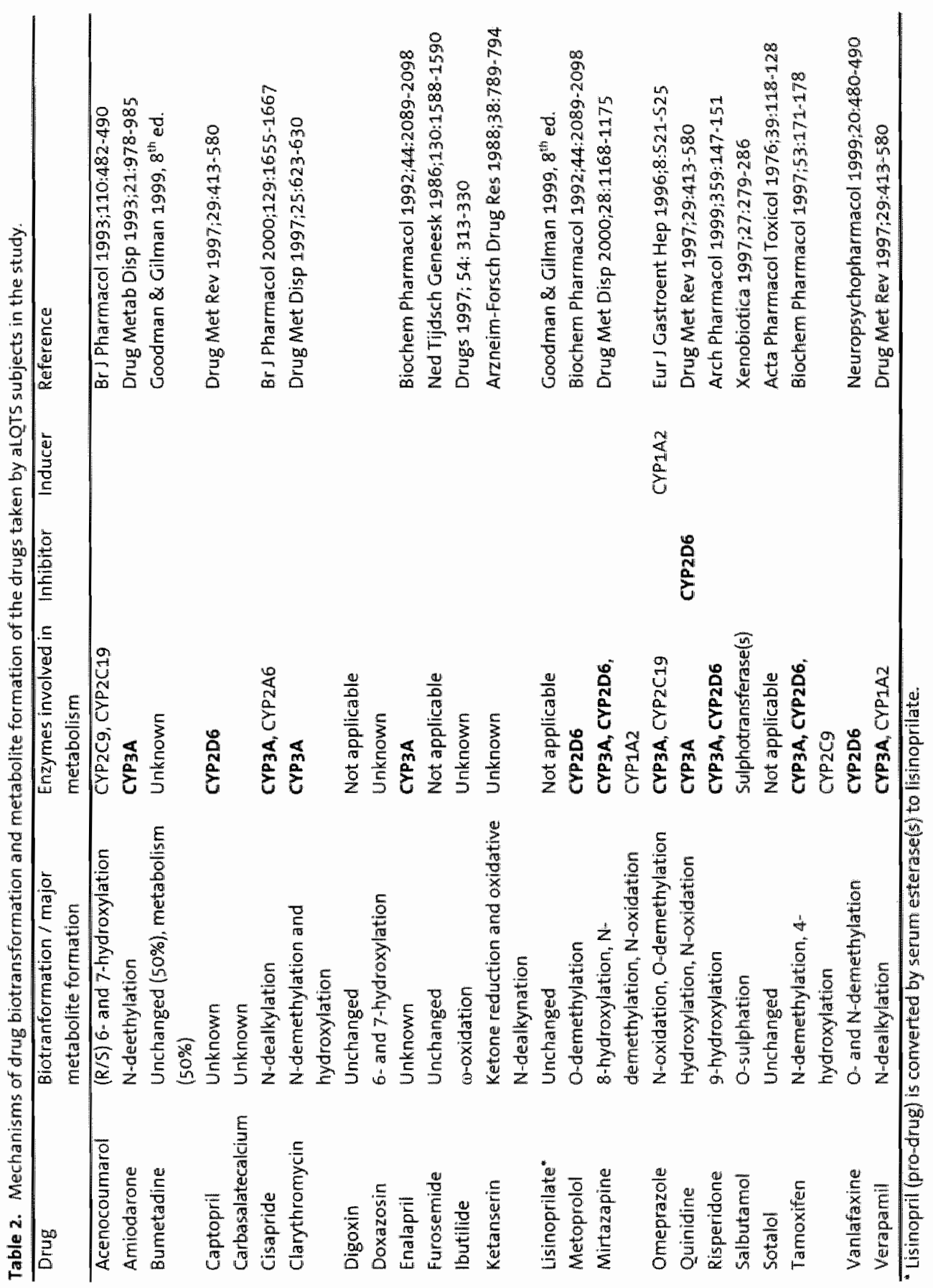




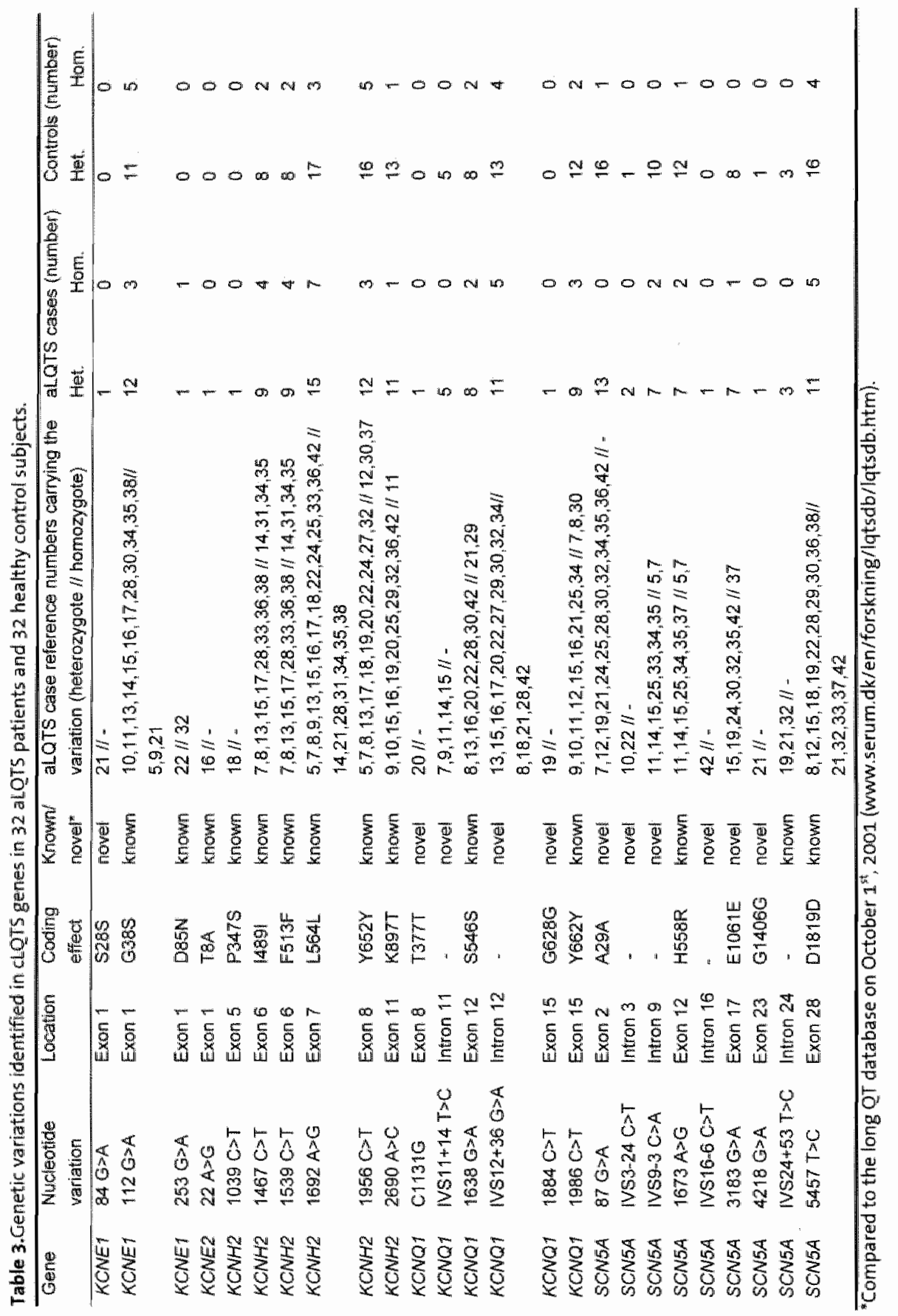




\section{CYP450 genotyping}

\section{CYP2D6}

Based on genotype, one aLQTS patient out of $32(3.1 \%)$ was predicted to be a phenotypic CYP2D6 poor metaboliser. This frequency was not statistically different from the $7 \%$ poor metabolisers identified in the control population $(n=300)$. The trigger drug for this CYP2D6 poor metaboliser (subject 15) was the antiarrhythmic drug amiodarone, which is a substrate for CYP3A and not CYP2D6 (20).

\section{CYP3A4}

One subject (case 32) was heterozygous for the CYP3A4 * $1 \mathrm{~B}$ allele; all other patients were homozygous wild type for the genotyped CYP3A4 variants. The trigger drug for the patient carrying the CYP3A4 * $1 \mathrm{~B}$ allele was quinidine, which is a known CYP3A4 substrate and CYP2D6 inhibitor. There were no statistically significant differences in CYP3A4 genotype or allele frequencies between aLQTS subjects $(n=32)$ and controls $(n=300)$, and both groups conformed to the Hardy-Weinberg equilibrium (data not shown).

\section{CYP3A5}

Four subjects (12.5\%) were heterozygous for the linked polymorphisms $-44 A>G$ and 369 T>C flanking the CYP3A5P1 pseudogene and that predict high CYP3A5 expression and activity in vitro (subjects $25,29,33$ and 36 ), compared to $18 \%$ in the control population ( 53 out of 300 ). One control individual was homozygous for the linked CYP3A5P1 polymorphisms (0.3\%); no cases of the latter genotype were detected in the aLQTS group. Neither the genotype frequencies nor the allele frequencies were statistically significantly different between the aLOTS group and controls, and both groups conformed to Hardy-Weinberg equilibrium (data not shown). Twelve out of 28 patients with the CYP3A5P1 genotype predictive of normal low CYP3A5 expression were taking suspected trigger drugs that are known to undergo CYP3A5 mediated metabolism. All four subjects with the CYP3A5P1 genotype that is predictive of high CYP3A5 expression were taking the antiarrhythmic drug sotalol, which does not undergo significant hepatic metabolism $(30,31)$. 


\section{Discussion}

We have investigated the genetic predisposition to development of TdP in a group of 32 aLQTS patients, all of whom were subjects confirmed by ECG to have experienced TdP as a consequence of drug administration. To this aim, we screened the entire coding region of all currently known cLQTS genes, and complemented these data by genotyping for well-documented variations in the cytochrome P450 genes CVP2D6, CYP3A4 and CYP3A5.

In the present study, female patients were twice as prevalent as male patients, supporting female gender as a determinant of susceptibility. The average QTc interval before drug treatment was below a recommended cut off point for defining $Q T$ prolongation (450 and $470 \mathrm{msec}^{1 / 2}$ for respectively men and women) (32), but was raised in most cases by more than $100 \mathrm{msec}^{1 / 2}$ after drug intake, clearly indicating the drug-induced nature of the disease. Individual case reports have shown that some patients with drug-induced TdP carry sporadic mutations in the genes involved in cLQTS $(8,9)$. In our group of 32 aLQTS subjects, only one case represented a true "forme fruste" of the CLOTS, while one other case carried a mutation that was reported earlier in a cLQTS family $(3,8)$. Perhaps a reluctance to publish negative results of the screening for these genes in other aLOTS cases may have suggested that this represents a more significant risk factor than it actually is.

We cannot exclude that any of the other variations in the CLQTS genes that were detected in this study might also be contributory risk factors in the individual cases, but further in vitro studies would be required to demonstrate their functional significance. Literature evidence, however, suggests that none of the four other identified missense mutations is likely to be causative for LQTS, but rather represent frequently occurring polymorphisms (26-29). It has been postulated that the K897T variation in $K C N H 2$ is QT-shortening and therefore "protective" in female cLQTS patients carrying both the Fin and K897T variation in the gene encoding the HERG channel (26). In our study, this frequent variation was detected both in aLOTS subjects and control subjects. The QT $_{c}$ interval of the aLQTS subject carrying the T897T genotype was not strikingly different from the other aLQTS cases that carried the K897K or K897T genotype. The D85N variation in KCNE1 was detected in two aLQTS cases but not in controls, and cannot, therefore, be excluded as a potential genetic risk factor. The patients in our study that carry this genetic variation received different drugs, sotallol and quinidine respectively. Literature reports "confirmed by the control group data reported here, indicated that this variation is a rare polymorphism, and excluded it as causative in the Jervell and Lange-Nielsen syndrome $(27,28)$. However, it has been shown for at least one rare polymorphism, namely T8A in KCNE2, that low frequency variations in CLOTS genes might be associated with drug induced LQTS (8). 
Therefore, functional studies including the electrophysiological characterisation are required to determine the clinical significance of the $D 85 \mathrm{~N}$ variant.

Numerous mutations have been identified in the genes currently known to be involved in CLQTS. Most of the affected families present with a "novel" gene mutation that is responsible for the syndrome in that particular family. When considering predicting susceptible individuals prior to drug prescription, the cLQTS genes will be difficult targetts, since it is unlikely that genotyping for a limited number of mutations would predict the majority of aLOTS cases. If the pattern of CLOTS were followed, then most of cases would carry different mutations making any screening assay difficult, especially until all relevant mutations have been found. In this respect, it is an important finding that the same functional variant in the KCNE2 gene can predispose to TdP with two different drugs acting through the KVLQT1 channel bactrim and amiodarone respectively). Non-specificity of the cLQTS gene variants in determining susceptibility to a number of drugs. would certainly be an advantage in an attempt to predict susceptible individuals.

Beside changes in channel function induced by mutations the local concentration of trigger drugs at the level of the cardiac myocyte is thought to be another risk factor in drug induced LQTS. Higher levels of trigger drugs can be attained due to overdose or concurrent medication with drugs that inhibit the metabolism of the trigger drugs $(33.34)$. Inter-individual variations in circulating plasma levels of drugs are also possible through mutations in the genes coding for the drug metabolising enzymes. Functional variations in the activity of cytochrome $\mathrm{P} 450$ enzymes that are responsible for the metabolic conversion of the majority of drugs, are becoming increasingly understood and several of the phenotypes are to a large extent predictable based on genotyping (35). To our knowledge, this is the first study in which genetic variations in the drug metabolising enzymes have been studied as a potential risk factor for aLOTS and TdP. Unfortunately, the study design did not allow to evaluate drug levels in serum or tissue in order to demonstrate the functional significance of the evaluated genetic variations, but our observations suggest that such analyses might reveal important information in future studies.

The genetic basis of CYP2D6 mediated metabolism is well understood; studies in Caucasians have demonstrated the ability to predict over $95 \%$ of the poor metabolizers by genotyping (36). The potential role of CYP2D6 in aLQTS has previously been eluded to, based on the expression of CYP2D6 in the human heart, the ability of psychotropics to lengthen the QTC and their metabolism by CYP2D6 $(5,37,38)$. The present study cannot, however, confirm this hypothesis since none of the trigger compounds were metabolised by CYP2D6 or have been stated as being psychotropic. The CYP3A family is involved in the metabolism of a large number of drugs, including antibiotics, antipsychotics and antiarrhythmic drugs indicated in aLQTS cases (39). 
Since CYP3A4 and CYP3A5 show a wide overlapping substrate specificity, it is likely that CYP3A mediated metabolism of drugs is an interaction of activity of both enzymes. Only a limited number of variations have been reported in the CYP3A4 gene, and conflicting reports on their functional consequences have been published (40-42). It is therefore difficult to appreciate the significance of the " $1 \mathrm{~B}$ allele as a contributing risk factor for a LQTS. The aLQTS patient in our population who carried the CYP3A4 ${ }^{*} 1 B$ allele also carried the CYP3A5P1 genotype that is predictive of low CYP3A5 expression. Because of the overlapping substrate specificity of CYP3A4 and CYP3A5, one might speculate that these combined genotypes could represent a risk factor that contributes to the development of aLQTS caused by drugs metabolised by CYP3A, although this needs to be elarified further. Interestingly, none of the four aLOTS patients in our study, which carried the CYP3A5P1 genotype predictive of high CYP3A5 activity were triggered by a drug that undergoes significant hepatic metabolism. We therefore hypothesise that this genotype might eventually represent a protective factor against the development of aLOTS caused by drugs that are metabolised by CYP3A. Further studies in a larger number of aLQTS patients whose arrhythmias were triggered by drugs that are substrates for CYP3A will be required to validate this hypothesis.

Due to the limited size of the aLOTS group and the different classes of trigger drugs, it is difficult to draw general conclusions. Nevertheless, this study represents the most in depth study of genetic predisposition to aLQTS to date. Sesti et al. (8) reported mutational screening in a larger population $(n=98)$, but these authors examined only the intronless KCNE2 gene compared to all five currently known cLOTS genes examined in the present study. Most likely, the low incidence of the disorder, as well as the difficulty to timely confirm the diagnosis by ECG, might explain why it appears to be difficult to collect a reasonably large group of aLQTS cases. Additionally, the control population does not represent a "true" control group, as it was not matched for age, sex, ethnicity, disease, or drug regime. The assembly of such control group was unfortunately not feasible within the design of our study. Finally, screening of the promoter regions of the LQTS genes could possibly add significant value to the study, but the genomic sequences of these regions were not publicly available when the present mutation screening was performed. We suggest this should be incorporated in future studies.

We initiated this study on a series of aLQTS cases in an attempt to make some generalisations that may be applied when determining susceptibility to TdP. The ability to predict susceptible individuals could save lives as well as allowing many otherwise beneficial drugs to reach or remain on the market. The picture that is developing, however, is that aLQTS results from a number of interacting risk factors, including the specific trigger drug, concurrent medication that competes for the relevant drug metabolising enzyme, a susceptible metabolic phenotype, and other 
additional risk factors (e.g., a mutation in one of the cLQTS genes, an underlying heart disease, etc.), in a manner that is unique to the individual. Each of these risk factors contributes only partially to the phenotypic outcome and is usually not sufficient on its own to lead to aLQTS. In conclusion, compared to the familial cases of cLQTS that are usually caused by a specific mutation in a single gene, drug induced LQTS appears to be a complex disease with the interaction of many genes and environmental factors all contributing to an individual-specific risk level for the disease. Further work is needed to establish additional candidate genes that may influence this risk, and to study the importance of such genes in an extended population.

\section{Acknowledgments}

We thank Rosemary Zvonar (Department of Pharmaceutical Services, The Ottawa Hospital, Canada) for providing a patient sample. Drs. Schulze-Bahr and Haverkamp are supported by grants from the Deutsche Forschungsgemeinschaft (grants Schu1082/2-2 and SFB556-A1) and the Foundation Leducq, France. Dr. Doevendans is supported by the Interuniversitary Cardiology Institute, The Netherlands.

\section{References}

1. Schwartz, PJ., Moss, Al., Vincent $G M$, Crampton, RS. Diagnostic criteria for the long $Q T$ syndrome. An update. Circulation 1993; 88:782-784.

2. The Long QT database. URL: http://www.ssi.dk/en/forskning/lqtsdb/lqtsdb.htm.

3. Splawskî $\mathrm{I}_{\mathrm{w}}$ Shen J, Timothy KW, Lehmann MH, Priori S, Robinson Jl, Moss AJ Schwartz P\$, Towbin JA, Vincent $C_{M}$, Keating MT. Spectrum of mutations in Long-QT Syndrome genes, KVLQT1, HERG, SCN5A, KCNE1 and KCNE2, Circulation 2000; 102-1178-1185.

4. Schott I, Charpentier F, Peltier S, Foley P, Drouin E, Bouhouir لB, Donnelly P, Vergnaud G, Bachner L, Moisan JP. Mapping of a gene for Long QT Syndrome to chromosome 4925-27. Am J Hum Genet $1995 ; 57: 1114-1122$.

5. Reilly JG, Ayis SA, Ferrier $\| N$, Jones SI, Thomas $S H$. QT,-interval abnormalities and psychotropic drug therapy in psychiatric patients. Lancet 2000; 355:1048-1052.

6. Taglialatela $M$, Timmerman H, Annunziato L. Cardiotoxic potential and CNS effects of firstgeneration antihistamines. Trends Pharmacol $5 \mathrm{ci} 2000 ; 21: 52.56$.

7. Vitola I, Vukanovic J, Roden D. Cisapride-induced Torsades de Pointes. J Cardiovasc Electr 1998; 9:1109-1113.

8. Sesti F, Abbott GW, Wei J, Murray KT, Saksena S, Schwartz PJ, Priori SG, Roden DM, Gewrge AL. Goldstein SA. A common polymorphism associated with antibiotic-induced cardiac arrhythmia. $P$ Natl Acad Sci USA 2000; 97:10613-10618.

9. Napolitano C, Schwartz PJ, Brown AM, Ronchetti E, Bianchi L, Pinnavaia A, Acqliaro G, Priori SG. Evidence for a cardiac ion channel mutation underlying drug-induced QT prolongation and lifethreatening arithythmias. I Cardiovasc Electr 2000; 11:691-696.

10. Evans WE, Relling MV. Pharmacogenomics: translating functional genomics into rational therapeutics. Science 1999; 286:487-491.

11. Haverkamp W. Shenasa M, Borggrefe M. Breithardt G: Torsades de Pointes. In: Zipes DP, Jalife J (eds): Cardiac Electrophysiology - From Cell to Bedside (2nd edition). Philadelphia: WB Saunders Company; 1995:886-899. 
12. Itoh $T$, Tanaka $T$, Nagai $R_{*}$ Kamiya $T$, Sawayama $T$, Nakayama $T$, Tomoike $H$, Sakurada $H$, Yazaki $\gamma_{\text {, }}$ Nakamura $Y$. Genomic organization and mutational analysis of HERG, a gene responsible for familial long or syndrome. Hum Genet 1998; 102:435-439.

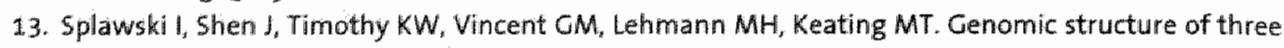
long QT syndrome genes: KVLQT1, HERG, and KCNE1. Genomics 1998; 51:86-97.

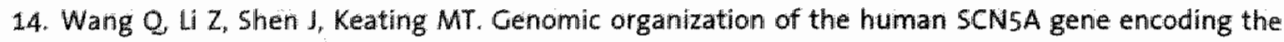
cardiac sodium channel. Genomics $1996 ; 34: 9-16$.

15. Abbott GW, Sesti F, Splawski I, Buck ME, Lehmann MH, Timothy KW, Keating MT, Goldstein SA. MiRP1 forms $\mathrm{K}$ r potassium channels with HERG and is associated with cardiac arrhythmia. Cell 1999:97:175-187.

16. Steen VM, Andreassen OA, Daly AK, Tefre T, Borresen AL, Idle JR, Gulbrandsen AK. Detection of the poor metabolizer-associated CYP2D6 (D) gene deletion allele by long-PCR technology. Pharmacogenetics 1995; 5:215-223.

17. Paulussen $A$, Lavrijsen $K$, Bohets $H$, Hendrickx J, Verhasselt $P$, Luyten $W$, Konings $F$, Armstrong $M$. Two linked mutations in transcriptional regulatory elements of the CYP3A5 gene constitute the major genetic determinant of polymor phic activity in humans. Pharmacogenetics 2000; 10:415-424.

18. Gelliner $K_{3}$ Eiselt $R$, Hustert $E$, Arnold $H$, Koch I, Haberl $M$, Deglmann CJ, Burk $O$, Buntefuss $D$, Escher $S$, Bishop C, Koebe HG, Brinkmann U, Klenk HP, Kleine $K$, Meyer UA, Wojnowski L. Genomic arganization of the human CYP3A locus: identification of a new inducible CYP3A gene. Pharmacogenetics 2001; 11:111-121.

19. Kuehl $P$, Zhang J, Lin $Y$, Lamba J. Assem $M$, Schuetz J, Watkins PB, Daly A, Wrighton SA, Hall SD, Maurel $P$, Relling $M$. Brimer $C$, Yasuda $K$, Venkataramanan $R$, Strom $S$, Thummel $K$, Boguski MS, Schuetz E. Sequence diwersity in CYP3A promotors and characterization of the genetic basis of polymorphic CYP3A5 expression. Nat Genet 2001; 27:383-391.

20. Fabre $G$, Julian $B$, Saint-Aubert $B$, Joyeux $H_{3}$ Berger $Y$. Evidence for CYP3A-mediated N-deethylation of amiodarone in human liver microsomal fractions. Drug Metab Dispos 1993; 21:978-985.

21. Piquette RK. Torsade de pointes induced by cisapride/clarithromycin interaction. Ann Pharmacother 1999; $33: 22-26$.

22. Mohammad S, Zhou $Z$, Gong $\mathrm{Q}$, lanuary $\mathrm{CT}$. Blockage of the HERGi human cardiac $\mathrm{K}+$ channel by the gastrointestinal prokinetic agent cisapride. Am J Physiol-Heart C 1997; 273:H2534-2538.

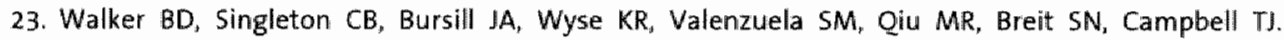
Inhibition of the human ether-a-go-go-related gene (HERG) potassium channel by cisapride: affinity for open and inactivated states. Brit J Pharmacol 1999"128:444-450.

24. Rodvold KA. Clinicall pharmacokinetics of clarithromycin. Clin Pharmacokinet 1999; 37:385-398.

25. Michalets EL, Williams CR. Drug interactions with cisapride: clinical implications. Clin Pharmacokinet $2000 ; 39: 49-75$.

26. Laitinen, P, Fodstad, H. Piipo, K, Swan, H., Toivonen, L., Viitasallo, M., Kaprio, J., Kontula, K. Survey of the coding region of the HERG gene in long QT syndrome reveals six novel mutations and an amino acid polymorphism with possible phenotypic effects. Hum Mutat 2000; Mutation in Brief \#324, Online.

27. Tessom, F., Donger, C., Denjoy, I., Berthet, M., Bennaceur, M., Petit, C., Coumell, P., Schwartz, K., Guicheney, $P$. Exclusion of KCNE1 (ISK) as a candidate gene for Jervell and Lange-Nielsen Syndrome. IMol Cell Cardiol 1996; 28:2051-2055.

28. Iwasa, H., Itoh, T., Nagail, R., Nakamura, Y., Tanaka, T. Twenty single nucleotide polymorphisms (SNPS) and their allelic frequencies in four genes that are responsible for familial long $\mathrm{QT}$ in the Japanese population. J Hum Genet 2000; 45:182-183,

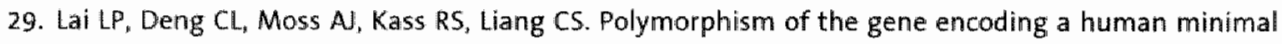
potassium ion chanmel (minK). Gene 1994; 151:339-340.

30. Funck-Brentano $\mathrm{C}$. Pharmacokinetic and pharmacodynamic profiles of d-sotalol and d,l-sotalol. Eur Heart J 1993: 14(Suppl H):30 35 . 
31. Hanyolk JJ. Clinical pharmacokinetics of sotalol. Am J Cardiol 1993; 72:19A-26A.

32. Berhorin, J. Kalman, Y.M., Medina, A, Towbin, J., Rave-Harel, Dyer, TD., Blangero, J., MacCluer, JW. Kerem, B. Evidence of genetic heterogeneity in the long OT syndrome: Science 1993; 260:1960-1961.

33. Pohjola-Sintonen $S$, Viitasalo $M_{s}$ Toivonen $L$, Neuvonen $P$. Itraconazole prevents terfenadine metabolism and increases risk of torsades de pointes ventricular tachycardia. Eur $f$ clin Pharmacol $1993 ; 45: 191-193$.

34. Tsai WC, Tsai LM, Chen JH. Combined use of astemizole and ketoconazole resulting in torsade de pointes. J Formos Med Assoc 1997; 96:144-146.

35. Daly AK. Molecular basis of polymorphic drug metabolism. J Mol Med 1995; 73:539-553.

36. Marez, D., Legrand, M., Sabbagh, N., Cuidice, J.M., Spire, C., Lafitte, J.J., Meyer, U.A., Broly, F. Polymorphism of the cytochrome P450 CYP2D6 gene in a European population: characterisation of 48 mutations and 53 alleles, their frequencies and evolution. Pharmacogenetics 1997; 7:193-202.

37. Thum T, Borlak J. Gene expression in distinct regions of the heart Lancet 2000; 355:979-983.

38. Idle JR. The heart of psychotropic drug therapy. Lancet 2000; 355:1824-1825.

39. Wilkinson GR, Cytochrome P4503A (CYP3A) metabolism: prediction of in vivo activity in humans. J Pharmacokinet Biop 1996; 24(5): 475-490.

40. Westlind A, Lofberg L, Tindberg $N$, Andersson TB, Ingelman-Sundberg $M$. Interindividual differences in hepatic expression of CYP3A4: relationship to genetic polymorphism in the $5^{\prime}$-upstream regulatory region. Biochem Bioph Res Comm 1999: 259:201-205.

41. Sata F, Sapone A, Elizondo G, Stocker P, Miller VP, Zheng W, Raunio H, Crespi CL, Gonzalez FJ. CYP3A4 allelic variants with amino acid substitutions in exons 7 and 12: evidence for an allelic variant with altered catalytic activity. Clin Pharmacol Ther 2000; 67:48-56.

42. Felix CA, Walker AH, Lange BJ, Williams TM, Winick NJ, Cheung NK, Lovett BD, Nowell PC, Blair IA, Rebbeck TR. Association of CYP3A4 genotype with treatment-related leukemia. P Natl Acad SCi USA 1998; 95:13176-13181. 
136 
CHAPTER

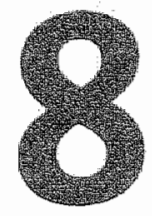

General discussion

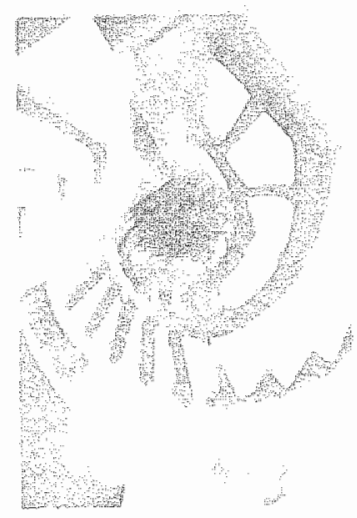




\section{Congenital long QT syndrome}

\section{Genetics of the congenital long QT syndrome}

Genetic approaches have contributed largely to defining the molecular basis of the long OT syndrome, a disease associated with serious arrhythmias. In the past two decades it has been recognized that at least one of the causes for these arrhythmias are mutations in cardiac ion channel genes. So far, five genes have been causally linked to LOTS. Extensive genetic screening in LOTS families has indicated that these mutations are not confined to a specific location or region, but rather spread over the complete sequence of each gene. Thus, in most families LOTS is caused by a specific, or "private" mutation. Today, genetic screening of LQTS families worldwide has resulted in the identification of more than 200 different mutations in these five different genes (summarized in Appendices 1 to 5). The majority of the mutations are detected in either KCNO1 (approximately 40\%) or KCNH2 (approximately 50\%).

Genetic testing of patients with clinically diagnosed LOTS can be very useful. Although therapy should be initiated immediately in these cases prior to genetic testing, specific modifications to therapy can be made if the affected gene is known. Genetic testing may, however, be even more useful for the diagnosis of otherwise asymptomatic family members of a proband. Based on the identified causative mutation in the proband, a simple mutation-specific test can identify other "silent" mutation carriers within the family (Chapter 2, 3 and 4). (Asymptomatic) mutation carriers within a LOTS family, who have decided to have children, may be informed about their probability of having an affected child and the accompanying risks involved. A mutation-specific test developed for this particular family can determine the genotype of a newborn shortly after birth.

An important shortcoming today is the relatively low sensitivity of genetic screening for LQTS, indicated by the fact that a mutation is identified in only $50-60 \%$ of all families that have been diagnosed with the syndrome (1). This implies that yet other LQTS genes need to be discovered before molecular diagnosis would enable the identification of the causing mutation in all newly presenting LQTS families. Today, therefore, a positive result of a genetic screening of the LOTS genes can confirm the diagnosis, but a negative result does not necessarily exclude the disease in the screened proband and his or her family members. Additionally, although a specific mutation identified in a LQTS family is generally assumed to be $100 \%$ predictive for the disease in that particular family, several individual cases $(2,3)$ - including the patient described in Chapter 3 - have been reported to carry more than one causative mutation (compound heterozygosity) in either of the LQTS genes, each with a different contribution to the phenotype. These examples stipulate the importance of a 
well set up screening strategy to optimise the outcome. The optimal strategy to follow may depend on many factors, including the applied screening methodology, the number of LQTS families to be screened simultaneously, the family size, and the available clinical data of each of the family members. In a large family with multiple symptomatic members, an identified mutation that is co-segregating with the LQTS symptoms is highly indicative for the causative nature of this mutation, and screening may be terminated at this point. In other cases (e.g. Chapter 3), an identified mutation may not co-segregate with LQTS symptoms or phenotypic characteristics, and screening should be continued. Sometimes, only the proband is symptomatic and no other family members are either available or symptomatic. When a mutation is identified in such patients, additional tests may be required to determine the causative nature of the identified mutation. These tests may include genotyping of a healthy control population to exclude the possibility that this mutation is a common polymorphism. Additionally, functional characterisation of the mutation in an electrophysiological expression system may be performed. Today, however, the latter tests are only performed in a research environment and not in clinical diagnostics.

In genetic research laboratories, one may want to expand the screening sequence to include introns and promoter regions of the LQTS genes. So far, only the coding regions and intron-exan boundaries are screened because mutations in these areas can change protein translation. However, this does not exclude the possibility that intronic or promoter region mutations can effect transcription or expression of the LQTS genes. This additional screening may be performed in LQTS families, in which no mutation was identified with traditional screening. In this respect, advances in highthroughput PCR and mutational screening technologies are expected to provide the tools to more efficiently perform such extended screenings. Also specific micro-arrays are being developed to simultaneously screen for hundreds of different mutations that cause a particular disease, such as LQTS, which may eventually decrease the need for PCR-based screening of all individual exons of genes.

\section{Functional consequences of mutations in LQTS genes}

The discovery that potassium and sodium ion channel genes are involved in LQTS has largely contributed to our current understanding of the arrhythmogenic nature of this disease. These ion channels are very important contributors to the cardiac action potential, which in its turn is directly linked to the length of the QT-interval. Therefore, the study of the functional consequences of identified mutations in these ion channel genes might reveal interesting new information to better understand LQTS. However, in contrast to the more general availability of molecular genetic laboratories that can perform mutation analysis of LQTS genes, functional screening of the identified mutations is yet only possible in relatively few specialised research laboratories with specific expertise and specialised "patch clamp" electrophysiology equipment available. 
The mutations that have been characterised in oocyte or mammalian expression systems have revealed a broad scala of functional defects, including persistent inward sodium currents caused by non-inactivation (4) and reduced potassium currents caused by non-expression, non-functionality or aberrant protein trafficking $(5,6)$, all leading to prolongation of the action potential. The T65P mutation in HERG described in chapter 2 exemplifies non-functionality of a mutant protein due to incorrect protein folding and subsequent lack of transportation to the cell membrane. In vitro temperature decrease and chemical "chaperone" binding enabled correct trafficking. Because channel function of the rescued channels resembled wild type channels, options for mutation-specific therapy may be possible for this particular mutation. In this respect, an initial study with fexofenadine has shown the ability to rescue trafficking of mutant HERG channels N470D and G6015 without blocking them (7). However, this method will only work for some of the mutations that show trafficking deficiency, and these mutations currently represent only a minority. The majority of mutations, such as the ones described in Chapter 4, cause (combinations of) nonexpression, non-functionality, or altered function of ion channels. These functional changes pose researchers for much more difficult challenges, because restoration of protein expression or correction of channel kinetic properties is usually much more difficult to accomplish.

In the future, one might possibly find an explanation for the discordance between functional severity of mutations observed in vitro and phenotypes observed in vivo. It could be expected that patients with dominant negative mutations show more severe phenotypes, although such general genotype-phenotype correlations are not observed. Today, the overall mechanisms underlying fatal arrhythmias in a given phenotype remain rather unclear. Functional studies in either native cells or animal models might increase the insights into these mechanisms (Table 1). Especially the studies of specific mutations that make use of newly developed in vivo models are expected to result in more closely related human phenotypes compared to in vitro systems.

Table 1. Overview of reported in wivo models on LQTS.

\begin{tabular}{|c|c|c|c|}
\hline Method & Speciesi/cells & Genefmutation & Ref \\
\hline Transgenic anmial model & mice & KCNQI knockout & (8) \\
\hline Transgenic animal model & mice & KCNE 1 knockout & $(10)$ \\
\hline Transgenic animal model & mice & KCNE1 hnockout & $(11)$ \\
\hline Viral gene transfer & guinea pig myocytes & KCNQ1/G306R & $(12)$ \\
\hline Transgenic animal model & mice & KCNH2HC628S & $(13)$ \\
\hline Viral gene transfer & guinea pig & KCNH2J C628S & $(1 / 4)$ \\
\hline Viral gene transfer & guinea pig & KCNENDT6N & $(14)$ \\
\hline Transgenic animal model & mice & SCN5AISKPQ & (9) \\
\hline
\end{tabular}


The number of LQTS mutation or gene knockout studies using in vivo native cells or animal models is presently still rather limited (Table 1), but these studies show promising results. For example, the $K C N Q 1$ knockout mouse (8) may be a good model to study mechanisms involved in JLNS, because several phenotypic characteristics of JLNS patients (deafness, abnormal T-wave morphology, and prollongation of the QT interval) are observed in this model. The SCN5A $\triangle \mathrm{KPO}$ mouse model (9) correlates well with LQT3 features observed in LQTS patients carrying this mutation.

\section{Genatype-phenotype correlations and climical implications}

Before genetic testing was available, it was assumed that the penetrance of LOTS was $100 \%$, implying that all genetically affected individuals would manifest the typical clinical symptoms of LOTS. However, genetic screening in many LQTS famillies showed that the penetrance is usually much lower. Earlier studies have shown that several LQTS family members with normal QT intervals experienced syncopes or cardiac arrest (15), and that several gene mutation carriers were asymptomatic and possessed normal OT intervals (16). It was recently reported that the penetrance could be as low as $25 \%$ (17). Also the families studied in this thesis showed a low penetrance of clinical symptoms, ranging between $18 \%$ in the LQTS family with mutation P872f5877 in KCNH2 (Chapter 4), over $33 \%$ in the families with mutations T65P in KCNH2 (Chapter 2) and V254M in KCNO1 (Chapter 3), up to $37 \%$ in the family with mutation E698X in $K C N H 2$ (Chapter 4). An explanation for this variable expression of the phenotype in mutation carriers remains unclear, but it may be beneficial to identify the asymptomatic mutation carriers and inform them about the potential risks and treatments. Treatment of asymptomatic children, of whom it is impossible to determine if or when they will become symptomatic, may be crucial especially because the first phenotypic event of LOTS is sudden death in 30 to $40 \%$ of the cases (18).

Increasing evidence indicates that the phenotypic differences in LQTS are not only influenced by a specific mutation in a LOTS gene, but also by the variable function or expression of other modifier genes that may affect susceptibility and severity. Because of the gender differences observed in LQTS phenotypes, it is hypothesized that these modifiers may include sex hormones (19). In addition, variable expression or functioning of other genes influencing the cardiac action potential and/or its response to triggers/stressors, such as adrenergic stimulation, is also thought to play a role (20). 


\section{Acquired long QT syndrome}

The list of drugs that have been reported to cause marked QT interval prolongation and torsades de pointes (TdP) is expanding rapidly. It is well recognized that $1-8 \%$ of the patients receiving antimarrhythmic drugs develop TdP. In the last two decades, however, an expanding number of non-cardiovascular agents including certain antihistamines, antibiotics and antipsychotics have also been implicated in druginduced ("acquired") LQTS. The list of risk factors contributing to acquired LOTS is also expanding and comprises gender, electrolyte disturbances, other heart disease, concomitant medication and underlying mutations in congenital LQTS genes (Figure 1). Despite the knowledge of these risk factors, the development of TdP in an individual patient remains very unpredictable. Drug action is very variable in the human population. This variability is the result of functionall polymorphisms in genes encoding molecules of drug metabolism, molecules that drugs target, or molecules that modulate the overall activity of the environment in which drugs act. For a long time, underlying "forme fruste" mutations in congenital LQTS genes have been assumed often to explain TdP development, because many drugs block the ion channels encoded by these genes. This assumption can be ascribed to the number of case reports describing acquired LQTS individuals in whom such a mutation was detected. Initially, our conviction of the importance of congenital LQTS mutations in acquired LQTS patients was reinforced by the identification of an Y667X mutation in the $\mathrm{KCNH} 2$ gene in a healthy volunteer participating in a clinical drug trial (Chapter 5). Somewhat surprisingly, however, genetic screening studies in larger groups of acquired LQTS patients demonstrated later that an underlying mutation in one of the congenital LQTS genes is found in only a small minority of patients $(21,22$, Chapter 7$)$. Presently, the importance of genetic polymorphisms causing inter-individual variation in drug metabolism has been largely unexplored as a risk factor for acquired LQTS. Yet it is well recognized that concomitant medication is a common factor in the majority of acquired LQTS cases. Almost all QT prolonging drugs are, at least in part, metabolised by the hepatic CYP3A family, with CYP3A4 and CYP3A5 being the most important enzymes. Overdosing of a drug, or co-administration of a second drug that competes for metabolism by the same enzyme, can eventually lead to elevated plasma levels of the drug that blocks the cardiac ion channel genes. 


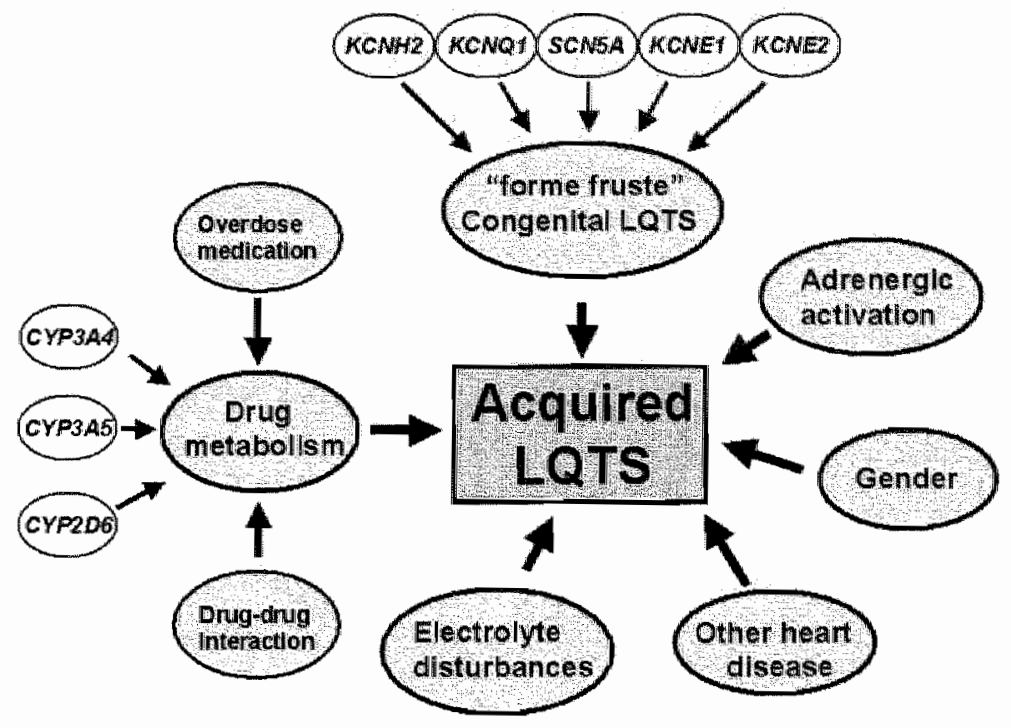

Figure 1. Acquired long QT syndrome - a complex genetic disorder. Schentatic overview of genetic and environmental factors contributing to acquired llong QT syndrome.

The highly variable expression level of $\mathrm{CYP}_{3} \mathrm{~A} 5$ within the general population is well documented, while the relative contribution of the CYP3A5 enzyme to the total CYP3A metabolism is largely unknown. Therefore, we searched for genetic variations in the CYP3A5 gene and identified two DNA polymorphisms in linkage disequilibrium that were predictable for CYP3A5 expression level. A preliminary study in acquired LQTS patients indicated that patients who received drugs that are metabolized by CYP3A4/5 enzymes are more likely to be low CYP3A5 metabolizers, although the number of patients was not large enough to determine statistical significance (Chapter 7). In the future, the statistical significance of the CYP3A5 expression level might be determined if a larger group of well defined acquired LoTS patients could be collected. In this respect, several research groups that collect DNA from drug-induced LQTS patients should intensively collaborate, as it is very difficult to assemble a group with sufficient statistical power. Obviously, screening for functional variations in drug metabolising enzyme genes should not be restricted to CYP3A4/5 and CYP2D6, but should eventually include all genes involved in the metabolism of the drugs that have been taken by acquired LOTS patients.

Another hypothesis that has been proposed to explain the role of genetic predisposition to acquired LQTS is to examine genes involved in the sympathetic nervous system, because adrenergic activation is often a trigger for life-threatening 
arrtythmias. Recently, the contribution of five validated non-synonymous coding region polymorphisms in genes encoding the $\beta 1$-adrenergic and $\beta 2$-adrenergic receptors has been explored in 93 patients with acquired LQTS, but none of these polymorphisms was associated with drug-induced torsades de pointes (23).

\section{Outlook for the future}

It is clear that significant progress has been made during the last decade in the elucidation of the genes and molecular mechanisms involved in congenital and acquired LOTS. Nevertheless, it might be expected that a significant amount of additional research will be required to fully understand the factors that modulate the expression of the LQTS phenotype. At this time, the trigger for TdP development in both congenital and acquired LQTS is one of the largest mysteries, and research is expected to focus on this issue. It is believed that this trigger is influenced by several factors, including the adrenergic control of cardiac electrophysiology, sex hormones, interaction of modifying factors with specific genes, and the control of differential ion channel expression. Further exploration of each of these areas may result in a better understanding of the idiosyncratic manner in which TdP develops in both syndromes.

\section{References}

1. Vincent $G M$, Timothy $K$, Fox J, Zhang $L$. The inherited long $Q T$ syndrome: from ion channel to bedside. Cardiol Rev 1999: 7: 44-55.

2. Larsen LA, Fosdal I, Andersen PS, Kanters IK, Vuust J, Wettrell G, Christiansen M. Recessive Romanoward syndrome associated with compound heterozygosity for two mutations in the KVLOT1 gene. Eur J Hum Genet 1999: 7: 724-728.

3. Berthet $M$, Denjoy I, Donger $C$, Demay L, Hammoude H, Klug D, Schulze-Bahr E, Richard P, Funke H, Schwartz $K$, Coumel $P$, Hainque $B$, Guicheney $P$. C-terminal HERG mutations: The role of hypokalemla and a KCNQ1-associated mutation in cardiac event occurrence. Circulation 1999; 99: $1464-1470$.

4. Dumaine R, Wang Q, Keating MT, Hartmann HA, Schwartz P! Brown AM, Kirsch GE. Multiple mechanisms of Na* channel-linked long $Q T$ syndrome. Circ Res 1996; 78:916-924

5. Sánguinetti MC, Curran ME, Spector PS, Keating MT. Spectrum of HERG K*-channel dysfunction in an inherited cardiac arrhythmia. Proc Notl Acad SCi USA 1996; 93: 2208-2212.

6. Zhou $Z$, Gong $\mathrm{Q}$, January $\mathrm{CT}$. Correction of defective protein trafficking of a mutant HERC potassiumi channel in human long QT syndrome. Pharmacological and temperature effects. I Biol Chem 1999; $274: 311.23-31126$.

7. Rajamani $\mathrm{S}$, Anderson $\mathrm{CL}$, Anson BD, January $\mathrm{CT}$. Pharmacological rescue of human $\mathrm{K}(+)$ channel long-QT2 mutations: human ether-a-go-gorrelated gene rescue without block. Circulation 2002: 105: $2830-2835$.

8. Casimiro MC, Knollmann BC, Ebert SN, Vary JC, Greene AE, Franz MR, Grinberg A, Huang SP, Pfeifer $K$. Targeted disruption of the K $\mathrm{cnq} 1$ gene produces a mouse model of lervell and Lange-Nielsen syndrame. Proc Natl Acad Sci USA 2001; 98: 2526-2531.

9. Nuyens D, Stengl M, Dugarmaa $S$, Rossenbacker $T$, Compernolle $V$, Rudy $Y$, 5 mits JF, Flameng $W$, Clancy CE, Moons L, Vos MA, Dewerchin M, Benndorf K, Collen D, Carmeliet E, Carmeliet P. Abrupt 
rate accelerations or premature beats cause life-threatening arhythmias in mice with longwQT3 syndrome. Nat Med 2001; 7: 1021-1027.

10. Drici $M D$, Arrighi I, Chouabe $C$, Mann $\Downarrow R$, Lazdunski $M$, Romey $G$, Barhanin J. Involvement of $i s k$ associated $\mathrm{K}^{+}$channell in heart rate control of repolarization in a murine engineered model of Jervell and Lange-Nielsen syndrome. Circ Res 1998; 83: 95:102.

11. Kupersmidt 5, Yang T, Anderson ME, Wessels A, Niswender KD, Magnuson MA, Roden DM. Replacement by homologous recombination of the mink gene with lacZ reveals restriction of mink expression to the mouse cardiac conduction system. Circ Res 1999: 84: 146-152.

12. Li RA, Miake J, Hoppe UC, Johns DC, Marban E, Nuss HB. Functional consequences of the arrhythmogenic C306R KVLOT1 $\mathrm{K}^{*}$ channel mutant probed by viral gene transfer in cardiomyocyte $5_{\text {i. }}$ J Physiol 2001; 533.1: 1.27-133.

13. Babij P, Askew GR, Nieuwenhuijsen B, Su CM, Bridal TR, Jow B, Argentieri TM, Kulik J, DeGennaro L, Spinelli $W$, Colatsky TJ. Inhibition of cardiac delayed rectifier $K^{+}$current by overexpression of the long QT syndrome HERG G628S mutation in transgenic mice. Circ Res 1998: 83: 668-678.

14. Hoppe UC Marban E, Jahns DC. Distinct gene-specific mechanisms of arrhythmia revealed by cardiac gene transfer of two long QT disease gene, HERG and KCNE1. Proc Natl ACad SCI USA 2001: 98: 5335-5340.

15. Schwartz PJ, Moss AJ, Locati E, Crampton RS, Tzivoni D, Garson A, Vincent GM. The long QT syndrome international prospective registry. J Am Coll Cardial 1989; 13: 20A.

16. Vincent $G M$, Timothy $K W$, Leppert $M$, Keating $M T$. The spectrum of symptoms and $Q T$ intervals in carriers of the gene for the long QT syndrome. N Eng J Med 1992; 327: 846 852.

17. Prilori SG, Napolitano $C_{\text {, }}$ Schwartz PJ. Low penetrance in the long OT syndrome. Clinical impact. Circulation 1999; 99: 529-533.

18. El-Sherif $N$, Turitto $G$. The long QT syndrome and torsade de pointes. PACE 1999; 22:91-110.

19. Lehmann MH, Timothy KW, Frankovich D, Fromm BS, Keating M. Locati EH, Taggert RT, Towbin JA, Moss. Al, Schwartz PJ, Vincent GM. Age-gender influence on the rate-corrected $\mathrm{QT}$ interval and the QT-heart rate relation in families with genotypically characterized long QT syndrome. $\triangle A C C 1997$; 29: 93-99.

20. Raden DM, Spooner PM. Inherited long QT syndromes: a paradigm for understanding arrhythmogenesis. J Cardiovasc Electrophysiol 1999; 10: 1664-1683.

21. Yang $\mathbb{P}$, Kanki $H$, Drolet B, Yang B, Wei J, Viswanathan PC, Hohmloser SH, Shimizu W, Schwartz PJ, Stanton M, Murray $K_{\text {, }}$ Norris $K$, George AL Jr., Roden DM. Alleleic variants in longQT disease genes in patients with drug as sociated torsade de pointes. Circulation 2002 105: 1943-1948.

22. Chevalier P, Rodriguez C, Bontemps L, Miquel M, Kirkorian G, Rousson R, Potet F, Schott J, Baro I. Touboul P. Non-invasive testing of acquired long QT syndrome: Evidence for multiple arrhythmogenic substrates. Cardiovasc Res 2001; 50: 386-398.

23. Kanki $H$, Yang $\mathrm{P}$, Xie HG, Kim RB, George AL Jr, Roden DM. Polymorphismis in beta-adrenergic receptor genes in the acquired long $\mathrm{QT}$ syndrome. J Cardiovasc Electrophysiol 2002; 13:252-256. 


\section{Summary}

Chapter 1 discusses the most common characteristics of long QT syndrome (LQTS). This syndrome is responsible for the majority of unexplained sudden deaths without any recognisable heart disease. The "beating" of a heart is set in motion by a series of electrical impulses that make the heart muscle contract, pump the blood through the body, and supply it with oxygen. In LQTS patients, the balance between these electrical impulses can be suddenly disrupted, which may trigger an uncoordinated heart rhythm. The result is a shortage of oxygen which can lead to sudden loss of consciousness or, when sustained, to sudden death. The syndrome is named after the distance between two characteristic waveforms visible on an ECG, respectively the QRS-complex and the T-wave. In the majority of LQTS patients this distance is too long, resulting in a heartbeat recovery time that is too small to initiate the next one. The chapter describes how ionic currents through ion channels in the cell membrane of ventricular cells are responsible for the balance in the electrical impulses. LQTS is caused by mutations in genes encoding the ion channels and is genetically inherited. The genes that have been identified so far are potassium channel genes KCNQ1, $K C N H 2$ and modulating $\beta$-subunits $K C N E 1$ and $K C N E 2$, and sodium channel gene SCN5A. The function of the genes is discussed, including the functional effects of mutations in these genes. The second part of the introduction deals with acquired LQTS, a form of LOTS caused by drug intake. All the different drug classes and some additional risk factors that can contribute to acquired LOTS are discussed.

Chapter 2 describes the detection and functional characterisation of a novel missense mutation in the $K \mathrm{CNH}_{2}$ gene that was detected in a LQTS family. This mutation causes trafficking deficiency of the HERG protein to the cell inembrane, where it should function as an ion channel. The trafficking deficiency could be restored by lower incubation temperatures or by incubation with chemical chaperones. Tetrimerisation of wild type subunits with mutant subunits was not possible at $37^{\circ} \mathrm{C}$, resulting in 50\% non-functional channels (haplo-insufficiency) but no dominant negative effect.

Chapter 3 describes a LOTS patient with two different missense mutations in two different LQTS genes. The first detected mutation (A572D, SCN5A) could not explain the LQTS symptoms, as this mutation was inherited from the maternal side of the family, while LOTS characteristics were only observed at the paternal side. Further screening of other LQTS genes led to the detection of a missense mutation in another gene (V254 M, KCNO1) that could explain the LOTS characteristics in family members from the paternal side. The observation that a LQTS patient can carry more than one mutation, each with a separate contribution to the phenotype, indicates the importance of a thorough screening of all LQTS genes.

Chapter 4 describes two large LQTS families, each with a different mutation that was identified in the $K C N H 2$ gene, respectively E698X and P872fs877. Both mutations lead 
to premature stop codons resulting in truncated HERG proteins. Only the HERG P872fs877 truncated protein was expressed; the HERG E698X protein was hardly detectable. The P872f5877 HERG protein was functional although transport of the protein to the cell membrane was disrupted by partial retention of the proteins in the endoplasmic reticulum. The kinetics of homomultimeric HERG P872f5877 were comparable to wild type homo-multimers. However, with formation of heteromultimers, kinetic differences as compared to will type kinetics were obserwed. In summary, the E698X mutation leads to $50 \%$ haplo-insufficiency and the P872fs 877 mutation leads to partial haplo-insufficiency combined with a kinetically dominant negative effect on channel function.

Chapter 5 illustrates the connection between the congenital LQTS and acquired LQTS by genetic screening of a healthy volunteer participating in a clinical trial. The volunteer was screened for mutations in all LQTS genes because of an observed prolongation of the QT-interval in response to drug treatment. A mutation in the KCNH2 gene ( $(667 X)$ was identified that was inherited from the maternal side. Both mother and son had a baseline prolongation of the QT-interval, although both were asymptomatic. This study shows that the percentage of congenital LQTS patients in the general population is underestimated, and that especially these asymptomatic unidentified LQTS patients may be vulnerable to the development of arrhythmia by drug intake.

Chapter 6 describes the search for a genetic background in variable CYP3A5 expression. Both the CYP3A4 and CYP3A5 proteins are responsible for the metabolism of many endoand exogenous compounds and show substantial overlapping substrate specificity. Many drugs that might induce acquired LOTS are metabolised by these enzymes. Human CYP3A5 expression in the liver is highly variable: CYP3A5 expression can be detected in only 10-30\% of Caucasians. We identified two polymorphisms in the promoter region of the CYP3A5P1 gene that were in linkage disequilibrium. The less frequent allele was associated with high expression levels of CYP3A5 MRNA and protein in the liver. The Caucasian population frequency of this allele was $18 \%$, in line with the percentage in the population that shows high CYP3A5 expression. The observations of chapter 5 and 6 were investigated in a population of 32 acquired LQTS patients (Chapter 7). Only a minority of these patients (6\%) was carrier of a mutation in one of the congenital LOTS genes. The patients in which arrhythmia were provoked by a CYP3A4/5 substrate were all carrier of the CYP3A5P1 genotype predictive of low CYP3A5 expression. Although statistical significance needs to be explored in a larger acquired LQTS population, one factor that influences the risk for acquired LQTS might be an impaired ability of CYP3A5 metabolism.

In summary, all the observations from previous chapters are discussed in Chapter 8 . The added value but also shortcomings of genetic screening in congenital and acquired LQTS are discussed as well as the novel insights into the functionall consequences of identified mutations. The chapter is concluded with possible future steps in the better understanding of several features characteristic for both congenital and acquired LOTS syndrome. 


\section{Samenvatting}

De voornaamste karakteristieken van het verlengde QT-interval syndroom (LOTS) worden besproken in Hoofdstuk 1 . Deze aandoening is verantwoordelijk voor het grootste percentage aan plotseling overlijden zonder verdere aantoonbare hartproblemen. Het "kloppen" van het hart wordt veroorzaakt door een aaneenschakeling van specifieke electrische impulsen die de hartspier doen samentrekken, het bloed rondpompt en hiermee het lichaam van zuurstof voorziet. Bij LQTS patienten kan de coördinatie tussen deze electrische impulsen verstoord raken, waardoor een ongecontroleerd hartritme ontstaat. Het gevolg is een tekort aan zuurstof dat kan leiden tot bewusteloosheid en eventueel ook tot overlijden. Een typisch kenmerk van deze aandoening is de verlengde afstand tussen het QRScomplex en de T-golf op een electrocardiogram. Door deze verlenging is bij de meeste LQTS patiënten de tijdsduur van hartslagen dusdanig lang dat de benodigde, tussenliggende herstelperiode in het gedrang komt. Hoofdstuk 1 beschrijft dat ionenkanalen in de celmembiaan van ventriculaire hartcellen verantwoordelijk zijn voor de electrische impulsbalansem. Congenitale LQTS is een erfelijke aandoening die wordt veroorzaakt door mutaties in genen die coderen voor deze ionenkanalen. De genen die tot nu toe zijn geïmpliceerd in congenitale LQTS, zijn de kaliumkanalen KCNQ1, KCNH2 en hun bijbehorende, modulerende $\beta$-subeenheden KCNE1 en KCNE2 " en het natriumkanaal SCN5A. De functie van deze genen wordt besproken, alsook de functionele effecten die mutaties in de genen tot gevolg kunnen hebben. Het tweede deel van de inleiding bespreekt de verworven vorm van LQTS. Er wordt een overzicht gegeven van de verschillende medicijnklassen die deze vorm kunnen veroorzaken en een aantal belangrijke additionele risicofactoren. Hoofdstuk 1 wordt afgesloten met een overzicht van de doelstellingen van dit proefschrift.

Hoofdstuk 2 beschrijft de detectie en functionele karakterisatie van een nieuwe mutatie in het KCNH2 gen die werd gedetecteerd in een LQTS familie. Deze mutatie verhindert een normaal transport van het eiwit (HERG) naar de celmembraan, waar het zijn functie als ionenkanaal dient te vervullen. Dit transportprobleem kon gecorrigeerd worden door de omgevingstemperatuur te verlagen of door chemische stoffen aan het eiwit te binden. Ondat tetrimerisatie van wild type met gemuteerde subeenheden niet mogelijk was op $37^{\circ} \mathrm{C}$, is de helft van het totaal aantal kanalen niet functioneel (haploinsufficientie) en kan men niet spreken van een dominant negatief effect.

Hoofdstuk 3 beschrijft een LQTS patient waarin twee missense mutaties in twee verschillende LQTS genen werden gevonden. De eerst gevonden missense mutatie (A572D, SCN5A) kon geen verklaring geven voor de LQTS symptomen omdat die werd overgeërfd langs de maternale tak van de familie terwijl LOTS karateristieken alleen in de patternale tak voorkwamen. Door verdere screening van andere LOTS genen werd een tweede missense mutatie gevonden in een ander gen (V254M, KCNQ1), die de 
LOTS karakteristieken in de familieleden langs paternale kant wél kon verklaren. De observatie dat een Lơ's patiént meer dan één mutatie kan dragen, elk met een verschillende pathogene bijdrage tot het fenotype, geeft het belang van een goede strategle voor grondige screening van alle gekende LQTS genen aan.

Hoofdstuk 4 beschijft twee grote LQTS families waarin een causale mutatie werd gevonden in het KCNH2 gen voor elke familie, respectievilijk E698X en P872f5877. Beide mutaties leiden tot eem prematuur stopcodon waardoor een gedeelte van het $C$ terminale eindstuk van het elwit ontbreekt. Enkel het P872f5877 gemuteerde HERG eiwit kwam tot expressie, terwijl het E698X HERG eiwit nauwelijks aantoonbaar was. Het P872f5877 HERG elwit was functioneel, maar het transport naar de celmembraan bleek verstoord door een gedeeltelijke retentie in het endoplasmatisch reticulum. De kinetiek van P872fs877 mutante homo-multimeren was vergelijkbaar met wild type homo-multimeren, maar bij de vorming van hetero-multimere kanalen ontstaan kinetische verschillen ten opzichte van wild type kanallen. Mutatie E698X geeft dus. aanleiding tot $50 \%$ haploinsufficiëntie; mutatie $P 872 f 5877$ resulteert in haploinsufficiëntie gecombineerd met een kinetisch dominant negatief effect.

Hoofdstuk 5 illustreert de link tussen congenitale en verworven LQTS. Het genomische DNA van een gezonde vrijwilliger, die deelnam aan een klinische studie, werd gescreened voor mutaties in LOTS genen vanwege een verlenging van het QT interval die werd geobserveerd als respons op de toediening van medicatie. Een KCNH2 nonsense mutatie (Y667X) werd gevonden, die was overgeërfid van zijn moeder. In beide familieleden bleek het QT interval verlengd, maar verder waren beiden asymptomatisch. Deze studie toont aan dat de frequentie van congenitaal LQTS in de normalle bevolking mogelijkerwijs onderschat wordt en dat de asymptomatische LOTS patiënten meer gevoelig kunnen zijn voor het ontstaan van ritmestoornissen door medicatie.

In Hoofdstuk 6 werd gezocht naar een genetische achtergrond van variabele CYP3A5 expressie. De CYP3A4 en CYP3A5 eiwitten zijn betrokken in het metabolisme van vele endo- en exogene stoffen, en vertonen qua substraatspecificiteit veel overlap. Een groot deel van de medicijnen die verworven LQTS kunnen veroorzaken worden door deze enzymen afgebroken. De expressie van CYP3A5 is zeer variabel: in slechts 10-30\% van de Caucasische populatie kan CYP3A5 expressie worden aangetoond in de lever. Door middel van mutatiescreening ontdekten we twee DNA polymorfismen in de promotor regio van het CYP3A5P1 gen, die in linkage desequilibrium zijn. Het minst frequente allel van deze polymorfismen is geassocieerd met een hogere, hepatische expressie van CYP3A5 mRNA en eiwit. De Caucasische populatiefrequentie van dit allel bedroeg $18 \%$, in lijn met het percentage van de populatie dat hogere CYP3A5 expressie vertoont.

In Hoofdstuk 7. werden de bevindingen van hoofdstuk 5 en 6 in een groep van 32 patiënten met verworven LQTS getest. Slechts een klein percentage (6\%) van deze patiënten blijkt drager van een overgeërfde mutatie in een LQTS gen. De patiënten waarin LQTS was geïnduceerd door een CYP3A4/CYP3A5 substraat bezaten allen een 
CYP3A5P1 genotype dat is geassocieerd met een lagere CYP3A5 expressie. Deze observatie dient in de toekomst in een grotere patientengroep bekeken te worden om de statistische relevantie te kunnen berekenen.

Tenslotte worden de bevindingen van de voorgaande hoofdstukken bediscussieerd in Hoofdstuk 8. De toegevoegde waarde, maar ook de beperkingen, van mutatiescreening van LQTS genes in congenitaall en verworven LQTS patiënten wordt besproken, alsook de nieuwe inzichten in de functionele consequenties wan de gevonden mutaties. Tenslotte worden mogelijkheden voorgesteld voor verder onderzoek in beide vormen van LQTS, die kunnen leiden tot een verbeterd inzicht in de aandoeningen en efficiëntere therapieën. 
$$
152
$$ 


\section{Dankwoord}

Wanneer je kunt spreken van een aparte manier van promoveren, dan denk ik dat mijn promotieperiode daar een goed voorbeeld van is. $\mathrm{Na}$ mijn studie scheikundige Technologie aan de TU Eindhoven wist ik all snel dat de genetica mijn interesse had gewekt en dat ik daarin verder wilde gaan. Als Research Assistant bij Janssen Pharmaceutica in de afdeling Experimentele Moleculaire Biologie onder leiding van Martin Armstrong en Walter Luyten, deed ik meer ervaring op in het vakgebied. Eind $1998 \mathrm{kreeg}$ ik de kans om binnen Janssen mijn promotie-onderzoek te beginnen. Met steun van Martin en Walter gaf Frank Konings mij toestemming om op het long QT project mijn promotie uit te voeren. Prof. dr. Marcel Borgers, die zowel binnen Janssen als op de Universiteit Maastricht werkzaam was, stemde toe om als mijn eerste Promotor op te treden. Mede dankzij hen is dit boekwerk tot stand gekomen en ik wil al deze mensen daarom enorm bedanken voor hum aanmoediging en steun die ik de afgelopen vier jaar van hen heb gekregen.

Door reorganisaties binnen Janssen Pharmaceutica kwam ik in de groep Pharmacogenomics terecht en kreeg hierdoor andere begeleiders en collega's. Ik wil graag Nadine Cohen, Ron Gilissen, Martin Armstrong en Jeroen Aerssens bedanken voor hun inzet, begeleiding en goede adviezen gedurende de afgelopen 4 jaar. I would like to give special thanks to the director of my department at J\&J, Nadine Cohen, for her advise, guidance and support during my PhD student period. Speciale dank ben ik verschuldigd aan Jeroen Aerssens. In de loop van de 4 jaar zijn we steeds beter gaan samenwerken, zelfs nog beter na de reorganisatie, die voor de hele PGX groep een lastige periode inhield. Jeroen is mijns inziens een zeer goede scientist met enorm veel kennis, inzicht en precisie. Met altijd een puntje van kritiek is hij een geweldige begeleider en leraar voor mij geweest en ik ben zeer blij dat ik mede dankzij hem als Post-Doc ben aangenomen in de afdeling Populatie Genetica aan de Universiteit Maastricht. Mijn "labcollega's" Ann Marien, Lieve van der Velde en Wim Keysers zijn naast collega's in de Pharmacogenomics groep ook zeer goede vrienden van mij geworden. I wil hen ontzettend bedanken voor de gezellige periode die ik met hen in het lab heb meegemaakt, alsmede de hulp die ik altijd van hen kreeg als ik daarom vroeg. Ondanks dat we niet meer dezelfde werkgever hebben ben ik ervan overtuigd dat we nog lang contact zullen houden. Ook mijn andere collega's van de PGX-afdeling Jean-Marc Neefs en Jan Aerts wil ik bedanken voor hun hulp en gezelligheid.

Tijdens mijn promotieonderzoek heb ik met verschillende groepen samengewerkt op het gebied van long QT syndrome research. Een van die groepen was het laboratorium voor Moleculaire Biophysica, Fysiologie en Farmacologie aan de Universiteit van Antwerpen (UIA) waar ik gedurende 6 maanden gastonderzoeker ben geweest. Ik denk dat ik tijdens deze periode me pas een echte AlO heb gevoeld gezien hier nog drie andere AlO's aan hun project bezig waren. Prof. dr. Dirk Snyders en Dr. Adam Raes hebben mij gedurende deze periode bekend gemaakt met de wereld van de "patch 
clamp" electrophysiology, een zeer interessante, doch moeilijke techniek. Deze techniek heeft ernorm veel bijgedragen aan mijn proefschrift en ik wil Dirk en Adam dan ook heel hartelijk bedanken voor hun goede begeleiding. Ook de andere mensen van dit labo, te weten Diane, Natascha, Alain, Wim, Iris, Evy en Tine wil ik graag bedanken voor hun hul $p$ en gezeligheid.

Ook met de afdeling Klinische Genetica van de Universiteit Maastricht heb ik veel samengewerkt voornamelijk met Roselie Jongbloed en Bert Smeets. Roselie zal ook haar proefschrift binnenkort indienen op het gebied van Long OT syndrome en we hebben samen enige projecten opgezet op LOTS families. Omdat we op een dusdanig gelijk onderwerp werkten was ik zeer verheugd dat Bert naast co-promoter van Roselie ook mijn co-promotor wilde zijn. Het was voor mij een zeer plezierige ervaring om met hen beiden over long QT syndrome te discussieren en nieuwe ideeen op te doen.

Verder wil ik mijn ouders, mijn vriend Maarten, zijn ouders en de leden en reunisten van Dispuut Briljant van harte bedanken voor de belangstelling en steun die ik van hen heb gekregen in de afgelopen jaren.

Mede dankzij alle mensen die ik hierboven heb genoemd ben ik zeer trots op het proefschrift dat tot stand is gekomen en nu voor u ligt! 


\section{Curriculum vitae}

Aimée Paulussen werd geboren op 17 december 1971 te Middelburg. Van 1984 tot 1990 doorliep zij het Voortgezet Wetenschappelijk Onderwijs (VWO) aan het Newman College in Breda. Vervolgens volgde zij de opleiding Scheikundige Technologie aan de Technische Universiteit Eindhoven (TUE). Tijdens deze opleiding deed zij haar bedrijfsstage bij PURAC Biochem in Gorinchem. Haar afstudeerstage volgde zij bij het Centraal Hematologisch Laboratorium (CHL) in het Academisch Ziekenhuis St. Radboud te Nijmegen. Na het behalen van haar ingenieursdiploma eind 1996, begon zij in 1997 haar loopbaan als research assistant bij Janssen Pharmaceutica in Beerse, Belgie. Eind 1998 begon zij binnen Janssen Pharmaceutica aan haar PhD project over long QT syndrome en werd tegelijkertijd ais Assistant in Opleiding (AlO) aangesteld aan de Universiteit Maastricht (Promotor: Prof. dr. Marcel Borgers, co-promotores: Dr. ir. Jeroen Aerssens, Dr. Bert Smeets).

Sinds 1 februari 2003 is Aimée aangesteld als Post-Doc aan de Universiteit Maastricht in de Department Genetics \& Cell Biology, sectie Population Genetics, Genomics and Bioinformatics. 


\section{Publications}

1. Aimée Paulussen, Ping Yang, Menelas Pangalos, Peter Verhasselt; Roger Marrannes, Christel Verfaille, Ine Vandenberk, Raf Crabbe, Frank Konings, Walter Luyten, Armstrong Martin. Analysis of the human KCNH2 (HERC) gene: Identification and characterisation of a novel mutation $\mathrm{Y} 667 \mathrm{X}$ associated with long QT syndrome and a mon-pathological 9 bp insertion. Human Mutation $2000 ; 15(5): 483$.

2. Aimée Paulussen, Karel Lavrijsen, Hilde Bohets Jan Hendrickx, Peter Verhasselt, Walter Luyten, Frank Konings, Martin Armstrong. Two linked variations in transcriptional regulatory elements of the CYP3A5 gene constitute the major genetic determinant of polymorphic activity in humans. Pharmacogenetics 2000; $10: 415-424$.

3. Aimée Paulussen, Adam Raes, Gert Matthijs, Dirk I Snijders "Nadine Cohen, Jeroen Aerssens. A novel mutation (T65P) in the PAS domain of the human potassium channel (HERG) results in the long OT syndrome by trafficking deficiency. Journal of Biological Chemistry $2002 ; 277$ (50): 48610-48616.

4. Aimée Paulussen, Gert Matthijs, Marc Gewillig, Peter Verhasselt, Nadine Cohen, Jeroen Aerssens. Mutation analysis in congenital long QT syndrome- a case with missense mutations in KCNQ1 and SCN5A. Genetic Testing 2003; 7(1): 57 61.

5. Aimée Paulussen, Ran Gilissen, Jeroen Aerssens, Pieter Doevendans, Peter Verhasselt, Bert Smeets, Eric Schulze-Bahr, Wilhelm Haverkamp, Günther Breithardt, Nadine Cohen, Martin Armstrong. Genetic susceptibility to acquired long OT syndrome: the impact of congenitall long QT genes and drug metabolising enzyme genes. Article submitted. 


\section{APPENDIX 1: KCNQ1 mutations}

\begin{tabular}{|c|c|c|c|c|c|c|c|}
\hline $\begin{array}{l}\text { Nucleotide } \\
\text { change }\end{array}$ & $\begin{array}{l}\text { Coding } \\
\text { change }\end{array}$ & Region & \#fam & Type & $\begin{array}{l}\text { Functional } \\
\text { effect }\end{array}$ & $\begin{array}{l}\text { Dom. } \\
\text { negative }\end{array}$ & Ref. \\
\hline $211-219$ del & $\begin{array}{l}71 \\
73 \text { delAAP }\end{array}$ & $\mathrm{N}$-term & 1 & RW5 & & & (30) \\
\hline $332 A>C$ & $\$ 111 C$ & $\mathrm{~N}$-term & 1 & RW5 & & & (21) \\
\hline $341 T>C$ & L14P & $\mathrm{N}$-term & 1 & RWS & & & $(109)$ \\
\hline $350 \subset \mathrm{T}$ & $P_{117 \mathrm{~L}}$ & $\mathrm{~N}$-term & 1 & SIDS & & & (43) \\
\hline $365 T \times C$ & L.122P & $S 2$ & 1 & RWS & & & (17) \\
\hline & $\mathrm{R} 130 \mathrm{C}$ & 52 & 1 & RWS & & & (35) \\
\hline 451delCT & & $\$ 2$ & 1 & JLNS & & & (15) \\
\hline $470 \mathrm{~T}>\mathrm{G}$ & $\mathrm{F} 157 \mathrm{C}$ & $S_{2}$ & 1 & RWS & & & (44) \\
\hline $477+1 G>A$ & 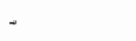 & 5.2 & 1 & JLNS & & & (21) \\
\hline $477+5 \cos A$ & - & 52 & 1 & JLNS & & & (18) \\
\hline $478 G>A$ & E160K & $\mathrm{S}_{2}$ & 1 & RWS & & & (21) \\
\hline $\begin{array}{l}500-502 \mathrm{del} \\
\text { (ATCGi) }\end{array}$ & $\begin{array}{l}\text { F167W/ } \\
\text { del168G }\end{array}$ & $\$ 2$ & 1 & RWS & & & (1) \\
\hline $502 G \times C / A$ & G168R & 5.2 & 8 & RWS & & & $\begin{array}{l}(4),(8) \\
(21),(109)\end{array}$ \\
\hline 504delG & - & 52 & 1 & RWS & & & (16) \\
\hline $513 C>G$ & $\gamma_{171 X}$ & $52-53$ & 1 & ILNS & & & (45) \\
\hline $520 C>T$ & $\mathbb{R} 174 \mathrm{C}$ & $52-53$ & 1 & RWS & non-functional & yes & $(4),(5)$ \\
\hline $521 G>A$ & R174H & $52-53 i$ & 1. & RWS & & & (21) \\
\hline $532 \mathrm{G} \times \mathrm{C}$ & A178P & $52-53$ & 1 & RWS & & & (1) \\
\hline $532 \mathrm{G}>\mathrm{A}$ & A $178 \mathrm{~T}$ & $52-53$ & 1 & RWS & & & (19) \\
\hline $535 G>A$ & G179s & $52-53$ & 1 & RWS & & & (21) \\
\hline 551. $A>C$ & $\gamma_{1845}$ & $52-53$ & 2 & RWS & & & $(21),(34)$ \\
\hline $565 \mathrm{G}>\mathrm{A}$ & G189R & $S 2.53$ & 3 & RW'S & & & $(1)(35)$ \\
\hline 567 inso & $G 189 \mathrm{fs} / 94$ & $52-53$ & & RWS & & & (21) \\
\hline $569 G \gg \mathrm{A}$ & R190Q & 52.53 & 2 & RWS & non-functional & no & (1), (4), (18) \\
\hline $572 \mathrm{~T}>\mathrm{C}$ & L.191P & $\$ 2.53$ & 1 & $\begin{array}{l}\text { RWS } \\
\text { (Chinese) }\end{array}$ & & & $(110)$ \\
\hline 572 del 5 & - & 52.53 & 7 & JLNS & non-functional & no & $\begin{array}{l}(31),(32) \\
(38)\end{array}$ \\
\hline $580 G>C$ & A194P & 52.53 & 1 & RWS & & & (21) \\
\hline $639+5, G>A$ & - & 53 & 1 & RWS & & & (30) \\
\hline $674 \mathrm{CPT}$ & $5225 \mathrm{~L}$ & $S_{4}$ & 2 & RWS ( $r)$ & $\begin{array}{l}\text { v.d.activation: } \\
\text { pos shift }\end{array}$ & yes & $\begin{array}{l}(21),(22) \\
(37)\end{array}$ \\
\hline $724 \mathrm{G}>\mathrm{A}$ & $D 242 N$ & $\$ 4-55$ & 1 & RWS & & & (36) \\
\hline $727 \mathrm{C}>\mathrm{T}$ & $2243 C$ & $54-55$ & 2 & RWS & & & (21) \\
\hline $728 \mathrm{G}>\mathrm{A}$ & $\mathrm{R} 243 \mathrm{H}$ & $54-55$ & 1 & JLNS & $\begin{array}{l}\text { v.d.activation/ } \\
\text { inactivation: } \\
\text { pos shift, d.r. } \uparrow\end{array}$ & yes: & $\begin{array}{l}(13),(14) \\
(18)\end{array}$ \\
\hline $742 \mathrm{C}>\mathrm{T}$ & W248R & $\$ 4-55$ & 1 & RWS & $\begin{array}{l}\text { v.d.activation/i } \\
\text { nactivation: } \\
\text { pos shift,a.r. } \downarrow\end{array}$ & yes. & $(14),(21)$ \\
\hline $749 \mathrm{~T}>\mathrm{A}$ & $\mathrm{L2} 250 \mathrm{H}$ & $54 \cdot 55$ & 1 & RWS & & & (36) \\
\hline
\end{tabular}




\begin{tabular}{|c|c|c|c|c|c|c|c|}
\hline $760 G>A$ & $\sqrt{254 M}$ & $54-55$ & 6 & RWS & & & $\begin{array}{l}(1),(2),(4), \\
(21)\end{array}$ \\
\hline $775 \mathrm{C}>\mathrm{T}$ & R259C & $54-55$ & 2 & $\begin{array}{l}\text { RWS/ } \\
\text { acquired } \\
\text { LQTS }\end{array}$ & $\begin{array}{l}\text { reduced } \\
\text { amplitude }\end{array}$ & yes. & (33). (109) \\
\hline $783 G>C$ & $E 2610$ & $54-55$ & 1 & RWS & non-functional & yes & $(32),(38)$ \\
\hline $781 G>A$ & E261K & $54-55$ & 1 & RWS & non-functional & no & $(4),(14)$ \\
\hline 797 T $>C$ & $L 266 \mathrm{P}$ & 55 & 1 & RWS & & & (21) \\
\hline $805 G>A$ & G26.95 & S5 & 1 & RWS & & & (30) \\
\hline $806 G>A$ & C269D & S5 & 3 & RWS & non-functional & yes & $(4),(5),(21)$ \\
\hline $817 C>\pi$ & $\mathrm{L} 273 \mathrm{~F}$ & 55 & 3 & RWS & & & $\begin{array}{l}(1),(21) \\
(38)\end{array}$ \\
\hline $8: 24 T>C$ & F275S & $\$ 5$ & 1 & $\begin{array}{l}\text { RWS } \\
\text { (Chinese) }\end{array}$ & & & $(110)$ \\
\hline $830 T>C$ & $5277 \mathrm{~L}$ & \$5 & 1 & $\begin{array}{l}\text { RWS } \\
\text { (Chinese) }\end{array}$ & & & (110) \\
\hline $842 A>G$ & $\mathrm{r} 281 \mathrm{C}$ & $\$ 5$ & 1 & RWS $(r)$ & non-functional & yes & $(22),(37)$ \\
\hline $8980>A$ & A300T & \$5-pore & 1 & RWS (r) & $\begin{array}{l}\text { w.diactivation: } \\
\text { neg shift }\end{array}$ & no & $(23),(37)$ \\
\hline $914 G>C$ & W305S & pore & 2 & JLNS & non-functional & yes & (5). (9) \\
\hline $916 \mathrm{G}>\mathrm{A}$ & G306R & pore & 1 & RWS & non-functional & yes: & (1). (7) \\
\hline $917 \mathrm{G}>\mathrm{T}$ & G306V & pore & 1 & $\begin{array}{l}\text { RWS } \\
\text { (Chinese) }\end{array}$ & & & $(110)$ \\
\hline $921+1 G>T$ & - & pore & 1 & RWS & & & (21) \\
\hline $922-1 G>C$ & & pore & 1 & RWS & & & $(12)$ \\
\hline $922-2 A>C$ & - & pore & 1 & RWS & & & (21) \\
\hline $926 \mathrm{C}>\mathrm{G}$ & T309R & pore & 1 & RWS & & & (4) \\
\hline $928 \mathrm{G}>\mathrm{A}$ & V310I & pore & 1 & RWS & & & (21) \\
\hline $932 C>T$ & T311! & pore & 1 & RWS & non-functional & yes & $(6),(26)$ \\
\hline $935 \mathrm{CP} \pi$ & $T 3121$ & pore & 2 & RWS & non-functional & yes & $(1),(7),(21)$ \\
\hline $939 \mathrm{C}>\mathrm{G}$ & $1313 M$ & pore & 1 & RWS & & & (19) \\
\hline $940 \mathrm{G}>\mathrm{A}$ & $G 3145$ & pore & 6 & RWS & non-functional & yes & $\begin{array}{l}(4),(5),(7) \\
(8),(25) \\
(36)\end{array}$ \\
\hline $944 \mathrm{~A}>\mathrm{C}$ & $\gamma / 3155$ & pore & 2 & RWS & non-functional & yes & (4). (5) \\
\hline $944 \mathrm{~A}>\mathrm{G}$ & $1 / 315 C$ & pore & 3 & $\begin{array}{l}\text { RWS } \\
\text { arcquired } \\
\text { LQTS }\end{array}$ & non-functional & yes & $\begin{array}{l}(8),(22) \\
(37),(41)\end{array}$ \\
\hline $946 \mathrm{G}>\mathrm{C}$ & G316R & pore & 1 & RWS & & & $(109)$ \\
\hline $949 C>A$ & D317N & pore & 2 & RWS & mon-functional & yes: & $(7),(26)$ \\
\hline $954 G>C$ & $\mathrm{~K} 318 \mathrm{~N}$ & pore & 1 & RWS & & & (8) \\
\hline $958 \mathrm{C}>\mathrm{G}$ & P320A & pore & 1 & RWS & & & (4) \\
\hline $973 G>A$ & G325R & $\$ 6$ & 4 & RWS & & & $\begin{array}{l}(4),(19) \\
(21)\end{array}$ \\
\hline $1008 \mathrm{delC}$ & . & S6 & 1 & JLNS & non-functional & no & $(39) \cdot(38)$ \\
\hline $\begin{array}{l}1015- \\
1017 \mathrm{del}\end{array}$ & delf339 & S6 & 1 & RWS & & & $(46)$ \\
\hline $\begin{array}{l}1017 \\
1019 \mathrm{del}\end{array}$ & delF340 & 56 & 1 & RWS & & & (21) \\
\hline$\triangle G G T$ & $5 P / N 341$ & $\$ 6$ & 1 & RWS & & & (10) \\
\hline
\end{tabular}




\begin{tabular}{|c|c|c|c|c|c|c|c|}
\hline $1022 \mathrm{Cs}$ & A34 $1 E$ & 56 & 5 & RWS & & & $\begin{array}{l}(1) \cdot(20) . \\
(21)\end{array}$ \\
\hline $1022 C \%$ & A341V & 56 & 9 & RWVS & & & $\begin{array}{l}(1) .(4) \\
(10) \cdot(25) \\
(27) .(109)\end{array}$ \\
\hline $1024 \mathrm{C}$. T & $1342 F$ & 56 & 1 & RWS & non-functional & yes & $(4),(5)$ \\
\hline $1031 \mathrm{Cs}$ & $\mathrm{A} 344 \mathrm{~V}$ & 56 & 1 & RWNS & & & (4) \\
\hline $1032 \mathrm{GSA}$ & A $344 . A$ & 56 & 9 & RWS & & & $\begin{array}{l}(10)(11) \\
(12),(21) \\
(36)\end{array}$ \\
\hline $1032 \mathrm{Ci}, \mathrm{C}$ & $\mathrm{A}_{344 \mathrm{~A}}$ & 56 & 1 & RWS & & & $(12)$ \\
\hline $1033 G>C$ & C.345R & 56 & 1 & RWS & & & $(28)$ \\
\hline $10336 \%$ & C345E & 56 & 1 & RWS & & & $(1)$ \\
\hline $1046 \mathrm{C}>0$ & $5349 \mathrm{~W}$ & 56 & 1 & RWS & & & $(21)$ \\
\hline $105 B \mathrm{~T}>\mathrm{C}$ & $\angle 353 P$ & 56 & 1 & RWS & & & $(8)$ \\
\hline $1066 \mathrm{C}>\mathrm{T}$ & Q356x & 56 & 1 & RWS & & & $(21)$ \\
\hline $1096 C>T$ & $\mathrm{R} 366 \mathrm{~W}$ & 56.Cterm & 1 & RWS & & & $(8)$ \\
\hline $1097 \mathrm{G}>\mathrm{A}$ & $\mathrm{R} 366 \mathrm{Q}$ & s6-cterm & 1 & RWS & & & $(21)$ \\
\hline $1097 \mathrm{G}>\mathrm{C}$ & $\mathrm{R} 366 \mathrm{P}$ & 56.Cterm & 1 & RWS & & & $(19)$ \\
\hline $1111 \mathrm{G}>\mathrm{A}$ & $A 371 T$ & 56-Cterm & 1 & RWS & & & $(4)$ \\
\hline $1117 T>C$ & $5373 P$ & 56-Cterm & 1 & RWS & & & $(34)$ \\
\hline $1172 \mathrm{Cs}$ & T391: & 56-ctern & 1 & RWS & & & $(21)$ \\
\hline $1174 C>T$ & W329R & 56-Cterm & $\mathbb{1}$ & RWS & & & $(34)$ \\
\hline 118 dele & - & S6-Cterm & 1 & لLNS & & & $(16)$ \\
\hline 13,43 delc & - & S6mCterm & 1 & RWS & & & $(24)$ \\
\hline $1343 \mathrm{C}>\mathrm{G}$ & P448R & 56-cterm & 2 & RWS & & & $(21)$ \\
\hline $1552 \mathrm{C}>\pi$ & $R 518 X$ & 56-Cterm & 9 & JNS/RWS & non-functional & no & $\begin{array}{l}(16),(21) \\
(29),(32) \\
(38)\end{array}$ \\
\hline $1557 \mathrm{G}>\mathrm{A}$ & $K .557 \mathrm{E}$ & S6.Cterm & 1 & RWS & & & $(109)$ \\
\hline $1573 G>A$ & $A 525 \mathrm{~T}$ & S6-Cterm & 1 & RWS (r) & & & $(29)$ \\
\hline${ }^{1} \mathrm{BS8} 6 \mathrm{C} \times$ & $\sin _{3} 3 x$ & $560+$ termi & 5 & $\begin{array}{l}\text { MNSi } \\
\text { RWS }\end{array}$ & 7ฉn-finfutonat & $\eta ⿻$ & $\begin{array}{l}(22),(32) \\
(38)\end{array}$ \\
\hline $1597 \mathrm{C}>\mathrm{T}$ & R533W & S6-Cterm & 1 & RWS $(\mathrm{r})$ & $\begin{array}{l}\text { vid.activation: } \\
\text { pos shift, d. } \mathrm{f} \text {. }\end{array}$ & yes & $(18)$ \\
\hline $1615 \mathrm{C}$ & $R 539 W$ & S6-Cterm & 1 & RWS & $\begin{array}{l}\text { v.dactivation: } \\
\text { pos slafft, d.r. }\end{array}$ & yes & $(18)$ \\
\hline $1630-7+8$ & - & 56-Cterm & 2 & JLNS & non-functional & yes & $(3),(5)$ \\
\hline $1663 \mathrm{C}>\mathrm{T}$ & R555C & C-term & 3 & RWS & $\begin{array}{l}\text { v.d.activation: } \\
\text { pos shift, deact } \\
\text { kin } \uparrow\end{array}$ & yes & (4). (5) \\
\hline $1697 \mathrm{COT}$ & $5566 \mathrm{~F}$ & C-term & 3 & RWS & & & $(21)$ \\
\hline $1747 \mathrm{Cs}$ & R583C & C-term & $\mathbb{1}$ & $\begin{array}{l}\text { Acquired } \\
\text { LQTS }\end{array}$ & $\begin{array}{l}\text { Reduced } \\
\text { amplitude } \\
\text { v.d.activation.: } \\
\text { pos. shift }\end{array}$ & & $(42)$ \\
\hline $1760 \mathrm{CST}$ & $\mathrm{T} 587 \mathrm{M}$ & C-term & 2 & $\begin{array}{l}\text { UNS/ } \\
\text { RWS }\end{array}$ & & & $(24),(36)$ \\
\hline $1766 \mathrm{O}>\mathrm{A}$ & 65890 & C-term & $34 / 2$ & RWS/ & & & $(45)$ \\
\hline
\end{tabular}




\begin{tabular}{|c|c|c|c|c|c|c|c|}
\hline & $\begin{array}{l}\text { (Finnish } \\
\text { founder) }\end{array}$ & & & JLNS & & & \\
\hline $1772 \mathrm{G}>\mathrm{A}$ & R591H & C-term & 1 & RWS & & & (24) \\
\hline $1781 \mathrm{G}>\mathrm{A}$ & R5940 & C-term & 4 & RWS & non-functional & no & $\begin{array}{l}(21),(38) \\
(109)\end{array}$ \\
\hline 1892 del 20 & - & C-term & 1 & JUNS & & & (24) \\
\hline 1893 ins & - & c-term & 1 & RWS & & & $(24)$ \\
\hline $1927 \mathrm{G}>\mathrm{A}$ & G6435 & C-term & $6(p)$ & RWS & $\begin{array}{l}\text { reduced } \\
\text { amplitude }\end{array}$ & no & (41) \\
\hline
\end{tabular}

Numbering from ATG startcodon in isoform 1 (Genbank accession number AFoo0 571). RWS=RomanoWard syndrome, JLNS=Jervell and Lange-Nielsen syndrome, SLDS $=$ sudden infant death syndrome. (p)= polymorphism, $(r)=$ recessive, $v . d .=$ woltage dependance, $d . r=$ deactivation rate, a.r. $=$ activation rate, pos $=$ positive, neg $=$ negative 


\section{APPENDIX 2: $\mathrm{KCNH} 2$ mutations}

\begin{tabular}{|c|c|c|c|c|c|c|c|}
\hline $\begin{array}{l}\text { Nucleotide } \\
\text { change }\end{array}$ & $\begin{array}{l}\text { Coding } \\
\text { change }\end{array}$ & Region & \#am & $\begin{array}{l}\text { Functional } \\
\text { effect }\end{array}$ & $\begin{array}{l}\text { Dominant } \\
\text { negative }\end{array}$ & Rescue & Refs. \\
\hline $77 G>T$ & 5261 & PAS & 1 & & & & (71) \\
\hline $87 C>A$ & F29L & PAS & 1 & d.r. $\uparrow$ & & & $(21),(59)$ \\
\hline $98 \mathrm{~A}>\mathrm{C}$ & N33T & PAS & 2 & d.r. $\uparrow$ & & & (21). (59) \\
\hline $131 G>T$ & C4.4F & PAS & 1 & & & & (78) \\
\hline $132 C>A$ & $C_{44} x$ & PAS & 1 & & & & (21) \\
\hline $140 \mathrm{G}>$ & $647 V$ & PAS & 1 & & & & (21) \\
\hline $157 \mathrm{G}>\mathrm{C}$ & G53R & PAS & 1. & d.r. $\uparrow$ & & & $(21),(59)$ \\
\hline $167 \mathrm{G}>\mathrm{A}$ & $\mathrm{R} 56 \mathrm{Q}$ & PAS & 1 & d.r. $\uparrow$ & $\begin{array}{l}\text { no(amp) } \\
\text { yes(kinetics) }\end{array}$ & & (21). (59) \\
\hline $172 \mathrm{G} \gg \mathrm{A}$ & E58K & PAS & 1 & & & & $(78)$ \\
\hline $193 \mathrm{~A}>\mathrm{C}$ & T65P & PAS & 1 & $\begin{array}{l}\text { Trafficking } \\
\text { deficient }\end{array}$ & no & $T+C$ & (58) \\
\hline $196 \mathrm{~T}>\mathrm{G}$ & C66G & PAS & 1 & d.r. $\uparrow$ & & & $(21),(59)$ \\
\hline $209 \mathrm{~A}>\mathrm{C}$ & H7OR & PAS & 2 & d.r. $\uparrow$ & & & $(21),(59)$ \\
\hline $21.5 \mathrm{C} \gg \mathrm{A}$ & P72O & PAS & 2 & & & & $21)$ \\
\hline 221-251del & $\mathrm{R} 73 \mathrm{fs} / 31$ & PAS & 1 & & & & (21) \\
\hline $232 G>C$ & A78P & PAS & 1 & d.r. $\uparrow$ & & & (21), (59) \\
\hline 234-25odup & A83fs/37 & PAS & 1 & & & & $(21)$ \\
\hline $241 C>T$ & Q81X & PAS & 1 & & & & $(21)$ \\
\hline $257 \mathrm{~T}>\mathrm{G}$ & L86R & PAS & 1 & d.r. $\uparrow$ & & & (21), (59) \\
\hline $260 T>C$ & L87P & PAS & 1. & & & & $(109)$ \\
\hline $296 A>C$ & Y9gs & PAS & 1. & & & & $(109)$ \\
\hline $340 \mathrm{C}>\mathrm{T}$ & P1145 & PAS & 1 & & & & $(78)$ \\
\hline $371 \mathrm{~T}>\mathrm{G}$ & $M 124 R$ & PAS-S1 & 1 & & & & $(71)$ \\
\hline $422-423$ ins $C$ & P141fs/2 & PAS-S1 & 1. & & & & (21) \\
\hline 453 delc & . & PAS-51 & 1 & & & & $(64),(73)$ \\
\hline $453-454$ ins $C$ & P151fs/179 & PAS-51 & 1 & & & & $(21)$ \\
\hline $526 C>T$ & R176W & PAS-51. & 1 & & & & $(64),(73)$ \\
\hline 558-600dup & - & PAS-S1. & 1 & & & & (74) \\
\hline $\begin{array}{l}582- \\
587 \text { délCCGTo }\end{array}$ & G192fs328 & PAS-S1 & 1 & & & & $(109)$ \\
\hline $724-725$ insc & P241fs/89 & PAS-S1 & 1 & & & & (21) \\
\hline 885 delc & $V_{2} 95 f s / 63$ & PAS-S1 & 1. & & & & (21) \\
\hline $934 C>T$ & R312C & PAS.51 & 1. & & & & (21) \\
\hline $1001 C>T$ & P334L & PAS-S1 & 1 & & & & (78) \\
\hline 1009 inst & $336 f 5355$ & PAS-S1 & 2 & & & & $(78)$ \\
\hline $1039 \mathrm{C}>\mathrm{T}$ & P3475 & PAS-51 & 3 & & & & $\begin{array}{l}(21) \\
(109)\end{array}$ \\
\hline $1128 \mathrm{G}>\mathrm{A}$ & Q376sp & PAS.S1 & 1 & & & & (21) \\
\hline $1129-2 \mathrm{~A}>\mathrm{G}$ & Q376sp & PAS-51 & 1. & & & & $(21)$ \\
\hline $1238 T>C$ & $\begin{array}{l}\text { L413P } \\
\text { (Chinese) }\end{array}$ & 51 & 1 & & & & $(110)$ \\
\hline 1261 delA & $Y_{420 f s 12}$ & 51 & 1 & non-functional & no & & $(47),(51)$ \\
\hline
\end{tabular}




\begin{tabular}{|c|c|c|c|c|c|c|c|}
\hline $1283 C>T$ & $5428 \mathrm{~L}$ & $51-52$ & 1 & & & & (71) \\
\hline $1283 \mathrm{C}>\mathrm{A}$ & $5428 x$ & $51-52$ & 1 & & & & $(22)$ \\
\hline $1307 \mathrm{CDT}$ & $\mathrm{T} 436 \mathrm{M}$ & $51-52$ & 1 & & & & $(22)$ \\
\hline 1332 G T & $\begin{array}{l}\text { E444D } \\
\text { (Chinese) }\end{array}$ & $\$ 1-52$ & 1 & & & & $(110)$ \\
\hline $1341 \mathrm{C}$ A & $Y 447 X$ & $\$ 1.52$ & 1 & & & & (109) \\
\hline $1352 \mathrm{C} \times \mathrm{T}$ & P451L & $\$ 2$ & 1 & & & & (64) \\
\hline $1408 \mathrm{~A}>\mathrm{G}$ & N4700 & $\$ 2$ & 1 & $\begin{array}{l}\text { Trafficking } \\
\text { deficient }\end{array}$ & yes & $\begin{array}{l}\text { yes } \\
(T+C)\end{array}$ & $\begin{array}{l}(47) \\
(51),(57)\end{array}$ \\
\hline $1.421 \mathrm{CDT}$ & $T 4741$ & $52-53$ & 1 & $\begin{array}{l}\text { v.d. act: neg } \\
\text { shift }\end{array}$ & & & (19) \\
\hline $1468 G>A$ & A490T & $\$ 2-53$ & 1 & $\begin{array}{l}\text { Reduced } \\
\text { amplitude }\end{array}$ & & & $(77)$ \\
\hline $1479 C>C$ & $\gamma_{493 X}$ & $52-53$ & 1 & & & & $(52)$ \\
\hline $1498-1525 \mathrm{del}$ & $\Delta 1500-F 508$ & 53 & 1 & non-functional & no & & $(47),(51)$ \\
\hline $1501 \mathrm{~A}>\mathrm{G}$ & DS01N & 53 & 1 & & & & $(109)$ \\
\hline $1592 \mathrm{G}>\mathrm{A}$ & $R 5,310$ & 54 & 1 & & & & (21) \\
\hline $1600 \mathrm{C}>T$ & $\mathrm{R} 53,4 \mathrm{C}$ & 54 & 2 & $\begin{array}{l}\text { w.d. act: neg } \\
\text { shift, a.r. } \uparrow \\
\text { d.r. } \uparrow, \text { s.s.i. } \downarrow\end{array}$ & no & & $\begin{array}{l}(52) \\
(60),(62)\end{array}$ \\
\hline 1631delAG & - & $54: 55$ & 1 & & & & $(64),(73)$ \\
\hline $1655 \mathrm{~T}>\mathrm{C}$ & $\begin{array}{l}\text { L552S } \\
\text { (Finninish } \\
\text { founder) }\end{array}$ & 55 & 3 & & & & $\begin{array}{l}(21) \\
(73) \\
(111)\end{array}$ \\
\hline 1671 delT & T556fs 7 & 55 & 1 & & & & $(21)$ \\
\hline $1672 \mathrm{G}>\mathrm{C}$ & A558P & $\$ 5$ & 1 & & & & (34) \\
\hline $1676 \mathrm{~T}>\mathrm{A}$ & $\begin{array}{l}\lfloor 559 \mathrm{H} \\
\text { (Chinese) }\end{array}$ & $\$ 5$ & 1 & & & & $(110)$ \\
\hline $1681 G>A$ & A561T & $\$ 5$ & 4 & & & & $(48),(21)$ \\
\hline $1682 \mathrm{C}>\mathrm{T}$ & A561V & $\$ 5$ & 6 & $\begin{array}{l}\text { Trafficking } \\
\text { deficient }\end{array}$ & yes & $\begin{array}{l}\text { no } \\
(T+C)\end{array}$ & $\begin{array}{l}(47),(51), \\
(19),(21), \\
(66), \\
(69),(22)\end{array}$ \\
\hline $1691 \mathrm{~T}>\mathrm{C}$ & $4564 \mathrm{P}$ & $\$ 5$ & 1 & & & & $(75)$ \\
\hline $1704.6 \mathrm{~T}$ & W568C & 55 & 1 & & & & (78) \\
\hline $1705 T \times C$ & $\mathrm{Y} 569 \mathrm{H}$ & 55 & 1 & & & & $(64),(73)$ \\
\hline $1714 G>T$ & G572C & 55 -pore & 1 & & & & (8) \\
\hline $1714 G \times C$ & G572R & 55-pore & 1 & & & & (63) \\
\hline $1724 \mathrm{~A}>\mathrm{G}$ & $E 5750$ & 55-pore & 1 & & & & (78) \\
\hline $1744 C>\pi$ & $\mathrm{R} 582 \mathrm{C}$ & s5i-pore & 1 & & & & (34) \\
\hline $1750 G>A$ & 65845 & 55-pore & 2 & & & & $\begin{array}{l}(21) \\
(64),(73)\end{array}$ \\
\hline $1755 \mathrm{G} \times \mathrm{T}$ & W585C & 55-pore & 1 & & & & $(21)$ \\
\hline $1762 A>G$ & N5880 & 55-pore & 1 & & & & (8) \\
\hline $1777 \mathrm{AsT}$ & $4593 x$ & 55-pore & 1 & & & & $(7 \pm)$ \\
\hline $1778 \mathrm{~T}>\mathrm{C}$ & $1593 R$ & 55-pore & 1 & non-functiona! & & & $(49),(54)$ \\
\hline $1778 \mathrm{~T}>\mathrm{C}$ & $1593 \mathrm{~T}$ & 55-pore & 1 & & & & $(21)$ \\
\hline $1787 \mathrm{C} \mathrm{T}$ & P596L & 55-pore & 1 & & & & (71) \\
\hline $1801 \mathrm{C}>\mathrm{A}$ & 06015 & 55-pore & 2 & Trafficking & no & & $(55),(56)$ \\
\hline
\end{tabular}




\begin{tabular}{|c|c|c|c|c|c|c|c|}
\hline & & & & deficient & & & $(64) \cdot(73)$ \\
\hline 1810 GISA & 66045 & S5-pore & 2 & & & & $(21),(34)$ \\
\hline $1825 \mathrm{Gi}>\mathrm{A}$ & D $609 \mathbb{N}$ & S5pore & 2 & & & & $(21) \cdot(78)$ \\
\hline $1831 \mathrm{~T}>\mathrm{C}$ & YG11H & 55-pore & 1 & $\begin{array}{l}\text { Trafficking } \\
\text { deficient }\end{array}$ & & & $(19) \cdot(54)$ \\
\hline $1834 \mathrm{Gi} T$ & V612L & 55-pore & 1 & non-functionall & yes & & $953) \cdot(70)$ \\
\hline $1838 \mathrm{CST}$ & T613M & pore & 4 & non-functional & yes & & $\begin{array}{l}(21),(64) \\
(70),(34)\end{array}$ \\
\hline $1841 \mathrm{CDT}$ & A61.4V & pore & 7 & & & & $\begin{array}{l}(8),(19) \\
(53),(22) \\
(76)\end{array}$ \\
\hline $1843 \mathrm{Cs} G$ & $4615 \mathrm{~V}$ & pore & 1 & $\begin{array}{l}\text { reduced } \\
\text { current }\end{array}$ & yes & & $(21) \cdot(70)$ \\
\hline $1862 \mathrm{G}>\mathrm{A}$ & $5621 \mathrm{~N}$ & pore & 1 & & & & (78) \\
\hline $1876 \mathrm{C}>\mathrm{A}$ & G6265 & pore & 1 & & & & (21) \\
\hline $1881 \mathrm{C}>\mathrm{G}$ & F $627 \mathrm{~L}$ & pore & 1 & & & & (21) \\
\hline $1882 \mathrm{G}>\mathrm{A}$ & 616285 & pore & 2 & non-functional & yes & & $\begin{array}{l}(47),(51) \\
(54),(21)\end{array}$ \\
\hline $1885 \mathrm{~A}>\mathrm{G}$ & N629D & pore & 1 & $\begin{array}{l}\text { gain of } \\
\text { function }\end{array}$ & yes & & $(53),(68)$ \\
\hline $1886 A>C$ & N6295 & pore & 1 & & & & (53) \\
\hline $1887 \mathrm{C}>\mathrm{A}$ & $\mathrm{N} 1629 \mathrm{~K}$ & pore & 1 & non-functional & yes & & $(61)$ \\
\hline $1888 G>C$ & V630L & pore & 1 & & & & (19) \\
\hline $1889 \mathrm{~T}>\mathrm{C}$ & V630A & pore & 1 & & & & (8) \\
\hline $1894 \mathrm{C}>\mathrm{T}$ & P6325 & pore & 1 & & & & (21) \\
\hline $1898 \mathrm{~A}>\mathrm{G}$ & $N 6335$ & pore & 1 & & & & (53) \\
\hline $1909 \mathrm{G}>\mathrm{A}$ & E637K & pore-56 & 1 & non-functional & yes & & (72) \\
\hline $1912 A>G$ & K638E & 56 & 1 & & & & (21) \\
\hline 1913-1915del & K638del & 56 & 1 & & & & (21) \\
\hline $1920 \mathrm{C}>\mathrm{A}$ & F640L & 56 & 1 & & & & (34) \\
\hline $1933 A>T$ & M645L & 56 & 1 & & & & (21) \\
\hline $\begin{array}{l}1951= \\
1952 \text { delAT }\end{array}$ & : & $\$ 6$ & 1 & & & & $(53)$ \\
\hline $2001 \mathrm{C}>\mathrm{A}$ & $Y 667 X$ & S6-CNBD & 1 & non-functional & no & & $(65)$ \\
\hline 2044 GST & $E 682 X$ & SG-CNBD & 1 & & & & (21) \\
\hline $2092 \mathrm{CPT}$ & E698x & 56-CNBD & 1 & & & & $(109)$ \\
\hline $2173 \mathrm{CPT}$ & Q725X & 56-CNBD & 1 & & & & (52) \\
\hline $\begin{array}{l}22118 \text { - } \\
2219 \text { inst }\end{array}$ & $H 739 f 5 / 63$ & S6-CNBD & 1 & & & & (21) \\
\hline $\mathrm{COT}$ & $R 744 x$ & 56-CNBD & 1 & & & & (71) \\
\hline $2254 \mathrm{C}>\mathrm{T}$ & R752W W & 56-CNBD & 1 & $\begin{array}{l}\text { Trafficking } \\
\text { deficient }\end{array}$ & no & $\begin{array}{l}\text { yes }(T) \\
\text { no }(C)\end{array}$ & $(21),(67)$ \\
\hline $2350 \mathrm{C}>\mathrm{T}$ & R784W & $\mathrm{CNBD}$ & 1 & $\begin{array}{l}\text { Reduced } \\
\text { amplitude } \\
\text { v.d.a.: pos shift }\end{array}$ & & & $(42)$ \\
\hline $2356-2376$ dup & 31bp dup & CNBD & 1 & & & & (52) \\
\hline 2395 delc & $1798 \mathrm{fs} / 10$ & CNBD & 1 & & & & (21) \\
\hline $2398+1 G>C$ & L799sp & CNBD & 2 & & & & $(47),(21)$ \\
\hline $2414 T>C$ & F805s & CNBD & 1 & & & & (21) \\
\hline $2414 \mathrm{~T}>\mathrm{G}$ & $\mathrm{F} 805 \mathrm{C}$ & CNBD & 1 & & & & $(21)$ \\
\hline
\end{tabular}




\begin{tabular}{|c|c|c|c|c|c|}
\hline $2453 \mathrm{C} T \mathrm{~T}$ & $5818 \mathrm{~L}$ & $C \mathbb{N B D}$ & 1 & \multirow{20}{*}{$\begin{array}{l}\text { Trafficking } \\
\text { deficient }\end{array}$} & (20) \\
\hline $2464 G>A$ & $V 822 \mathrm{M}$ & $\mathbb{N} \mathbb{N B D}$ & 2 & & $\begin{array}{l}(50) \\
(54),(20)\end{array}$ \\
\hline $2467 \mathrm{C}>\mathrm{T}$ & R823W & $\mathrm{CNBD}$ & 2 & & (21) \\
\hline 2471 ins $G$ & $R: 823 f 5828$ & CNBD & 1 & & $(109)$ \\
\hline $2582 \mathrm{~A}>\mathrm{T}$ & N.8611 & c-term & 1 & & (21) \\
\hline $2592+1 G>A$ & D864sp & C-term & 2 & & $(20) \cdot(21)$ \\
\hline 2616 delc & $P 872 f 5877$ & C-term & 1 & & $(109)$ \\
\hline 266odela & $K 886 f_{5} / 85$ & C-term & 1 & & (21) \\
\hline $2750 \mathrm{CDT}$ & P917L & C.term & 1 & & (21) \\
\hline 2762 delA & $R 920 f 5 / 51$ & C-term & 1 & & (21) \\
\hline $2764 \mathrm{CDT}$ & R922W & C-term & 1 & & (21) \\
\hline $\begin{array}{l}2775- \\
2776 \operatorname{ins} \mathrm{G}\end{array}$ & $G 925 f s / 13$ & C-term & 1 & & (21) \\
\hline $2879 G>A$ & $5960 \mathrm{~N}$ & C-term & 1 & & $(78)$ \\
\hline 2906delG & $P 968 \mathrm{fs} / 4$ & C-term & 1 & & (21) \\
\hline $\begin{array}{l}2959- \\
2960 \text { delCT }\end{array}$ & $\mathrm{P} 986 \mathrm{fs} / 130$ & C-term & 1 & & (21) \\
\hline - & W10o1X & c-term & 1 & & (71) \\
\hline $3040 \mathrm{C}>\mathrm{T}$ & $R 1014 X$ & C-term & 2 & & (21) \\
\hline 3094 delc & $G 1031 \mathrm{fs} / 24$ & c-term & 1 & & (21) \\
\hline 3108 insG & - & C-term & 1 & & (20) \\
\hline $\begin{array}{l}3303- \\
3304 \text { insc }\end{array}$ & P1101fs & C-term & 1 & & (21) \\
\hline \multicolumn{6}{|c|}{$\begin{array}{l}\text { Numbering from ATG startcadon (Genbank accession number U04270), fs= last amino-acid unaffected } \\
\text { by a frameshift (number after fs is the number of amino acids before termimation), sp= last unaffected } \\
\text { amino acid before predicted splice mutation, } T=\text { lower cell culture incubation temperature, } \\
\text { C=incubation with chemical thaperones, v.d. a=voltage dependance of activation, a.r. =activation rate, } \\
\text { d.r.=deactivation rate, s.s.i.=steady-state inactivation. }\end{array}$} \\
\hline
\end{tabular}




\section{APPENDIX 3: SCN5A mutations}

\begin{tabular}{|c|c|c|c|c|c|c|}
\hline $\begin{array}{l}\text { Nucteotide } \\
\text { change }\end{array}$ & $\begin{array}{l}\text { Coding } \\
\text { change }\end{array}$ & Region & \#am & Functional effect & Phenotype & Refs \\
\hline $\begin{array}{l}\text { IVS7DS +4 } \\
\text { InsAA }\end{array}$ & - & DI55.56 & 1 & & IVF & (85) \\
\hline $1715 \mathrm{C}>\mathrm{A}$ & $\mathrm{A} 5572 \mathrm{D}$ & DI-DII & 1 & & RWS & (2) \\
\hline $1844 \mathrm{CDA}$ & G615E & DI/DII & 1 & $\begin{array}{l}\text { No effect (without } \\
\text { drug) }\end{array}$ & acquired & (42) \\
\hline $1852 \mathrm{CST}$ & $1618 \mathrm{~F}$ & $\mathrm{DI} / \mathrm{DI}$ & 1 & $\begin{array}{l}\text { No effect (without } \\
\text { drug) }\end{array}$ & acquired & (42) \\
\hline 2971 AA $>T C$ & S941N & DII-DII & 1 & $\begin{array}{l}\text { Persistent and } \\
\text { increalsed inward } \\
\text { current }\end{array}$ & $\begin{array}{l}\text { SIDS/ } \\
\text { RWS }\end{array}$ & (96) \\
\hline $2989 G>T$ & A9975 & DII S6-D\|lI $\$ 1$ & 1 & $\begin{array}{l}\text { Persistent and } \\
\text { increased inward } \\
\text { current }\end{array}$ & SIDS & (94) \\
\hline $3340 G>A$ & $\mathrm{D} 114 \mathrm{~N}$ & DII-DIII & 1 & & RWS & (21) \\
\hline $\begin{array}{l}3694 C>T \\
4859 C>T\end{array}$ & $\begin{array}{l}\text { R1232W + } \\
T 1620 M\end{array}$ & $\begin{array}{l}\text { DIII } 51-52 \\
\text { DIV } 53-54\end{array}$ & 1 & $\begin{array}{l}\text { v.d. s.s.i.: pos shift, } \\
\text { recov inact: } \uparrow\end{array}$ & BrS & (85) \\
\hline $3748 \mathrm{~T}>\mathrm{C}$ & F125OL & DIII 52 & 1 & $\begin{array}{l}\text { No effect (without } \\
\text { drug) }\end{array}$ & acquired & $(42)$ \\
\hline $3883 G>A$ & E1295K & DIII 54 & 1 & $\begin{array}{l}\text { Pos. shift window } \\
\text { current }\end{array}$ & RWS & (91) \\
\hline IVS $22+2 T>C$ & - & DIII S4 & 1 & & PCCD & (89) \\
\hline $3912 C>T$ & T1304M & DIII 54 & 1 & & RWS & (97) \\
\hline $3974 A>G$ & N1325S & DIII S4-55 & 1 & Inactivation $\downarrow, I_{\text {Mat }} \uparrow$ & RWS & $(80),(8.2)$ \\
\hline $3988 \mathrm{G}>\mathrm{C}$ & A1330P & DIII S4-S5 & 1 & $\begin{array}{l}\text { v.d. s.s.i.: pos shift, } \\
\text { inactivation } \downarrow \text {, recov. } \\
\text { inact. } \uparrow\end{array}$ & SIDS & (92) \\
\hline 4190delA & $V / 1398 x$ & Dill 56 & 1 & & IVF & (85) \\
\hline \multirow[t]{2}{*}{$4216 G>T$} & G1406R & Dill $\$ 5-56$ & 1 & non-functional & $\begin{array}{l}\text { Birs/ } \\
\text { ICCD }\end{array}$ & (93) \\
\hline & $1500 \mathrm{AK}$ & DIII-DIV & 1 & $\begin{array}{l}\text { Inactivation: neg shift, } \\
\text { Activation: pos shift }\end{array}$ & $\begin{array}{l}\text { Combi of } \\
\text { LQTS, BrS } \\
\text { ICCD }\end{array}$ & $(112)$ \\
\hline $4501 \mathrm{C}>\mathrm{G}$ & L1501V & DIII-DIV & 1 & & RWS & (21) \\
\hline $\begin{array}{l}4511- \\
4520 \text { del }\end{array}$ & $\begin{array}{l}1505 \\
1507 \mathrm{AKPQ}\end{array}$ & DIII-DIV & 4 & Inactivation $\downarrow, I_{\text {nat }} \uparrow$ & RWS & $\begin{array}{l}(79), \\
(80), \\
(81),(82)\end{array}$ \\
\hline $\begin{array}{l}4850- \\
4852 \mathrm{del}\end{array}$ & DelF 1617 & DIV $53-54$ & 1 & & RWS & (21) \\
\hline $4868 \mathrm{G}>\mathrm{A}$ & R.1623Q & DIV 54 & 2 & $\begin{array}{l}\text { Inactivation } \downarrow \downarrow \text {, } \\
\mathrm{I}_{\text {Nat }} \uparrow \uparrow\end{array}$ & RWS & $\begin{array}{l}(83) \\
(88),(21)\end{array}$ \\
\hline $4868 G>T$ & R1623L & DIN 54 & 1 & & RWS & (21) \\
\hline $4931 G>A$ & $\mathrm{R} 1644 \mathrm{H}$ & DIV S4 & 2 & Inactivation $\downarrow, I_{N a} \uparrow$ & RWS & $\begin{array}{l}(80), \\
(82),(21)\end{array}$ \\
\hline
\end{tabular}


arowers

\begin{tabular}{|c|c|c|c|c|c|c|}
\hline $4934 \mathrm{CDT}$ & T16.45M & DIV 54 & 1 & & RWS & $(97)$ \\
\hline $4999 G>A$ & $V_{1667}$ & DIV 55 & 1 & & $\begin{array}{l}\text { RWSI } \\
\text { acquired }\end{array}$ & $98)$ \\
\hline $5280 \mathrm{de} / \mathrm{G}$ & - & DIV $55-56$ & 1 & & PCCD & (89) \\
\hline $5298 \mathrm{~A} \times \mathrm{C}$ & M1766L & $\begin{array}{l}\text { Divs6- } \\
\text { C-term }\end{array}$ & 1. & $\begin{array}{l}\text { persistent late sodium } \\
\text { current }\end{array}$ & RWS & (99) \\
\hline $5329 \mathrm{G}>\mathrm{A}$ & V1777M & C-term & 1 & $\begin{array}{l}\text { W.d. s.s.i.: neg shift, } \\
\text { w.d. s.s.a.: pos shift, } \\
\text { persistent inward } \\
\text { current }\end{array}$ & RWS(r) & (95) \\
\hline $5349 G>A$ & E1784K & C-term & 2 & Inactivation $\downarrow,\left.\right|_{N 3} \uparrow$ & RWS & $(90) \cdot(21)$ \\
\hline $5360 G>A$ & $51787 \mathrm{~N}$ & C-term & 1 & & RWS & $(21)$ \\
\hline $5369 A>C$ & D1790G & C-term & & $\begin{array}{l}\text { Inactiwation: neg shift } \\
\text { interaction with } \beta \text { - } \\
\text { subunit, persistent } \\
\text { inward current }\end{array}$ & RWS & $(84)$ \\
\hline $538: 3 T>C$ & Ү1795H & C-term & 1 & $\begin{array}{l}\text { channel avail: neg } \\
\text { shift } \\
\text { reduced ampl, inact } \uparrow\end{array}$ & Brs & $(87)$ \\
\hline $5384 \mathrm{~A}>\mathrm{G}$ & $Y 1795 C$ & C-term & $\mathbb{1}$ & Inactivation $\downarrow$ & RWS & $(87)$ \\
\hline 5385 insTGA & $1795 \mathrm{ins} D$ & C-term & 1 & $\begin{array}{l}\text { v.d. 5.s.li: neg shift } \\
\text { v.d. s.s.a.: pos shift, } \\
\text { reduced window } \\
\text { current }\end{array}$ & RWS/IVF & $(86)$ \\
\hline $5474 \mathrm{~T}>\mathrm{C}$ & L.1825P & C-term & 1 & $\begin{array}{l}\text { Slow } 1_{\text {Nar }} \text { decay, with } \\
\text { non-inactivating } \\
\text { component, loss of } \\
\text { function }\end{array}$ & acquired & $(100)$ \\
\hline $5477 G>A$ & $\mathrm{R} 1826 \mathrm{H}$ & C-term & 1 & $\begin{array}{l}\text { Persistent and } \\
\text { increased inward } \\
\text { current }\end{array}$ & SHDS & (94) \\
\hline $5516 \mathrm{~A} \times \mathrm{G}$ & D1840G & C-term & 1 & & RWS & (101) \\
\hline
\end{tabular}

Numbering from startcodon ATC (Genbank accession number $\mathrm{M} 77235$ ). $\mathrm{PCCD}=$ progressive cardiac conduction defect, ICCD $=$ isolated cardiac conduction defect, IVF $=$ idiopathic ventricular fibrillation, $\mathrm{Br} S=$ Brugada syndrome, RWS=Romano-Ward syndrome, SIDS= Sudden Arrhythmic Death Syndrome, $(r)=$ recessive form. v.d.a. =voltage dependence of activation, a.r.=activation rate, s.s.i.ssteady-state inactivation ${ }_{*}$ s. s.a. $=$ steady-state activation. 


\section{APPENDIX 4: KCNE1 mutations}

\begin{tabular}{|c|c|c|c|c|c|c|}
\hline $\begin{array}{l}\text { Nucleotide } \\
\text { change }\end{array}$ & Mutation & \#fam & $\begin{array}{l}\text { Phenotyp } \\
e\end{array}$ & Functional effect & $\begin{array}{l}\text { Dominant } \\
\text { negative }\end{array}$ & Refs \\
\hline $\begin{array}{l}20 C>T+226 \\
G>A\end{array}$ & T71+076N & 1 & JLNS & & & (103) \\
\hline $95 \mathrm{C}>\mathrm{A}$ & $\mathrm{R} 32 \mathrm{H}$ & 1 & RWS & & & (21) \\
\hline $\begin{array}{l}139 \mathrm{G}>\mathrm{T}_{+} \\
152 \mathrm{~T}>\mathrm{A}\end{array}$ & $\begin{array}{l}\text { V47Ft } \\
\mathrm{L} 51 \mathrm{H}\end{array}$ & 1 & JLNS & $\begin{array}{l}\text { Trafficking } \\
\text { deficient (L51H), } \\
\text { reduced } \\
\text { amplitudes (V47F), } \\
\text { d.r. }{ }^{\uparrow} \text {, vid.a.: pos } \\
\text { shift (V47F) }\end{array}$ & $\begin{array}{l}\text { no } \\
\text { yes }\end{array}$ & (105) \\
\hline $172 \mathrm{~A}>\mathrm{C}, 176$ & T59P+ & 1 & JLNS & & no & (31) \\
\hline$T>C, 177 G>T$ & LGOP & & & & & \\
\hline $221 \mathrm{C}>\mathrm{T}$ & $\$ 74 \mathrm{~L}$ & 1 & RWS & $\begin{array}{l}\text { d.r. T, v.d.a.: pos } \\
\text { shift }\end{array}$ & & (102) \\
\hline $226 G>A$ & D76N & 2 & $\begin{array}{l}\text { RWS (d) } \\
J \text { JWS(r) }\end{array}$ & $\begin{array}{l}\text { Reduced } \\
\text { amplitude, } \\
\text { d.r. } \uparrow \text {,v.d.a.: pos } \\
\text { shift }\end{array}$ & yes & $\begin{array}{l}(102), \\
(104), \\
(105)\end{array}$ \\
\hline $259 \mathrm{~T}>\mathrm{C}$ & W87R & 1 & RWS & v.d.a.: pos shift, d.r. $\uparrow$ & & $(105)$ \\
\hline $292 \mathrm{C>T}$ & R98W & 1 & RWS & & & (21) \\
\hline $325 \mathrm{G}>\mathrm{A}$ & $V_{1091}$ & 1 & RWS & & & $(106)$ \\
\hline $379 C>A$ & P127T & 1 & RWS & & & (21) \\
\hline
\end{tabular}

Numbering from ATG startcodon (Genbank accession number L28168). RWS=Romano-Ward syndrome, JLNS=Jervell and Lange-Nielsen syndrome, $d=$ dominant, heterozygous, $r=$ recessive, homozygous. w.d. a=volltage dependance of activation, a.r.=activation rate, d.r. = deactivation rate, s.s.i. =steady-state inactivation. 


\section{APPENDIX 5: KCNE2 mutations}

\begin{tabular}{|c|c|c|c|c|c|}
\hline $\begin{array}{l}\text { Nucleotide } \\
\text { change }\end{array}$ & Mutation & \# fam & Phenotype & $\begin{array}{l}\text { Functional } \\
\text { effect }\end{array}$ & Refs \\
\hline $25 \mathrm{C}>\mathrm{G}$ & Q9E & 1 & $\begin{array}{l}\text { Drug-induced } \\
\text { arrhythmia }\end{array}$ & arr. $\downarrow$, d. ${ }^{\prime}$ & $(107)$ \\
\hline $161 \mathrm{~T} \times \mathrm{C}$ & M5.4T & 1 & $\begin{array}{l}\text { Inherited and drug } \\
\text { induced arrhythmia }\end{array}$ & a.r. $\downarrow, d, r . \uparrow$ & $\begin{array}{l}(107) \\
(108)\end{array}$ \\
\hline $170 T>C$ & $157 \mathrm{~T}$ & 1 & $\begin{array}{l}\text { RWS, drug-induced } \\
\text { arrhythmia }\end{array}$ & a.t. $b$ d.r. $\uparrow$ & $\begin{array}{l}(107) \\
(108)\end{array}$ \\
\hline $347 \mathrm{C}>\mathrm{T}$ & A116V & 1 & $\begin{array}{l}\text { Drug-induced } \\
\text { arrhythmia }\end{array}$ & & $(108)$ \\
\hline \multicolumn{6}{|l|}{ Polymorphisms } \\
\hline $22 A \times G$ & T8A & $1.4 \%$ & $\begin{array}{l}\text { Drug-induced } \\
\text { arrhythmia }\end{array}$ & & $\begin{array}{l}(107) \\
(108)\end{array}$ \\
\hline
\end{tabular}

Numbering from ATG startcodon (Genbank accession number AF071002). a.r. activation rate, d. $r$. m deactivation rate 


\section{Appendix references}

1. Wang Q Curran ME, Splawsiki I, Burn TC, Millholland JM, VanRaay TI, Shen I, Timothy KW, Vincent CMM, de Jager T, Schwartz Pi., Towbin JA, Moss AJ, Atkinson DL, Landes GM, Connors TD, Keating MT. Positional cloning of a novel potassilum channel gene:KVLOTI mutations cause cardiac arrhythmias. Nat Genet 1996; 12:17-23.

2. Paulussen $A_{r}$ Matthijs $G$, Gewillig $M$, Verhasselt $\mathbb{P}_{\text {, Cohen }} N_{n}$ Aerssens J. Mutation analysis in congenital long QT syndrome - a case with missense mutations in KCNOI and SCN5A. Gen Test $2002_{;}$in press.

3. Neyroud $N_{\text {s }}$ Tesson $F$, Denjoy I "Leibovici $M$, Donger $C$, Barhanin J, Fauré S, Gary $F$, Coumel P, Petit $C$, Schwartz $K$, Guicheney $P$. A novel mutation in the potassium channel gene KVLOT1 causes Jervell and Lange-Nielsen syndrome. Nat Genet 1997; 15: 186-189.

4. Donger C, Denjoy I, Berthet $M$, Neyroud $N$, Cruaud C, Bennaceur $M$, Chivoret $G$, Schwartz $K$, Coumel $P$, Guicheney P. KVLQTI C-terminal missense mutation causes a forme fruste long QT syndrome. Circulation 1997; 96: 2778-2781.

5. Chouabe $C$, Neyrould $N_{*}$ Guicheney P, Lazdunski $M$, Romey $C_{n}$ Barhanin J. Properties of KvLOT1 K" channel mutations in Romamo-Ward and Jervell and Lange-Nielsen inherited cardiac arrbythmias. EMBO 1997; 16: 5472-5.479.

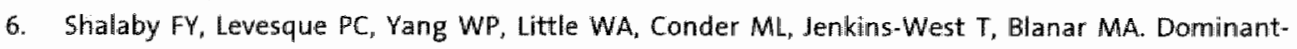
negative KVLQT1 mutations underlie the LOT1 form of long OT syndrome. Circulation 1997; 96 : $1733-1736$.

7. Wollinik $B$, Schroeder $B C$, Kubisch $C$, Esperer HD, Wieacker $P$, Jentsch TJ. Pathophysiological mechanilsms of dominant and recessive KVLT1 $K^{*}$ channel mutations found in inherited cardiac arrhythmias. Hum Mol Genet 1997; 6: 1943-1949.

8. Splawski I, Shen J, Timothy KW, Vincent CM, Lehmann MH, Keating MT, Genomic structure of three long QT syndrome genes: KVLLT1, HERG and KCNE1. Genomics 1998; 51: 86-97.

9. Neyroud N, Denjoy I, Donger C, Gary F, Villain E, Leemhardt A, Benali $K$, Schwartz $K$, Coumel $P$, Guicheney $P$. Heterozygous mutation in the pore of potassium channell gene KVLT1 causes an apparently normal phenotype in long QT syndrome. Eur J Hum Genet 1998;6:129-133.

10. Li H, Chen $Q$, Moss AJ, Robinson J, Goytial V, Perry JC, Vincent GM, Priori SG, Lehmann MH, Denfield SW, Duff D Kaine S, Shimizu W, Schwartz PJ" Wang $Q$, Towbin JA. New mutations in the KVLQTI potassium channel that cause long QT syndrome. Circulation 1998; 97: 1264-1269.

11. Kanters JK, Larsen LA, Orholm M, Agner E, Andersen PS, Vuust I, Christiansen M. Novel donor splice site mutation in the KVLQTI gene is associated with long QT syndrome. 1 Cardiovasc Electrophysial 1998; 620-624.

12. Murray A, Donger C, Fenske C, Spillmann I, Richard P, Dong $Y B$, Neyroud $\mathbb{N}$, Chevalier $P$, Denjoy 1 , Carter N, Syrris P, Afzal AR, Patton MA, Guicheney P, Jeffery S. Splicing mutations in KCNQ1. A mutation hot spot at codon 344 that produces in frame transcripts. Circulation 1999; 100: 1077 1084.

13. Mohammad-Panah R, Demolombe S, Neyroud $N$, Guicheney P, Kyndt F, van den Hoff $M$, Baró $\|$ Escande D. Mutations in a dominant-negative isoform correlate with phenotype in inherited cardiac arrhythmias. Am I Hum Genet 1999; 64: 1015-1023.

14. Franqueza L, Lin M, Splawski I, Keating MT, Sanguinetti MC. Long QT syndrome-associated mutations in the 54 -S5 linker of KWLQT1 potassium channels modify gating and interaction with mink subunits. J Biol Chem 1999; 274: 21063-21070.

15. Chen $Q$, Zhang D, Gingell RL, Moss AJ, Napolitano C, Priori SG, Schwartz PJ, Kehoe E, Robinson IL, Schulze-Bahr E, Wang $Q$. Towbin JA. Homozygous deletion in KVLOT1 associated with Jervell and Lange-Nielsen syndrome. Circulation 1999; 99: 1344-1347. 
16. Wei J, Fish FA, Myerburg RJ, Roden DM, George AL. Novel KCNQ1 mutations associated with recessive and dominant congenitall long OT syndromes: Evidence for variable hearing phenotype associated with R518X. Hum Mut 2000; \#317 MIB.

17. Krahn AD, Wang J, 5pindler $B$, Skanes AC, Yee R, Klein Gl, Hegele RA. A novel mutation in KVLQT1, L122P, found in a familly with autosomal dominant long QT syndrome. Am Heart $J 2000 ; 140: 146-$ 149.

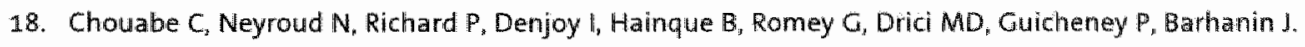
Novel mutations in KVLQT1 that affect $I_{\text {Ks }}$ activation through interactions with IsK. Cardiovasc Rex 2000; 45: 971-980.

19. Tanaka $T$, Nagai $R$, Tomoike $H$, Takata 5 , Yano $K$, Yabuta $K$, Haneda $N$, Nakano $O$, Shibata $A$, Sawayama $T$, Kasai $H$, Yazaki $Y$, Nakamura $Y$. Four novel KVLQTI and four novel HERG mutations in familial long QT symdrome. Circulation 1997: 95: 565-567.

20. Berthet $M$, Denjoy $\|_{\text {, Donger }} C_{\text {, }}$ Demay $L_{\text {, Hammoude }} H_{*}$ Klug $D$, Schulze-Bahr E, Richard $\mathbb{P}$, Funke $H_{*}$ Schwartz K, Coumel P, Hainque $B$. Guicheney P. C-terminal HERC mutations: The role of hypokalemia and a KCNQ1-associated mutation in cardiac event occurrence. Circulation 1999; 99 : 1464-1470.

21. Splawski I, Shen ], Timothy K, Lehmann MH, Priori S, Robinson JL, Moss AJ, Schwartz PJ, Towbin IA, Vincent GM, Keating MT. Spectrum of mutations in long QT syndrome genes KVLQT1, HERG, SCNSA, KCNEI and KCNE2. Circulation 2000; 102: 1178-1185.

22. Priori SG, Napolitamo C, Schwartz PJ. Low penetrance in the long OT syndrome. Clinical impact. Circulation 1999; 99: 529-533.

23. Priori SG, Schwartz PJ, Napolitano C, Bianchi L, Dennis A, De Fusco M, Brown AM, Casarì G. A recessive variant of the Romano-Ward long $Q T$ syndrame. Circulation 1998; 97: 2420-2425.

24. Neyroud N, Richard P, Vignier $N$, Donger C, Denjoy I, Demay L, Shkolnikaova M, Pesce R, Chevalier P, Hainque B, Coumel P, Schwartz K, Guicheney P. Genomic organisation of the KCNQ1 K' channel gene and identification of C-terminal mutation's in the long, $Q T$ syndrome. Circulation 1999; 84: 290 297.

25. Russell MW, MacDonald M, Collins FS, Brody LC. KVLQT1 mutations in three families with familtal or sporadic long QT syndrome. Hium Mal Genet 1996; 5: 1319-1324.

26. Saarinen $\mathrm{K}$, Swan $\mathrm{H}$, Kainulainen $\mathrm{K}$, Toivonen $\mathrm{L}$, Viitasalo $\mathrm{M}$, Kontula $\mathrm{K}$. Molecular genetics of the long QT syndrome: Two novel mutations of the KVLQT1 gene and phenotypic expression of the mutant gene in a large kindred. Hum Mut 1998; 11: 158-165.

27. De Jager $T$, Corbett $\mathrm{CH}_{3}$, Badenhorst $\mathrm{IC}$, Brink PA, Corfield VA. Evidence of a long $Q T$ founder gene with varying phenotypic expression in South African familles / Med Genet 1996; 33: 567-573.

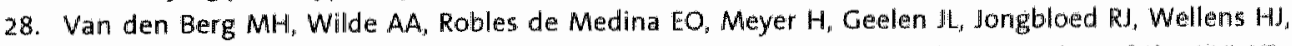
Geraedts JP. The long QT syndrome; a novel missense mutation in the 56 region of the KVLQT1 gene. Hum Genet 1997; 100: 356-361.

29. Larsen LA, Fosdal I, Andersen PS, Kanters IK, Vuust J, Wettrell G, Christiansen M. Recessive Romano* ward syndrome associated with compound heterozygosity for two mutations in the KVLOT1 gene. Eur I Hum Genet 1999; 7: 724-728.

30. Ackerman M, Tester DJ, Porter CJ, Edwards WD. Molecular diagnosis of the inherited long QT syndrome in a woman who died after near-drowning. New Eng J Med 1999; 341: 1121-1125.

31. Tyson $\mathrm{J}_{n}$ Tranebjaerg $\mathrm{L}$, Bellman $S$, Wren C, Taylor JFN, Biathen $\mathrm{d}$, Aslaksen B, Sorland SJ, Lund O, Malcolm S, Pembrey $M$, Bhattacharya 5 , Bitner-Glindzicz $M$. IsK and KvLQT1:mutation in either of the two subunits of the slow component of the delayed rectifier potassium channel can cause Jervell and Lange-Nielsen syndrome. Hum Mol Genet 1997; 6: 2179-2185.

32. Tranebjaerg L, Bathen J, Tysion $\rfloor$, Bitner-Glindzicz $M$. Jervell and Lange-Nielsen syndrome: A Norwegian perspective. Am J Med genet 1999; 89: 137-146. 


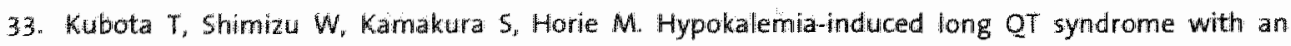
underlying novel misserise mutation in $54-55$ linker of KCNQ1. $/$ Cardiovasc Electrophysiol 2000; 11 : 1048-2054

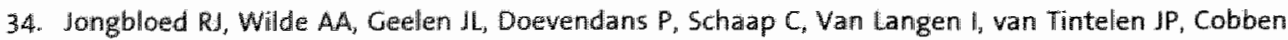
$J M$, Beaufort-Krol GC, Gerafdits JP, 5 meets HJ. Novel KCNQ1 and HERG missense mutations in Dutch long-QT familles. Hum Mut 1999; 13: 301-310.

35. Wilde AAM, Jongbloed RIE, Doevendans PA, Duren DR, Hauer RNW, van Langen IM, wan Tintelen JP, Smeets HJM. Meyer H, Geelen JLMC. Auditory stimuli as a trigger for arrhythmic events differentiate HERG-related (LOTS2) patients from KVLOT1-related patients (LOTS1). IACC 1999; 33: $327-332$.

36. Itoh T, Tanaka T, Nagai R, Kikuchi K, Ogawa 5, Okada S, Yamagata S, Yano K, Yazaki Y, Nakamura Y. Genomic organization and mutational analysis of KVLOT1, a gene responsible for familial long $Q T$ syndrome. Hum genet 1998; 103: 290-294.

37. Bianchi L, Priori SG, Mapolitano C, Surewicz KA, Dennis AT, Mernmi M, Schwartz PI, Brown AM. Mechanisms of Is suppression in LQT1 mutants. Am J Physial Heart Circ Physiol 2000; 279: H3003H3011.

38. Huang $L$, Bitner-Glindzicz M, Tranebjaerg $L$, Tinker A. A spectrum of functional effects for disease causing mutations in the Jervell and Lange-Nielsen syndrome. Cardiovac Res 2001; $51: 670-680$.

39. Tyson J, Tranebjaerg L, McEntagart M, Larsen LA, Christiansen M, Whiteford ML, Bathen I, Aslaksen B, Sorland 5l, Lund $O$, Pembrey ME, Malcolm 5 , Bitner-Glindzicz M. Mutational spectrum in the cardioauditory syndrome of Jervell and Lange-Nielsen. Hum Genet 2000; 107: 499-503.

40. Napolitano C, Schwartz PJ, Brown AM, Ronchetti E, Bianchi L, Pinravaia A, Acquaro G, Priori SG. Evidence for a cardiac ion channel mutation underlying drug winduced QT prolongation and lifethreatening arrhythmias. I Cardiovasc Electrophysiol 2000; 11: 691-696.

41. Kubota T, Horie M, Takano M, Yoshida H, Takenaka K, Watanabe E, Tsuchiya T, Otani H, Sasayama S. Evidence for a single nucleotide polymorphism in the KCNQ1 potassium channel that underlies susceptibility to life-threatening arrhythmias. $J$ Cardiovasc Electrophysiol 2001: 12: 1223-1229.

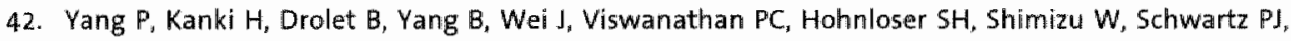
Stanton M, Murray KT, Norris K, George AL Jr., Roden DM. Allelic variants in longQT disease genes in patilents with drug-associated torsade de pointes. Circulation 2002; 105: 1943-1948.

43. Schwartz PJ, Priori SG, Bloise R, Napolitano C, Ronchetti E, Piccini A, Goj C, Breithardt G, Schulze-Bahr E. Wedlekind $H$, Nastoli $\downarrow$. Molecular diagnos is in a child with sudden infant death syndrome. Lancet 2001: $358: 1342-1343$

44. Larsen LA, Christiansen M, Vuust J, Andersen PS. High-throughput single-sitrand conformation polymorphism analysis by automated capillary electrophoresis: robust multiplex analysis and pattern based identification of allelic variants. Hum Mut 1999; $13: 318-327$.

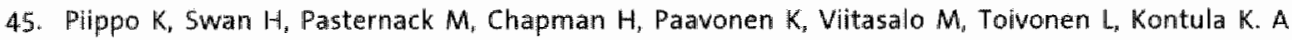
founder mutation of the potassium channel KCNQ1 in long QT syndrome: implications for estimation of disease prevallence and molecular diagnostics. \& Am Coll Cardiol 2001: 37:562-568.

46. Ackermann MJ, Schroeder J], Berry R, Schaid DJ, Porter CJ, Michels WV. Thibodeau SN. A nowel mutation in KVLQT1 is the molecular basis of inherited Hong OT syndrome in a near-drownimg patient's family. Pediatr Res 1998; 44: 148-153.

47. Curran ME, Splawski I, Timothy KW, Vincent GM, Green ED, Keating MT. A umolecular basis for cardlac arrhythmia: HERG mutations cause long QT syndrome. Cell 1995; 80: 795-803.

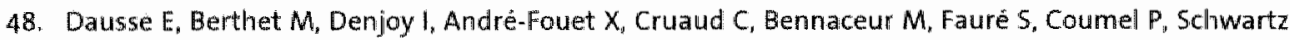
$K$, Guicheney $P$. A mutation in HERG associated with notched $T$ waves in Long $Q T$ syndrome. IMol Cell Cardiol 1996; 28: 1609-1615.

49. Benson DW, MacRae CA, Vesely MR, Walsh EP, Seidman IG, Seidman CE, Satler CA. Missense mutation hin the pore region of HERG causes famillial long QT syndrome. Circulation 1996; $93: 1791$. 1795. 
50. Satler CA, Walsh EP, Vesely MR, Plummer MH, Ginsturg CS, Jacob HI. Novel missense mutation in the cyclic nucleotide-binding domain of HERG causes long QT syralrome. Am J Med Genet 1996; 65: $27-35$

51. Sanguinetti MC, Curran ME, spectar PS, Keating, MT. Spectrum of HERG K ${ }^{+}$chatinel dysfunction in an inherited cardiac arrhythmia. Proc Nati Acod Sici U5A 1996; 93 : 2208-2212.

5.2. Itoh T. Tanaka T, Nagai R, Kamiya T, Sawayama T. Nakayama T, Tomoike H, Salkurada H, Yazakil Y, Nakamura $Y$. Genomic organisation and mutational analysis of HERC, a gene responsible for famillal long QT syndrome. Hum Genet 1998; 102: 435-439.

53. Satler CA, Vesely MR, Duggal P, Ginsburg GS, Beggs AH. Multiple different missense mutations in the pore region of HERG in patients with long QT syndrome. Hum Genet 1998; 102: $265-272$.

54. Zhou $Z$, Gong $Q$, Epstein ML, January CT. HERG channel dysfunction in human long QT syndrome. Intracellular transport and functional defects. I Biol Chem 1998; 273: 21061-21066.

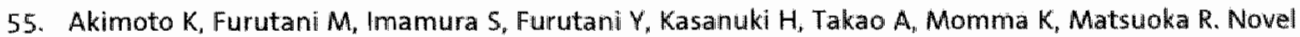
missense mutation (G601S) of HERG in a Japianese long OT syndrome family. Hum Mut 1997; MIB \#5

56. Furutani $M$. Trudeau MC, Hagiwara N, Seki A, Gong $Q$, Zhou Z, Imamura S, Nagashima H, Kasanuki

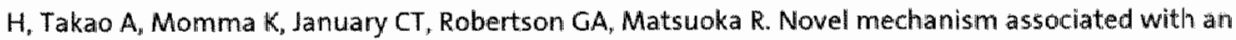
inherited cardiac arrhythmia. Defective protein trafficking by the mutant HERG (G601S) potassium channel. Circulation 1999; 99: 2290-2294.

57. Zhou $\mathrm{Z}$, Gong $\mathrm{Q}$, January $\mathrm{CT}$. Correction of defective protein trafficking of a mutant HERG potassium channel in human long QT syndrome. J Biol Chem $1999 ; 274: 31123-31126$.

58. Paulussen A, Raes A, Matthijs $G$, Snyders D, Cohen N, Aerssens I. A novel mutation (I65 P) in the PAS domain of HERG results in long QT syndrome by trafficking deficiency. JBC submitted.

59. Chen J, Zou A, Splawski I, Keating MT, Sanguinetti MC. Long QT syndrome-associated mutations in the Per-Arnt-Sim (PAS) domain of HERG potassium channels accelerate channel deactivation. $J$ Biol Chem 1999; 274: 10113-10118.

60. Nakajima T, Furukawa T, Hirano Y, Tanaka T, Sakurada H, Takahashi T, Nagai R, Itoh T, Katayana Y. Nakamura $Y$, Hiraoka $M_{4}$ Voltage-shift of the current activation in HERG S4 mutation (R534C) in LOT2. Cardiovasc Res 1999; 44: 283-293.

61. Yoshida $H$, Horie $M$, Otani $H$, Takano $M$, Tsuji K, Kubota $T$, Fukunamil M. Sasayama $S$. Characterisation of a novel missense mutation in the pore of HERG in a patient with long QT syndrome. J Cardiovasc Electrophysiol 1999; 10: 1262-1270.

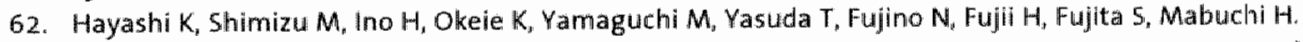
Identical twins with long QT syndrome associated with a missense mutation in the 54 region of HERG. lap Heart J 2000; 41:399:404.

63. Larsen LA, Svendsen IH, Jensen AM, Kanters IK, Andersen PS, Moller M, Sorensen SA, Sandoe EE, Jacobsen JR, Vuust $J$, Christiansen $M$. Long $Q T$ syndrome with a high mortallity rate caused by a novel G572R missense mutation in KCNH2. Clin Genet 2000; 57: 125-130.

64. Lattinem $P$, Fordstad H, Pilppo K, Swan $H$, Toiwonen L, Vittasalo M, Kaprio J, Kontula K. Suirvey of the coding region of the HERG gene in long $Q T$ syndrome revealls six novell mutations and an amino acid polymorphism with possible phenotypic effects. Hum Mut 2000; MIB 334 .

65. Paulusisen A, Yang P. Pangalos $M$, Verhasselt. $P$, Marrannes $R$, Verfaille C. Vandenberk 1, Crabbe $R$, Konings F, Luyten W, Armstrong $M$. Analysis of the human KCNH2(HERG) gene: Identification and characterisation of a novel mutation $\$ 667 X$ assiociated with long QT syndrome and a nonpathologicall 9 bp insertion. Hum Mut 2000; MIB \#325.

66. Ficker E, Dennis AT, Obejero-Paz CA, Castaildo $P$. Taglialatela $M$, Brown AM. Retention in the endoplasmic reticulum as a mechanism of dominantmegative current suppresision in human long QT syndrome I Mol Cell Cardiol 2000; $32: 2327-2337$.

67. Ficker $E$. Thomas D, Viswanathan PC, Dennis AT, Priori SG, Napolitano $C$, Memmil M, Wible BA, Kaufman ES, Hyengar S, Schwartz PJ, Rudy Y, Brown AM. Vovel characteristics of a misprocessed 
mutamt HERG channet linked to hereditary long QT syndrome. Am I Physiol Heart Circ Physial 2000; 279: $41748-41756$.

68. Lews-Miller JP, Duan $Y$, Teng GQ Thorstad, Duff HJ. Novel gain-of-function mechanism in K* chanmel related long QT syndrome: Altered gating and selectivity in the HERC1 N629D mutant. Circ Res 2000; 86:507-513.

69. Kagan $A, Y u, Z$; Fishman Gi, McDonald TV. The dominant negative LQT2 mutation A561V reduces wild-type HERG expression. I Biol Chem 2000; 275: 11241-11248.

70. Huang $F D$, Chen $J_{\text {, Lin } M}$, Keating MT, Sanguinetti MC. Long OT syndrome-associated missense mutations in the pore helix of the HERG potasium channel. Circulation 2001; 104: 1071-1075.

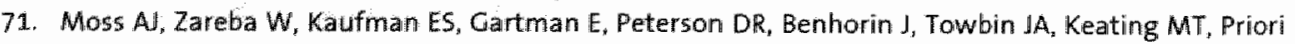
$S G_{3}$ Schwartz PJ, Wincent M, Robinson JL, Andrews $M L$, Feng $C$, Hall, Medina A, Zhang L, Wang $Z$. Increased risk of armythmic events in long QT syndrome with mutations in the pore region of the human ether-a-go-go-related gene potassium channel. Circulation 2002; 105: 794-799.

72. Hayashi $K$, shimizu $M$, Ino $H$, Vamaguchi $M$, Mabuchi H, Hoshi N, Higashida H. Characterisation of a novel missense mutation E637K in the pore-S6 loop of HERG in a patient with long OT syndrome. Cardiovasc Res 2002; $54: 67-76$.

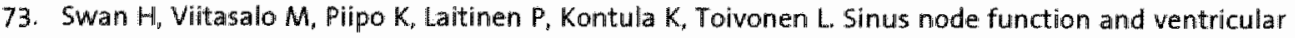
repolarization during exercise test in long QT syndrome patients with KVLQT1 and HERG potassium channel defects. Am Coll Cardiol 1999; 34:823-829.

74. Hoorntje T, Alders M, van Tintelen P, van der Lip K, Sreeram N, van der Wal A, Mammens M, Wilde A. Homozygous premature truncation of the HERG protein. The human HERG knockout. Circulation $1999 ; 100: 1264-1267$.

75. St-Pierre J, Roy $N$, Bller L, Plante $E$, Cote $M$, Gilbert $M$, Chahine $M$. The distinct HERG missense mutation L564P causes long QT syndrome in one French Canadian family. Can J Cardiol 2000; 16 : 304-306.

76. Lee-Chen GJ, Tai DY, Chu CH, Teng WN. Romanomard long QT syndrome: identification of a HERC mutation in a Taiwanese kindred. I Formos Med Assoc 1999; 98: 649-52.

77. Yoshida $H$, Horie $M$, Otani $H$, Kawashima $T$, Onishi $Y_{n}$ Sasayama $S$. Bradycardiaminduced long QT syndrome caused by a de movo missense mutation in the S2-S3 inner loop of HERG. Am I Med Genet 2001: $98: 348-352$.

78. Lupoglazoff IM, Denjoy 1, Berthet M, Neyroud N, Demay L, Richard P. Hainque B, Vaksmann G, KIug

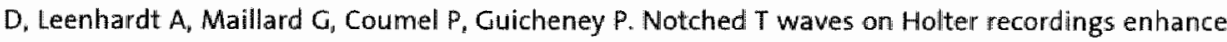
detection of patients with LQT2 (HERG) mutations. Circulation 2001: 103: 1095-1101.

79. Waing Q, Shen J, Splawiski I, Atkinson D, Li Z, Robinson JL, Moss A., Towbin JA, Keating MT. SCN5A mutations associated with an inherited cardiac arribythmia, long QT syndrome. Cell 1995; 80; 805811 .

80. Wang $Q$, Shen J, Li Z Timothy K, Vincent GM. Priori SG, Schwartz PJ, Keating MT. Cardiac sodium channel mutations in patients with long QT syndrome, an inherited cardiac arrhythmia. Hum Mol Genet 1995; 4: 1603-1607.

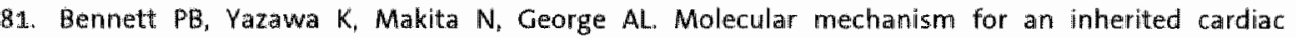
arrhythmia. Nature 1995:376:683-685.

82. Dumaine $R$, Wang $Q$, Keating MT, Hartmann HA, 5chwartz PI, Brown AM, Kirsch GE. Multiple mechanisms of Na* channellinked long QT syndrome. Circ Res 1996; 78: 916-924.

83. Makita $N$, Shirai $N$, Nagashima M, Matsuoka $R$, Yamada $Y$, Tohse $N$, Kitabatake A. A de novo mutation of human cardiac $\mathrm{Na}^{*}$ channel exhibiting novel molecular mechamisms of long QT syndrome. FEBS letters 1998; $423: 5 ;-9$.

84. An RH, Wang XL, Kerem B, Benhorin $J_{1}$ Medina A, Goldmit $M$, Kass RS. Novel LQT-3 mutation affects $\mathrm{Na}^{*}$ channel activity through interactions between $\alpha$-and $\beta_{4}-5$ ubunits. Circ Res 1998; 83:14:1-146.

85. Chen Q, Kirsch GE, Zhang D, Brugada $R_{r}$ Brugada J Brugada P, Potenza D, Moya A, Borggrefe M,

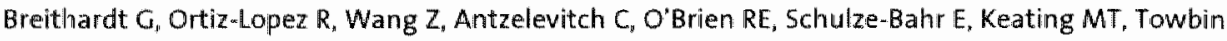


JA, Wang $Q$. Genetic basis and molecular mechanism for idiopathic ventricular fibrillation. Nature 199:8; 392: 293-295.

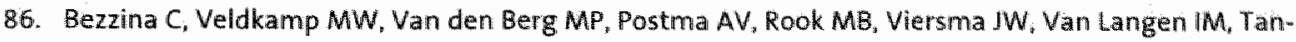
Sindhunata $G$, Bink-Boelkens MthE , Van der Hout AH, Mannens MAM, Wilde AAM. A single Na* channel mutation causing both long-QT and Brugada syndromes. Circ Res 1999: 85: 120611213.

87. Rivolta I, Abriel H, Tateyama $M$, Liu H. Memmi M, Vardas P, Napolitano C, Priori SG, Kass RS. Inherited Brugada and long QT-3 syndrome mutations of a single residue of the cardiac sodium channel confer distinct channel and clinical phenotypes. J Biol Chem 2001; 276; 30623-30630.

88. Kambouris NG, Nuss HB, Johns DC, Tomaselli GF, Marban E, Balser JR. Phenotypic characterisation of a novell long-QT syndrome mutation (R1623O) in the caqrdiac sodium channel. Cinculation 1998; 97 : 640-644.

89. Schott JJ, Alshinawa $C$, Kyndt $\mathbb{F}$, Probst V, Hoorntje TM, Hulsbeek $M$, Wilde AAM, Escande $D$, Mannens MMAM, Le Marec H. Cardiac conduction defects associated with mutations in SCN5A. Nat Genet 1999: 23: 20-21.

90. Wei J, Wang DW, Alings $M$, Fish $F$, Wathen $M$, Roden $D M_{\text {w }}$ George Al Jr. Congenital long QT syndrome caused by a novel mutation in a conserved acidic domain of the cardiac Na channel. Circulation 1999; 99: 3165-3171.

91. Abriel H, Cabo C, Wehrens XHT, Rivolta I, Motoike HK, Memmi M, Napolitano C, Priori SG. Kass RS. Novel arrhythmogenic mechanism revealed by a long QT syndrome mutation in the cardiac $\mathrm{Na}^{\prime}$ channel. Circ Res 2001; 88: 740-745.

92. Wedekind $H$, Smits JPP, Schulze-Bahr $E_{v}$ Arnold $R_{r}$ Veldkamp MW, Bajanowski $T$, Borggrefe $M$, Brinkmann B, Warnecke I, Funke $H$, Bhuiyan ZA, Wilde AAM, Breithardt G, Haverkamp W. De novo mutation in the SCNSA gene associated with early onset of sudden infant death. Circulation 2001; 104: 1158-1164.

93. Kyndt F, Probst W, Potet F, Demolombe $S_{0}$ Chevalier JC, Baro I, Moisan JP, Boisseau P, Schott J, Escande D, Le Marec H. Novel SCN5A mutation leading either to isolated cardiac conduction defect or Brugada syndrome in a large French family. Circulation 2001; 104: 3081-3086.

94. Ackerman MI, siu BL, Sturner WQ Tester DJ, Valdivia CR, Makielski $ل \mathbb{C}$, Towbin JA. Postmortem molecular analysis of SCN5.A defects in suidden infant death syndrome. JAMA 2001; 286: 2.264-2269.

95. Lupoglazoff $M M$, Cheav T. Baroudi $G$, Berthet $M$, Denjoy I, Cauchemez B, Extramiana $F$, Chahine $M$, Quicheney $P$. Homozygous SCNSA mutation in long-QT syndrome with functional two-to-one atriovantricular block. Circ Res 2001: 89: e16-e21.

96. Schwartz PJ, Priori SG. Dumaine R, Napolitano C. Antzelevitch C, Stramba-Badiale M, Richard TA, Berti MR, Bloise R. A molecular link between the sudden infant death syndrome and the long $Q T$ syndrome. N Eng I Med 2000; 343:262-267.

97. Wattanasirichaigoon D, Vesely MR, Duggal P, Lewine JC, Blume ED, Wolff GS, Edwards SB, Beggs AH. Sodium channel abnormalities are infrequent in patients with long QT syndrome: identification of two novel SCN5A mutations. Am IMed Genet 1999; 86:470-476.

98. Piipo $K$, Holmistrom $S$, Swan $H$, Viitasalo $M$, Raatikka $M$, Toivonen L, Kontula $K$. Effect of the antimalarial drug halofantrine in the long OT syndrome due to a mutation of the cardiac sodium channel gene SCN5A. Am i Cardiol 2001; 87: 909-911.

99. Valdivia CR, Ackerman MJ, Tester DJ. Wada T, McCormack J, Ye B, Makielski JC. A novel SCN5A arrhythmia mutation, M1766L, with expression defect rescued by mexilletine. Cardiovasc Res 2002: 55:279-289.

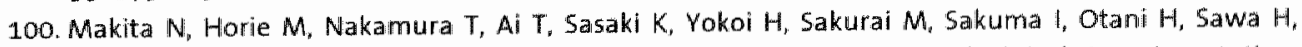
Kitabatake A. Drug-induced long QT syndrome assaciated with a subclinical SCN5:A mutation. Circulation 2002; 106: 1269-1274.

101. Benhorin J, Goldmit m, MacCluer $\mathrm{WW}$, Blangera J, Goffen R, Leibovitch A, Rahat A, Wang $\mathrm{Q}$, Medina $\mathrm{A}_{\text {, }}$ Towbin J, Kerem B. Identification of a new SCN5A mutation, D1840G, associated with the long QT syndrome. Hum Mut 1998; MIB \#153, 12: 72. 
102. Splawshe 1, Tristani-Firouzi $M_{1}$ Lehmanin MH, Sanguinetti MC, Keating MT. Mutations in the hmink gene cause long QT syndrome and suppress $I_{k,}$ function. Nat Genet 1997; 17: 338-340.

103. Schulze-Bahr $\mathrm{E}_{v}$ Wang $\mathrm{Q}$, Wedekind $\mathrm{H}$, Haverkamp W, Chen $\mathrm{Q}$, Sun $\gamma$. KCNE1 mutations cause Jervell and Lange Nielsen syndrome Nat Genet 1997; 17:267-268.

104. Duggal P, Vesely MR, Wattanasirichaigoon D, Villafane J, Kaushik V, Beggs AH. Mutation of the gene for IsK associated with both Jervell and Lange-Nielsen and Romano-Ward forms of long-QT syndrome. Circulation 1998; 97: 142-146.

105. Bianchi L, Shen Z, Dennis AT, Priori SG. Napolitano C, Ronchetti E, Bryskin R, Schwartz PJ, Brown AM.

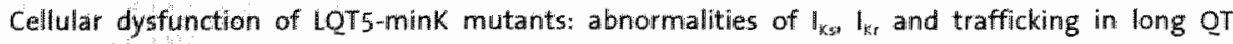
synd rome. Hum Mol Genet 1999; 8: 1499-1507.

106. Schulze-Bahr E, Schwartz $M$, Hauenschild S, Wedekind H, Funke $H$, Haverkamp $W$, Breithardt $W$,

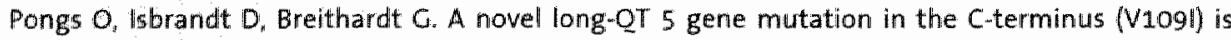
associated with a mill phenotype. I Mol Med 2001; $79: 547$.

107. Abbott GW, Sesti F, Splawski I, Buck ME, Lehmann MH, Timothy KW, Keating MT, Goldstein SAN, MIRP1 forms $1_{K, i}$ potassium channels with HERG ans is associated with cardiac arrhythmia. Cell 1999; 97: $175-187$.

108. Sesti F, Abbott GW, Wei J, Murray KT, Saksena 5, Schwartz PJ, Priori SG, Roden DM, George AL Jr, Gotdstein SAN. A common polymorphism associated with antibiotic-induced cardiac arrhythmia. PNAS 2000; 97: 10613-10618.

109. Jongbloed R, Marcelis C, Velter C, Doevendans P, Geraedts J, Smeets H. DHPLC analysis of potassium ion channel genes in congenital long QT syndrome. Hum Mut 2002; 20: 38.2-391.

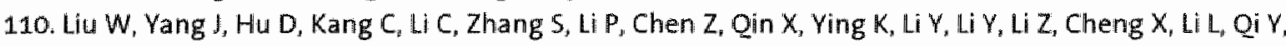
Chen $S_{\text {, Wang }} \mathrm{Q}$ KCNQ1 and KCNH2 mutations assaciated with long $\mathrm{QT}$ syndrome in a Chinese population. Hum Mut 2002; MiB \#556.

111. Lunetta P, Levo A, Mannikko A, Pentilla A, Sajantila A. Death in bathtub revisited with molecular genetics: a victim with suicidal traits and a LQTS gene mutation. Forensic Sci Int 2002: 130: 122-124.

112. Grant AO, Carboni MP. Neplioueva V. Starmer CF, Memmi M. Napolitano C. Priori S. Long QT syndrome, Brugada syndrame, and conduction system disease are linked to a single sodium chanme mutation. J Clin invest 2002; 110(8): 1201-1209. 
